\section{RESEARCH ONLINE}

University of Wollongong Thesis Collection

\section{University of Wollongong \\ Research Online}

University of Wollongong Thesis Collections

2011

\title{
Polyelectrolyte complex materials from chitosan and gellan gum
}

Khairul Anuar Mat Amin

University of Wollongong

\section{Recommended Citation}

Mat Amin, Khairul Anuar, Polyelectrolyte complex materials from chitosan and gellan gum, Doctor of Philosophy thesis, School of Chemistry, University of Wollongong, 2011. http://ro.uow.edu.au/theses/3452 


\section{UNIVERSITY OF WOLLONGONG COPYRIGHT WARNING}

You may print or download ONE copy of this document for the purpose of your own research or study. The University does not authorise you to copy, communicate or otherwise make available electronically to any other person any copyright material contained on this site. You are reminded of the following:

Copyright owners are entitled to take legal action against persons who infringe their copyright. A reproduction of material that is protected by copyright may be a copyright infringement. A court may impose penalties and award damages in relation to offences and infringements relating to copyright material. Higher penalties may apply, and higher damages may be awarded, for offences and infringements involving the conversion of material into digital or electronic form. 


\section{POLYELECTROLYTE COMPLEX MATERIALS FROM CHITOSAN AND GELLAN GUM}

A thesis submitted in fulfillment of the requirements for the award of the

DOCTOR OF PHILOSOPHY

from

UNIVERSITY OF WOLLONGONG

by

KHAIRUL ANUAR MAT AMIN, B.Sc, M.Sc

SCHOOL OF CHEMISTRY

August, 2011 
To my wife Majidah Hassan, my daughter Iman Huwaida and my mother Ramlah Khatib Mamat for their understanding and love. 


\section{CERTIFICATION}

I, Khairul Anuar Mat Amin, declare that this thesis submitted in fulfilment of the requirement for the award of Doctor of Philosophy, in the School of Chemistry at the University of Wollongong, is wholly my own work unless otherwise referenced or acknowledged. The document has not been submitted for any qualifications at any other academic institution.

Khairul Anuar Mat Amin

August 2011 


\section{ACKNOWLEDGEMENTS}

There are several individuals that I owe a special gratitude. First, my sincere thankfulness and appreciation go to my supervisor, Assoc. Prof. Marc in het Panhuis for the intellectual guidance, insight and wise support throughout the course of thesis project. My profound gratitude also goes to Prof. Mark J. Walker, Dr. Stephen Poon and Dr. Kerry Gilmore with cell studies, Prof. Mark. R. Wilson and Dr. Jake Matic with antibacterial studies, as well as Prof. Suresh Mahalingam from the University of Canberra with antiviral studies. Also my sincere thanks to Dr. Tony Romeo for scanning electron microscopy is appreciated.

My heartfelt appreciations are extended to the helpful assistance from the staff at the School of Chemistry and Soft Material Groups, University of Wollongong. In particular, I would like to thanks Dr. Yoke Berry for proof-reading. Aids provided by the Malaysian community around Wollongong are deeply appreciated. I would also like to thanks Azreen, Masnizan Mamat and Khalilah Muhammud on their willingness to look after my daughter throughout my PhD journey.

The PhD scholarship provided by the Government of Malaysia and University Malaysia Terengganu is gratefully acknowledged.

Last but definitely not the least, my deepest appreciation to my beloved wife Majidah Hassan and my lovely daughter Iman Huwaida for their understanding and unending support. Also the supports from my relatives have meant so much to me.

Thank you. 


\begin{abstract}
The demand for wound management treatment especially advanced and active wound care products are huge. Polyelectrolyte complex (PEC) materials have been reported as a promising and novel way to develop wound dressings. The research presented in this thesis aimed to utilise the biopolymers chitosan (CH) and gellan gum (GG) in the preparation of PEC films. These films were prepared by dipping free-standing CH and GG films into oppositely charged solutions. Studies on PEC films showed that the mechanical characteristics depend on the solution and film $\mathrm{pH}$, as well as the order of addition of the biopolymers. GG films immersed into $\mathrm{CH}$ solutions were found to consist of an inner GG layer and two outer $\mathrm{CH}$ layers, whereas in the reverse addition process, GG diffuses into the $\mathrm{CH}$ layer. The different in film composition was related to differences in $\mathrm{pH}$ and persistence length of GG and CH. Similar mechanical characteristics were observed for PEC coated wool fibres. The observation of the inability of $\mathrm{CH}$ solutions to diffuse into GG materials was used to develop dual layer films for future wound dressing applications. The upper layer was designed to act as a bacterial resistance layer, while the bottom layer was designed to promote cell viability and proliferation. Titanium dioxide $\left(\mathrm{TiO}_{2}\right)$, silver and zinc oxide nanoparticles as well as the antibiotic levofloxacin (Lev) were incorporated into CH and GG films to assess their ability to improve the biopolymers' antibacterial and cell viability properties. CH-Lev films displayed strong bacterial resistance against Escherichia coli, which was attributed to fast release (within $30 \mathrm{~min}$ ) of levofloxacin. GG$\mathrm{TiO}_{2}$ composites exhibited the best cell viability and cell proliferation of all materials considered. Dual layer films consisting of a CH-Lev upper layer and GG- $\mathrm{TiO}_{2}$ composite as bottom layer were found to be mechanically robust and flexible. The water vapour transmission rates (WVTR) of dual layer films is comparable to WVTR values reported for commercial wound dressing such as Cutifilm, Tegaderm, Bioclusive, Duoderm and Intrasite. As conclusion, PEC materials from CH and GG designed with future wound dressing applications were successfully prepared.
\end{abstract}




\section{ABBREVIATIONS}

\begin{tabular}{|c|c|}
\hline$\gamma$ & strain-at-break \\
\hline Ag & silver \\
\hline ALP & alkaline phosphatise \\
\hline CD & circular dichroism \\
\hline CFU & colony-forming unit \\
\hline $\mathrm{CH}$ & chitosan \\
\hline $\mathrm{cm}$ & centimetre \\
\hline cP & centipoise \\
\hline $\mathrm{d}$ & day \\
\hline $\mathrm{d}$ & diameter \\
\hline $\mathrm{Da}$ & Dalton \\
\hline DD & degree of deacetylation \\
\hline DMEM & Dulbecco’s Modified Eagle’s Medium \\
\hline $\mathrm{E}$ & Young's modulus \\
\hline EDTA & ethylenediaminetetraacetic acid \\
\hline Escherichia coli & E. coli \\
\hline FBS & fetal bovine serum \\
\hline g & gram \\
\hline GG & gellan gum \\
\hline GlCNAc & N-acetyl-glucosamine \\
\hline Gly & glycerine \\
\hline h & hour \\
\hline
\end{tabular}




\begin{tabular}{|c|c|}
\hline HMW & high molecular weight \\
\hline $\mathrm{kHz}$ & kiloHertz \\
\hline $\mathrm{kN}$ & kiloNewton \\
\hline L929 & mouse fibroblast cell \\
\hline Lev & levofloxacin \\
\hline $\mathrm{m}$ & metre \\
\hline M & molar \\
\hline mg & milligram \\
\hline $\min$ & minute \\
\hline $\mathrm{mJ}$ & milli-Joules \\
\hline $\mathrm{mL}$ & millilitre \\
\hline $\mathrm{mm}$ & millimetre \\
\hline MMW & medium molecular weight \\
\hline MTS & 3-(4,5-dimethylthiazol-2-yl)-5-(3- \\
\hline & carboxymethoxyphenyl)-2-(4-sulfophenyl)- \\
\hline & 2H tetrazolium \\
\hline Mw & molecular weight \\
\hline $\mathrm{m} \Omega$ & milliOhm \\
\hline $\mathrm{NH}_{3}^{+}$ & amine group \\
\hline $\mathrm{nm}$ & nanometre \\
\hline $\mathrm{D}$ & viscosity \\
\hline $\mathrm{P}$ & permeance \\
\hline PEC & polyelectrolyte complex \\
\hline PEMs & polyelectrolyte multilayers \\
\hline ppm & part per million \\
\hline
\end{tabular}




$\begin{array}{ll}\mathrm{RH} & \text { relative humidity } \\ \mathrm{rpm} & \text { rotation per minute } \\ \mathrm{SD} & \text { second } \\ \mathrm{SEM} & \text { standard deviation } \\ \mathrm{t} & \text { scanning electron microscopy } \\ \mathrm{T} & \text { time } \\ \mathrm{TCPP} & \text { toughness } \\ \mathrm{TiO}{ }_{2} & \text { tissue culture polystyrene plate } \\ \mathrm{TS} & \text { titanium dioxide } \\ \mathrm{UV}-\mathrm{Vis} & \text { tensile strength } \\ \mathrm{WVP} & \text { ultraviolet visible } \\ \mathrm{WVTR} & \text { water vapour permeability } \\ \mathrm{ZnO} & \text { water vapour transmission rates } \\ \end{array}$




\section{TABLE OF CONTENTS}

ABSTRACT

\section{CHAPTER 1}

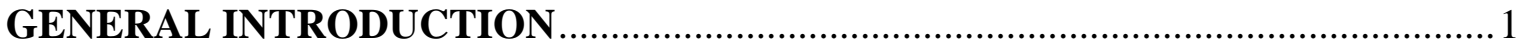

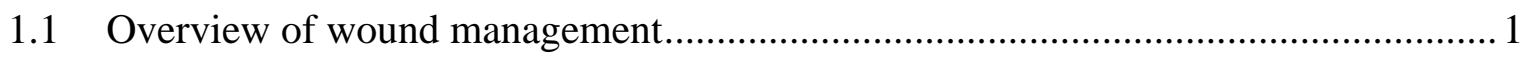

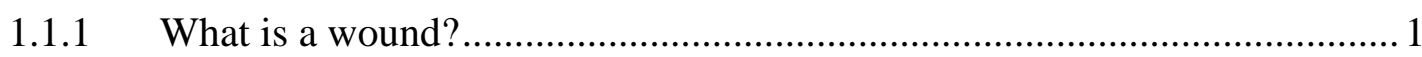

1.1.2 What is wound healing? .................................................................. 4

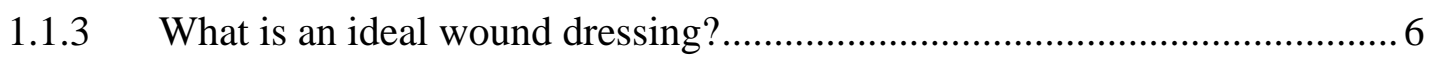

1.1.4 Types of wound dressings available on the market ..................................10

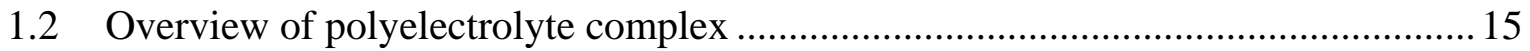

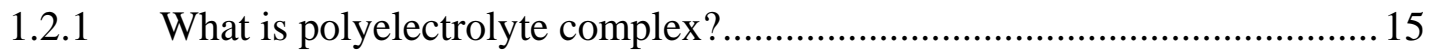

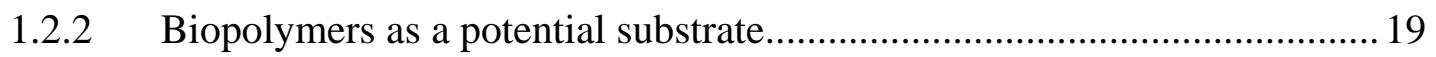

1.2.3 Polysaccharides as substrate for a polyelectrolyte complex ....................... 19

1.2.4 Textile as substrate for a polyelectrolyte complex ................................... 21

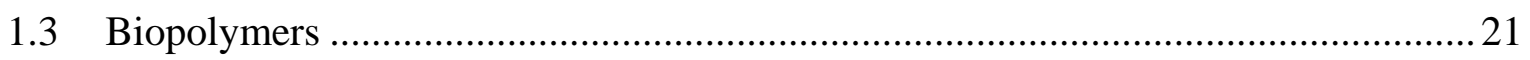

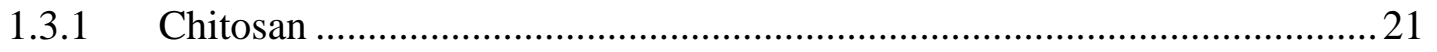

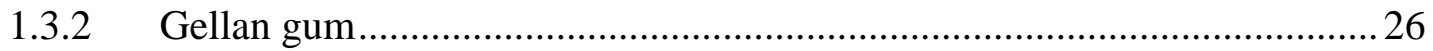

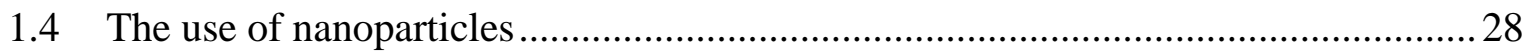

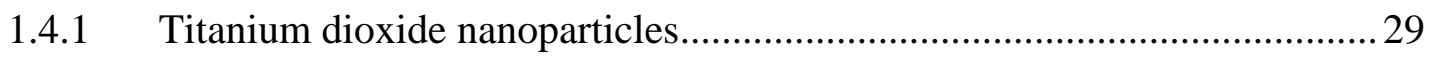

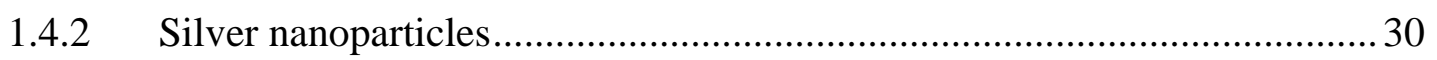

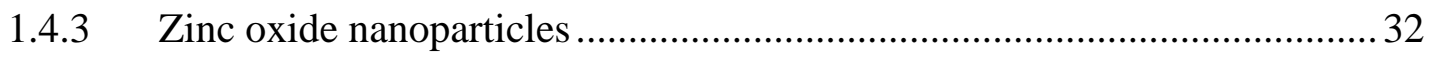

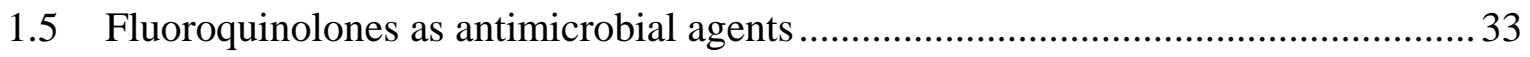

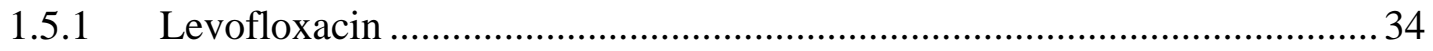

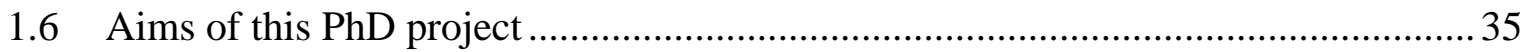




\section{CHAPTER 2}

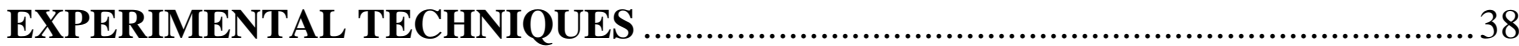

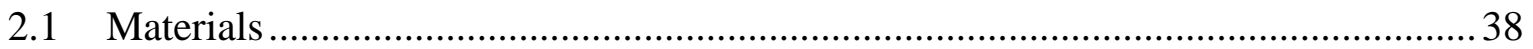

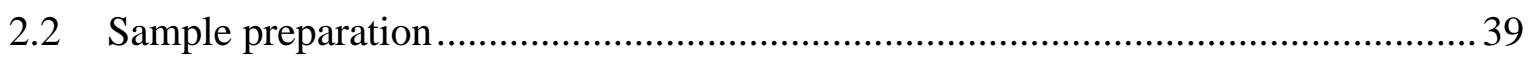

2.2.1 Preparation of chitosan-nanoparticle composites ......................................39

2.2.2 Preparation of gellan gum-nanoparticle composites................................. 40

2.2.3 Polyelectrolyte complex film of chitosan and gellan gum......................... 41

2.2.4 Polyelectrolyte complex coated wool fibres using chitosan and

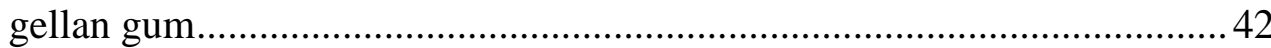

2.2.5 Polyelectrolyte complex film of chitosan-levofloxacin and

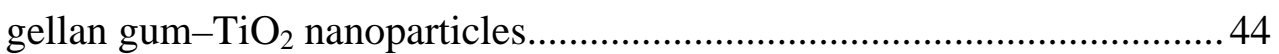

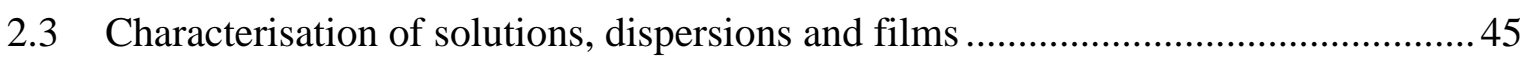

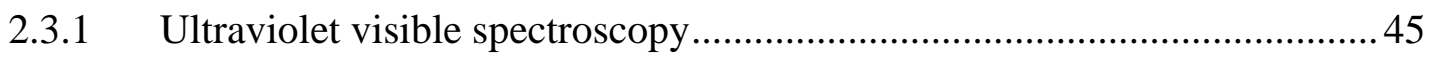

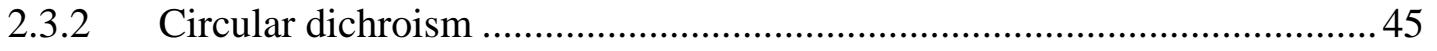

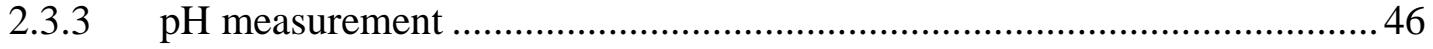

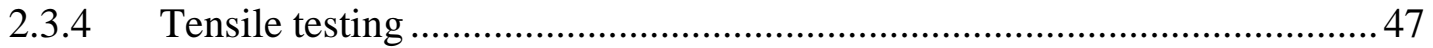

2.3.5 Optical and Electron Microscopy …........................................................... 48

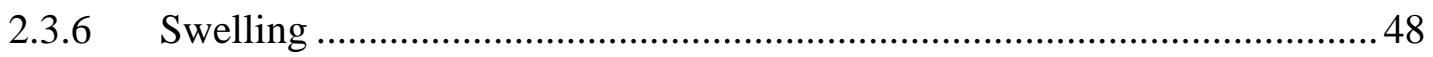

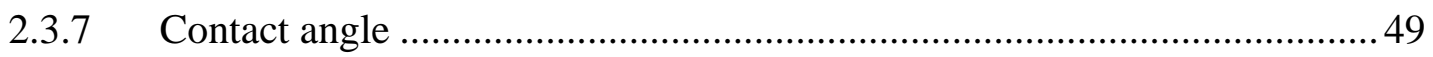

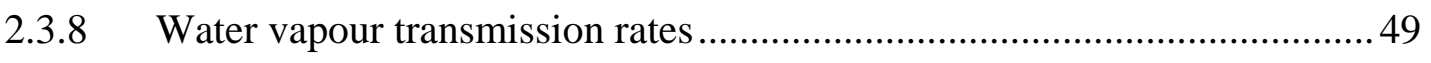

2.3.9 Kubelka-Munk analysis ...................................................................... 51

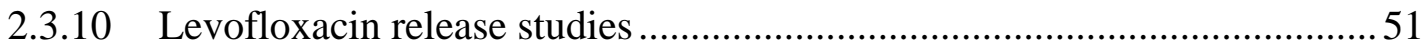

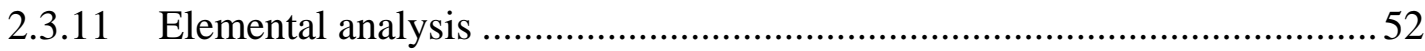

2.3.12 In-Vitro Cell Studies .............................................................................. 52

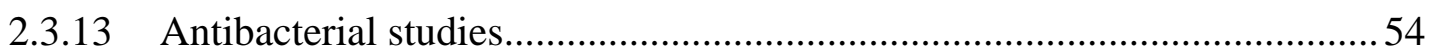

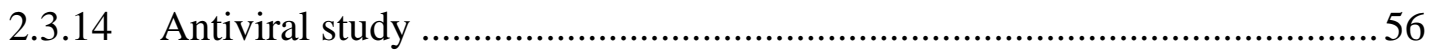

\section{CHAPTER 3}

CHARACTERISATION OF COMPOSITE MATERIALS FROM CHITOSAN WITH TITANIUM DIOXIDE AND SILVER NANOPARTICLES...........................58

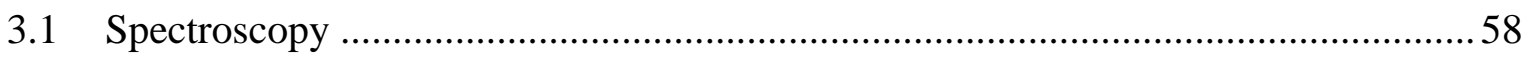

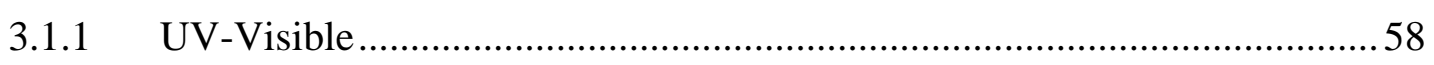

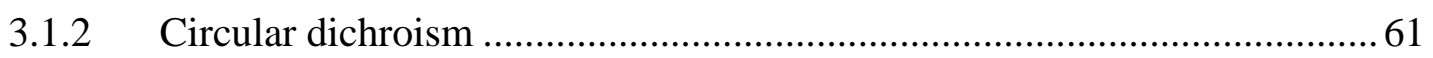




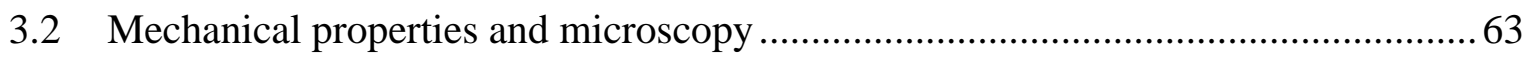

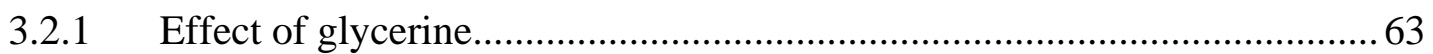

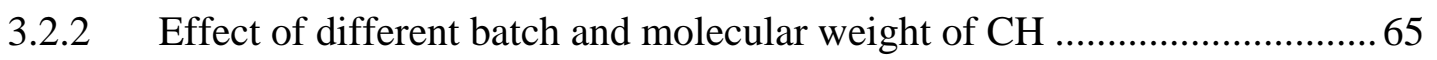

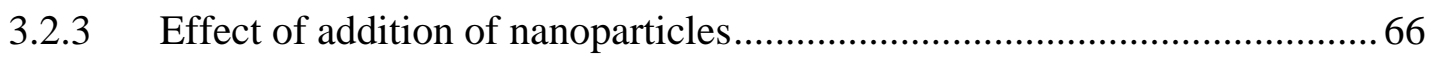

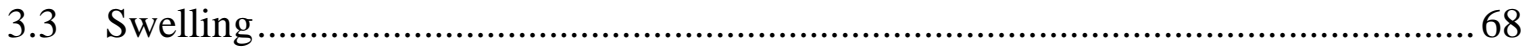

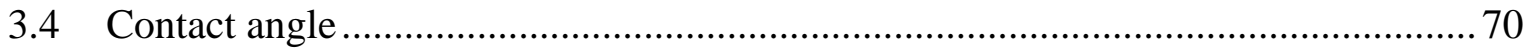

3.5 Water vapour transmission rates (WVTR) ............................................................ 71

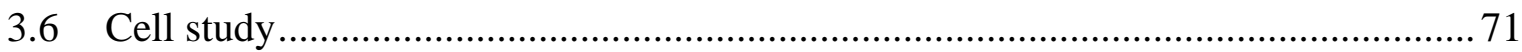

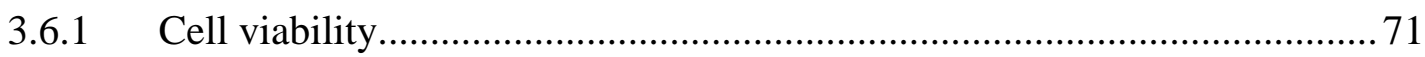

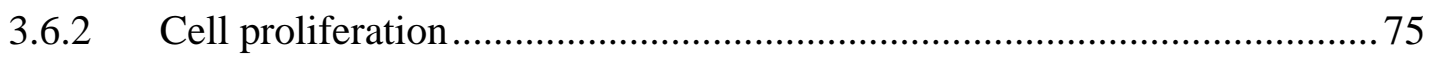

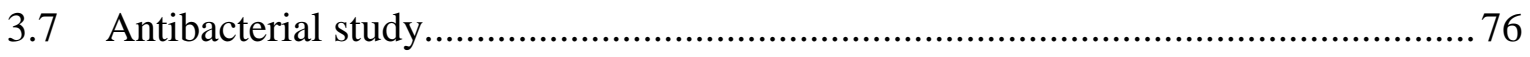

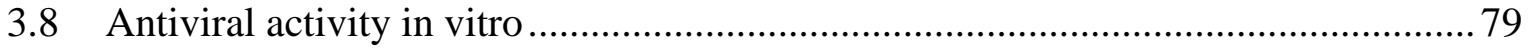

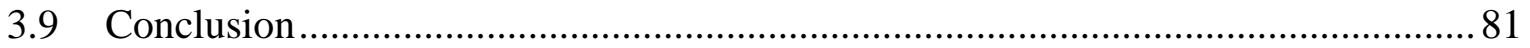

\section{CHAPTER 4}

CHARACTERISATION OF COMPOSITE MATERIALS FROM GELLAN GUM WITH TITANIUM DIOXIDE, SILVER AND ZINC OXIDE

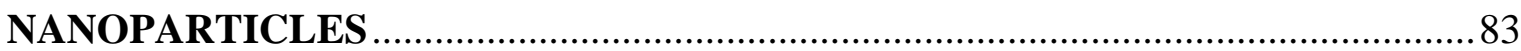

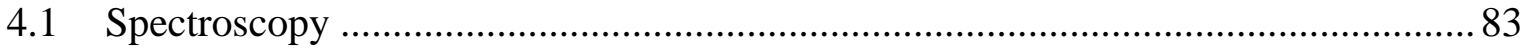

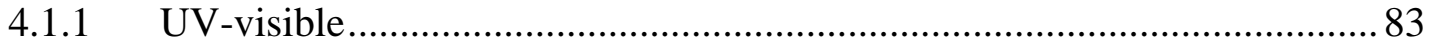

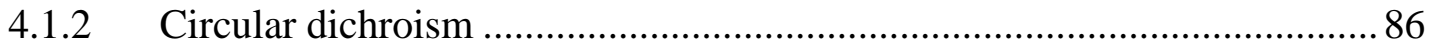

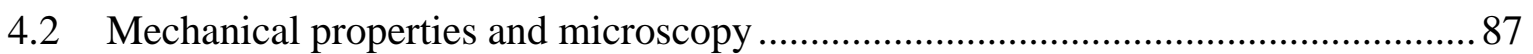

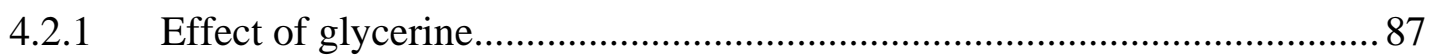

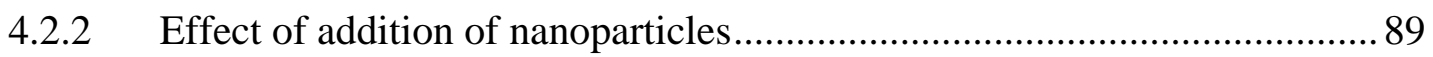

4.3 Water vapour transmission rates (WVTR) .............................................................. 92

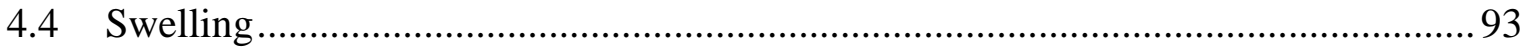

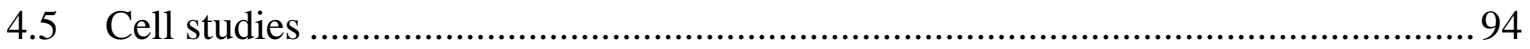

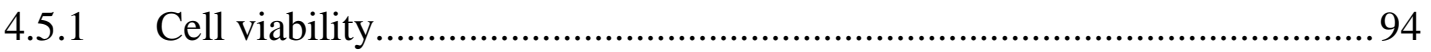

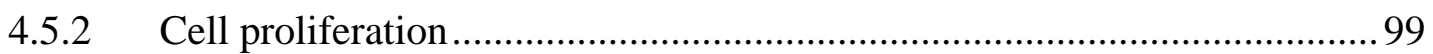

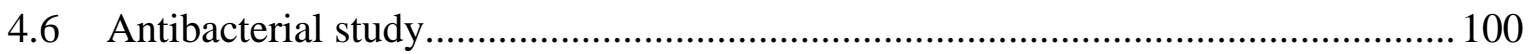

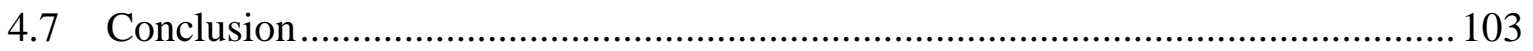




\section{CHAPTER 5}

\section{CHARACTERISATION OF POLYELECTROLYTE COMPLEX FILMS}

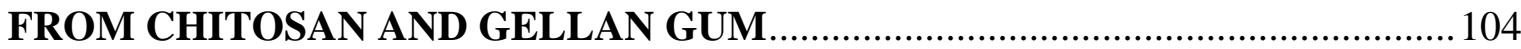

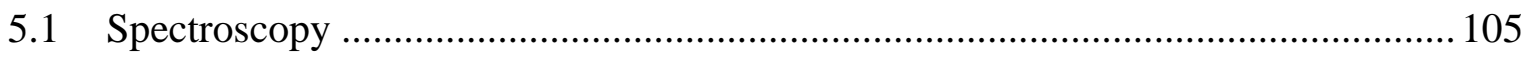

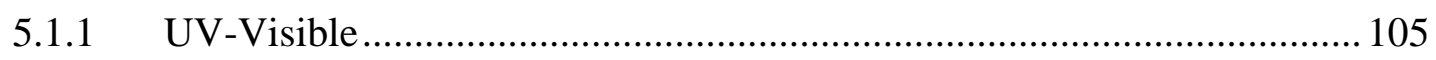

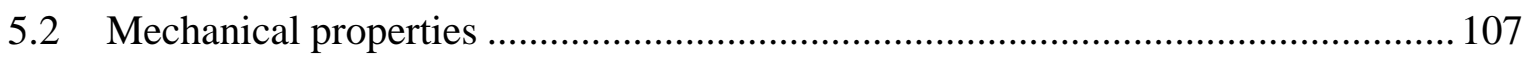

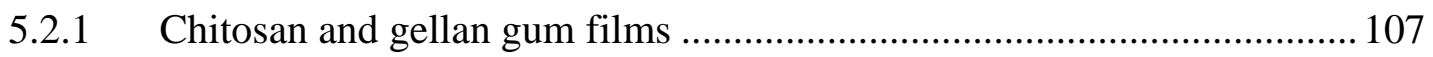

5.2.2 pH adjusted chitosan and gellan gum films ...........................................108

5.2.3 Polyelectrolyte complex-films ................................................................ 109

5.2.4 $\mathrm{pH}$ adjusted polyelectrolyte complex (PEC) films ................................. 111

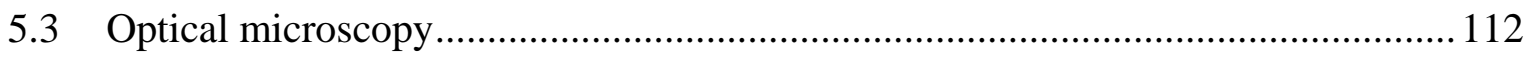

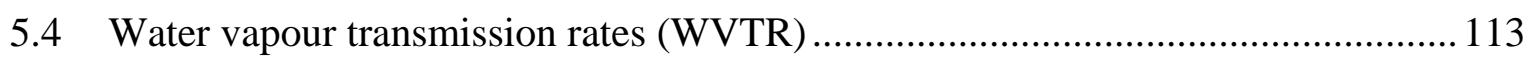

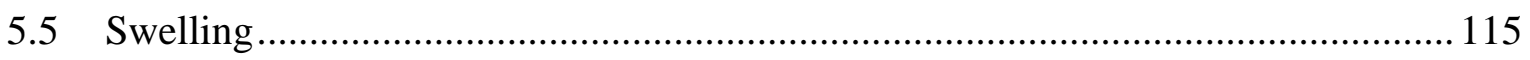

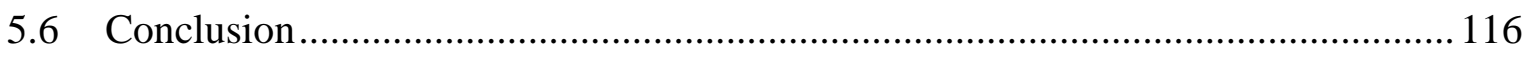

\section{CHAPTER 6}

MECHANICAL PROPERTIES OF POLYELECTROLYTE COMPLEX

COATED WOOL FIBRES USING CHITOSAN AND GELLAN GUM..................117

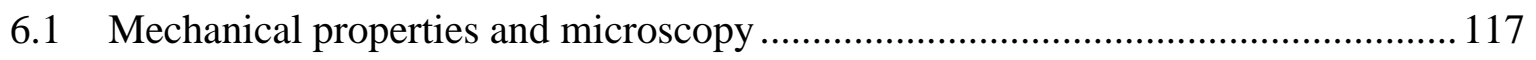

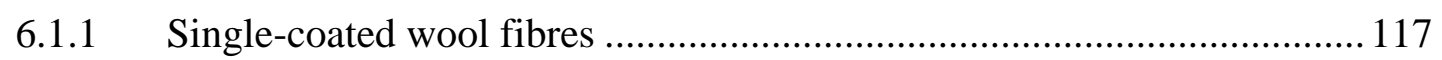

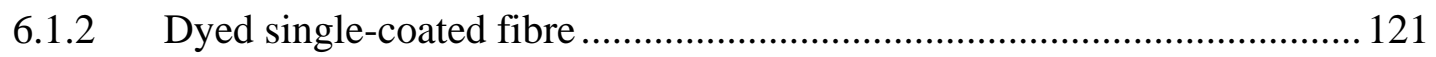

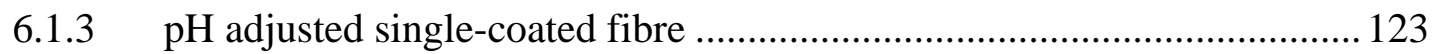

6.1.4 Dyed and pH adjusted polyelectrolyte complex-coated fibre.................... 123

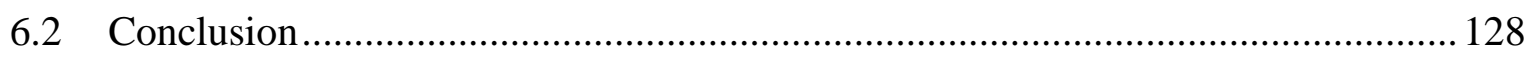

\section{CHAPTER 7}

POLYELECTROLYTE COMPLEX FILMS CONSISTING OF ANTI-BACTERIAL

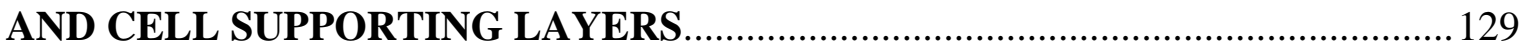

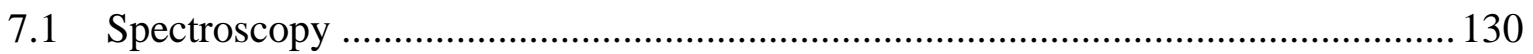

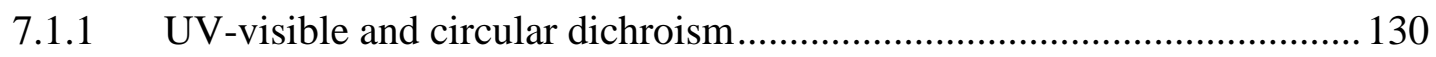

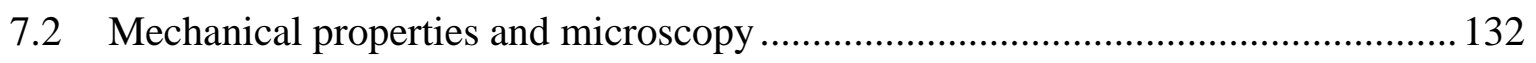




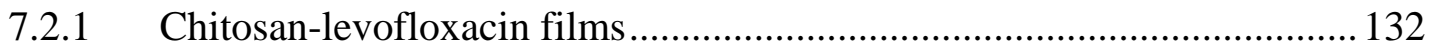

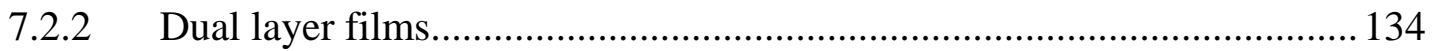

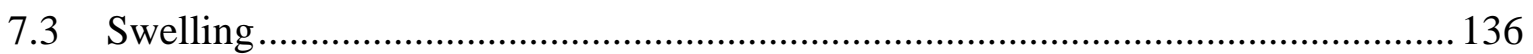

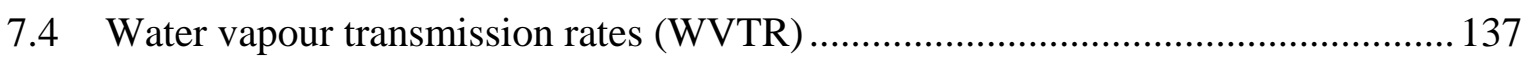

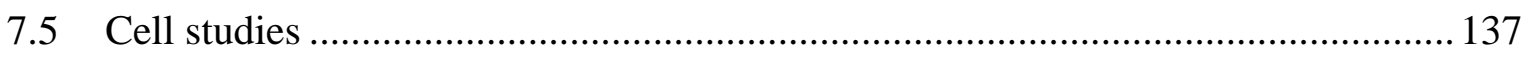

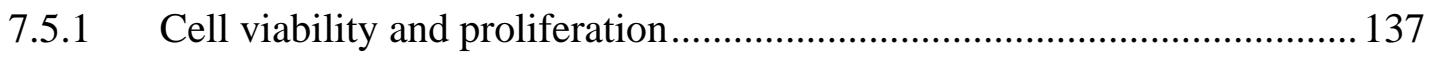

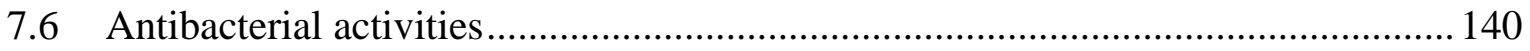

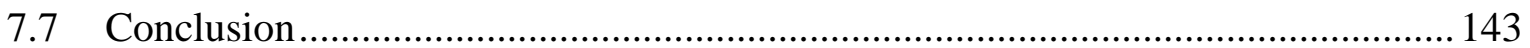

\section{CHAPTER 8}

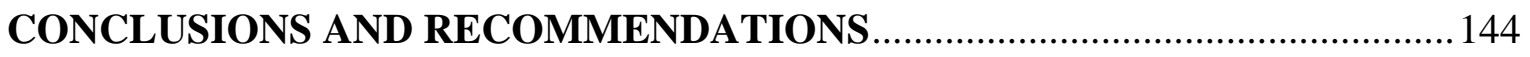

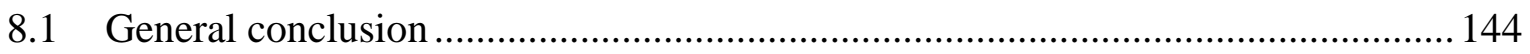

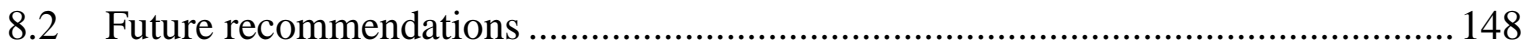

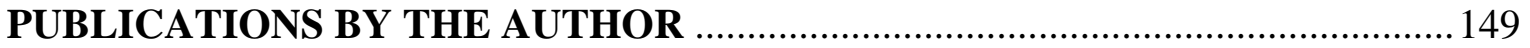

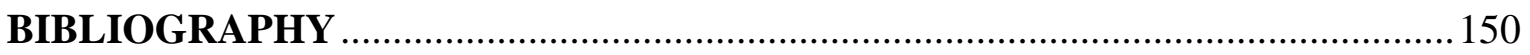




\section{LIST OF FIGURES}

Figure 1.1 : (A) Primary healing, (B) secondary healing, and (C) delayed primary healing (reproduced from reference 8).

Figure 1.2 : Radii of curvature of various body regions and suitable wound dressings (reproduced from reference 35).

Figure 1.3 : (A) Schematic of the film deposition process, and (B) molecular picture of the first two steps of deposition (reproduced from reference 86)................................16

Figure 1.4 : The formation of a polyelectrolyte complex of two oppositely charged polyelectrolytes in aqueous solution of different $\mathrm{pH}$. (reproduced from reference 95).

Figure 1.5 : Encapsulation process of alkaline phosphatase by polyelectrolyte complex technique between CH-GG ((reproduced from 149).

Figure 1.6 : Structure of chitosan ( $l=$ acetylated unit, $m=$ deacetylated unit).... .21

Figure 1.7 : Schematic illustrating the versatility of fabrication of chitosan. At low $\mathrm{pH}(<6)$, chitosan's amine is protonated and active as polyelectrolyte solution to be used in polyelectrolyte complex. At higher $\mathrm{pH}(>6.5)$, chitosan's amine is deprotonated and the molecular structure can be altered by grafting or crosslinking to form film, fiber or gel network (reproduced from reference 168)......

Figure 1.8 : The structure of gellan gum; (A) high acyl gellan gum, and (B) low acyl gellan gum (Ac: acetate group, Gly: glycerate group) (reproduced from reference 202).26

Figure 1.9 : Schematic of mechanism of antibacterial activities exerted by Ag (reproduced from reference 230). . .32

Figure 1.10 : General structure of fluoroquinolone (reproduced from reference 262)................34

Figure 1.11: The chemical structure of levofloxacin (reproduced from reference 264)....... .34

Figure 2.1 : Schematic of the preparation of free standing $\mathrm{CH}$ and $\mathrm{CH}$ films by evaporative casting technique.

Figure 2.2 : Schematic of the preparation of polyelectrolyte complex film. CH and GG films were laid flat into the solution of oppositely charge for $30 \mathrm{~s}$ on each side.

Figure 2.3 : Schematic of the formation of polyelectrolyte complex (PEC) on wool fibre; (A) pristine wool fibre immersed into chitosan or gellan gum solutions at different immersion of durations, (B) wool fibres were dried on the retort stand, (C) coated wool fibres were immersed into solutions of oppositely charge at different 
immersion of durations and (D) the PEC-coated wool fibres were dried on the retort stand.

Figure 2.4 : Schematic of the preparation of dual layer films. CH-Lev01 solution is pouring onto the surface of GGTi20 composite in the acrylic plate and dried . .45

Figure 2.5 : (A) Metrohm $826 \mathrm{pH}$ mobile, (B) electrode plus glass electrode dips into the solution or dispersion and (C) flat-membrane glass electrode is attached on the film surface or coated-wool fibres. .46

Figure 2.6 : (A) Film and (B) coated-wool fibre are clamped between the grips for tensile testing, respectively . .47

Figure 2.7 : Contact angle $(\theta)$ measurement of water droplet on the sample. .49

Figure 2.8 : (A) Film is fixed on the circular opening of a permeation bottle and stored in a temperature humidity chamber at $21^{\circ} \mathrm{C}$ and $50 \pm 5 \%$ RH... . .50

Figure 2.9 : Escherichia coli suspension evenly spread on the surface of LB agar and solutions/dispersions were filled up into the holes. .55

Figure 3.1 : (A) UV-visible absorption spectra of CH and CH30 films (pathlength=5 mm), (B) UV-visible absorbance spectra of CH-Ag dispersions with 10\%, 20\% and 30\% of nanoparticle loadings (by weight relative to $\mathrm{CH}$ ) (pathlength=0.01 mm); inset: characteristic absorption band of Ag at $420 \mathrm{~nm}$ (C) UV-visible absorbance spectra of $\mathrm{CH}-\mathrm{TiO}_{2}$ dispersions with $10 \%, 20 \%$ and $30 \%$ of nanoparticles loadings (by weight relative to $\mathrm{CH}$ ) (pathlength $=0.01 \mathrm{~mm}$ ).

Figure 3.2 : (A) Correlation of the transmittance (wavelength at $600 \mathrm{~nm}$ ) against thickness of the $\mathrm{CH}$ films with $10 \%$ to $50 \%$ of glycerine (by weight relative to $\mathrm{CH}$ ); inset: transmittance of the $\mathrm{CH}$ film and (B) transmittance of $\mathrm{CH}-\mathrm{Ag}$ and $\mathrm{CH}-\mathrm{TiO}_{2}$ composite films at $10 \%$ of nanoparticles loading (by weight relative to $\mathrm{CH}$ ). ......60

Figure 3.3 : (A) CH30 film, (B) CHTi20 composite, (C) CHAg20 composite and (D) CH30, CHTi20 and CHAg20 (left to right) dispersions after 6 months. All measurements of UV absorbance were carried out at $21^{\circ} \mathrm{C}$. Films dimension are $2 \mathrm{~cm}$ x $2 \mathrm{~cm}$. .61

Figure 3.4 : (A) Comparison between $\mathrm{CH}$ and $\mathrm{CH} 30$ solutions (pathlength=0.01 mm), (B) typical temperature dependence of $\mathrm{CH} 30$ solution at $10^{\circ} \mathrm{C}, 21^{\circ} \mathrm{C}, 37^{\circ} \mathrm{C}$ and 50 ${ }^{\circ} \mathrm{C}$ (pathlength $=0.01 \mathrm{~mm}$ ) and (C) CD spectra of CH30, CHAg10, CHAg20, and CHAg30 composite films (pathlength=5 mm). All measurements were carried out at $21^{\circ} \mathrm{C}$ unless stated otherwise.

Figure 3.5 : Typical stress-strain curves of (A) $\mathrm{CH}$ film containing $0 \%, 15 \%, 30 \%$ and $50 \%$ glycerine (by weight relative to $\mathrm{CH}$ ), (B) $\mathrm{CH}-\mathrm{TiO}_{2}$ composites containing $10 \%$, $20 \%$ and $30 \%$ nanoparticle loadings (by weight relative to $\mathrm{CH}$ ), (C) $\mathrm{CH}-\mathrm{Ag}$ composites containing 10\%, 20\% and 30\% nanoparticle loadings (by weight 
relative to $\mathrm{CH}$ ) and (D) comparison between the $\mathrm{CH} 30$ film, $\mathrm{CH}-\mathrm{TiO}_{2}$ and $\mathrm{CH}-\mathrm{Ag}$ composite films with 30\% nanoparticle loadings (by weight relative to $\mathrm{CH}$ ). ......64

Figure 3.6 : Scanning electron microscopy images of cross-sectional areas of (A) CH-Ag composite film with $10 \%$ nanoparticle loading (by weight relative to $\mathrm{CH}$ ) (CHAg10), (B and C) enlarged view of CHAg10 composite film, (D) CH-Ti composite film with $10 \%$ nanoparticle loading (by weight relative to $\mathrm{CH}$ ) (CHTi10), and (E-F) enlarged view of CHTi10 composite film. . .68

Figure 3.7 : Swelling of films in Milli-Q water for 24h; (A) CH15 film, (B) CH50 film, (C) CHAg20 composite and (D) CH-Ti nacomposite. Scale bars represent $1 \mathrm{~cm}$.......69

Figure 3.8 : (A) As prepared CH30 films (without $1 \mathrm{M} \mathrm{NaOH}$ treatment), (B) CH30 film with $1 \mathrm{M} \mathrm{NaOH}$ treatment, (C) fluorescent image of adherent L929 cells on CHTi10 composite, (D) fluorescent image of cells death on CHAg10 composite, and (F) cell proliferation of CH30 film and CH-Ti composites cultured in L929 cell for 72h. Errors represent one standard deviation from the measured values $(n=3)$. Scale bars represent $50 \mu \mathrm{m}$. .72

Figure 3.9 : In-direct contact assay of the CH-composites after incubated with L929 cell for 72h; (A) TCPP, (B) CHTi10, and (C) CHAg10. Scale bars represent $100 \mu \mathrm{m} . . . .74$

Figure 3.10: Antibacterial activity of samples quantified by a qualitative method against Escherichia coli incubated at $37^{\circ} \mathrm{C}$ for $24 \mathrm{~h}$. (A) CHAg20 dispersion, (B) CHTi20 dispersion, (C) CHAg20 composite, (D) CHTi20 composite, and (E) inhibition zone on the $\mathrm{CH}-\mathrm{Ag}$ dispersions and films. Errors represent one standard deviation from the measured mean values $(n=3)$. . .78

Figure 3.11: Vero cells infected by green fluorescent protein restrain of Ross-river virus (in boxes) on tissue culture polystyrene plate (TCPP) (as control) and CH30 film after incubated for $6 \mathrm{~h}, 12 \mathrm{~h}$ and $24 \mathrm{~h}$. Scale bars represent $50 \mu \mathrm{m}$. .80

Figure 4.1 : (A) UV-visible absorbance of the GG and GG50 films (pathlength=5 mm), (B) UV-visible absorbance of the GG-composite dispersions (pathlength=0.01 mm), (C) UV-visible transmittance of the GG-composites films (pathlength=5 $\mathrm{mm}$ ); inset: transmittance of the GG50 film. All measurements of UV absorbance were carried out at $21^{\circ} \mathrm{C}$.

Figure 4.2 : Photographs of the films; (A) GG50, (B) GGTi20 composite, (C) GGAg20 composite and (D) GGZn20 composite. Films dimension are $2 \mathrm{~cm} \times 2 \mathrm{~cm}$. . .85

Figure 4.3 : Circular dichroism (CD) spectra: (A) GG and GG50 films (pathlength=5 mm), (B) GG50 solution (pathlength=0.01 mm) and film (pathlength=5 mm), and (C) GG50 and GG-composite dispersions (pathlength $=0.01 \mathrm{~mm}$ ). All measurements were carried out at $21^{\circ} \mathrm{C}$. .86 
Figure 4.4 : Typical stress-strain curves; (A) gellan gum (GG) with 15\% (GG15), 30\% (GG30), 50\% (GG50), 60\% (GG60) and 70\% (GG70) (by weight relative to GG) glycerine contents and (B) comparison of GG50 film and GG-composites films containing 20\% (by weight relative to GG) of $\mathrm{TiO}_{2}$ (GGTi20), Ag (GGAg20) and ZnO (GGZn20) nanoparticles loading.

Figure 4.5 : (A) Illustration of the intercalation of nanoparticles into GG matrix, (B-D) SEM images of cross-section of GG-composite films; (B) GGTi20 composite, (C) GGAg20 composite, (D) GGZn20 composites, (E-G) SEM images of nanoparticles agglomeration; (E) GGTi20 composite, (F) GGAg20 composite, and (G) GGZn20 composite.

Figure 4.6 : L929 cells grown on GG (A-C) and GG50 (D-F) films at different time intervals; (A and D) 24h, (B and E) 72h, and (C and F) 144h. The cells were viable on both films which indicate the films support cell growth. Scale bars represent $50 \mu \mathrm{m} . . .95$

Figure 4.7 : Fluorescence microscope images of the cytotoxic effect of incorporated $\mathrm{TiO}_{2}, \mathrm{Ag}$ and $\mathrm{ZnO}$ nanoparticles into the GG films after culture in the medium containing L929 cell lines for (A-C) 24h and (D-F) 72h; (A and D) GGTi20 composite, (B and E) GGAg20 composite, and (C and F) GGZn20 composite. Scale bars represent $50 \mu \mathrm{m}$. . .96

Figure 4.8 : Cytotoxicity of the media containing L929 cells incubated with GG- $\mathrm{TiO}_{2}$, GG-Ag and GG-ZnO composites for 72h; (A) TCPP (negative control), (B) GGTi20 (C) GGAg20 and (D) GGZn20. Scale bars represent $50 \mu \mathrm{m}$.

Figure 4.9 : Representative fluorescent micrographs of live (green) surface of L929 cells in GGTi20 composite film after (A, B and C) 48h and (D, E, F) 144h of culture.....98

Figure 4.10: (A-C) Schematic of the attachment and proliferation of 2929 cells in response to the gellan gum surface after $24 \mathrm{~h}, 72 \mathrm{~h}$ and $144 \mathrm{~h}$ following cell seeding and (D) the increase in attached L929 cell numbers after $24 \mathrm{~h}, 72 \mathrm{~h}$ and $144 \mathrm{~h}$ of culture on GG, GG50 and GGTi20 composite films. Error bars represent standard errors of triplicate assays. . .99

Figure 4.11: (A-D) Antibacterial activity of the GG50 film and GG-composites films quantified by qualitative method after incubated at $37^{\circ} \mathrm{C}$ for $24 \mathrm{~h}$; (A) GG50 film, (B) GGAg30 composite, (C) GGTi30 composite and (D) GGZn30 composite. .101

Figure 4.12: (A-C) SEM images of surfaces' of GG-composites; (A) GGAg20 composite, (B) GGTi20 composite and (C) GGZn20 composite. Scale bars represent $1 \mu \mathrm{m} . . . . .102$

Figure 5.1 : UV-visible absorbance spectra; (A) CH and GG films, (B) pH adjusted CH and GG films using $\mathrm{CH}(\mathrm{pH}=1.80)$ and $\mathrm{GG}(\mathrm{pH}=12.00)$ solutions and (C-D) polyelectrolyte complex (PEC)-films of CH and GG. 105 
Figure 5.2 : (A-B) Free-standing films; (A) $\mathrm{CH}$, (B) $\mathrm{CH}(\mathrm{pH})$, (C-F) PEC-films with the order of addition of $\mathrm{CH}^{\text {into }} \mathrm{GG}$; (C) $\mathrm{CH}^{\text {into }} \mathrm{GG}$, (D) $\mathrm{CH}(\mathrm{pH}){ }^{\text {into }} \mathrm{GG}$, (E) $\mathrm{CH}^{\text {into }} \mathrm{GG}(\mathrm{pH})$ and (F) $\mathrm{CH}(\mathrm{pH}){ }^{\text {into }} \mathrm{GG}(\mathrm{pH})$. The naming of PEC-films as followed. For example, freestanding $\mathrm{CH}(\mathrm{pH})$ films dipped into GG solution is hereafter named as $\mathrm{CH}(\mathrm{pH}){ }^{\text {into }} \mathrm{GG}$. 106

Figure 5.3 : (A-B) Free-standing films; (A) GG, (B) GG(pH), (C-F) PEC-films with the order of addition of $\mathrm{GG}^{\text {into }} \mathrm{CH}$; (C) $\mathrm{GG}^{\text {into }} \mathrm{CH}$, (D) $\mathrm{GG}(\mathrm{pH}){ }^{\text {into }} \mathrm{CH}$, (E) $\mathrm{GG}^{\text {into }} \mathrm{CH}(\mathrm{pH})$ and (F) $\mathrm{GG}(\mathrm{pH}){ }^{\mathrm{into}} \mathrm{CH}(\mathrm{pH})$. The naming of PEC-films as followed. For example, freestanding $\mathrm{GG}(\mathrm{pH})$ films dipped into $\mathrm{CH}$ solution is hereafter named as $\mathrm{GG}(\mathrm{pH}){ }^{\mathrm{into}} \mathrm{CH}$. 107

Figure 5.4 : Stress-strain curves of films; (A) $\mathrm{CH}$ and $\mathrm{CH}(\mathrm{pH})$ and (B) GG and GG(pH)....108 Figure 5.5 : Stress-strain curves of films; (A) $\mathrm{CH}$ and $\mathrm{CH}^{\text {into }} \mathrm{GG}$ and (B) GG and $G \mathrm{G}^{\text {into }} \mathrm{CH} .109$ Figure 5.6 : (A) Tensile strength, (B) toughness, (C) strain-at-break and (D) density as a function of $\mathrm{CH}$ :GG ratio for polyelectrolyte complex-films prepared by dipping CH into GG (spheres) and GG into CH (squares).

Figure 5.7 : Optical microscope images of cross-section of films; (A) $\mathrm{CH}$, (B) $\mathrm{CH}^{\text {into }} \mathrm{GG}$, (C) GG and (D) $G G^{\text {into }} \mathrm{CH}$.

Figure 6.1 : (A) Tensile strength, (B) Young's modulus, (C) toughness (D) strain-at-break and (E) diameter of $\mathrm{CH}$-fibre (triangles) and GG-fibre (squares) as function of immersion duration time (min).

Figure 6.2 : (A-C) Cross sectional area of single-coated fibres; (A) pristine wool fibre, (B) CH-fibre after 20 min of immersion, (C) GG-fibre after 5 min of immersion, (D-F) fractured topography (side view) of coated fibres from tensile testing; (D) pristine wool fibre, (E) CH-fibre after $20 \mathrm{~min}$ of immersion and (F) GG-fibre after $5 \mathrm{~min}$ of immersion.

Figure 6.3 : (A) Colour transformation of $\mathrm{CH}(\mathrm{pH}){ }^{\text {into }} \mathrm{GG}(\mathrm{pH})$ PEC-coated fibre at $0.5,1,5,10$, 15 and 20 min of immersions and (B) K/S values of red $(\diamond)$ and green ( $\square$ ) channels as a function of duration of immersions. 125

Figure 6.4 : (A) Single-coated fibres GG-dyed fibres before and after $\mathrm{pH}$ modification, (B-D) PEC-coated fibres; (B) $\mathrm{GG}^{\mathrm{into}} \mathrm{CH},(\mathrm{C}) \mathrm{GG}^{\mathrm{into}} \mathrm{CH}(\mathrm{pH})$ and (D) $\mathrm{GG}(\mathrm{pH}){ }^{\mathrm{into}} \mathrm{CH}(\mathrm{pH})$. Those PEC-coated fibres are covered with a green colour on the outer layer and yellow colour at core of each fibre. 126

Figure 7.1 : (A) UV-visible absorption of CH, CH-Lev01, CH-Lev1 and CH-Lev5 films, (B) UV-visible absorption of CH-Lev01 film and dual layer films (C) transmittance of the CH, CH-Lev01, CH-Lev1, and CH-Lev5 films and (D) circular dichroism 
spectra of $\mathrm{CH}$ film with different amounts of levofloxacin. All measurements were carried out at $21^{\circ} \mathrm{C}$ using a $5 \mathrm{~mm}$ cuvette.

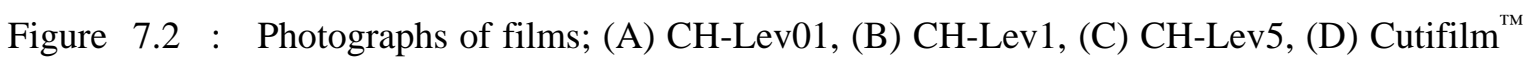
and (E-G) dual layer films at different angles. The dual layer films were robust and flexible which could be easily folded and rolled-up without breaking. Scale bars represent $1 \mathrm{~cm}$.

Figure 7.3 : (A) Typical stress-strain curves of the CH-Lev01, CH-Lev1 and CH-Lev5 films, and (B) comparison stress-strain curves of the CH-Lev01 film, GGTi20 composite and dual layer films.

Figure 7.4 : Representative of (A) tensile strength, (B) Young's modulus, (C) toughness and (D) strain-at-break of chitosan films as a function of levofloxacin contents (by weight relative to $\mathrm{CH}$ ).

Figure 7.5 : (A) Optical imaging of cross-section of dual layer films (upper layer is CH-Lev01, bottom layer is GGTi20 composite), (B) field emission-SEM (FE-SEM) imaging of a freeze-fractured dual layer films, (C) enlargement of finely dispersed titanium dioxide $\left(\mathrm{TiO}_{2}\right)$ nanoparticles throughout the GG matrix and (D) aggregation of $\mathrm{TiO}_{2}$ nanoparticles in the GG matrix. .135

Figure 7.6 : Fluorescence microscope images of L929 cells on the CH-Lev01 film after (A) 24h, (B) $72 \mathrm{~h}$ and (C) 144h. Scale bars indicate $20 \mu \mathrm{m}$.

Figure 7.7 : Fluorescence microscope images of L929 cells on the (A) CH-Lev01 and (B) GGTi20 surfaces of a dual layer film after incubating for $72 \mathrm{~h}$. Scale bar represents $20 \mu \mathrm{m}$.

Figure 7.8 : Photograph of qualitative antimicrobial test of (A) CH-Lev01, (B) CH-Lev1 and (C) CH-Lev5 films against E. coli. The inhibition zone is indicated by the arrow. Scale bars indicate $6 \mathrm{~mm}$. 140

Figure 7.9 : (A) Inhibition zones for CH-Lev films against E. coli after 24h of incubation and (B) Effectiveness expressed in a viable colony counts (CFU/mL) for CH-Lev01, $\mathrm{CH}$ and control (innoculum without film) against E. coli after $1 \mathrm{~h}$. “0 h" indicates the number of colonies in the inoculums. 141

Figure 7.10: (A) UV-vis spectra of PBS solution at $37{ }^{\circ} \mathrm{C}$ at increasing CH-Lev01 film immersion time, (B) absorbance of levofloxacin from a CH-Lev01 film at $287 \mathrm{~nm}$ versus immersion time, (C) absorbance of levofloxacin from a CH-Lev01 film at $287 \mathrm{~nm}$ versus levofloxacin concentration, and (D) loss of levofloxacin from a CH-Lev01 film (squares) compared with theoretical prediction of calculated loss assuming diffusion coefficient of $1.0 \times 10^{-7} \mathrm{~cm}^{2} \mathrm{~s}^{-1}$ (solid line). 142 


\section{LIST OF TABLES}

Table 1.1 : Global cases of wound management worldwide (Source: MedMarket Diligence report \#S247)

Table 1.2 : The evaporative water loss of damaged skin as reported by Lamke et al. ${ }^{30}$...........7

Table 1.3 : Water vapour transmission rates (WVTR) of commercial wound dressings obtained by Queen et al. ${ }^{32}$.

Table 1.4 : Different types of wound dressings available on the market (reproduced from reference 8).

Table 3.1 : Properties of chitosan films with different percentages of glycerine (Gly). Thickness (thick), tensile strength (TS), Young's modulus (E), toughness (T), strain-at-break $(\gamma)$, swelling and contact angle (CA) are given for each film......64

Table 3.2 : Properties of films prepared using chitosan from various sources (source), degree of deacetylation (DD), viscosity ( $\eta$ ), glycerin (Gly) (by weight relative to chitosan). "CH1" and "CH2" indicate two different batches of medium molecular weight chitosan, while “CH3” indicates high molecular weight chitosan, respectively. Tensile strength (TS), Young's modulus (E), and strain-at-break ( $\gamma$ ) of those $\mathrm{CH}$ films.

Table 3.3 : Properties of composite films prepared using chitosan with titanium dioxide $\left(\mathrm{TiO}_{2}\right)$ and silver (Ag) nanoparticles. Nanoparticles content (NP), thickness (Thick), tensile strength (TS), Young's modulus (E), toughness (T), strain-atbreak $(\gamma)$, water vapour transmission rates (WVTR), swelling and contact angle (CA) are listed for the different composite materials. All samples were prepared with $30 \%$ glycerine content by weight relative to chitosan. .67

Table 3.4 : The number of viable bacterial colonies after 24 hours ( $n_{\text {viable }}$ ) of control, commercial antibiotic (ampicillin), CH30, and $\mathrm{CH}$-composites. Errors represent one standard deviation from the measured mean values $(n=3)$. . .76

Table 4.1 : Mechanical properties of gellan gum film containing different percentages of glycerine. Thickness (Thick), tensile strength (TS), Young's modulus (E), toughness $(\mathrm{T})$ and strain-at-break $(\gamma$ ) for the different GG materials are given...89 
Table 4.2 : Properties of GG50 and GG-composite films. Thickness (Thick), tensile strength (TS), Young's modulus (E), toughness (T), strain-at-break $(\gamma)$ and swelling for the different composite materials. All samples were prepared with 50\% glycerine content by weight relative to gellan gum.

Table 4.3 : Water vapour properties of GG50 and GG-composites films. Water vapour transmission rates (WVTR), water vapour permeability (WVP), and permeance (P) for the different composite materials are given.

Table 5.1 : Summary of composition of the films determined using elemental analysis, CH:GG ratios, tensile strength (TS), Young's modulus (E), toughness (T) and strain-at-break $(\gamma)$ values. 110

Table 5.2 : Water vapour transmission rates (WVTR), water vapour permeability (WVP), permeance $(\mathrm{P})$ values, and percentage swelling upon immersion into buffer of $\mathrm{pH}$ 1 and $\mathrm{pH} 7$ for 24 hours.

Table 6.1 : Mechanical properties of CH-fibre and GG-fibre at different immersion duration time. Tensile strength (TS), Young's modulus (E), toughness (T) and strain-atbreak $(\gamma)$ for different single-coated fibre are given.

Table 6.2 : Mechanical properties of dyed single-coated fibre (unless stated otherwise), $\mathrm{pH}$ adjusted single-coated fibre and dyed with $\mathrm{pH}$ adjusted polyelectrolyte complex (PEC)-coated fibres. CH-fibres and $\mathrm{CH}$ solutions were dyed with food colour (blue); and GG-fibres and GG solutions were dyed with yellow colour. Singlecoated fibres immersed in $\mathrm{CH}$ and GG solution for $20 \mathrm{~min}$ and $5 \mathrm{~min}$, respectively. For PEC-coated fibres, $\mathrm{CH}$ single-coated fibre immersed in GG solution for 20 min $\left(\mathrm{CH}^{\text {into }} \mathrm{GG}\right)$ and $\mathrm{GG}$ single-coated fibre immersed in $\mathrm{CH}$ solution for $5 \mathrm{~min}\left(\mathrm{GG}{ }^{\text {into }} \mathrm{CH}\right)$. Tensile strength (TS), Young's modulus (E), toughness $(\mathrm{T})$ and strain-at-break $(\gamma)$ of coated fibres are given.

Table 7.1 : Mechanical properties of CH film, CH-Lev01 film, CH-Lev1 film, CH-Lev5 film, GGTi20 composite, dual layer films and Cutifilm ${ }^{\mathrm{TM}}$. Thickness (Thick), tensile strength (TS), Young's modulus (E), toughness (T) and strain-at-break ( $\gamma$ ) for the different materials are given.

Table 7.2 : Properties of films. Thickness (Thick), water vapours transmission rates (WVTR), water vapour permeability (WVP), permeance (P) and swelling for the different materials are given. 


\section{CHAPTER 1}

\section{GENERAL INTRODUCTION}

\subsection{Overview of wound management}

\subsubsection{What is a wound?}

A wound is a type of injury in which the skin or living tissue is torn, cut or punctured as the results of surgical incisions, diseases, or burns ${ }^{1}$. Every year, there are approximately 165 million cases worldwide requiring wound treatment across different types of wounds as shown in Table 1.1. Surgical wounds are the vast majority of injuries (103 million) followed by lacerations (20 million), diabetic ulcers (11 million) and burn wounds (10 million) (Table 1.1) ${ }^{2}$. Surgical wounds are classified to three types: (i) skin grafts or muscle flaps, (ii) wound dehiscence, and (iii) surgically debrided wounds and left to close by secondary intention ${ }^{1}$.

Laceration is the common type of trauma that occurs as a result of a graze due to the dressing sticking to the wound. Chronic wounds such as diabetic and venous ulcers are caused by an autoimmune disorder of pancreatic $\beta$-cells and arterial problems, respectively ${ }^{3}$. Burn injuries occur when energy is transferred from a heat source (electrical, thermal, chemical) to the body which may result in cell death 
depending on burn size and depth ${ }^{4}$. Burn depth is described in terms of degrees: (i) first-degree burns (superficial burns), involves only the epidermis ${ }^{5}$, (ii) seconddegree burns (superficial-thickness burns), involves the epidermis and dermis, (iii) third-degree burns (full-thickness burns), involves the epidermis and dermis in subcutaneous tissues ${ }^{6}$, and (iv) fourth-degree burns (subdermal burns), involves epidermis, dermis, fat, muscle, tendon and/or bone ${ }^{6}$.

Table 1.1: Global cases of wound management worldwide (Source: MedMarket Diligence report \#S247).

Wound Type

Worldwide Prevalence

(millions)

Surgical wounds

102.8

Traumatic wounds

Lacerations

Burn wounds (out-patient)

Burn wounds (medically treated)

Burn wounds (hospitalized)

Pressure ulcers

Venous ulcers

Diabetic ulcers

Amputations

Carcinomas

Melanoma

0.1

Complicated skin cancer

0.1

Total 
There are more than 3000 wound products available on the market to fulfil the specific functions of healing ${ }^{7}$. They cover a wide range of treatments such as passive dressings (gauze, bandages), advanced and active wound care products (semipermeable dressing, multilayer absorbent dressing, calcium alginate dressing, hydrogel, hydrocolloid), physical therapies for wound care (electrical stimulation, ultrasound), closure products (sutures, staples, tapes), internal wound products for surgery (locking plate, nails, screws), and last, but not least tissue engineering (scaffolds) ${ }^{8}$.

Approximately $80 \%$ of the surgical wounds are treated with wound closure products such as sutures, staples and tapes, however in the case of surgically debrided wounds, a wound dressing is used to cover the open wound, which is then filled by granulation and closed by epithelialisation ${ }^{9}$. A significant problem of this type of wound healing is the likelihood of pathological infection. The average level of infections in surgical wounds is 7 to $10 \%$, dependent on the procedure, surgical discipline and skills. Infections can be prevented by wound care products with antibacterial properties ${ }^{10}$.

It is crucial that laceration and chronic wounds are treated using advanced and active wound care products which provide a moist wound environment and absorb exudates, and an antibacterial barrier ${ }^{11,12}$. Burn wounds (minor burns, medically treated, and hospitalized) have been healed by using hydrogel and advanced wound care products to increase tissue proliferation and to improve the healing process ${ }^{13-17}$. 


\subsubsection{What is wound healing?}

Wound healing is an organized process consisting of three overlapping phases, i.e. inflammation, proliferation, and maturation/ remodelling ${ }^{8,18,19}$. Inflammation occurs within hours of wound formation. It allows the body to control blood loss and fight bacterial invasion. Polymorphs and macrophages combine in a defence against bacteria and begin the process of repairing by clearing debris, damaged tissue, as well as recruiting fibroblast cells ${ }^{20}$. These cells are responsible for synthesizing collagen which reforms the structure of protein around the wound area. The cellular and enzymatic activities in the wound are responsible for increasing the osmolality (exudates) and fracturing of the skin edges around the wound site ${ }^{21,22}$. This process results in patients experiencing pain due to swelling, and leads to a slow healing process. Therefore, it is important to provide a wound product which is capable of absorbing the exudates.

The proliferation process begins within $48 \mathrm{~h}^{23}$ after injury and highly depends on the number of fibroblasts that produce the collagen ${ }^{18}$. The proliferation phase consists of three crucial parts: granulation tissue, wound contraction, and epithelialization ${ }^{24}$. The cellular and chemical activity of the wound site results in the formation of granulation tissue ${ }^{18}$. Wound contraction occurs during this phase. It is the drawing together of the wound margins, and is affected by the shape, depth, and size of the wound. ${ }^{25}$. As the wound area is filled with granulation tissue, epithelial cells (keratinocytes) begin to multiply and migrate across the wound bed ${ }^{26}$. This process accelerates fast because of the moist environment around the wound. The proliferation phase is completed when the wound is resurfaced with epithelial tissue. During this process, the tensile strength of the wound is improved depending on the 
area of the wound. The speed of the healing process is dependent on many factors such as, age of the patient and levels of red blood cells, oxygen and zinc in the body ${ }^{8}$.

The maturation phase is the last stage in the healing process, in which the vascularity of scar progressively decreases, the numbers of fibroblast are reduced, and the enlargement and reorientation of the collagen fibres strengthens the wound tissue. The strength of the wound site increases rapidly within 6 weeks and the amount of collagen formation in the scar increases for several months, or in some cases even up to 2 years ${ }^{23,27}$. Even after the wound area is fully remodelled, scar tissue is at most only $80 \%$ of the original tissue's strength and elasticity ${ }^{23,28}$.

There are three categories of wound healing: (i) primary healing, (ii) secondary healing and (iii) delayed primary healing ${ }^{8}$ (Figure 1.1). Primary healing relates to a wound that can be treated with simple sutures, tape or passive dressing (Figure $1 \mathrm{~A}$ ). When a wound is left open and allowed to heal by proliferation, the term secondary healing (Figure $1 \mathrm{~B}$ ) is used. Delayed primary healing relates to larger wounds that are infected or fail to successfully close by secondary healing (Figure 1.1 C).

A

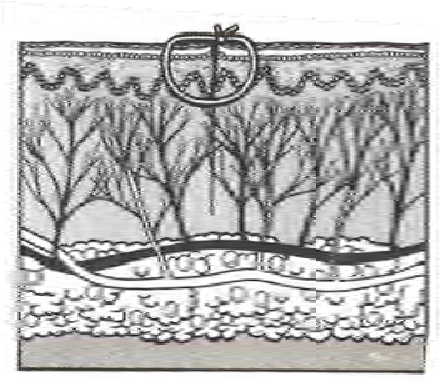

B

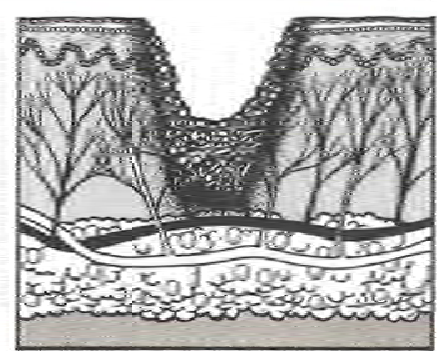

C

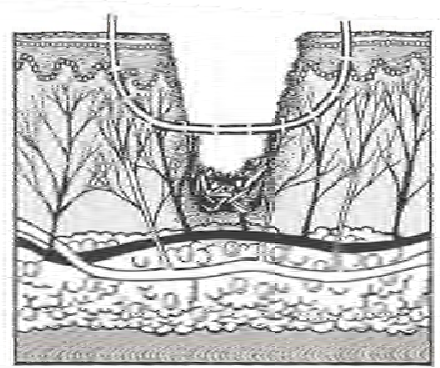

Figure 1.1: (A) Primary healing, (B) secondary healing, and (C) delayed primary healing (reproduced from reference 8). 


\subsubsection{What is an ideal wound dressing?}

An ideal wound dressing should be capable of maintaining a moist environment at the wound interface, be permeable to water, air and gas, able to remove an excess of exudates, offer an adequate toughness, be non-toxic, and be resistant to bacteria or micro-organism ${ }^{8,}{ }^{29-33}$. The human body is constantly losing water to the environment by evaporations through the skin to control the body's temperature. This process requires energy; approximately $2.43 \mathrm{~mJ}$ of energy is needed to evaporate one litre of water and an excessive water loss associated with enormous heat loss can affect the metabolism of the body ${ }^{34}$. Normal healthy skin evaporates about $204 \mathrm{~g} \mathrm{~m}^{-2} \mathrm{~d}^{-1}$ at $35.8{ }^{\circ} \mathrm{C}$ which increases depending on the activity ${ }^{35}$. First degree burns evaporate about 36\% higher than normal skin, and second degree burns evaporate almost 2000\% higher compared to normal skin (Table 1.2).

When a wound is covered with non-evaporative materials, the evaporative water loss from the wound results in the build-up of exudates and can lead to back pressure on the wound which causes considerable pain to the patient ${ }^{36}$. It also possible for dressings to move around the wound in accommodating exudates buildup which can results in dehydration and bacterial infection. It also results in leakage from the edge of the dressing and forms a pocket of fluids, in a process to relieve the pressure associated with exudates build-up, thus causing pain and discomfort to the patient ${ }^{37}$. Therefore, it is essential for wound dressing to have similar water vapour transmission rates (WVTR) as the skin, and provide a satisfactory moisture balance within the repairing wound. WVTR values which are too low might slow down the healing process, whereas WVTR values which are too high may result in faster

wound drying, leading to formation of scars ${ }^{38}$. The recommended WVTR is 500- 
$2000 \mathrm{~g} \mathrm{~m}^{-2} \mathrm{~d}^{-1}$, which would provide adequate moisture and prevent wound dehydration ${ }^{37}$.

Table 1.2: The evaporative water loss of damaged skin (reproduced from reference 35).

\begin{tabular}{lcc}
\hline Studied area & $\begin{array}{c}\text { Evaporative water loss } \\
\left(\mathrm{g} \mathrm{m}^{-2} \mathrm{~d}^{-1}\right)\end{array}$ & $\begin{array}{c}\text { Skin temperature } \\
\left({ }^{\circ} \mathrm{C}\right)\end{array}$ \\
\hline Normal skin & $204.0 \pm 12.0$ & $35.8 \pm 2.0$ \\
First-degree burn & $278.4 \pm 26.4$ & $35.3 \pm 0.1$ \\
Second-degree burn & $4274.4 \pm 132.0$ & $35.3 \pm 0.4$ \\
Third-degree burn & $3436.8 \pm 108.0$ & $34.5 \pm 0.4$ \\
Granulating wound & $5138.4 \pm 201.6$ & $34.7 \pm 0.2$ \\
Donor site & $3590.4 \pm 180.0$ & $35.3 \pm 0.2$ \\
\hline
\end{tabular}

Queen et al. ${ }^{37}$ was reported the WVTR of a few commercial wound dressings that were measured at $35^{\circ} \mathrm{C}$ and $35 \%$ of relative humidity $(\mathrm{RH})$, see Table 1.3. Wound dressings with the thickness below $0.2 \mathrm{~mm}$ exhibit WVTR values ranging from $139 \mathrm{~g} \mathrm{~m}^{-2} \mathrm{~d}^{-1}$ to $491 \mathrm{~g} \mathrm{~m}^{-2} \mathrm{~d}^{-1}$. WVTR values increased with decreasing thickness up to $3052 \pm 684 \mathrm{~g} \mathrm{~m}^{-2} \mathrm{~d}^{-1}$ (Table 1.3). For example, in a recent study, membranes of chitosan and alginate polyelectrolyte complex with thickness about $0.015 \mathrm{~mm}$ resulted in WVTR values between $442 \mathrm{~g} \mathrm{~m}^{-2} \mathrm{~d}^{-1}-618 \mathrm{~g} \mathrm{~m}^{-2} \mathrm{~d}^{-1}$ depending on amount of alginate ${ }^{39}$. The WVTR values of poly(vinyl) alcohol/Dextran hydrogel are about $1900 \mathrm{~g} \mathrm{~m}^{-2} \mathrm{~d}^{-1}-2000 \mathrm{~g} \mathrm{~m}^{-2} \mathrm{~d}^{-1} 40$. In addition, membrane with thickness < $0.1 \mathrm{~mm}$ will likely to record the WVTR values below than $1000 \mathrm{~g} \mathrm{~m}^{-2} \mathrm{~d}^{-1} 39,41$, whereas values for thicker dressing $(>0.1 \mathrm{~mm})$ such as hydrogel, hydrocolloid and foams are excess of $1000 \mathrm{~g} \mathrm{~m}^{-2} \mathrm{~d}^{-1}$ 40, 42-44 . Regardless, all these WVTR values are 
within the recommended range (500-2000 $\left.\mathrm{g} \mathrm{m}^{-2} \mathrm{~d}^{-1}\right)$ for providing a moist environment around the wound. Wu and co-workers ${ }^{45}$ also reported the comparison of WVTR without and with dressing on different types of burns and ulcer and reported that the dressing reduced the water transmission in of all burn types.

Table 1.3: Water vapour transmission rates (WVTR) of commercial wound dressings (reproduced from reference 37).

\begin{tabular}{lcc}
\hline Materials & Thickness & WVTR \\
& $(\mathrm{mm})$ & $\left(\mathrm{g} \mathrm{m}^{-2} \mathrm{~d}^{-1}\right)$ \\
\hline Stretch 'n' seal & 0.01 & $362 \pm 44$ \\
Vigilon cover film & 0.03 & $139 \pm 23$ \\
Vigilon + cover film & 1.16 & $168 \pm 32$ \\
Tegaderm & 0.03 & $491 \pm 44$ \\
Bioclusive & 0.10 & $382 \pm 26$ \\
Lyofoam & 10.3 & $3052 \pm 684$ \\
Synthaderm & 0.73 & $2005 \pm 203$ \\
Coraderm & 0.76 & $2859 \pm 296$ \\
Geliperm & 1.13 & $10973 \pm 998$ \\
Corethium & 0.36 & $10419 \pm 689$ \\
Free water surface & - & \\
\hline
\end{tabular}

The capability of a film, hydrogel, scaffold membrane or porous material to hold water is an important parameter in evaluating a wound dressing. Optimum water absorption might prevent the wound from accumulating of unwanted body fluid. This accumulation of wound exudates commonly causes maceration and 
facilitates infection ${ }^{46,47}$. It also facilitates a moist wound environment, which is helpful for the healing process ${ }^{48}$.

A wound dressing should provide an adequate toughness and flexibility to allow conformation to an uneven body surface. It should have a high tensile strength, and optimum strain-at-break to allow application on different body regions. As shown in Figure 1.2, no wound dressing is completely applicable to all body regions 49 . Some wound dressings can cover multiple regions (e.g. Coraderm, Bioclusive, Tegaderm and Synthaderm). Highly flexible materials and strong adhesives are needed to apply on elbow and finger joints ${ }^{49}$.

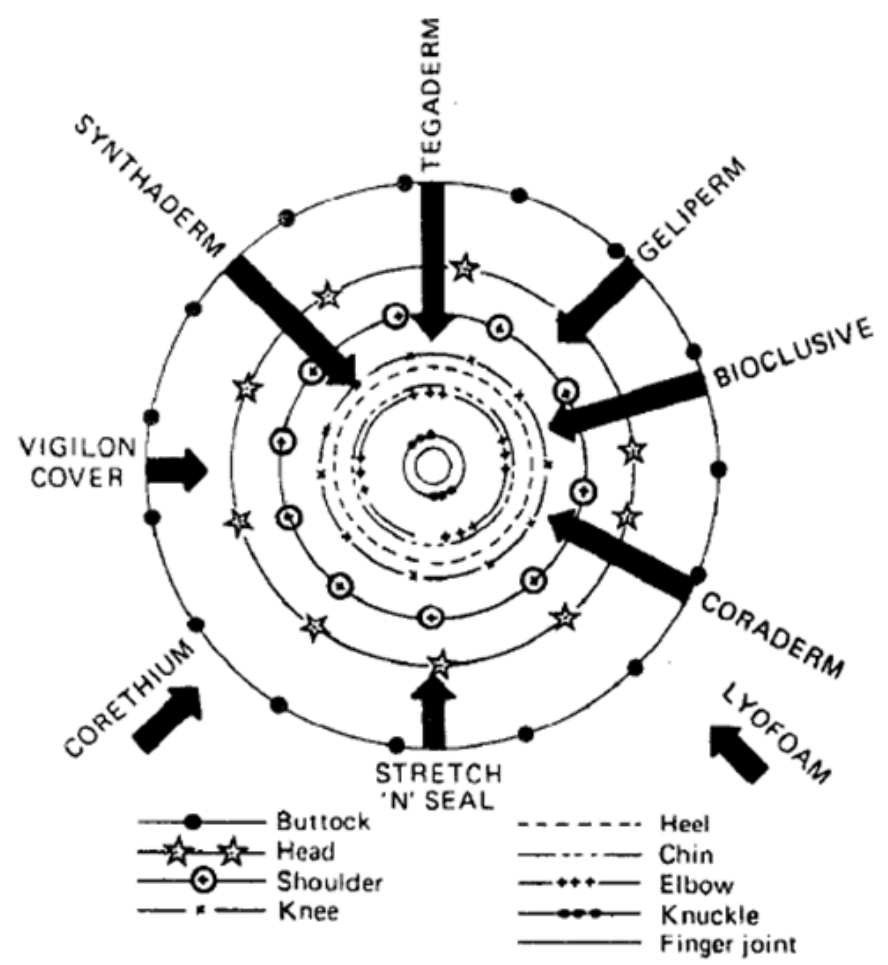

Figure 1.2: Radii of curvature of various body regions and suitable wound dressings (reproduced from reference 49).

Biocompatibility of wound materials or implants is involves low or no toxicity or carcinogenic effects, either locally or systemically in local tissue ${ }^{50-53}$. 
Biocompatibility evaluation consists of tissue compatibility (in-vitro and in-vivo) studies and blood compatibility ${ }^{54,55}$. Numerous studies have demonstrated successful in-vitro and in-vivo biocompatibility characteristics of biopolymers materials as dressings ${ }^{56-63}$, fixation devices, or replacement implants in musculoskeletal tissues ${ }^{64-}$ 66.

Bacterial contamination of a wound seriously threatens and affects the healing process. As an example, infection in burn wounds is the major complication reported, and it is estimated that about $75 \%$ of mortality cases following burn injuries is related to infection rather than to excessive exudate or hypervolemia ${ }^{67}$. Infection can lead to the formation of a biofilm in the wound within approximately 10 hours after infection 68. This biofilm protects the bacteria, which then become immune to antibiotics ${ }^{69,} 70$. Therefore, there is a need for the development of improved wound dressings that prevent, slow down or avoid the proliferation of bacteria and biofilms. An antimicrobial effect can be achieved by eluting germicidal compounds such as silver ions, titanium dioxide and iodine from the wound dressing ${ }^{71-73}$.

\subsubsection{Types of wound dressings available on the market}

A great variety of dressing types fulfil a specific requirement such as type of healing, location and age of wound, size and stage, level of exudates, wound infection, tissue loss or maceration to improve the speed and effectiveness of wound healing ${ }^{3,7,8}$. Gauze dressings (natural or synthetic fibres) are the most commonly used today because they are inexpensive and can be applied to most of body parts. However, the granulation tissue and keratinocytes get trapped within the dressing and these fragile 
tissues are often dislodged together with the dressing thereby delaying wound healing 7

To improve on this problem, advance and active wound care products such as, semipermeable films, multilayer absorbent dressings, calcium alginate dressings, hydrogels, and hydrocolloids have been developed. Newer developments are the evaporation technique, gelation process, hydrogels, scaffold, dual layer film, dry/ wet phase separation method, and hybrid peptides ${ }^{74-83}$. Table 1.4 gives an overview of different types of commercially available wound dressings and describe the advantages and disadvantages of each of them.

Table 1.4: Different types of wound dressings available on the market (reproduced from reference 8$)$.

\begin{tabular}{llll}
\hline Type & Example and & Advantage & Disadvantage \\
& manufacturer & & \\
Natural fibre dry & Cotton wool, gauze, linen & Provides dry wound & Granulation tissue \\
dressing & product & healing environment & can grow into the \\
& & & mesh of product \\
Synthetic fibre & Topper 8, Johnson \& & More absorbent than & Creates a dry \\
gauze & Johnson & cotton & and gives trauma \\
Non-adherent, & Tricotex, Smith \& & Non-adherent dry & Not absorbent \\
non-absorbent & Nephew & dressing & \\
dressing & & & to the patient \\
Non-adherent & Melolin, Smith \& & Non-adherent contact & Dressing may stick \\
dry or film & Nephew & layer, highly & and dry out, \\
coated dressing & Telfa, Kendall (Tyco & absorbent core and & causing trauma to \\
\hline
\end{tabular}




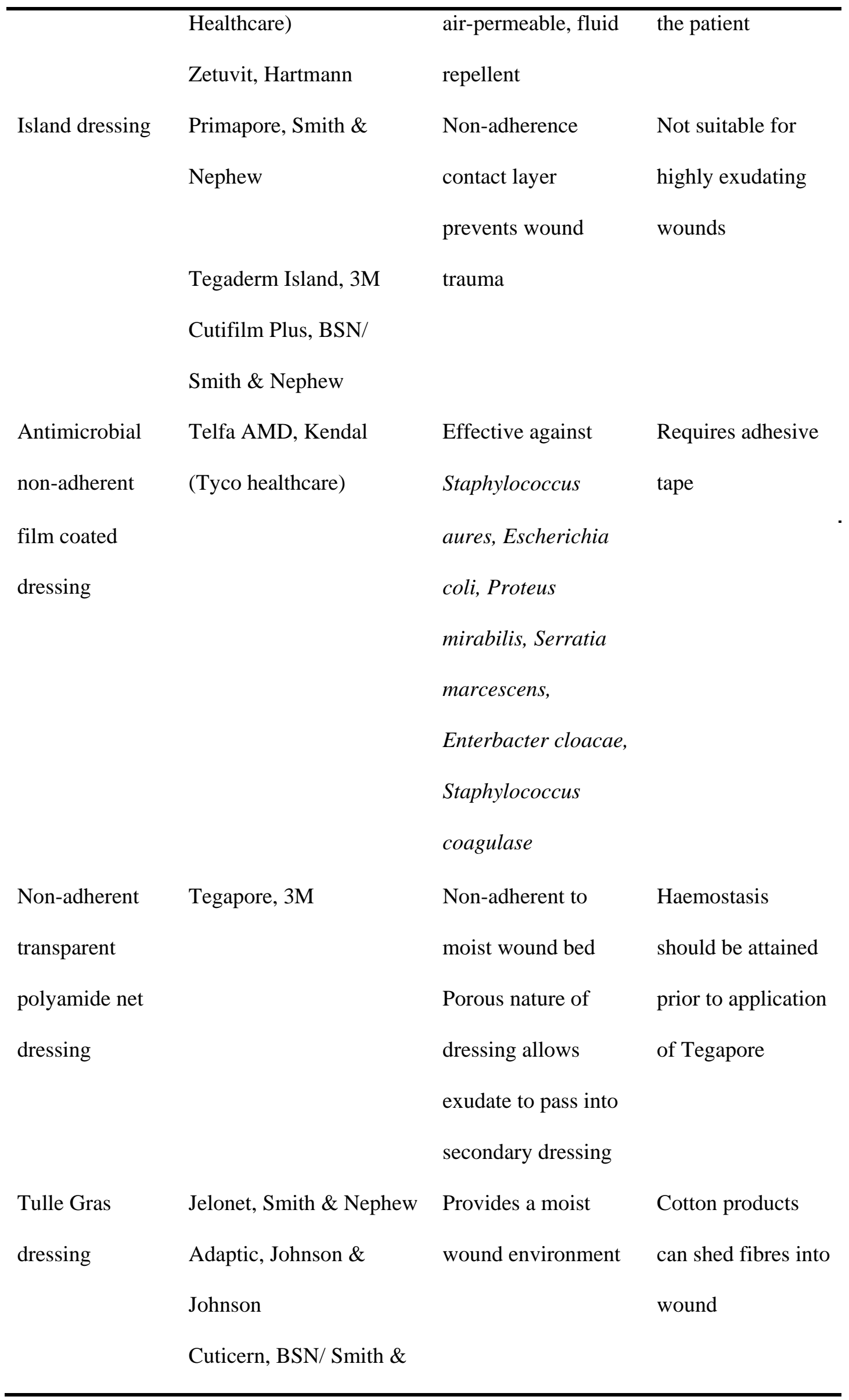




\begin{tabular}{|c|c|c|c|}
\hline \multirow[b]{2}{*}{ Semipermeable } & \multicolumn{3}{|l|}{ Nephew } \\
\hline & Opsite Flexigrid, & Permeable to & Non-absorbent \\
\hline \multirow[t]{5}{*}{ film dressing } & Flexifix, IV 3000, Smith & moisture vapour and & \\
\hline & \& Nephew & gases & \\
\hline & Tegaderm, 3M & Allows inspection of & \\
\hline & Bioclusive, Johnson \& & wound & \\
\hline & Johnson & & \\
\hline \multirow[t]{10}{*}{ Foam dressing } & Lyofoam, Medlock & Highly absorbent & Autolysis problem \\
\hline & Allevyn, Smith \& & Facilitates a moist & \\
\hline & Nephew & wound environment & \\
\hline & Tielle, Johnson \& & & \\
\hline & Johnson & & \\
\hline & Biatain, Coloplast & & \\
\hline & Suprasorb P, Lohmann \& & & \\
\hline & Rausher & & \\
\hline & Trufoam NA, & & \\
\hline & Unomedical & & \\
\hline \multirow{8}{*}{$\begin{array}{l}\text { Calcium } \\
\text { alginate dressing }\end{array}$} & Kaltostat, ConvaTec & Absorbent & Gel may be \\
\hline & Sorbsan, Unomedical & Biodegradable in & confused for \\
\hline & Algoderm, Johnson \& & wounds & slough in wound \\
\hline & johnson & & \\
\hline & Curasorb, Kendall & & \\
\hline & Tegagen, 3M & & \\
\hline & Algisite M, Smith \& & & \\
\hline & Nephew & & \\
\hline \multirow[t]{2}{*}{ Hydrocolloids } & Comfeel Plus, Coloplast & Water repellent & Not recommended \\
\hline & DuoDERM, ConvaTec & Gel formation & on wounds \\
\hline
\end{tabular}




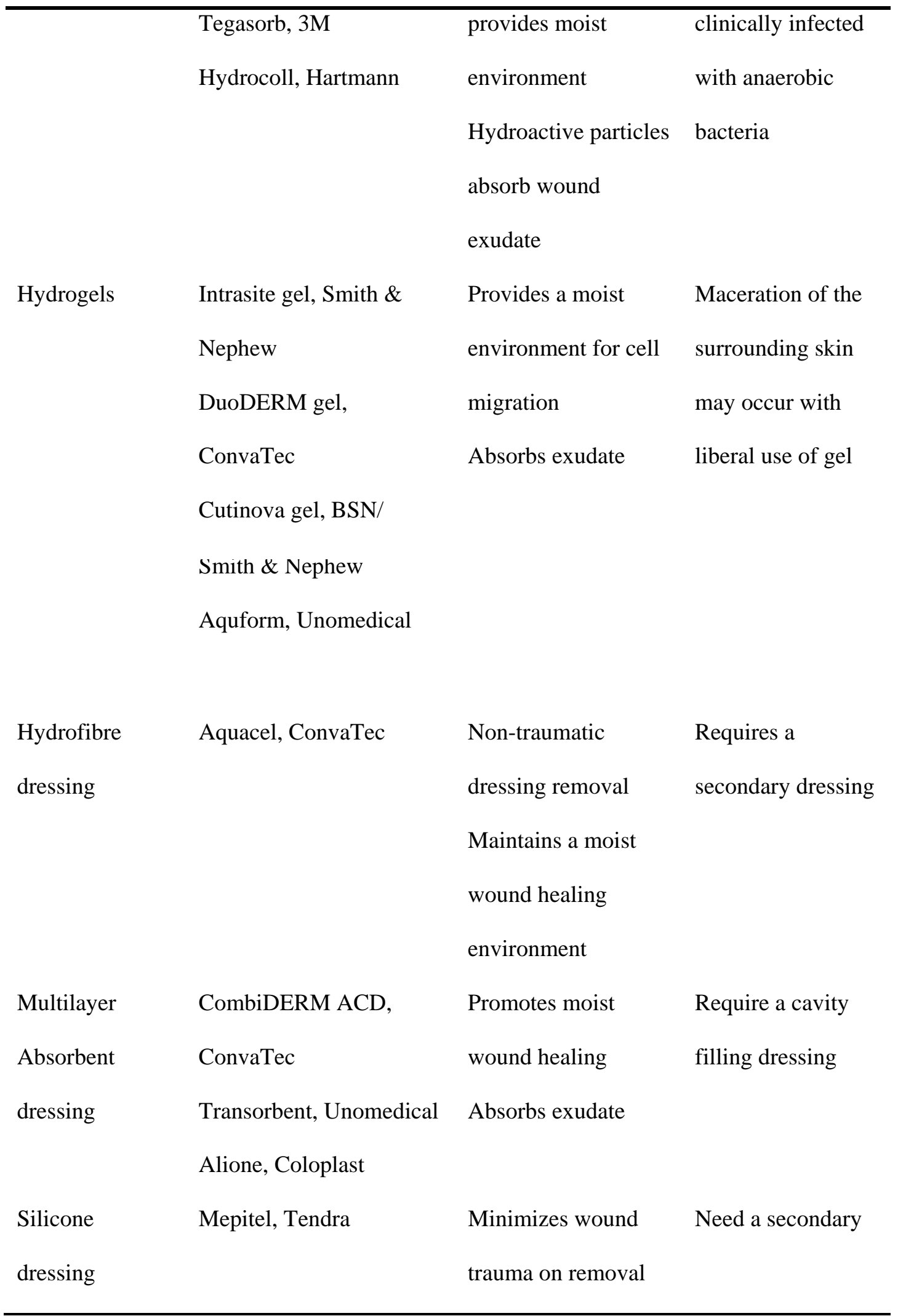




\subsection{Overview of polyelectrolyte complex}

\subsubsection{What is polyelectrolyte complex?}

A polyelectrolyte complex (PEC) or electrostatic self-assembly (ESA) is formed by alternate absorption of a charged substrate into dilute solutions of a polycation or polyanion ${ }^{84}$. This process has attracted the interest of many scientists not only to solve the mechanism of polyelectrolyte complexation ${ }^{85-87}$, but also to develop a wide range of applications, such as nanofiltration ${ }^{88-90}$, pervaporation ${ }^{91,92}$, coating ${ }^{93,94}$, wound healing ${ }^{95}$, tissue engineering ${ }^{96-98}$ and encapsulation (capsules) ${ }^{99,100}$.

The PEC method was introduced by Decher's group in the early 1990s ${ }^{101-103}$ and has greatly increased in popularity due to its simplicity to create nanolayers ${ }^{104}$. A number of interacting macromolecules have been successfully observed for polyelectrolyte multilayer build-up, ranging from synthetic polyelectrolyte to charged biopolymers such as, polysaccharides, proteins and nucleic acids ${ }^{93,105-107}$. Figure 1.3 is a reproduction of the image Decher used in his Science publication to describe this process $^{103}$.

In this schematic, the films are alternately dipped into polycations and polyanion solutions. The adsorption of molecules allows for charge repulsion on the surface and charged molecules will be repulsed allowing for the formation of a single layer film. In the second step, an oppositely charged molecule can be adsorbed on top of the first one. This process can be repeated cyclically to form multilayer structures on the surface of a substrate ${ }^{103}$. 


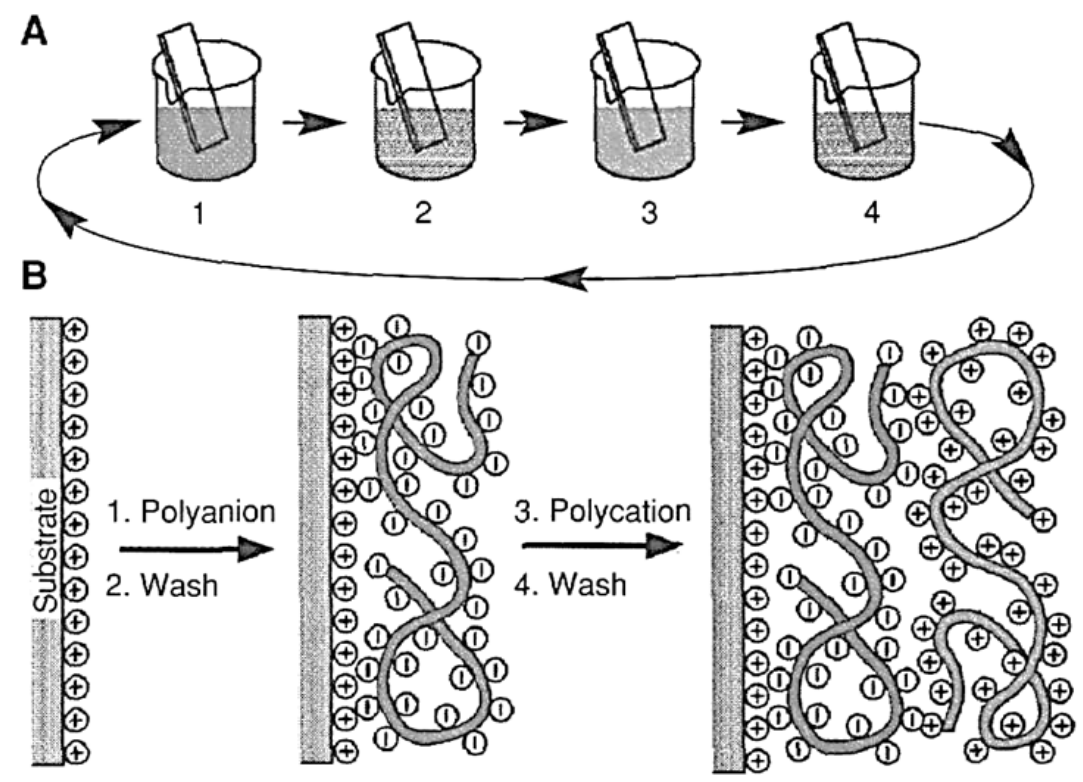

Figure 1.3: (A) Schematic of the film deposition process, and (B) molecular picture of the first two steps of deposition (reproduced from reference 103).

The resulting multilayer films are made up of a number of layers each with its own individual structure and properties. They can then be tailored as biological compounds, conducting polymers, light emitting polymers, drug release agents by manipulating these self-assembled nanolayers onto a suitable substrate ${ }^{108,109}$. The strong electrostatic attraction between charged surfaces and oppositely charged molecules in solution is understood to be the dominant factor in the adsorption of polyelectrolytes as shown in Figure $1.4^{101,110-112}$.

The substrates are normally deposited into absorbate concentrations of polyelectrolyte solution. Adsorption duration per layer can be varied from minutes for polyelectrolyte to hours for certain colloids/gels depending on factors such as the molar mass, $\mathrm{pH}$ and concentrations of the polyelectrolyte solution ${ }^{85}$. 


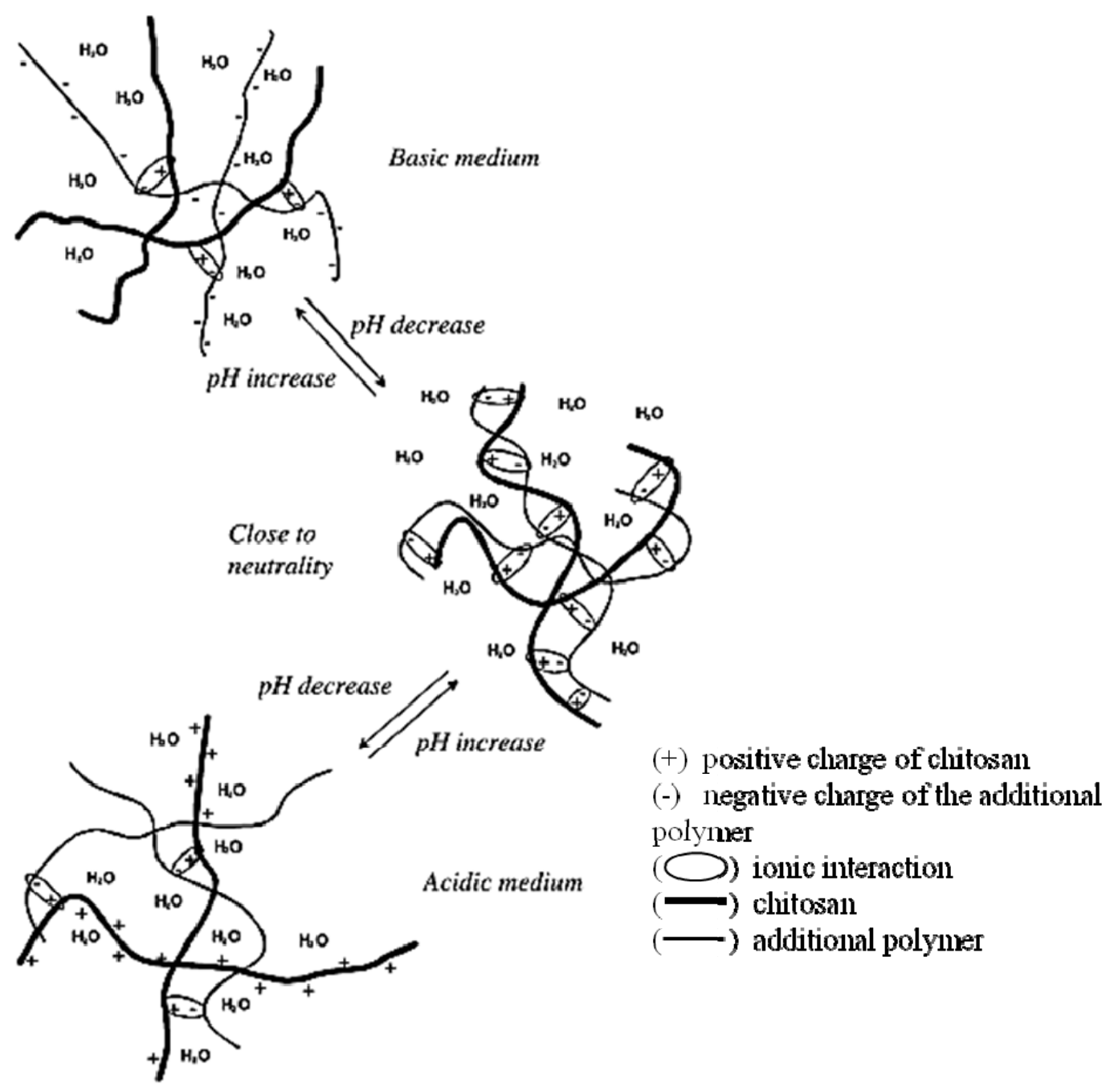

Figure 1.4: The formation of a polyelectrolyte complex of two oppositely charged polyelectrolytes in aqueous solution of different $\mathrm{pH}$ (reproduced from reference 112).

The composition of the polyelectrolyte complex and the characteristics of the individual layers are affected by several aspects such as thickness. Polyelectrolyte systems can exhibit a linear growth in both the thickness and mass of the films depending on the number of deposition step, however growth is also observed to be of an exponential mechanism which gives an unpredictable thickness increment ${ }^{113}$.

Poly(styrene sulfonate)/poly(allylamine hydrochloride) ${ }^{114}$, 115 , poly(Llysine)/alginate ${ }^{116}$, poly(L-lysine)/hyaluronan ${ }^{117}$ are the most prominent examples of 
linearly growing systems or thickness, which usually form a stratified structure. Films of poly(L-glutamicacid)/poly(L-lysine)

118 , poly(3,4ethyenedioxythiophene)/poly(styrene sulfonate) ${ }^{119}$ show a growing thickness that increases exponentially depending on alternate layers applied. The proposed explanation for this exponential growth mechanism is related to the diffusion of polyelectrolyte "in", and "out" of the film ${ }^{118,120}$. Another hypothesis is that the exponential growth of polyelectrolyte complex is a result of an increase in surface roughness as the film build up ${ }^{115,121}$, but no observation of such a rough surface has been found on exponentially growing film made of polypeptides ${ }^{118,}{ }^{120}$. The linear and exponent thickness increases of polyelectrolyte complex are dependent on deposition conditions such as concentration of the polyelectrolyte, adsorption duration, ionic strength, temperature, dipping speed, drying duration ${ }^{113,122}$ and the underlying surface. The charge density, local mobility, and salt concentration also appear to have an influence on the thickness of the layer ${ }^{113,121-123}$.

Polyelectrolyte complexes have been successfully developed on a number of

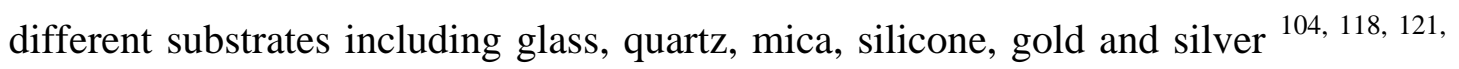
124-126. The choice of substrate depends on the application, as well as the convenience of analysis 104, 127 . Each of the different types of substrate differs with regards to surface charge of the structure (regardless of roughness), smoothness and surface topology ${ }^{128}$. Fou and Rubner proved this by modifying the surface charge of microscopic glass slides to hydrophilic, hydrophobic, negatively charged, and positively charged and found that the surface charge influenced the deposition time, thickness and layer uniformity of the substrates ${ }^{128}$. Because of that, a polyelectrolyte complex can be applied on various substrates of different sizes and shapes based on 
their surface charge. While glass, silicon wafers, gold coated particles, quartz and mica have been the dominating choice of substrates for polyelectrolyte complexes, the use of bio-polymer film and textile (wool fibre) as a substrate have rarely been considered.

\subsubsection{Biopolymers as a potential substrate}

At present, biopolymers are receiving greater attention than synthetic petrochemicalbased polymers due to environmental concerns ${ }^{129}$. The trend of using synthetic polymers started more than half a century ago to substitute natural materials in almost every daily used product because of their properties. Today, the trend has turned back to using natural abundant materials that are more environmentally sound in terms of biodegradability and pollution in general. A variety of renewable biopolymers such as polysaccharides, proteins, lipid, and their composites, derived from plant and animal resources have been studied for the development of edible/biodegradable packaging materials ${ }^{130,131}$, scaffold films ${ }^{132-134}$, wound dressing with antibacterial properties ${ }^{135-}$ 137,138-142 and drug delivery ${ }^{141,143,144}$.

\subsubsection{Polysaccharides as substrate for a polyelectrolyte complex}

Recently, polyelectrolyte complexes based on polysaccharides have been explored using combinations of chitosan-alginate ${ }^{145,146}$, chitosan-carrageenan ${ }^{147-149}$, chitosanguar gum ${ }^{150}$, chitosan-heparin ${ }^{124}$, chitosan-xanthan ${ }^{151}$, chitosan-kondagogu gum ${ }^{152}$ and chitosan-gelatin ${ }^{153}$. Chitosan-alginate is among the most popular polyelectrolyte complex studied. Research into this PEC has mainly focused on hydrogels for drug release ${ }^{154-156,142,143}$, wet-spun nanocomposite-fibre ${ }^{157,}{ }^{158}$, wound healing ${ }^{95}$, and scaffold in cartilage tissue engineering ${ }^{159}$. Iwasaki et al. ${ }^{159}$ reported the advantage of 
this technique for cell adhesion (rabbit chondrocytes) on alginate-based chitosan hybrid polymer fibers that proved superior compared to alginate polymer fibers ${ }^{159}$. In another study, Boddohi et al. ${ }^{160}$ reported that the polyelectrolyte multilayers (PEMs) of chitosan-heparion induced greater cell density and higher proliferation rate of mesenchymal stem cells (MSC), which is suitable to apply on surface coatings to stabilize and potentiate growth factors in therapeutic applications ${ }^{160}$.

Up to date, a limited number of CH-GG polyelectrolyte complexes have been reported as the focus has been on the development of capsules and fibers ${ }^{161-167}$. For example, Yamamoto and co-workers studied the characteristic structures of the interface between CH-GG due to charge overcompensation on the formation of fibers and capsule ${ }^{162}$. This interface reaction could form a hemisphere, honeycomb shape or spaced droplets of polyelectrolyte complex. While the interface can be pulled out to form fibres, as reported by Amaike and co-workers ${ }^{167}$. Another study by Fujii et al. 166 reported the encapsulation of alkaline phosphatase (ALP) by utilizing the polyelectrolyte complex technique of $\mathrm{CH}-\mathrm{GG}$ as shown in Figure 1.5.

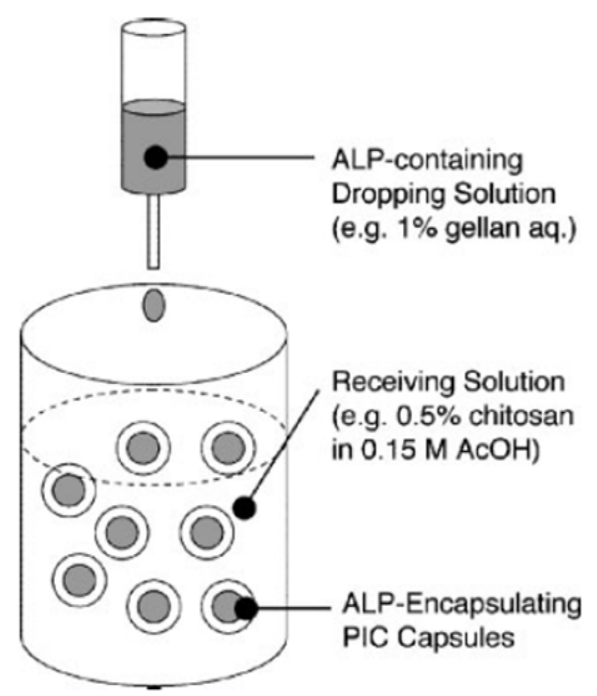

Figure 1.5: Encapsulation process of alkaline phosphatase by polyelectrolyte complex technique between CH-GG (reproduced from 166). 


\subsubsection{Textile as substrate for a polyelectrolyte complex}

Not many studies have been published on coating and dyeing of textile fabrics by the polyelectrolyte complex technique ${ }^{168,169}$. Polowinski's team has popularized the use of the polyelectrolyte complex for modifying the surface of textile fabrics ${ }^{170-172}$. The fabrics were treated by a grafting technique using acrylic or methacrylic or by chemical modification (irradiation). This changed the surface charge of textile fabrics, as well as their hydrophilicity and electro kinetic potential, while also improving dye ability. A basic group was then applied (poly (allylamine hydrochloride) onto acidic treated fabric to form a polymer complex. Dubas et al. ${ }^{169}$ also successfully coated nylon and silk fibers containing silver nanoparticles using a polyelectrolyte complex. The nylon and silk coated with silver nanoparticles exhibited antimicrobial activity against Staphylococcus aureus at 50\% and 80\%, respectively.

\subsection{Biopolymers}

\subsubsection{Chitosan}

Chitosan is a product of deacetylation of chitin either by chemical or microbiological treatments and it composed of randomly distributed $\beta$-(1-4)-linked D-glucosamine (deacetylated unit) and N-acetyl-D-glucosamine (acetylated unit) (Figure 1.6) ${ }^{173174,}$ 175 .

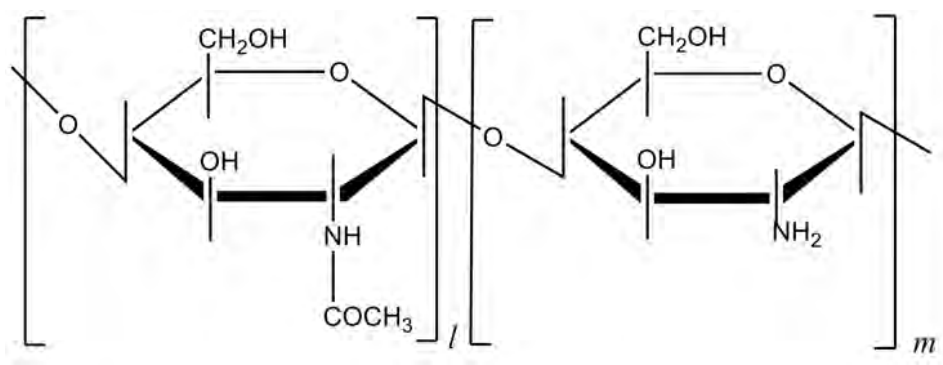

Figure 1.6: Structure of chitosan ( $l=$ acetylated unit, $m=$ deacetylated unit). 
$\mathrm{CH}$ is widely used in the field of biomedicine in wound dressings 57,176 141, 177, ${ }^{178}$, pharmaceutical delivery and medicine control ${ }^{179}$, scaffolds ${ }^{180}$, by promoting bone cell division as well as bone growth ${ }^{181}$ due to its biocompatibility ${ }^{182}$, biodegradability ${ }^{54}$ and strong anti-bacterial properties ${ }^{136}$. It is also used as a component in surgical appliances, contact lenses and in anticoagulant, and anticancer substances ${ }^{173,183,184}$. The versatility of $\mathrm{CH}$ fabrication to form products such as membranes, three-dimensional structures (scaffold), fibers or by modifying the $\mathrm{CH}$ solution to form a polyelectrolyte promotes the usability of this material (Figure 1.7).

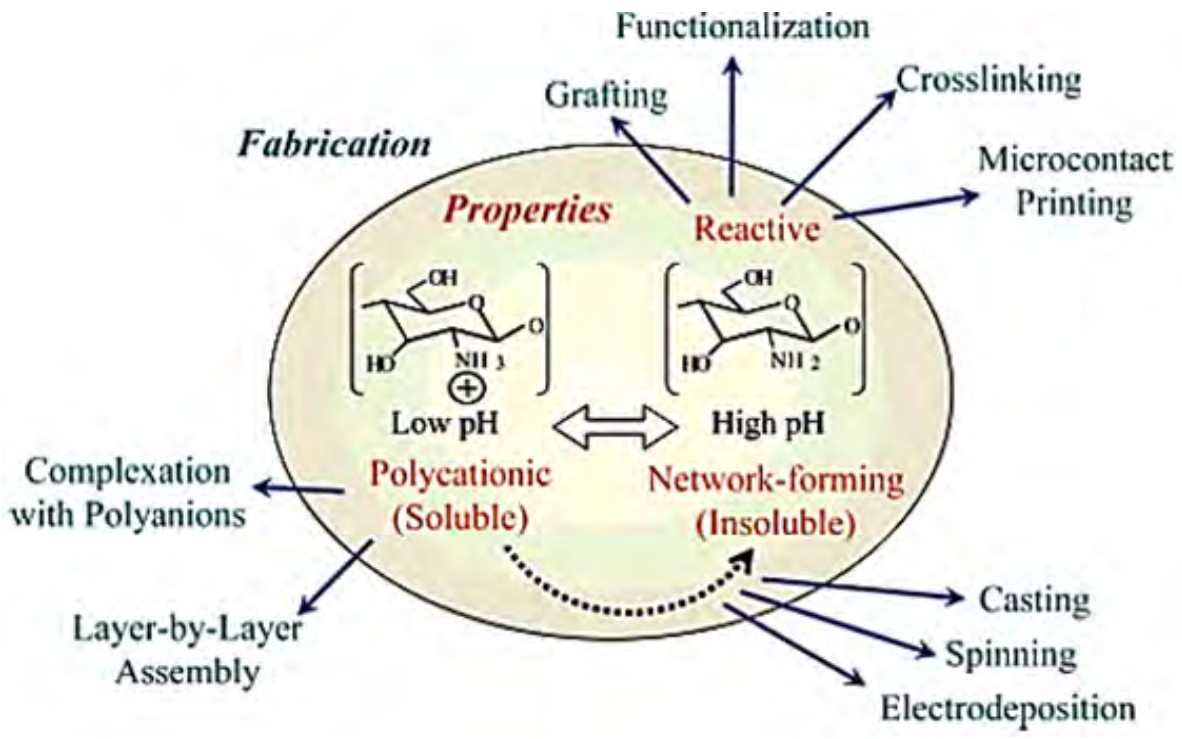

Figure 1.7: Schematic illustrating the versatility of fabrication of chitosan. At low $\mathrm{pH}(<6)$, chitosan's amine is protonated and active as polyelectrolyte solution to be used in polyelectrolyte complex. At higher $\mathrm{pH}(>6.5)$, chitosan's amine is deprotonated and the molecular structure can be altered by grafting or crosslinking to form film, fiber or gel network (reproduced from reference 185).

The properties of chitosan in solution depend on its molecular weight, degree of deacetylation, $\mathrm{pH}$ and ionic strength. $\mathrm{CH}$ is insoluble in water due to the $\mathrm{pK}_{\mathrm{a}}$ of glucosamine which is around 6.2-7.8 ${ }^{186}$. $\mathrm{CH}$ is soluble in diluted acids on account of 
a protonation of free amine groups. The dissociation constant $\mathrm{K}_{\mathrm{b}}$ of an amine group is obtained from the equilibrium of:

$$
\begin{gathered}
\mathrm{NH}_{2}+\mathrm{H}_{2} \mathrm{O} \leftrightarrow \mathrm{NH}_{3}^{+}+\mathrm{OH}^{-} \\
\mathrm{K}_{\mathrm{b}}=\frac{\left[\mathrm{NH}_{3}^{+}\right]\left[\mathrm{OH}^{-}\right]}{\left[\mathrm{NH}^{2}\right]} \text { and } \mathrm{pk}_{\mathrm{b}}=-\log \mathrm{K}_{\mathrm{b}}
\end{gathered}
$$

while the dissociation constant of the conjugated acid, $K_{a}$ is obtained from the equilibrium of:

$$
\begin{gathered}
\mathrm{NH}_{3}^{+}+\mathrm{H}_{2} \mathrm{O} \leftrightarrow \mathrm{NH}^{2}+\mathrm{H}_{3} \mathrm{O}^{+} \\
\mathrm{K}_{\mathrm{a}}=\frac{\left[\mathrm{NH}_{2}\right]\left[\mathrm{H}_{3} \mathrm{O}^{+}\right]}{\left[\mathrm{NH}_{3}^{+}\right]} \text {and } \mathrm{pK}_{\mathrm{a}}=-\log \mathrm{K}_{\mathrm{a}}
\end{gathered}
$$

The dissociation constant of $\mathrm{CH}$ depends on the degree of dissociation and the method of deacetylation used. The dissolved $\mathrm{CH}$ flocculates at a $\mathrm{pH}$ range of 5.5 - $6.0^{186}$. At higher $\mathrm{pH}$ values, charge density of the chitosan solution is decreased due to less amine group being protonated, and vice versa, at lower $\mathrm{pH}(<6.5)$ the charge density of $\mathrm{CH}$ is increased due to a higher amount of protonated amino groups. This factor is therefore crucial for optimizing the formation of a polyelectrolyte complex.

Many factors such as molecular weight ${ }^{187-189}$, type of solvent ${ }^{190,191}$, different drying condition ${ }^{192}$, and humidity ${ }^{193}$ contribute to the formation of $\mathrm{CH}$ films. Different sources and whether $\mathrm{CH}$ is prepared chemically or microbiologically contribute to varying degrees of deacetylation (DD), acetyl group arrangement, and chain length, which all affect the characteristics of $\mathrm{CH}^{136,194}$. Acetic acid has been 
reported as the optimum acid to dissolve $\mathrm{CH}$ giving optimum tensile strength and resistance against water, compared to acids such as citric acid, formic acid and lactic acid ${ }^{190}$. Such $\mathrm{CH}$ films (2\% $\mathrm{CH}, 1 \%$ acetic acid) have high tensile strength and Young's modulus, because of strong electrostatic repulsion between chitosan chain segments ${ }^{190}$.

Glycerine is reported to be the optimum plasticizer for $\mathrm{CH}$ films compared to ethylene glycol (EG), polyethylene glycol (PEG), and propylene glycol (PG) ${ }^{193,} 195$. However, glycerine reduced the tensile strength and Young's modulus, and improved the strain-at-break. It also affected the hydrophobicity and hydrophilicity of the materials. Suyatma and co-workers found that chitosan films with glycerine improved surface hydrophobicity after 20 weeks ${ }^{195}$ and a number of studies reported the influence of hydrophobicity and hydrophilicity of the materials on biological response 196-198

Cell viability on $\mathrm{CH}$ film of different cell lines such as on mouse connective tissue (L929), rat primary schwann cell, nerve cell (PC12), rat osteoblast (UMR-106) and baby hamster kidney cells (BHK21(C13)) is well known 134, 199-203. The biocompatibility is affected by the chemical composition or degree of deacetylation of $\mathrm{CH}^{203}$. A high degree of deacetylation of $\mathrm{CH}$ carries more active free amino groups, which protonate in acidic solution to form a cationic amine group $\left(\mathrm{NH}_{3}{ }^{+}\right)$. The opposite charges between cell surface and $\mathrm{NH}_{3}{ }^{+}$groups are responsible for ionic interaction. Prasitsilp et al. ${ }^{199}$ studied the effect of different sources of CH (shrimp and cuttle fish) on the different degree of deacetylation and tested on mouse connective tissue (L929) and baby hamster kidney cells (BHK21(C13)) ${ }^{199}$. The 
results show that the different sources of $\mathrm{CH}$ did not affect cell growth significantly, providing they had a high degree of deacetylation (> 85\%). The same observation was found by Chatelet et al. ${ }^{204}$, CH films with the degree of deacetylation (53\%-97.5\%) are cytocompatible.

$\mathrm{CH}$ exhibits antibacterial activity depending on its concentration, molecular weight and degree of deacetylation ${ }^{135,136,188}$. Liu et al. ${ }^{188}$ reported that the effective concentration of $\mathrm{CH}$ to kill Escheria. coli is $200 \mathrm{ppm}$. $\mathrm{CH}$ with molecular weight range from $5.5 \times 10^{4}$ to $15.5 \times 10^{4}$ Da also showed antibacterial activity at the optimum concentration of 200 ppm. No et al. ${ }^{205}$ reported that Gram-positive (Listeria monocytogenes, Bacillus megaterium, B. cereus, Staphylococcus aureus, Lactobacillus plantarum, L. brevis, and L. bulgaricus) and Gram negative (Escherichia coli, Pseudomonas fluorescens, Salmonella typhimurium, and Vibrio parahaemolyticus) bacteria respond differently to varying concentrations and molecular weights of $\mathrm{CH}$. Although many studies have been conducted showing that CH has antibacterial activity ${ }^{205-207}$, no clear evidence has been provided to demonstrate the relationship between the antibacterial activity of $\mathrm{CH}$ and surface characteristics of the bacterial cell wall. El-Ghaouth et al. ${ }^{208}$ have proposed possible antibacterial actions of $\mathrm{CH}$. Firstly, $\mathrm{CH}$ is believed to react with the cell surface which alters cell permeability and further prevents the entry of material or causes leakage of material.

$\mathrm{CH}$ has also been reported to offer resistance to viral infection especially in plants, but also in some animal cells ${ }^{209-211}$. CH is able to imitate phyopathogens, and induces a wide spectrum of protective reactions and limits the spread of the viruses 
through the plant ${ }^{212,213}$. For example, by spraying or inoculating leaves with $\mathrm{CH}$, various plant species were protected against viruses such as, tobacco necrosis virus (TNV), peanut stunt virus (PSV), cucumber mosaic virus (CMC), potato virus $\mathrm{X}$ (PVX), and alfalfa mosaic virus (ALMV) ${ }^{210,214,215}$. The effectiveness of $\mathrm{CH}$ to inhibit viral infection depends on the concentration, deacetylation degree, and molecular weight of $\mathrm{CH}$ besides charge value and the character of the chemical modifications of the molecule ${ }^{187,211,213}$. In mammals, $\mathrm{CH}$ can stimulate the inductive phase of the immune response to virus antigens and nerves of the immune system.

\subsubsection{Gellan gum}

Gellan gum (GG) was discovered in $1977^{216}$. It is produced by Pseudomonas elodea and consists of a repeating unit of tetrasaccharide: 1,3-linked $\beta$-D-glucose, 1 , 4-linked $\beta$ - D -glucoronic acid, 1,4-linked $\beta$ - D -glucose, and 1,4-linked $\alpha$-L-rhamnose (Figure 1.7) ${ }^{217}$. Glucose is the highest percentage of the main constituents (at $60 \%$ ) followed by rhamnose and glucoronic (20\% each) ${ }^{217}$. Gellan gum exists in two types, i.e. high acyl and low acyl and is differentiated by two acyl substituents of acetate and glycerate in the high acyl type (Figure 1.8) ${ }^{218}$.

A

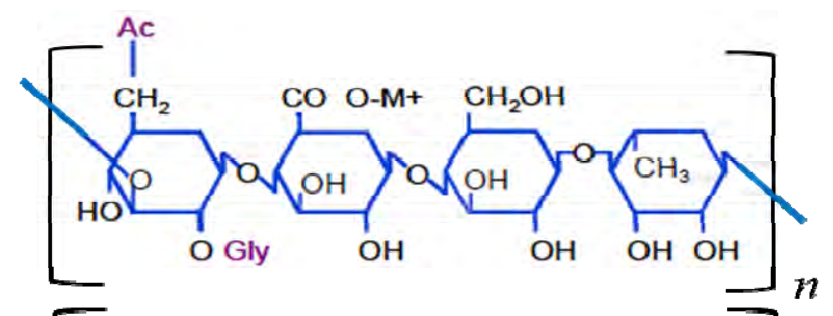

B

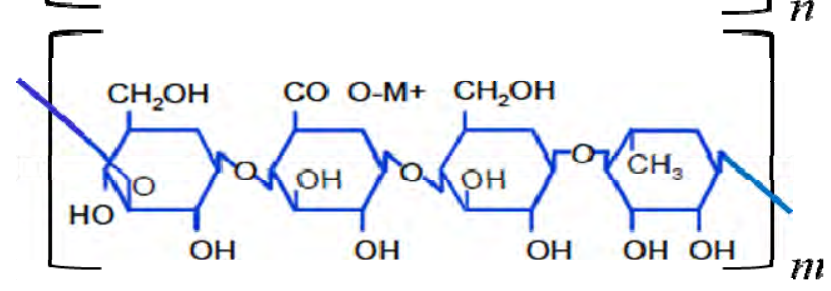

Figure 1.8: The structure of gellan gum; (A) high acyl gellan gum, and (B) low acyl gellan gum (Ac: acetate group, Gly: glycerate group) (reproduced from reference 219). 
In low acyl gellan gum, both acyl groups are completely removed by alkaline treatment ${ }^{220}$. As a result, the high acyl gellan gum produces soft, elastic, non-brittle gels, whereas the low acyl form produces firm, non-elastic and brittle gels. In this study, the focus is on low acyl gellan gum due to its firmness which is important in the development of wound dressing.

Low acyl gellan gum is sensitive to an ionic environment and divalent ions during the evaporation process. Because of that, the properties of low acyl gellan gum such as gel strength, setting temperature, and melting temperature can be controlled by altering the cations and $\mathrm{pH}^{221}$. Furthermore, heat $\left(75^{\circ} \mathrm{C}\right)$ can further help to complete the evaporation process.

The conformation and structure of gellan gum depends on the concentration of polymer used, setting temperature, ionic environment and the presence of any cations in the solution ${ }^{222-224}$. In the absence of cations, low acyl gellan gum gels around $30{ }^{\circ} \mathrm{C}{ }^{224,} 225$. The gelation temperature increases with addition of cations. At high temperature $\left(>50^{\circ} \mathrm{C}\right.$ ), gellan forms a coil structure or single-stranded and at low temperature $\left(<30^{\circ} \mathrm{C}\right)$, gellan forms an ordered double helix ${ }^{223,}{ }^{226}$. The transition temperature from single-stranded to double helix is around $30^{\circ} \mathrm{C}$. After transition, the double helix of gellan gum can be associated with cations $\left(\mathrm{Ca}^{2+} \mathrm{Na}^{+}\right.$, $\mathrm{K}^{+}$) to form junction zones, which will aggregate leading to the formation of an interconnected three-dimensional gel network.

Gellan gum is approved by the United States Food and Drug Administration (US FDA) and the European Union (it is labelled as E 415 in EU regulation) for use 
in the food industry and is commonly used in gelled based products, beverages, dairy foods, emulsions, edible film to improve food experiences ${ }^{227-229}$. Gellan gum is also used as a culture medium for bacteria and plant tissue culture ${ }^{230,231}$. Studies on the medical and pharmaceutical applications of gellan gum have also been reported. For example, it has been used as a scaffold material for the application of tissue engineering ${ }^{232,233}$, as a vehicle for ophthalmic drugs ${ }^{234,235}$, and in eye drops ${ }^{236}$. Gellan gum has shown to have a good compatibility in hydrogel form for live cells such as mouse fibroblast (L929 cell line) ${ }^{237}$, human dermal fibroblasts (HDFs), human fetal osteoblasts (hFOBs 1.19$)^{238}$, human nasal cartilage ${ }^{239}$, and rat bone marrow cells (rBMC) ${ }^{233}$.

\subsection{The use of nanoparticles}

Most bio-polymers have low tensile strength and Young's modulus compared to ceramics and metals. To overcome this problem, composites can be reinforced with micron-sized inclusions such as fibres, platelets, or particles to improve the polymer properties ${ }^{240,241}$. The processing techniques have been hugely improved in the last few years as the size of inclusions are now on a nanoscale $(1-100 \mathrm{~nm})$. This has improved the material properties dramatically especially on the mechanical level due to the extremely high surface to volume ratios ${ }^{242,243}$. Furthermore, inclusion of nanoscale into biopolymers also improved cell biocompatibility ${ }^{244}$, antibacterial and antiviral properties $^{245-249}$.

In this study, three nanoparticles were chosen to improve the biopolymer composites: (i) titanium dioxide, (ii) silver and (iii) zinc oxide. Most of the reviews discussed in this chapter are based on incorporation of nanoparticles into chitosan. An 
extremely limited number of researches have been done on gellan gum incorporated with nanoparticles.

\subsubsection{Titanium dioxide nanoparticles}

Titanium dioxide $\left(\mathrm{TiO}_{2}\right)$ is widely used in the cosmetic, coating and paint industry ${ }^{250}$. It also has been used as a filter to absorb heavy metal ions, organic pollutants ${ }^{251}$ and in the preparation of a photodegradable insecticide ${ }^{252}$.

Inclusion of $\mathrm{TiO}_{2}$ nanoparticles into biopolymers has shown promising effects on mechanical properties, as well as on cell viability and antimicrobial activity ${ }^{253,254}$. As an example, chitosan and $\mathrm{TiO}_{2}$ nanoparticles (diameter range 20-60 nm) have been used to prepare films by crosslinking a chitosan- $\mathrm{TiO}_{2}$-gelatin dispersion followed by evaporative casting and ultraviolet-sterilisation ${ }^{255}$. These composites showed 17\% biodegradability after 6 days (against lysozyme), antibacterial activity against the Gram-positive bacterium Staphylococcus aureus (SA) and wound healing characteristics when applied to wounded Sprague-Dawley rats. Chitosan- $\mathrm{TiO}_{2}$ scaffolds prepared through a freeze-drying technique resulted in improved mechanical properties and cell attachment (hepatic immortal cell lines- HL-7702) compared to pure chitosan scaffolds ${ }^{254}$. While hybrid multilayer film prepared via layer-by-layer assembly of chitosan-heparin films containing $\mathrm{TiO}_{2}$ and $\mathrm{Ag}$ were found to act as contact-active and release-active antibacterial agents ${ }^{177}$.

Incorporating $\mathrm{TiO}_{2}$ nanoparticles (diameter $\sim 100 \mathrm{~nm}$ ) into electrospun chitosan-poly(vinyl alcohol) fibers enhanced the fiber's antibacterial activity against Escherichia Coli from $72 \%$ to $85 \%{ }^{256}$. $\mathrm{TiO}_{2}$ films also exhibited an antiviral effect 
by causing significant changes in the virus structure and resulting in the loss of the ability by the virus to attack host cells ${ }^{72}$. Other reports showed the ability of $\mathrm{TiO}_{2}$ to destroy Hepatitis B virus surface antigen (HBsAg) ${ }^{257}$.

$\mathrm{TiO}_{2}$ antibacterial and antiviral activity are expected originates from its photocatalytic properties ${ }^{72,258-260}$. Upon exposure to a light source that contains ultraviolet (UV) light, $\mathrm{TiO}_{2}$ generates superoxide ions and hydroxyl radicals. It has been proposed that these ions and radicals operate in concert to attack phospholipids in bacteria. The resulting lipid peroxidation reaction causes disruption of the bacterial cell membrane, leading to loss of viability ${ }^{72}$.

\subsubsection{Silver nanoparticles}

Antibiotic-resistance of bacterial strains has become a major problem in public health and the focus has shifted to silver (Ag), known for its ability to control infections ${ }^{261 \text {, }}$ 262. Continuous improvements are sought on products containing silver nanoparticles ranging from ointment to bandages for wound dressing that need to be effective in retarding and preventing bacterial infections ${ }^{245,248}$.

The use of Ag cations in wound care and hygiene products implies that Ag is not considered to have adverse effects to humans ${ }^{262}$. It has been shown that combining chitosan or modified chitosan with Ag into composites resulted in films and hydrogel materials with enhanced cell antimicrobial activity, increased tensile strength, but decreased water vapour permeability ${ }^{79,244,263}$. The chitosan-Ag films yielded a significant reduction in the number of viable bacterial colonies compared to the control sample for both Gram-positive and Gram-negative bacteria ${ }^{244}$. 
Ag nanoparticles (diameter $15 \mathrm{~nm}$ ) have also been incorporated into genipincrosslinked chitosan films ${ }^{244}$. This study showed that chitosan films with Ag nanoparticles contents between 50 and 200 ppm increased the number of viable L929 cells attached to the film surface, compared to genipin-crosslinked chitosan. The genipin-crosslinked chitosan film did not exhibit any antibacterial activity against the Gram-negative bacterium (Escherichia Coli). The composite films with Ag contents larger than 100 ppm were found to be highly effective, which was attributed to the leaching of Ag ions from the composite materials. Ag nanoparticles (diameter $34 \mathrm{~nm}$ ) were also incorporated into hydrogels based on lactose-substitute chitosan ${ }^{263}$. These hydrogels did not show any cytotoxic effect against three different eukaryotic cell lines, while being very effective against both Gram-negative and Gram-positive bacteria. This was attributed to the hydrogel's ability to impede the uptake of nanoparticles by the cells, while allowing these particles to exert their antibacterial effect through contact with the bacterial membrane ${ }^{263}$. In other work, composite materials were prepared by immobilizing Ag on sterilized chitosan films which were found to promote wound healing and combat infection in Sprague-Dawley rats ${ }^{264}$.

Chitosan-Ag composite materials with low Ag content (2.15\% by weight) have also been prepared by converting $\mathrm{AgNO}_{3}$ into $\mathrm{Ag}$ nanoparticles ${ }^{265}$. The antibacterial activity of chitosan was significantly enhanced by the inclusion of $\mathrm{Ag}$ nanoparticles, while fluorescence spectroscopy measurements revealed that bacterial growth stopped immediately after exposure of Escherichia Coli to the composite. It has been proposed that Ag nanoparticles can act in three ways against Gram-negative bacteria (summarised in Figure 1.9): (i) they attach to the surface of the bacterial cell membrane, significantly inhibiting permeability and respiration; (ii) they penetrate 
inside the bacteria and cause further damage; and (iii) they release silver ions resulting in bacterial deoxyribonucleic acid (DNA) losing its capacity for replication as well as inactivation of bacterial proteins ${ }^{245,247}$.

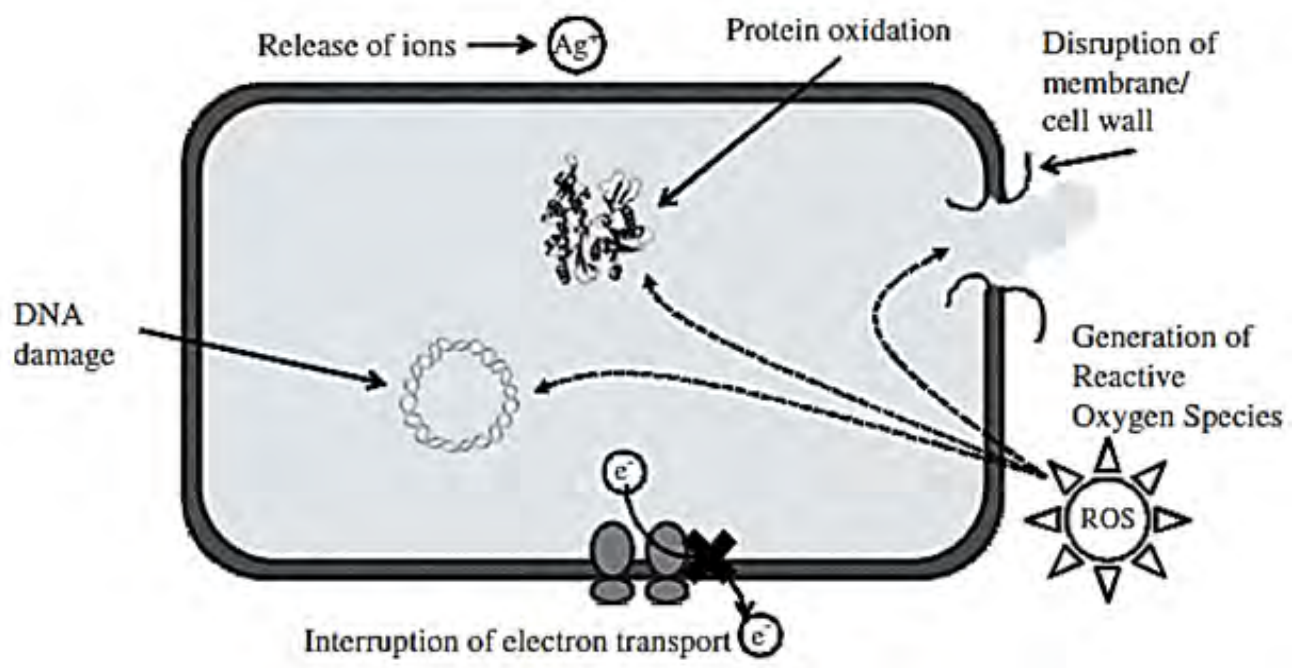

Figure 1.9: Schematic of mechanism of antibacterial activities exerted by Ag (reproduced from reference 247).

\subsubsection{Zinc oxide nanoparticles}

Similar to $\mathrm{TiO}_{2}$, zinc oxide $(\mathrm{ZnO})$ is photocatalytic and has been used in cosmetics, sunscreens, coatings, and in the paint industry ${ }^{266}$. $\mathrm{ZnO}$ combined with eugenol, also known as zinc oxide eugenol, has been used as a filling or cement material in dentistry where it avoids the formation of bio-film. ${ }^{267}$.

Up to date, no study has been reported on the biocompatibility of a biopolymer incorporated with $\mathrm{ZnO}$ nanoparticles with a focus on antimicrobial activities 268. Direct studies of $\mathrm{ZnO}$ nanoparticle in the media cultured with live cells such as L929, HeLa cell, and peripheral blood mononuclear cells show that this nanoparticle inhibits cell growth ${ }^{269,270}$. Furthermore, Dechsakulthorn and co-workers assessed the 
cytotoxicity of $\mathrm{ZnO}$ nanoparticles (diameter range of 50-70 nm) in human skin fibroblasts using 3-(4,5-dimethylthiazol-2-yl)-5-(3-carboxymethoxyphenyl)-2-(4sulfophenyl)-2H tetrazolium (MTS assay) and reported that higher toxicity was observed at both 4 and $24 \mathrm{~h}{ }^{271}$. Lin and co-workers also demonstrated that $\mathrm{ZnO}$ particles with diameters of $70 \mathrm{~nm}$ and $420 \mathrm{~nm}$ significantly reduced cell viability and caused oxidative deoxyribonucleic acid (DNA) damage in a dose and time dependant manner on adenocarcinomic human alveolar basal epithelial cells (A549 cells) ${ }^{272}$.

ZnO nanoparticles exhibit strong antibacterial activities on a broad spectrum of bacteria ${ }^{273-275}$. The antibacterial property is considered to be due to the generation of hydrogen peroxide $\left(\mathrm{H}_{2} \mathrm{O}_{2}\right)$ from $\mathrm{ZnO}{ }^{276}$ which leads to penetration and disorganization of the cell membrane ${ }^{275,277}$. However, it is not yet clear what the role of $\mathrm{Zn}^{2+}$ is on antibacterial activity ${ }^{266,274}$.

\subsection{Fluoroquinolones as antimicrobial agents}

The increasing concern about penicillin resistance of Streptococcus pneumonia has led to more intensive research into the use of new antibacterial agents. Fluoroquinolones are among the rapid growing class of antimicrobial agents that has proved effective in the treatment of bacterial infection ${ }^{278}$. The general structure of fluoroquinolone, shown in Figure 1.10, has a fluorine at position 6 of a naphthyridine ring ${ }^{279}$. Levofloxacin, gatifloxacin, lemofloxacin and pefloxacin are fluoroquinolone that have different functional groups (R1, R2, R3, and $\left.R_{4}\right)^{279}$. 


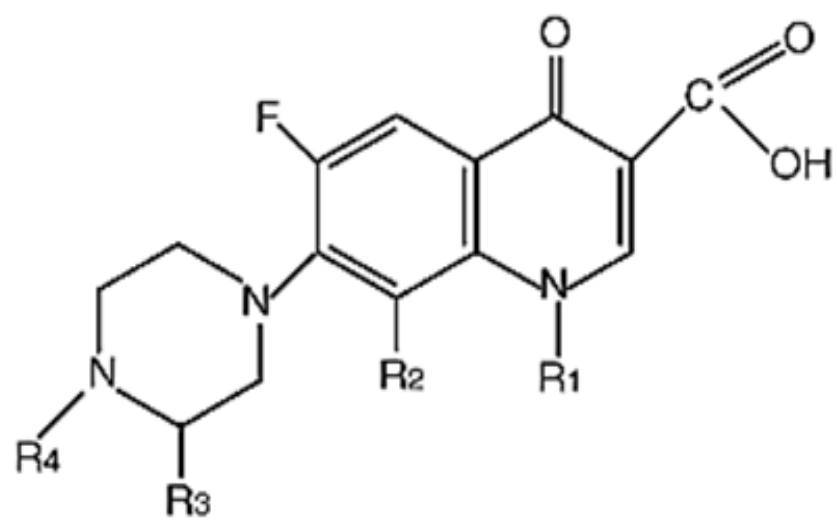

Figure 1.10: General structure of fluoroquinolone (reproduced from reference 279).

\subsubsection{Levofloxacin}

Levofloxacin is (-)-(s)-9-fluoro-2,3-dihydro-3-methyl-10-(4-methyl-1-1-piperazinyl)7-oxo-7H-pyrido [1,2,3-de]-1,4-benzoxazine-6-carboxcylic acid hemihydrate (Figure $1.11)^{280}$<smiles>C[C@@H]1COc2c(N3CCN(C)CC3)c(F)cc3c(=O)c(C(=O)O)cn1c23</smiles>

Figure 1.11: The chemical structure of levofloxacin (reproduced from reference 281).

It is an antibacterial agent with a broad spectrum of activity against Grampositive and Gram-negative bacteria especially aerobes and with a limited activity against anaerobes ${ }^{282}$. It is also effective in the treatment of a wide range of clinical infections including respiratory pathogens, skin infections, and in the urinary tract ${ }^{283}$. 
It was discovered in 1962 and approved by the Food Drug Administration (FDA) in December 1996 and since then has been essentially used in broad pharmaceutical applications such as in oral administration ${ }^{284}$.

Levofloxacin has been used actively in ophthalmic solutions ${ }^{285-287}$ for the treatment of ocular bacterial infections ${ }^{288}$. Bezwada et al. ${ }^{289}$ reported the intrinsic cytotoxicity of ophthalmic solutions containing levofloxacin in on human corneal keratocytes (HCK) and human corneal endothelial cells (HCE). The results show that levofloxacin least affected on human corneal keratocytes (HCK) and human corneal endothelial cells (HCE). Levofloxacin also shows no effect on osteoblast-cell (MC3T3-E1) growth at 24h and relatively mild effect at $72 \mathrm{~h}$ compared to ciprofloxacin and trovafloxacin ${ }^{290}$.

The strong antibacterial activity of levofloxacin against broad spectrums of bacteria has been reported in many studied such as on Escheria coli, Staphylococcus aureus, Xanthomonas malthophuia, Bacteroides fragilis and methicillin-resistant Staphylococcus aureus ${ }^{291-293}$. Furthermore, in-vivo mouse protection studied indicated that levofloxacin more active than ciprofloxacin against selected Gramnegative organisms due to greater tissue penetration ${ }^{291}$.

\subsection{Aims of this PhD project}

As reviewed in this chapter, the development of wound care products are growing to cater different need of varied damage skins. Biopolymers such as chitosan (CH) and gellan gum (GG) have been receiving great attention particularly in the field of biomedicine due to their biocompatibility and biodegradability properties. Various 
methods have been used in the development of wound dressing based on either $\mathrm{CH}$ or GG such as evaporation, gelation process and dry/wet phase separation method ${ }^{74,75 \text {, }}$ 79, 82 , whereas polyelectrolyte complex (PEC) technique is rarely considered. The main aim of this study is to explore the formation of wound dressing through a simple polyelectrolyte complex using chitosan (CH) and gellan gum (GG). The mechanical properties, biocompatibility and antibacterial activity of free-standing $\mathrm{CH}$ and GG films are improved by incorporating titanium dioxide $\left(\mathrm{TiO}_{2}\right)$, silver $(\mathrm{Ag})$ and zinc oxide (ZnO) nanoparticles ${ }^{293-297}$. Levofloxacin, an antibiotic is also included into $\mathrm{CH}$ films to improve the biopolymer's antibacterial properties. The polyelectrolyte complex films of $\mathrm{CH}$ and GG are attached to wound area which designed to act as a bacterial resistance on the upper layer and promote cell viability and proliferation at the bottom layer. The mechanical characteristics, water vapour transmission rates and swelling of the polyelectrolyte complex films are assessed and compared to commercial wound dressings.

The challenge faced in the formation of a CH-GG PEC-film is to prevent the formation of a precipitate in the form of fibers or a capsule $162,163,167,294$. In comparison, polyelectrolyte complexes from polysaccharides such as chitosanalginate ${ }^{95,295}$, chitosan-carrageenan ${ }^{149}$, chitosan-heparin ${ }^{160}$ are mixable by stirring and the resulting solution can be easily cast into films. This problem is overcome in the development of a PEC-film of CH-GG by immersing a single biopolymer $\mathrm{CH}$ or GG substrate into an oppositely charge polyelectrolyte solution. The following steps were taken towards the aim of developing wound dressings based on PECs from $\mathrm{CH}$ and GG: 
Aim 1: Improvement of mechanical characteristics of $\mathrm{CH}$ and GG films through addition of glycerine and nanoparticles $\left(\mathrm{TiO}_{2}, \mathrm{Ag}\right.$ and $\left.\mathrm{ZnO}\right)$ without comprising their ability to support cell growth and antibacterial activity (chapter 3 and 4);

Aim 2: To prepare polyelectrolyte complex-films (PEC-film) (chapter 5) and polyelectrolyte complex-wool fibres (PEC-wool fibres) (chapter 6) from CH and GG by optimised the parameters, i.e. duration of immersion, order of addition and $\mathrm{pH}$ to improve the mechanical characteristics;

Aim 3: To prepare a dual layer film consists of a bacterial resistance on upper layer and promote cell viability and proliferation at bottom layer for future wound dressing applications (chapter 7). 


\section{CHAPTER 2}

\section{EXPERIMENTAL TECHNIQUES}

\subsection{Materials}

Chitosan (CH: medium molecular weight, 75\% degree of deacetylation (DD), viscosity $\approx 453 \mathrm{cP}$, product number 448877 - lot number 07918TE; CHM: medium molecular weight, $79 \% \mathrm{DD}$, viscosity $\approx 915 \mathrm{cP}$, product number 448877 - lot number 04609LD; and CHH: high molecular weight, 75.6\% degree of deacetylation, viscosity $\approx$ 1,406 cP, product number 419419 - lot number 10305DD), glycerine (Gly), levofloxacin (Lev) ( $\geq$ 98.0\%, catalogue number: 28266), titanium dioxide nanoparticles (99.9\% $\mathrm{TiO}_{2}$, diameter, $\mathrm{d}<100 \mathrm{~nm}$, lot number $\left.12908 \mathrm{CH}\right)$, silver nanoparticles (99.5\% Ag, d < $100 \mathrm{~nm}$, lot number 07916BH), and zinc oxide nanoparticles (99.9\% Zn, d $<100 \mathrm{~nm}$, lot number 04011AH) were obtained from Sigma Aldrich, Australia. Viscosity (1\% chitosan in 1\% acetic acid, Brookfield method) and DD are as specified in Sigma-Aldrich's Certificate of Analysis. Gellan gum (GG; low acyl, Mw 2-3 x 105 Da, lot number 7K1383A) was a gift from CP Kelco, USA. According to the manufacturer's specification, all acyl groups have been removed from the glucose residue for this form of gellan gum. Raw threads (100\% wool, dreamtime 4 ply, colour 0051 (light colour), lot number 760840) were 
purchased from Patons, Australia. Food colours (blue and yellow) were purchased from Queen Essence Food Colours, Australia. All materials were used as received.

\subsection{Sample preparation}

\subsubsection{Preparation of chitosan-nanoparticle composites}

$\mathrm{CH}$ solutions were prepared by dissolving $2 \mathrm{~g}$ chitosan in an acetic acid solution $(0.08$ M) under continuous stirring (500 rpm) for $2 \mathrm{~h}$ at $70{ }^{\circ} \mathrm{C}$. $\mathrm{CH}-\mathrm{Gly}$ solutions were prepared by additions of $15 \%, 30 \%$ and $50 \%$ of glycerine (by weight relative to $\mathrm{CH}$ ) and hereafter referred to as $\mathrm{CH} 15, \mathrm{CH} 30$, and $\mathrm{CH} 50$, respectively. $\mathrm{CH}-\mathrm{TiO}_{2}$ and $\mathrm{CH}-$ Ag dispersions were prepared by bath sonication at $40 \mathrm{kHz}$ (Unisonics FXP 12D, Australia) of $200 \mathrm{mg}, 400 \mathrm{mg}$, and $600 \mathrm{mg} \mathrm{TiO}$ or $\mathrm{Ag}$ in $90 \mathrm{~mL}$ Milli-Q water (18.2 $\mathrm{M} \Omega$ ) for $30 \mathrm{~min}$. This was followed by additions of $\mathrm{CH}$ (2 g), glycerine (30\% by weight relative to $\mathrm{CH}$ ) and $10 \mathrm{~mL}$ acetic acid (5\% v/v) under continuous stirring (500 $\mathrm{rpm}$ ) for $2 \mathrm{~h}$ at $70{ }^{\circ} \mathrm{C}$. The dispersions were sonicated in bath sonicator for an additional 10 min prior casting.

Films were prepared by evaporative casting, i.e. solutions or dispersions were deposited onto an acrylic plate and allowed to dry for 2 days under controlled conditions $\left(21^{\circ} \mathrm{C}, 60 \pm 10 \%\right.$ relative humidity, $\mathrm{RH}$ ) (Figure 2.1). The films were peeled off and cut into rectangular strips depending on the characterisation. The films were pre-conditioning in desiccators $\left(21^{\circ} \mathrm{C}, 50 \pm 5 \% \mathrm{RH}\right)$ for another 2 days prior to testing. The resulting $\mathrm{CH}-\mathrm{TiO}_{2}$ and $\mathrm{CH}-\mathrm{Ag}$ composites containing $10 \%, 20 \%$ and $30 \%$ nanoparticles loadings (by weight relative to $\mathrm{CH}$ ) are hereafter referred to CHTi10, CHTi20, CHTi30 and CHAg10, CHAg20, CHAg30, respectively. 


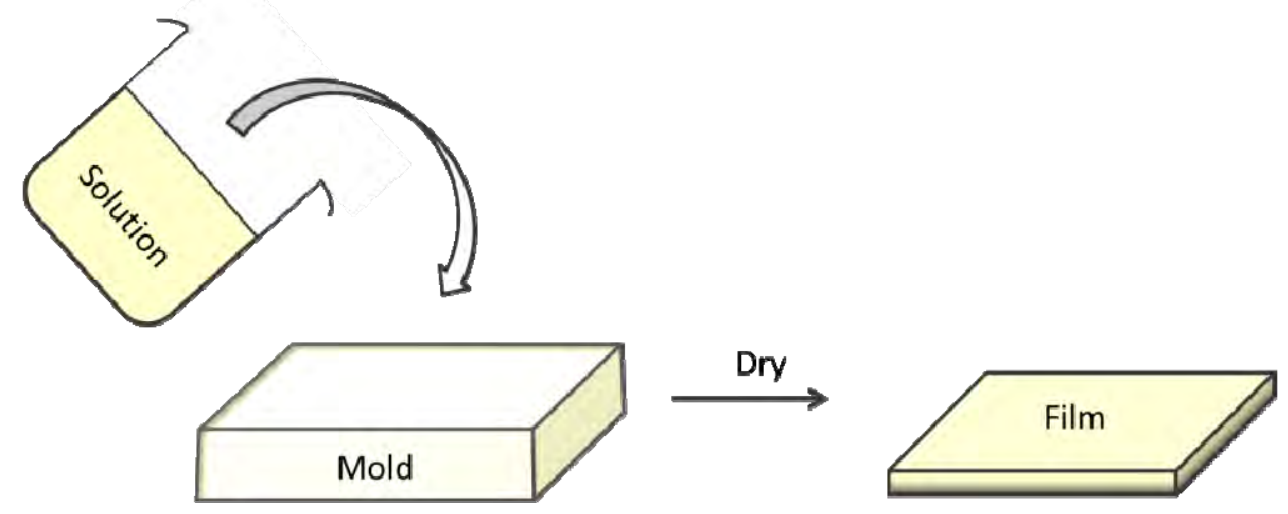

Figure 2.1: Schematic of the preparation of free standing $\mathrm{CH}$ and $\mathrm{CH}$ films by evaporative casting technique.

\subsubsection{Preparation of gellan gum-nanoparticle composites}

GG solutions were prepared by dissolving $1 \mathrm{~g}$ gellan gum in $100 \mathrm{~mL}$ Milli-Q water (18.2 $\mathrm{M} \Omega \mathrm{cm}$ ) under continuous stirring (500 rpm) for $2 \mathrm{~h}$ at $70{ }^{\circ} \mathrm{C}$. GG-Gly solutions were prepared by additions of 15\%, 30\%, 50\%, 60\% and 70\% of glycerine (by weight relative to GG) and hereafter referred to as GG15, GG30, GG50, GG60 and GG70, respectively. GG-TiO 2 , GG-Ag and GG-ZnO dispersions were prepared by bath sonication at $40 \mathrm{kHz}$ (Unisonics FXP 12D, Australia) of $200 \mathrm{mg}, 400 \mathrm{mg}$, and $600 \mathrm{mg}$ $\mathrm{TiO}_{2}$, Ag or $\mathrm{ZnO}$ in $100 \mathrm{~mL}$ Milli-Q water for $30 \mathrm{~min}$. This was followed by an addition of GG (1 g), and glycerine ( $50 \%$ by weight relative to GG) under continuous stirring (500 rpm) for $2 \mathrm{~h}$ at $70{ }^{\circ} \mathrm{C}$. The dispersions were sonicated in bath sonicater for an additional 10 min prior casting.

Films were prepared by evaporative casting, i.e. solution or dispersions were deposited onto an acrylic plate and allowed to dry for 2 days in a temperature humidity chamber (Thermoline scientific, TRH-460) $\left(21^{\circ} \mathrm{C}, 50 \pm 5 \% \mathrm{RH}\right)$. The resulting films were cut to rectangular strips and pre-conditioned for another 2 days in 
the humidity chamber at $21{ }^{\circ} \mathrm{C}, 50 \pm 5 \% \mathrm{RH}$ prior to testing. The resulting films of GG-TiO 2 , GG-Ag and GG-ZnO containing 10\%, 20\% and 30\% of nanoparticles loadings (by weight relative to GG) are hereafter referred to GGTi10, GGTi20, GGTi30， GGAg10， GGAg20， GGAg30， GGZn10， GGZn20 and GGZn30, respectively.

\subsubsection{Polyelectrolyte complex film of chitosan and gellan gum}

CH solution (30\% glycerine) and GG solution (50\% glycerine) were prepared as described in section 2.2.1 and 2.2.2, respectively. $\mathrm{pH}$ modified solutions were prepared by adjusting the $\mathrm{pH}$ of $\mathrm{CH}$ to $\mathrm{pH} \sim 1.8$ and GG to $\mathrm{pH} \sim 12$ through additions of concentrated acetic acid (glacial, $17 \mathrm{M}$ ) and sodium hydroxide (1 M), respectively. These solutions with adjusted $\mathrm{pH}$ are hereafter referred to as $\mathrm{CH}(\mathrm{pH})$ and $\mathrm{GG}(\mathrm{pH})$. Solutions were deposited onto an acrylic plate and allowed to dry for 2 days in a temperature humidity chamber at $21^{\circ} \mathrm{C}$ and $50 \pm 5 \%$ RH before peeling off.

Polyelectrolyte complex (PEC) films were prepared by immersing the $\mathrm{CH}$ or GG film into the solution of oppositely charge for $30 \mathrm{~s}$ on each side, i.e. they were laid flat for $30 \mathrm{~s}$, before turning over, and laid flat for another $30 \mathrm{~s}$ (Figure 2.2).

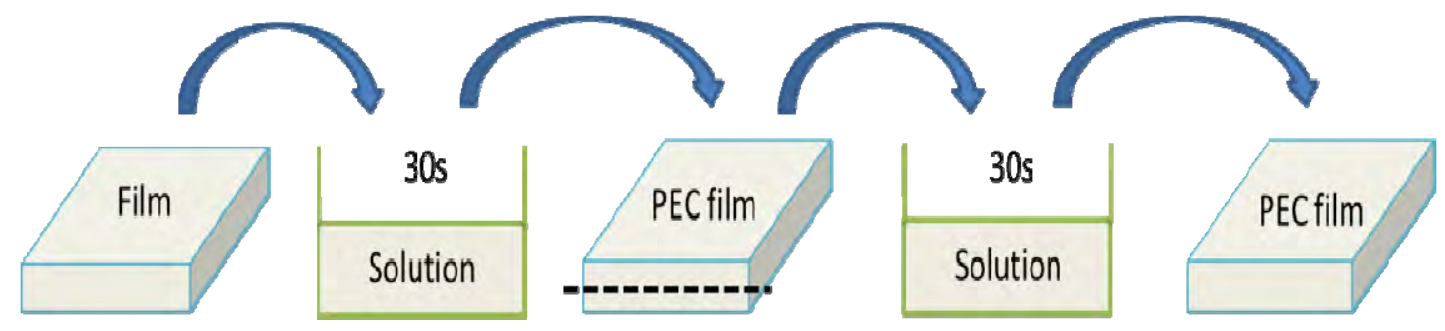

Figure 2.2: Schematic of the preparation of polyelectrolyte complex film. CH and GG films were laid flat into the solution of oppositely charge for $30 \mathrm{~s}$ on each side. 
The resulting films were dried on a custom build rack under controlled ambient conditions $\left(21^{\circ} \mathrm{C}, 60 \pm 10 \% \mathrm{RH}\right)$ for 2 days. The films were then preconditioned for another 2 days in a temperature humidity chamber at $21^{\circ} \mathrm{C}$ and $50 \pm$ $5 \% \mathrm{RH}$ prior to testing. The $\mathrm{CH}$ film immersed into the $\mathrm{GG}$ solution $\left(70{ }^{\circ} \mathrm{C}\right)$ is hereafter referred to as $\mathrm{CH}^{\text {into }} \mathrm{GG}$, and the GG film immersed into the $\mathrm{CH}$ solution (25 ${ }^{\circ} \mathrm{C}$ ) is hereafter referred to as $\mathrm{GG}{ }^{\text {into }} \mathrm{CH}$. Meanwhile, a pH adjusted film or solution is named with $\mathrm{pH}$ after the film or solution. For example, a $\mathrm{pH}$ adjusted $\mathrm{CH}$ film into GG solution is hereafter referred to as $\mathrm{CH}(\mathrm{pH}){ }^{\text {into }} \mathrm{GG}$, and a $\mathrm{pH}$ adjusted $\mathrm{CH}$ film into a pH adjusted GG solution is hereafter referred to as $\mathrm{CH}(\mathrm{pH}){ }^{\mathrm{into}} \mathrm{GG}(\mathrm{pH})$.

\subsubsection{Polyelectrolyte complex coated wool fibres using chitosan and gellan gum}

CH solutions (30\% glycerine) and GG solutions (50\% glycerine) were prepared as described in section 2.2.1 and 2.2.2, respectively. CH and GG-dyed solutions were prepared by additions of $0.25 \%$ (v/v) of blue and yellow food dyes, respectively. The $\mathrm{pH}$ adjusted $\mathrm{CH}$ and GG-dyed solutions were prepared by adjusting the $\mathrm{pH}$ of $\mathrm{CH}$ to $\mathrm{pH} \sim 1.8$ and GG to $\mathrm{pH} \sim 12$ through additions of concentrated acetic acid (glacial, 17 M) and sodium hydroxide (1 M).

$\mathrm{CH}$ coated fibre (CH-fibre) and GG coated fibre (GG-fibre) were prepared by immersing pristine wool fibres $(30 \mathrm{~cm})$ into $\mathrm{CH}$ solution $\left(25^{\circ} \mathrm{C}\right)$ and $\mathrm{GG}$ solution $(70$ ${ }^{\circ} \mathrm{C}$ ) in a beaker for 2, 5, 10, 20 and $30 \mathrm{~min}$. CH-dyed and GG-dyed fibres were prepared by immersing wool fibres into $\mathrm{CH}$-dyed and GG-dyed solutions for 20 min and 5 min, respectively. Meanwhile, $\mathrm{pH}$ adjusted $\mathrm{CH}$ and GG-dyed fibres were prepared by immersing wool fibres into $\mathrm{pH}$ adjusted $\mathrm{CH}$ and GG-dyed solutions for $20 \mathrm{~min}$ and $5 \mathrm{~min}$, respectively. The coated wool fibres were dried by hanging on the 
retort stand under controlled temperature $\left(21 \pm 5{ }^{\circ} \mathrm{C}, 60 \pm 10 \% \mathrm{RH}\right)$ for 2 days (Figure 2.3), and pre-conditioned for another 2 days in the temperature humidity chamber $\left(21 \pm 5{ }^{\circ} \mathrm{C}, 50 \pm 5 \% \mathrm{RH}\right)$ prior to testing.

PEC-coated wool fibres were prepared by immersing CH-dyed and GG-dyed fibres into dyed solutions of oppositely charge at $20 \mathrm{~min}$ and $5 \mathrm{~min}$, respectively. $\mathrm{CH}-$ dyed fibre immersed into the GG-dyed solution is hereafter referred to as $\mathrm{CH}^{\text {into }} \mathrm{GG}$, meanwhile GG-dyed fibre immersed into the CH-dyed solution is hereafter referred to as $\mathrm{GG}{ }^{\mathrm{into}} \mathrm{CH}$. The $\mathrm{pH}$ adjusted of dyed-fibres or dyed solutions are named after $\mathrm{pH}$. For example, a pH adjusted CH-dyed fibre into GG-dyed solution is hereafter referred to as $\mathrm{CH}(\mathrm{pH}){ }^{\mathrm{into}} \mathrm{GG}$, and a $\mathrm{pH}$ adjusted $\mathrm{CH}$ dyed fibre into a $\mathrm{pH}$ adjusted GG-dyed solution is hereafter referred to as $\mathrm{CH}(\mathrm{pH}){ }^{\mathrm{into}} \mathrm{GG}(\mathrm{pH})$. The PEC-coated fibres were dried by hanging on the retort stand under controlled temperature $\left(21 \pm 5{ }^{\circ} \mathrm{C}, 60 \pm\right.$ $10 \% \mathrm{RH}$ ) for 2 days, and pre-conditioned for another 2 days in the temperature humidity chamber at $21^{\circ} \mathrm{C}$ and $50 \pm 5 \% \mathrm{RH}$ prior to testing.

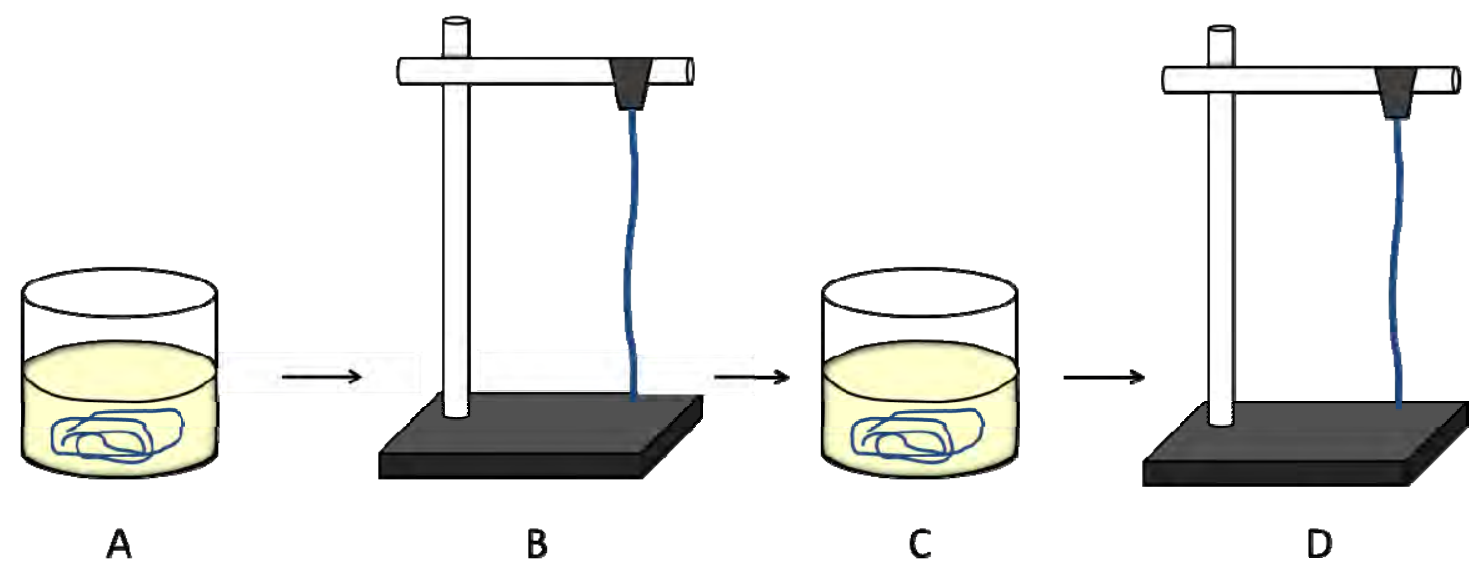

Figure 2.3: Schematic of the formation of polyelectrolyte complex (PEC) on wool fibre; (A) pristine wool fibre immersed into chitosan or gellan gum solutions at different immersion of durations, (B) wool fibres were dried on the retort stand, (C) coated wool fibres were immersed into solutions of oppositely charge at different immersion of durations and (D) the PEC-coated wool fibres were dried on the retort stand. 


\subsubsection{Polyelectrolyte complex film of chitosan-levofloxacin and gellan gum- $\mathrm{TiO}_{2}$ nanoparticles}

GGTi20 composites were prepared as described in section 2.2.2. CH-Lev01, CHLev1 and CH-Lev5 solutions were prepared by additions of levofloxacin at 0.4 w/w\%, $4 \mathrm{w} / \mathrm{w} \%$, and $20 \mathrm{w} / \mathrm{w} \%$ (percentage weight relative to $\mathrm{CH}$ ) into $100 \mathrm{~mL}$ of $0.08 \mathrm{M}$ acetic acid. Chitosan (2 g) and glycerine (30\%, by weight relative to $\mathrm{CH}$ ) were added into the levofloxacin solutions with stirring (500 rpm) for 2 hours at 70 ${ }^{\circ} \mathrm{C}$. CH-Lev films were prepared by evaporative casting, i.e. solutions were deposited onto an acrylic plate and allowed to dry for 2 days in a temperature humidity chamber at $21^{\circ} \mathrm{C}$ and $50 \pm 5 \% \mathrm{RH}$. The films were peel off and cut into the rectangular strips depending on the characterisations. The films were pre-conditioning for another 2 days in the temperature humidity chamber at $21{ }^{\circ} \mathrm{C}$ and $50 \pm 5 \% \mathrm{RH}$ prior to testing.

PEC-films were prepared by pouring a CH-Lev01 solution onto the surface of a dry GGTi20 composite in an acrylic plate (Figure 2.4). This PEC-film hereafter referred to as dual layer films. The dual layer films were dried for 2 days in the temperature humidity chamber at $21{ }^{\circ} \mathrm{C}$ and $50 \pm 5 \% \mathrm{RH}$. The dual layer films were then peeled off and cut into rectangular strips depending on the characterisation, and pre-conditioned for another 2 days in the humidity chamber at $21^{\circ} \mathrm{C}$ and $50 \pm 5 \% \mathrm{RH}$ prior to testing. 


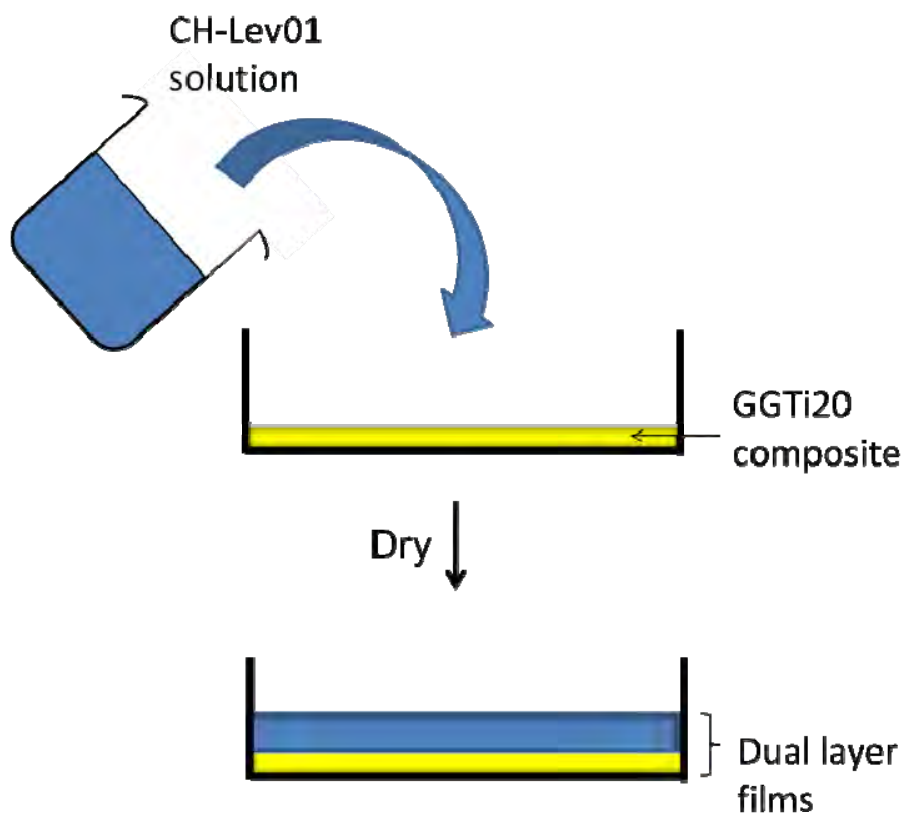

Figure 2.4: Schematic of the preparation of dual layer films. CH-Lev01 solution is pouring onto the surface of GGTi20 composite in the acrylic plate and dried.

\subsection{Characterisation of solutions, dispersions and films}

\subsubsection{Ultraviolet visible spectroscopy}

Ultraviolet-visible (UV-Vis) spectroscopy of solutions, dispersions and films were performed using a spectrophotometer (Varian, Cary 500 UV-Vis NIR) with data interval $=0.5 \mathrm{~nm}$, scan speed=300 $\mathrm{nm} / \mathrm{min}$ and wavelength range $200-800 \mathrm{~nm}$. Quartz cells with path length $0.01 \mathrm{~mm}$ and $5 \mathrm{~mm}$ were used and detailed on caption to each figures. The UV absorption and transmittance of films were measured by attached the film on the cuvette's surface.

\subsubsection{Circular dichroism}

Circular dichroism (CD) spectra were recorded using a spectropolarimeter (Jasco J810) equipped with a temperature controller (Jasco CDF-426S), at a scan rate 100 $\mathrm{nm} / \mathrm{min}$, temperature $=20^{\circ} \mathrm{C}$, and a CD-matched cuvette with $0.01 \mathrm{~mm}$ and $5 \mathrm{~mm}$ path 
lengths for solution and film, respectively (unless stated otherwise). CD intensity was

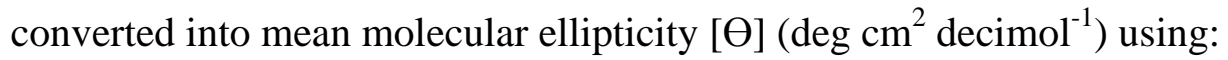

$$
[\Theta]=\Theta_{\mathrm{p}} /\left(10 * \mathrm{n}_{\mathrm{r}} * \mathrm{C}_{\mathrm{p}} * l\right),
$$

where $\Theta_{p}$ is the ellipticity (CD intensity, mdeg) of the polysaccharide (i.e., minus the solvent), $l$ is the path length $(\mathrm{cm}), \mathrm{n}_{\mathrm{r}}$ and $\mathrm{C}_{\mathrm{p}}$ are the number and molar (moles/L) concentration of repeating tetrasaccharide units within a chain of $\mathrm{CH}$ and GG. The average number of repeating units of GG chain reported at $800^{296}$.

\subsection{3 pH measurement}

The $\mathrm{pH}$ of solutions, dispersions, films and coated-wool fibres were measured using a $\mathrm{pH}$ meter (Metrohm $826 \mathrm{pH}$ mobile) (Figure 2.5). The $\mathrm{pH}$ of solutions and dispersions were determined by electrode plus glass electrodes (Metrohm), while the $\mathrm{pH}$ of films and coated-wool fibres were measured by a flat-membrane glass electrode (Metrohm) (Figure 2.5 C).
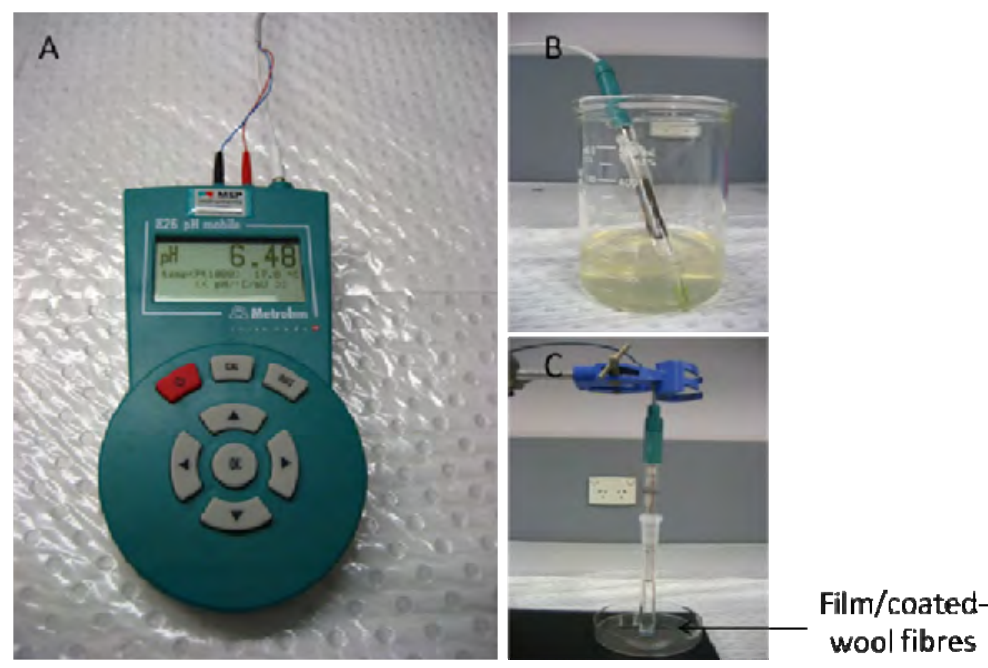

Figure 2.5: (A) Metrohm $826 \mathrm{pH}$ mobile, (B) electrode plus glass electrode dips into the solution or dispersion and (C) flat-membrane glass electrode is attached on the film surface or coated-wool fibres. 


\subsubsection{Tensile testing}

Stress-strain measurements were obtained using an Instron Universal Testing Machine (model 5566) with $\pm 10 \mathrm{kN}$ grips and cross-head speed set at $20 \mathrm{~mm} / \mathrm{min}$. All films were cut to $25 \mathrm{~mm}$ x $100 \mathrm{~mm}$, wheareas the coated-wool fibres were cut to 100 mm. The films and coated-wool fibres were clamped in between of the grips at distance of $50 \mathrm{~mm}$ (Figure 2.6). The thickness of each film was measured using a hand-held micrometer (Mitutoyo) at 10 different positions along the gauge length of each specimen and the mean values were calculated. The diameters of coated-wool fibre were measured with an optical microscope (Leica Z16 APO) and analysed with software kit (Leica DFC290). At least 10 diameter values were measured on each coated-wool fibre and the mean values were calculated.

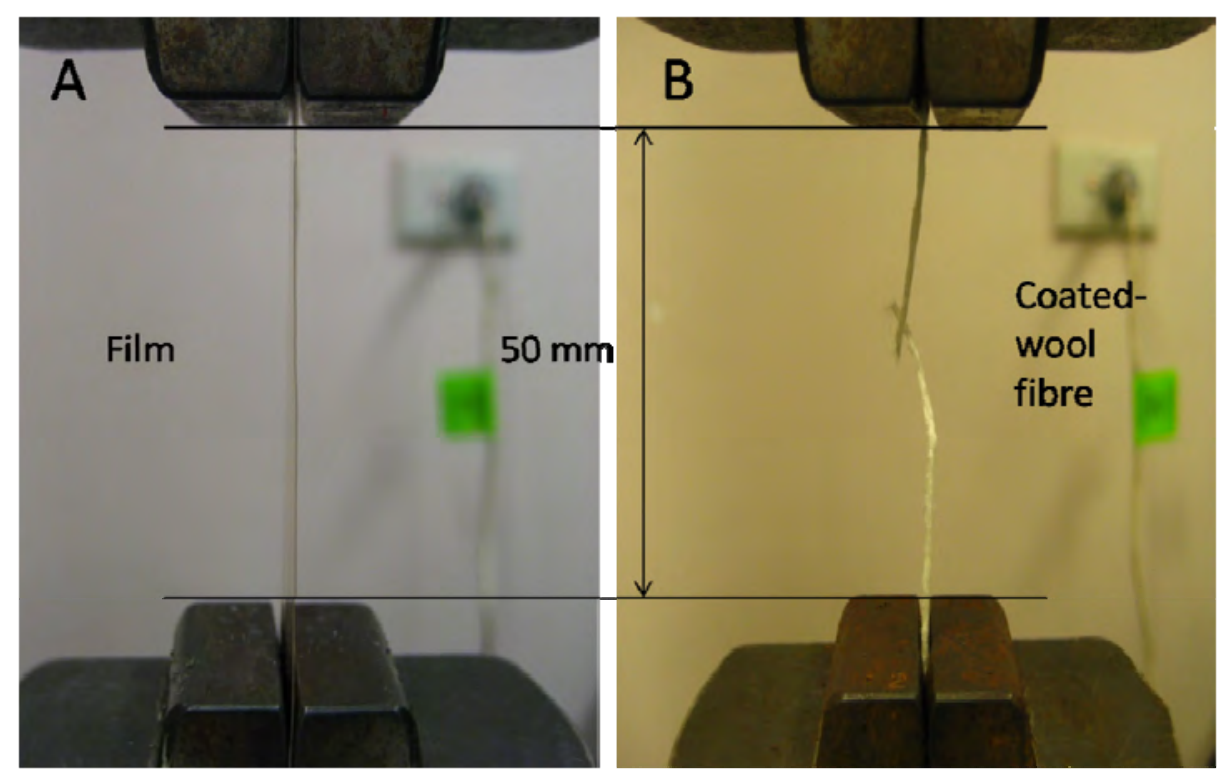

Figure 2.6: (A) Film and (B) coated-wool fibre are clamped between the grips for tensile testing, respectively.

Tensile strength (TS), Young's modulus (E) and toughness (T) were calculated from the slope of the linear part of the stress-strain curve, the maximum stress, and by integrating the area under the stress-strain curve, respectively. 
Meanwhile, strain-at-break $(\gamma)$ is the strain recorded when it breaks. A minimum of five independent stress-strain measurements were obtained per sample.

\subsubsection{Optical and Electron Microscopy}

The cross-section morphology of CH-composite, GG-composite and dual layer films were observed using a field emission scanning electron microscope (FE-SEM) (JEOL JSM-7500 FA). Samples were prepared for observation using the freeze-fracture technique; i.e. the samples were dipped in liquid nitrogen $\left(-196{ }^{\circ} \mathrm{C}\right)$ and fractured at $-150{ }^{\circ} \mathrm{C}$.

The cross-section of the polyelectrolyte complex (film and coated-wool fibre) of $\mathrm{CH}$ and GG were observed using an optical microscope (Leica, Z16 APO). The film $(2 \mathrm{~cm} \times 2 \mathrm{~cm})$ and coated-wool fibre $(1 \mathrm{~cm})$ were vertically alligned under the optical axis of the microscope, and photographs of the cross section were captured.

\subsubsection{Swelling}

Swelling was measured by using four types of solutions, i.e. Milli-Q water, and three buffer solutions, (pH 1, pH 7 and $\mathrm{pH} 12$ ) (Sigma Aldrich) at $21^{\circ} \mathrm{C}$. The films were removed after 24h in solutions, gently wiped with a tissue to expel surface water and weighed. Water swelling (WS) was determined from the equilibrium-swelling ratio according to:

$$
W S=\left(L_{\text {wet }}-L_{\text {dry }}\right) / L_{\text {dry }} \text {, }
$$

where $L_{\text {dry }}$ and $L_{\text {wet }}$ are the weight of the dry and wet films, respectively. A minimum of five independent measurements were obtained per sample. 


\subsubsection{Contact angle}

Contact angle $(\theta)$ is the angle at which a liquid interface meets the solid surface as shown in Figure 2.7.

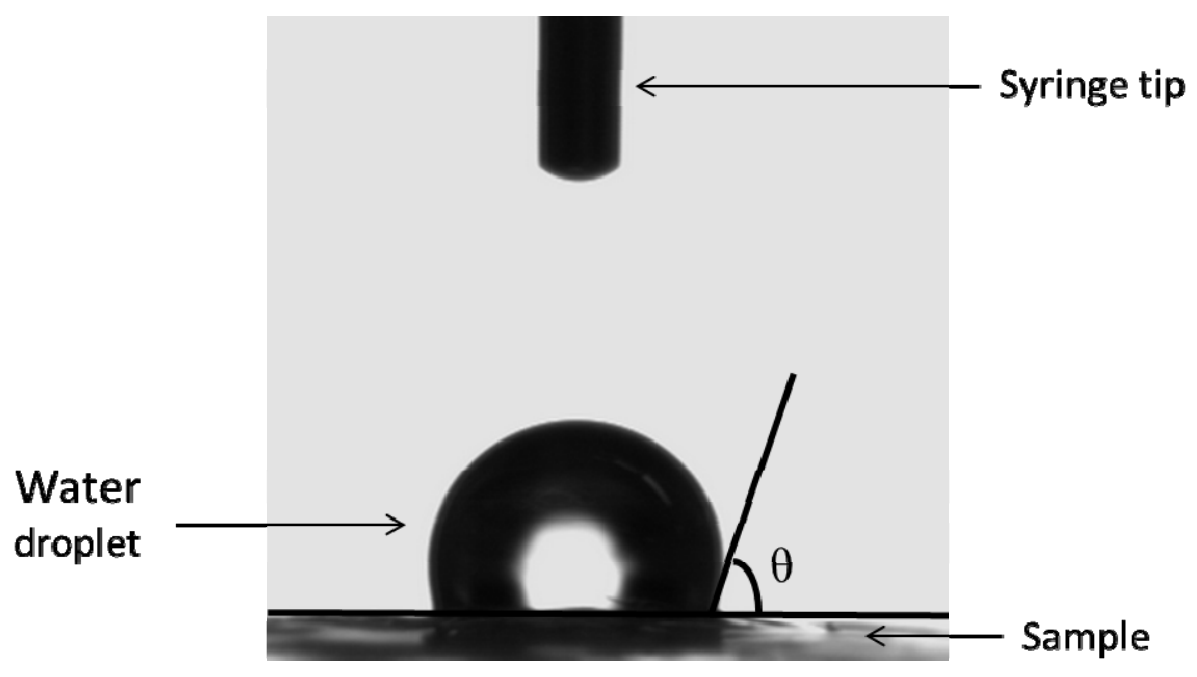

Figure 2.7: Contact angle $(\theta)$ measurement of water droplet on the sample.

A goniometer (Dataphysics OCA40) video-based optical system was used for all contact angle measurements. $2 \mu \mathrm{L}$ of distilled water was placed on the sample's surface. The images of the water spreading on the polymer surface were recorded by a video camera and analysed with the instrument's software kit (SCA20). The contact angle is recorded immediately after a droplet placed on the surface without waiting distilled water to reach equiblirium due to hydrophilic behaviour of the samples. A minimum of 5 measurements were made across the sample and the mean value calculated.

\subsubsection{Water vapour transmission rates}

The water vapour transmission rates (WVTR), water vapour permeability (WVP) and permeance $(P)$ were measured following a modified ASTM International standard method ${ }^{297}$. Each film is fixed on the circular opening of a permeation bottle 
$($ diameter $=1.5 \mathrm{~cm}$, height $=5.0 \mathrm{~cm})$ with the effective transfer area $(A)$ of $1.33 \mathrm{~cm}^{2}$ (Figure 2.8).

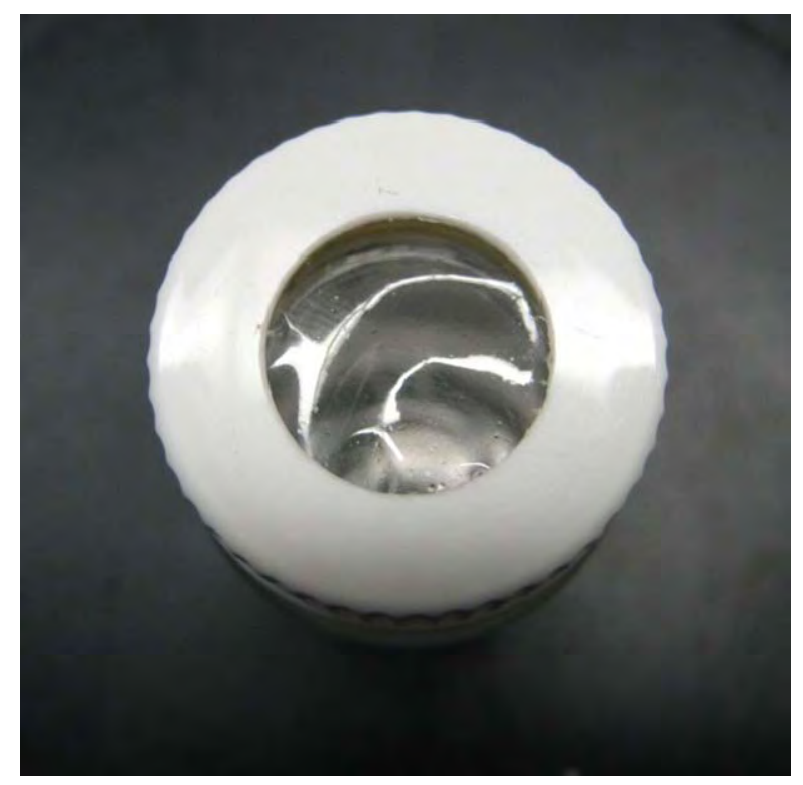

Figure 2.8: (A) Film is fixed on the circular opening of a permeation bottle and stored in a temperature humidity chamber at $21^{\circ} \mathrm{C}$ and $50 \pm 5 \% \mathrm{RH}$.

The permeation bottle is placed in the temperature humidity chamber at $21{ }^{\circ} \mathrm{C}$ and $50 \pm 5 \%$ RH unless stated otherwise. The equilibrium moisture penetration was determined by weighing the bottles at $0 \mathrm{~h}, 24 \mathrm{~h}, 48 \mathrm{~h}$, and $96 \mathrm{~h}$, respectively. The WVTR, WVP and P were obtained using Eqn. 2.3, 2.4 and 2.5, respectively as below:

$$
\begin{array}{ll}
\text { WVTR } & =(m / \Delta t) / A, \\
\text { WVP } & =[(\mathrm{m} \cdot \mathrm{X}) /(\Delta t \cdot A \cdot \Delta \mathrm{P})], \\
\mathrm{P} & =[(\mathrm{m} /(\Delta t \cdot A \cdot \Delta \mathrm{P})],
\end{array}
$$

where $\mathrm{m} / \Delta t$ is the amount of water gain per unit time of transfer, $\mathrm{X}$ is the film thickness (m), $A$ is the area exposed to water transfer $\left(\mathrm{m}^{2}\right)$, and $\Delta \mathrm{P}$ is the water vapour pressure difference between inside and outside of permeation bottle (Pa). 


\subsubsection{Kubelka-Munk analysis}

The images of dyed-wool fibre were captured by microscope (Leica Z16 APO) which saved to 8-bit colour data in the red, green and blue channels. These images were analysed using the Kubelka-munk (K-M) equation for each of the three channels implemented in MATLAB software tools (Eqn. 2.6) ${ }^{298}$;

$$
K / S=(1-\mathrm{R})^{2} / 2 \mathrm{R},
$$

where $K$ is the coefficient of absorption, $S$ is scattering spectrum, and $\mathrm{R}$ is the fraction of light reflected, which the ratio $(K / S)$ obtained are proportional to the concentration of the colourant ${ }^{299}$. A minimum of 5 measurements were made across the dyed-wool fibre and the mean value calculated.

\subsubsection{Levofloxacin release studies}

Levofloxacin release studies from CH-Lev films was determined as follows, CH-Lev films ( $2 \mathrm{~cm} \times 2 \mathrm{~cm}$ ) were immersed in a $100 \mathrm{~mL}$ PBS buffer solution $(\mathrm{pH}=7)$ at 37 ${ }^{\circ} \mathrm{C}$. Thief samples were taken at $1,2,5,10,20$, and 30 min to determine absorbance spectra (Varian Cary 500 Scan UV-VIS-NIR spectrophotometer, between 200 and 800nm). A standard curve was constructed from diluting a $1 \mathrm{mg} / \mathrm{mL}$ levofloxacin solution and measuring the absorbance $(A)$ at $287 \mathrm{~nm}$. The extinction coefficient was obtained using Beer-Lambert law:

$$
A=\varepsilon l c,
$$

where $\varepsilon$ is the molar absorptivity, $l$ is pathlength and $c$ is the concentration of the solution. The resulting extinction coefficient was used to determine the levofloxacin concentration in PBS, which was then converted into fraction remaining in the film. 


\subsubsection{Elemental analysis}

Elemental analysis (C, H, N) of raw powders (CH and GG) and films were carried out by the University of Otago, New Zealand. This information is converted into one matrix $\left(M_{s}\right)$ for the raw powders, and several arrays, one for each of the films. The film's composition in terms of percentage of each of the biopolymers is then obtained from the matrix product of the films array and the inverse of the matrix $M_{s}$.

\subsubsection{In-Vitro Cell Studies}

Routine cell-culture

L929 mouse fibroblast cells (American Type Tissue Collection) were cultured in Dulbecco’s modified Eagle’s medium (DMEM, Sigma Aldrich) supplemented with $10 \%(\mathrm{v} / \mathrm{v})$ foetal calf serum (FCS, Sigma Aldrich) and 1\% antibiotic (Penicillin/ Streptomycin, Sigma Aldrich) at $37{ }^{\circ} \mathrm{C}$ in a humidified atmosphere of $5 \% \mathrm{CO}_{2}$. Cells were sub-cultured every 3 days using established protocols. The cells were harvested at $60-80 \%$ of confluence, washed twice with DMEM, and then trypsinized for 5 min with $0.2 \%$ trypsin (Sigma Aldrich) containing $0.02 \%$ ethylenediaminetetraacetic acid (EDTA, Sigma Aldrich). The resulting cell suspension was centrifuged and resuspended in DMEM-FCS followed by cell counting with a hemocytometer (Hausser Scientific, USA).

\section{Cell viability}

Specimens were placed into wells of 96-well culture plates and sterilized in a laminar airflow chamber using UV radiation for $20 \mathrm{~min}$. Prior to cell seeding, specimens in 96-well culture plates were soaked in media (DMEM only) for 24h and supernatant removed. Suspensions of L929 cells (5000 cell/well) were seeded into wells containing specimens and cultured at $37^{\circ} \mathrm{C}$ in humidified atmosphere of $5 \% \mathrm{CO}_{2}$ for 
24h, $72 \mathrm{~h}$ and $144 \mathrm{~h}$. Media were replaced after $96 \mathrm{~h}$. Tissue culture polystyrene plates (TCPP) were used as control contained the same number of cells. Cell viability of specimens was imaged after $24 \mathrm{~h}, 72 \mathrm{~h}$ and $144 \mathrm{~h}$ incubations by light microscope (Zeiss Axiovert 40 CFL).

CH-composite and GG-composite films were imaged by staining with calceinAM (Fluka Biochemika). $1 \mu \mathrm{L}$ of calcein-AM added to each well containing specimens and incubated for 15 min prior to imaging. Calcein-AM is membranepermeable and is cleaved in the cytosol of viable cells to release calcein, which remains trapped inside cells and endows them with bright green fluorescence when excited with blue light. Imaging of cells growing on specimens was achieved utilizing an inverted light microscope (Zeiss Axiovert 40 CFL) with fluorescent light source (HBO 50).

\section{Indirect contact assay}

Specimens were placed into wells of 96-well culture plates and sterilized in a laminar airflow chamber using UV radiation for 20 min. The media (DMEM, 10\% FCS) were added into wells containing specimens and incubated at $37{ }^{\circ} \mathrm{C}$ in humidified atmosphere of $5 \% \mathrm{CO}_{2}$ for $24 \mathrm{~h}$. The specimens were removed and the media containing L929 cell in wells were then observed by light microscope (Leica DC $500)$.

\section{Cell proliferation}

Cell proliferations were quantified by MTS assay (3-(4, 5-dimethylthiazol-2-yl)-5-(3carboxymethoxyphenyl)-2-(4-sulfophenyl)-2H tetrazolium)). Prior to addition of MTS reagent (1 mg/mL), the specimens-cell culture (L929) and specimens-free cell 
culture (positive control) were transferred to new wells with fresh media and incubated for $4 \mathrm{~h}$ at $37 \mathrm{C}^{\circ}$ in an atmosphere containing $5 \% \mathrm{CO}_{2}$. The absorbance of specimens measured at $490 \mathrm{~nm}$ with a microplate reader (FLUOstar Omega, BMG Labtech, Germany). The absorbance was then related to cell numbers using calibration curves of L929 cells in 96-well plates by triplicate serial dilution of known cell number in DMEM-FCS solution.

\subsubsection{Antibacterial studies}

\section{Culture conditions}

A model microbe, i.e. a laboratory adapted version of the Gram-negative bacterium $E$.

coli (JM 109) was used for antibacterial assays ${ }^{300}$. Luria-Bertani (LB) standard growth medium consisting (perliter) of $5 \mathrm{~g}$ yeast extract (Difco), $10 \mathrm{~g}$ tryptone (Difco) and $10 \mathrm{~g} \mathrm{NaCl}$ are sterilized by autoclave for $20 \mathrm{~min}$ at $120^{\circ} \mathrm{C}$. E. coli was grown in LB broth and incubated aerobically at $41{ }^{\circ} \mathrm{C}$ in a rotary action incubator shaker (Bioline 472) at $200 \mathrm{rpm}$. E. coli suspensions were grown to an optical density of 1.0 (wavelength $600 \mathrm{~nm}$ ) in LB broth which measured using a spectrophotometer (Ultrospec 10, Amersham Biosciences).

Qualitative study - solution/dispersion

$100 \mathrm{uL}$ of E. coli suspensions were evenly pipette-loaded on the solid LB agar and dried in a laminar airflow chamber. The solutions/dispersion were filled into holes on solid LB agar (diameter $6 \mathrm{~mm}$ ) (Figure 2.9) and incubated at $37^{\circ} \mathrm{C}$ for $24 \mathrm{~h}$. The presence of any clear zone around the hole on the plate was recorded as an indication of inhibition against the E. coli. 


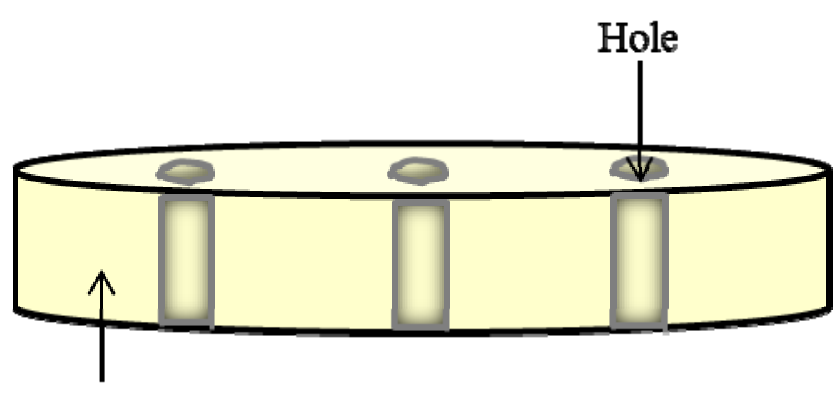

LB Agar

Figure 2.9: Escherichia coli suspension evenly spread on the surface of LB agar and solutions/dispersions were filled up into the holes.

Qualitative study - film

$100 \mu \mathrm{L}$ of E. coli suspensions were evenly spread on the solid LB agar and dried in a laminar airflow chamber. The sample discs (diameter $\sim 6 \mathrm{~mm}$ ) were then placed on the LB agar and incubate at $37^{\circ} \mathrm{C}$ for $24 \mathrm{~h}$. The presence of any clear zone around the discs on the LB agar was recorded as an indication of inhibition against the $E$. coli.

Quantitative study - solution/dispersion

Solutions/dispersions (50 $\mu \mathrm{L}$ ) were added into a $15 \mathrm{~mL}$ Falcon tube containing $4 \mathrm{~mL}$ LB broth and $1 \mathrm{~mL}$ of $E$. coli suspension. The mixing of LB broth and E. coli suspension is hereafter referred as inoculum. The solutions/dispersions were incubated at $37{ }^{\circ} \mathrm{C}$ with shaking at $200 \mathrm{rpm}$ for $3 \mathrm{~h}$. The viable population of E. coli is enumerated by sequentially diluted $200 \mu \mathrm{L}$ solution containing $20 \mu \mathrm{L}$ inoculum and $180 \mu \mathrm{L}$ phosphate buffered saline (PBS) in 96-well plates to obtain serial dilutions $\left(10^{1}-10^{8} \mathrm{CFU} / \mathrm{mL}\right)$. Then, $20 \mu \mathrm{L}$ of each of the dilutions was aseptically plated in triplicate on LB agar plates and incubated at $37^{\circ} \mathrm{C}$ for $24 \mathrm{~h}$. LB broth with inoculum was used as a positive control. Growth inhibition was also compared to the ampicillin solution (5 mg/ L) (Amresco). Colonies appearing on the plates after 24h of 
incubation at $37{ }^{\circ} \mathrm{C}$ were counted and reported as the $E$. coli viable population in CFU per mL.

\section{Quantitative study - film}

A film $(1 \mathrm{~cm} \times 2 \mathrm{~cm})$ was added into a $15 \mathrm{~mL}$ Falcon tube containing $4 \mathrm{~mL}$ LB broth and $1 \mathrm{~mL}$ of $E$. coli suspension. This falcon tubes with contents were incubated at 37 ${ }^{\circ} \mathrm{C}$ with shaking at $200 \mathrm{rpm} .10 \mu \mathrm{L}$ inoculums were taken at intervals of $0 \mathrm{~h}$ and $1 \mathrm{~h}$. The viable population of $E$. coli is enumerated by sequentially diluted $100 \mu \mathrm{L}$ solution containing $10 \mu \mathrm{L}$ inoculum and $90 \mu \mathrm{L}$ phosphate buffered saline (PBS) in 96-well plates to obtain a serial dilution $\left(10^{1}-10^{8} \mathrm{CFU} / \mathrm{mL}\right)$. Then, $20 \mu \mathrm{L}$ of each of the dilutions was aseptically plated in triplicate on LB agar plates and incubated at 37 ${ }^{\circ} \mathrm{C}$ for $24 \mathrm{~h}$. Colonies appearing on the plates after $24 \mathrm{~h}$ of incubation at $37{ }^{\circ} \mathrm{C}$ were counted and reported as the E. coli viable population in CFU per mL.

\subsubsection{Antiviral study}

Antiviral studies were carried out in collaboration at the Centre for Biomedical, Molecular and Chemical Sciences (CBMCS), University of Canberra, Australia under supervision of Prof. Suresh Mahalingam.

\section{Cell culture}

Vero cells, a line of African green monkey kidney cells (T48) (American Type Culture Collection) were cultured in optiMEM culture media (Gibco, Invitrogen) containing 3\% newborn bovine serum (NBS) (Gibco, Invitrogen) at $37{ }^{\circ} \mathrm{C}$ under an atmosphere of $5 \% \mathrm{CO}_{2}$. Cells were sub-cultured every 3 days using established protocols. The cells were harvested at $60-80 \%$ of confluence, washed with optiMEM, 
and then trypsinized for 5 min with $0.2 \%$ trypsin (Sigma-Aldrich). The resulting cell suspension was centrifuged and re-suspended in optiMEM followed by cell counting with a hemocytometer (Hausser Scientific, USA).

\section{Virus stock}

The green fluorescent protein restrain of Ross-river virus (GFP-RRV) was kept in freezer at $-80^{\circ} \mathrm{C}$. The virus is thawed inside ice for 30 min prior use.

\section{Virus survival}

The $\mathrm{CH}$ films were cut to the rounded shape which fix the size of 24-well culture plates, then soaked into optiMEM media in $50 \mathrm{~mL}$ falcon tube for $3 \mathrm{~h}$. The films were then rinsed with $70 \%$ ethanol, and placed into 24 -well culture plates and sterilized in a laminar airflow chamber under UV-light for $20 \mathrm{~min}$. Suspension of Vero cells (1.5 x $10^{5}$ cells/well) were seeded into well containing film and cultured at $37^{\circ} \mathrm{C}$ in atmosphere of $5 \% \mathrm{CO}_{2}$ for $20 \mathrm{~h}$. GFP-RRV virus ( $3 \times 10^{4} \mathrm{PFU} /$ well) were seeded into the well containing adherent Vero cell on $\mathrm{CH}$ film and incubated at $37{ }^{\circ} \mathrm{C}$ in atmosphere of $5 \% \mathrm{CO}_{2}$ for $6 \mathrm{~h}, 12 \mathrm{~h}$ and $24 \mathrm{~h}$. Virus activity was then imaged using fluorescent microscope (Nikon ECLIPSE Ti) equipped with a light source (Nikon Intensilight, C-HGFI). 


\section{CHAPTER 3}

\section{CHARACTERISATION OF COMPOSITE MATERIALS FROM CHITOSAN WITH TITANIUM DIOXIDE AND SILVER NANOPARTICLES}

Chitosan (CH) films containing glycerine (Gly) were prepared and characterised to find optimum mechanical properties (tensile strength, Young's modulus, toughness and strain-at-break) as well as swelling and water vapour transmission rates (WVTR). Titanium dioxide $\left(\mathrm{TiO}_{2}\right)$ and silver (Ag) nanoparticles were incorporated in $\mathrm{CH}$ film to improve the mechanical properties. The swelling, contact angle (CA) and WVTR values of $\mathrm{CH}$-composites were measured. In addition, the cell viability and cell proliferation of all samples were investigated in vitro using mouse fibroblast cells (L929). Antibacterial and antiviral activities of the $\mathrm{CH}$-composites were evaluated on Gram-negative bacteria (Escherichia coli) and green fluorescent protein restraint of Ross-river virus (GFP-RRV), respectively.

\subsection{Spectroscopy}

\subsubsection{UV-Visible}

The UV-visible absorbance spectra of the $\mathrm{CH}$ (without glycerine) and CH30 (containing $30 \%$ of glycerine by weight relative to $\mathrm{CH}$ ) films as well as $\mathrm{CH}-\mathrm{Ag}$ and $\mathrm{CH}-\mathrm{TiO}_{2}$ dispersions are shown in Figure 3.1. Addition of $30 \%$ glycerine (by weight 
relative to $\mathrm{CH}$ ) to the $\mathrm{CH}$ solutions increased the absorbance intensity in the spectral region (300-800 $\mathrm{nm}$ ) which could be due to the formation of hydrogen bonding between $\mathrm{CH}$ and Gly (Figure 3.1 A).
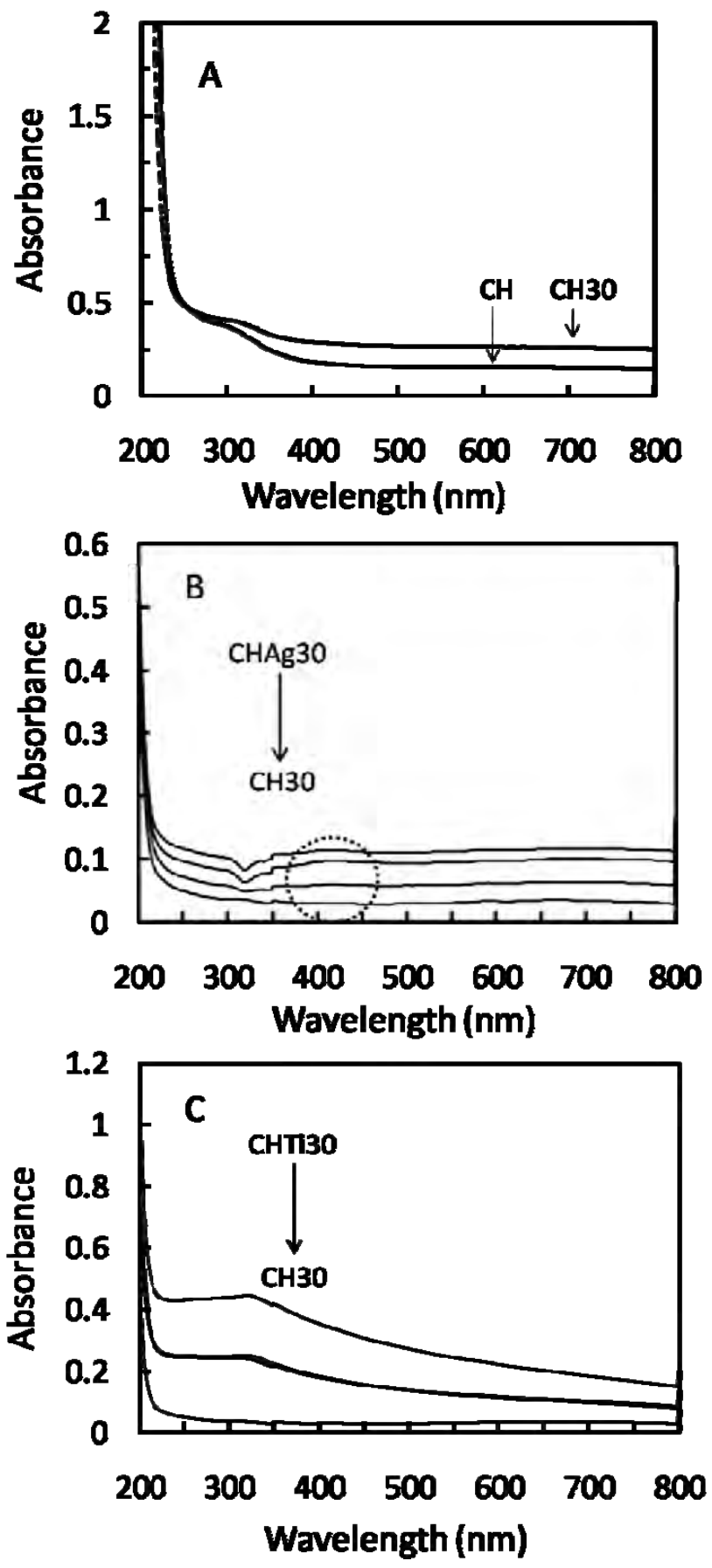

Figure 3.1: (A) UV-visible absorption spectra of $\mathrm{CH}$ and $\mathrm{CH} 30$ films (pathlength=5 mm), (B) UV-visible absorbance spectra of $\mathrm{CH}-\mathrm{Ag}$ dispersions with $10 \%, 20 \%$ and $30 \%$ of nanoparticle loadings (by weight relative to $\mathrm{CH}$ ) (pathlength $=0.01 \mathrm{~mm}$ ); inset: characteristic absorption band of $\mathrm{Ag}$ at $420 \mathrm{~nm}(\mathrm{C}) \mathrm{UV}$-visible absorbance spectra of $\mathrm{CH}-\mathrm{TiO}_{2}$ dispersions with $10 \%, 20 \%$ and $30 \%$ of nanoparticles loadings (by weight relative to $\mathrm{CH}$ ) (pathlength $=0.01 \mathrm{~mm}$ ). 
The addition of $\mathrm{Ag}$ and $\mathrm{TiO}_{2}$ to $\mathrm{CH}$ solutions resulted in characteristic absorption bands at $420 \mathrm{~nm}$ and $330 \mathrm{~nm}$, respectively (Figure $3.1 \mathrm{~B}$ and C) $244,263,301$, 302. The narrow absorption band observed for GG-Ag dispersions at $420 \mathrm{~nm}$ could be due to the electrostatic attraction between Ag ions and amine groups of chitosan (Figure $3.1 \mathrm{~B})^{303}$. As expected, the intensity of the characteristic absorption bands (420 nm and $330 \mathrm{~nm}$ ) increased with increasing $\mathrm{Ag}$ and $\mathrm{TiO}_{2}$ concentration (Figure 3.1 B and C).

The transmittance of $\mathrm{CH}$ films in the visible wavelength range $(500-750 \mathrm{~nm})$ is $70 \%$ (Figure $3.2 \mathrm{~A}$ ), see also Figure $3.3 \mathrm{~A}$.
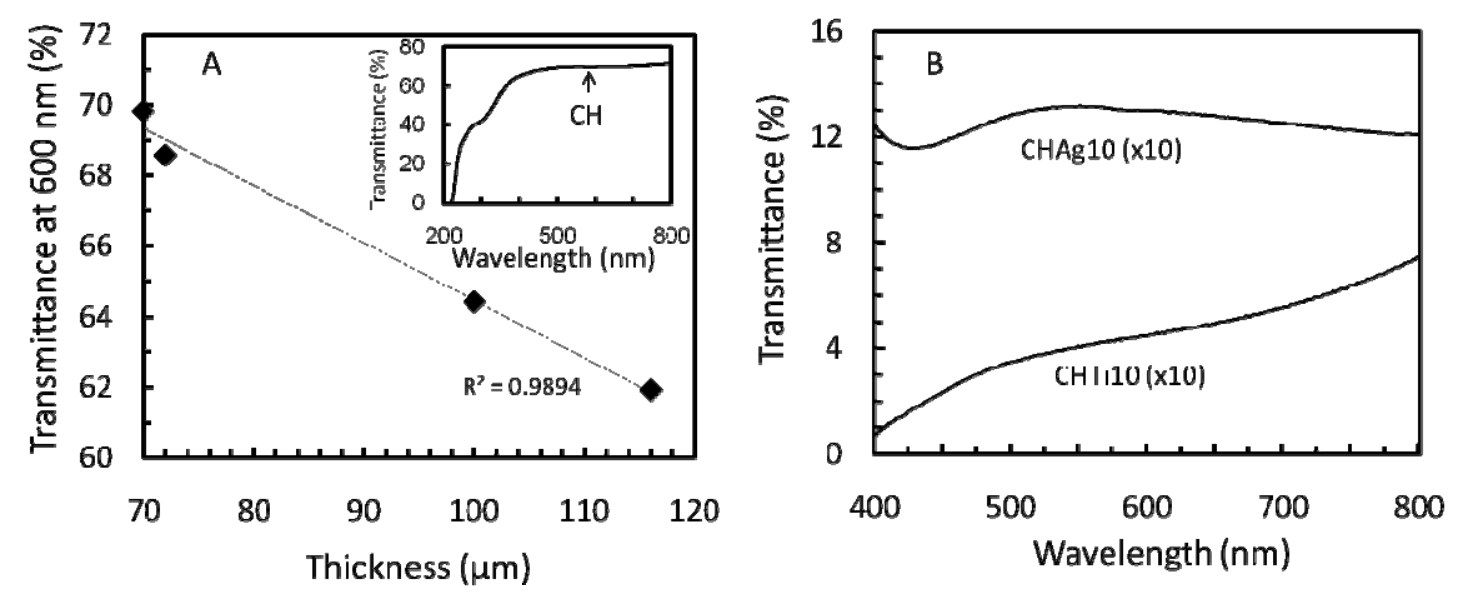

Figure 3.2: (A) Correlation of the transmittance (wavelength at $600 \mathrm{~nm}$ ) against thickness of the $\mathrm{CH}$ films with $10 \%$ to $50 \%$ of glycerine (by weight relative to $\mathrm{CH}$ ); inset: transmittance of the $\mathrm{CH}$ film and (B) transmittance of $\mathrm{CH}-\mathrm{Ag}$ and $\mathrm{CH}-\mathrm{TiO}_{2}$ composite films at $10 \%$ of nanoparticles loading (by weight relative to $\mathrm{CH}$ ).

Increasing the glycerine concentrations from $10 \%$ to $50 \%$ leads to an increase in $\mathrm{CH}$ film thickness from $70 \pm 15$ to $116 \pm 7 \mu \mathrm{m}$, which resulted in a $10 \%$ reduction in transmittance (Figure $3.2 \mathrm{~A}$ ). The $\mathrm{CH}-\mathrm{Ag}$ and $\mathrm{CH}-\mathrm{TiO}_{2}$ composite films were not optically transparent as evident from the transmittance spectra (Figure $3.2 \mathrm{~B}$ ) and the 
photographs (Figure $3.3 \mathrm{~B}$ and $\mathrm{C}$ ). $\mathrm{CH}$ solution and $\mathrm{CH}$-composite dispersions were stable up to 6 months (Figure $3.3 \mathrm{D}$ ).
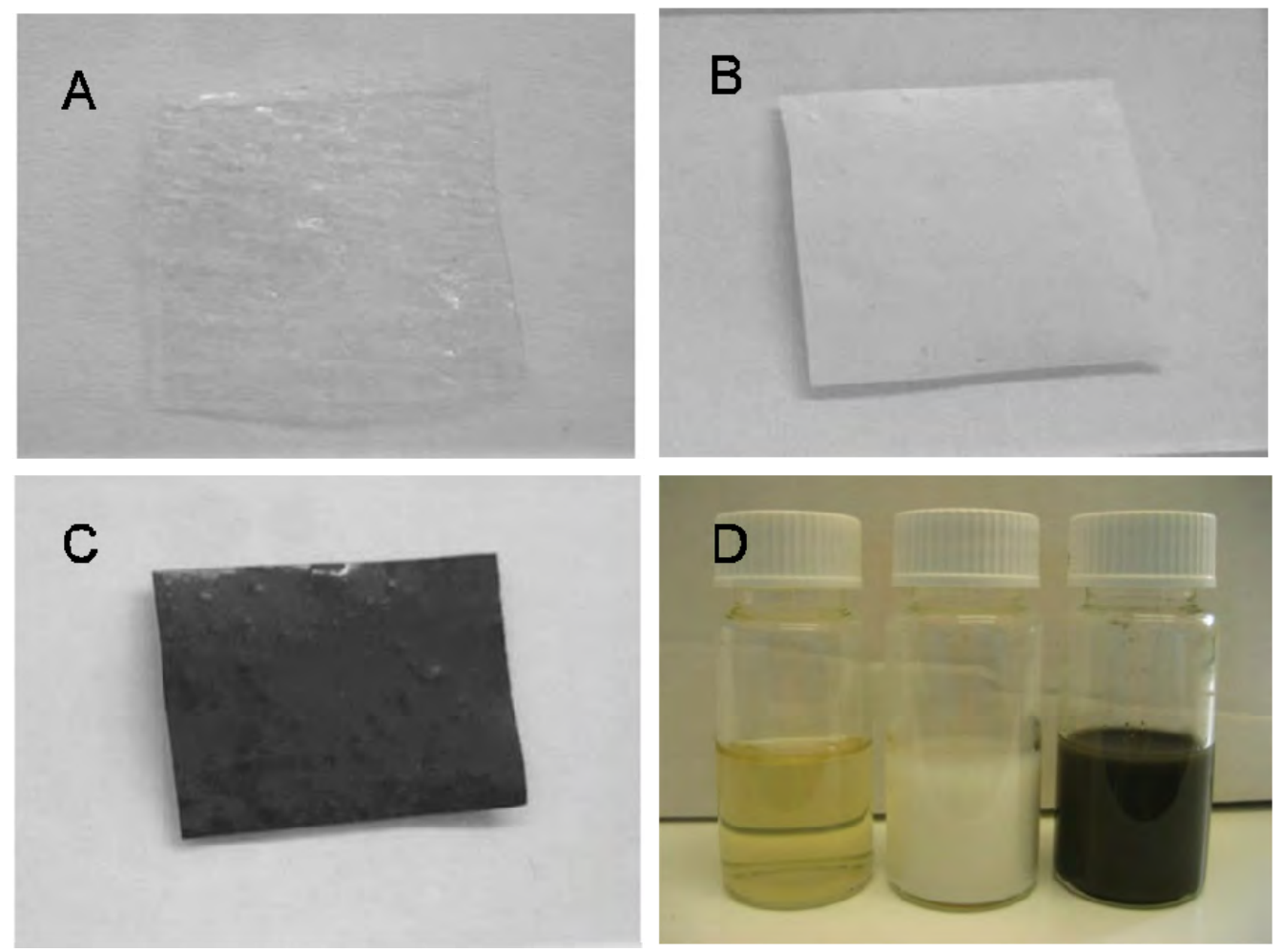

Figure 3.3: (A) CH30 film, (B) CHTi20 composite, (C) CHAg20 composite and (D) CH30, CHTi20 and CHAg20 (left to right) dispersions after 6 months. All measurements of UV absorbance were carried out at $21^{\circ} \mathrm{C}$. Films dimension are $2 \mathrm{~cm} \times 2 \mathrm{~cm}$.

\subsubsection{Circular dichroism}

Circular dichroism (CD) spectra of $\mathrm{CH}$ solutions show a band at $210 \mathrm{~nm}$ due to the presence of N-acetyl-glucosamine (GlCNAc) (Figure 3.4 A) ${ }^{304-306}$. Addition of 30\% glycerine to the $\mathrm{CH}$ solution resulted in enhanced molar ellipticity (at $210 \mathrm{~nm}$ ) due to an increased number of hydrogen bonds between CH-Gly (Figure 3.4 A) ${ }^{307}$. A comparison between $\mathrm{CH} 30$ solution and film shows that the CD band shifted from $210 \mathrm{~nm}$ to $226 \mathrm{~nm}$ (Figure $3.4 \mathrm{~A}$ and C). This shift corresponds to the $\mathrm{CH}$ chain adopting a helical conformation ${ }^{308}$. 
The temperature dependence of $\mathrm{CH} 30$ solutions showed that the molar ellipticity of the absorption band at $210 \mathrm{~nm}$ increased with decreasing temperature (Figure $3.4 \mathrm{~B}$ ). This has been previously been attributed to changes in orientational order and the electronic dipole of the chromophoric groups of $\mathrm{CH}^{308,309}$.

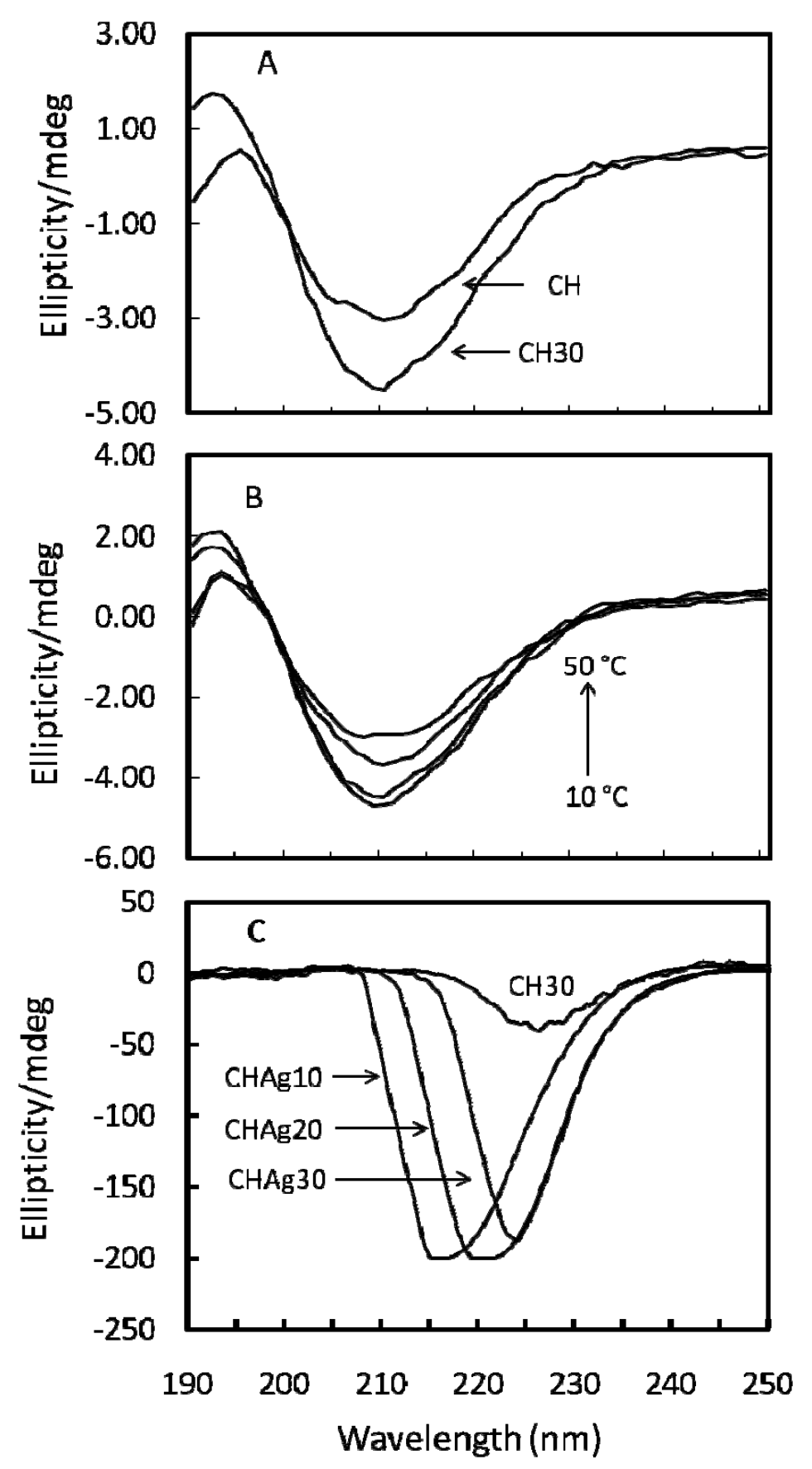

Figure 3.4: (A) Comparison between $\mathrm{CH}$ and $\mathrm{CH} 30$ solutions (pathlength $=0.01 \mathrm{~mm}$ ), (B) typical temperature dependence of $\mathrm{CH} 30$ solution at $10{ }^{\circ} \mathrm{C}, 21{ }^{\circ} \mathrm{C}, 37{ }^{\circ} \mathrm{C}$ and $50{ }^{\circ} \mathrm{C}$ (pathlength $=0.01 \mathrm{~mm}$ ) and (C) CD spectra of CH30, CHAg10, CHAg20, and CHAg30 composite films (pathlength $=5 \mathrm{~mm}$ ). All measurements were carried out at $21{ }^{\circ} \mathrm{C}$ unless stated otherwise. 
The CD spectra of the $\mathrm{CH}$-Ag composites exhibited observable changes compared to $\mathrm{CH} 30$ film (Figure $3.4 \mathrm{C}$ ). The increase in molar ellipticity of the $\mathrm{CH}-\mathrm{Ag}$ composites at 215-226 nm indicated that the helical conformational of CH30 film was changed, which could be a result of binding between amine groups and silver ions. The absorption bands of $\mathrm{CH}-\mathrm{Ag}$ composites shifted to higher wavelength for higher nanoparticle loading (Figure 3.4 C). For example, the CD bands of $\mathrm{CH}$-Ag composite with $10 \%$ nanoparticle loading (by weight relative to $\mathrm{CH}$ ) is at $215 \mathrm{~nm}$; and shifted to $226 \mathrm{~nm}$ with 30\% nanoparticle loading (by weight relative to $\mathrm{CH}$ ). It is not clear what the reason of this shifting.

\subsection{Mechanical properties and microscopy}

\subsubsection{Effect of glycerine}

$\mathrm{CH}$ films are brittle and not easy to handle. The tensile strength (TS), Young's modulus $(\mathrm{E})$, toughness $(\mathrm{T})$, and strain-at-break $(\gamma)$ values of $\mathrm{CH}$ film are $39 \pm 5$ MPa, $1223 \pm 173 \mathrm{MPa}, 2.45 \pm 0.08 \mathrm{~J} \mathrm{~g}^{-1}$ and $10 \pm 2 \%$, respectively, (Figure $3.5 \mathrm{~A}$ and Table 3.1). Inclusion of glycerine significantly reduces the mechanical properties, but increases the strain-at-break (Table 3.1). This is a result of a decreased in hydrogen bonding interactions between $\mathrm{CH}-\mathrm{CH}$ due formation of hydrogen bonding between $\mathrm{CH}-\mathrm{Gly}$. This decreases the intermolecular forces along $\mathrm{CH}$ chains ${ }^{310}$, leading to an increase in the strain-at-break values. For example, addition of 30\% glycerine (by weight relative to $\mathrm{CH}$ ) to chitosan resulted in a decreases in $\mathrm{E}$ (from $1223 \pm 173 \mathrm{MPa}$ to $25 \pm 7 \mathrm{MPa}$ ), TS (from $39 \pm 5 \mathrm{MPa}$ to $6 \pm 1 \mathrm{MPa}$ ) and $\mathrm{T}$ (from $2.45 \pm 0.08 \mathrm{~J} \mathrm{~g}^{-1}$ to $1.27 \pm 0.01 \mathrm{~J} \mathrm{~g}^{-1}$ ), while the $\gamma$ increased from $10 \pm 1 \%$ to $32 \pm 2 \%$ (Table 3.1 ). 

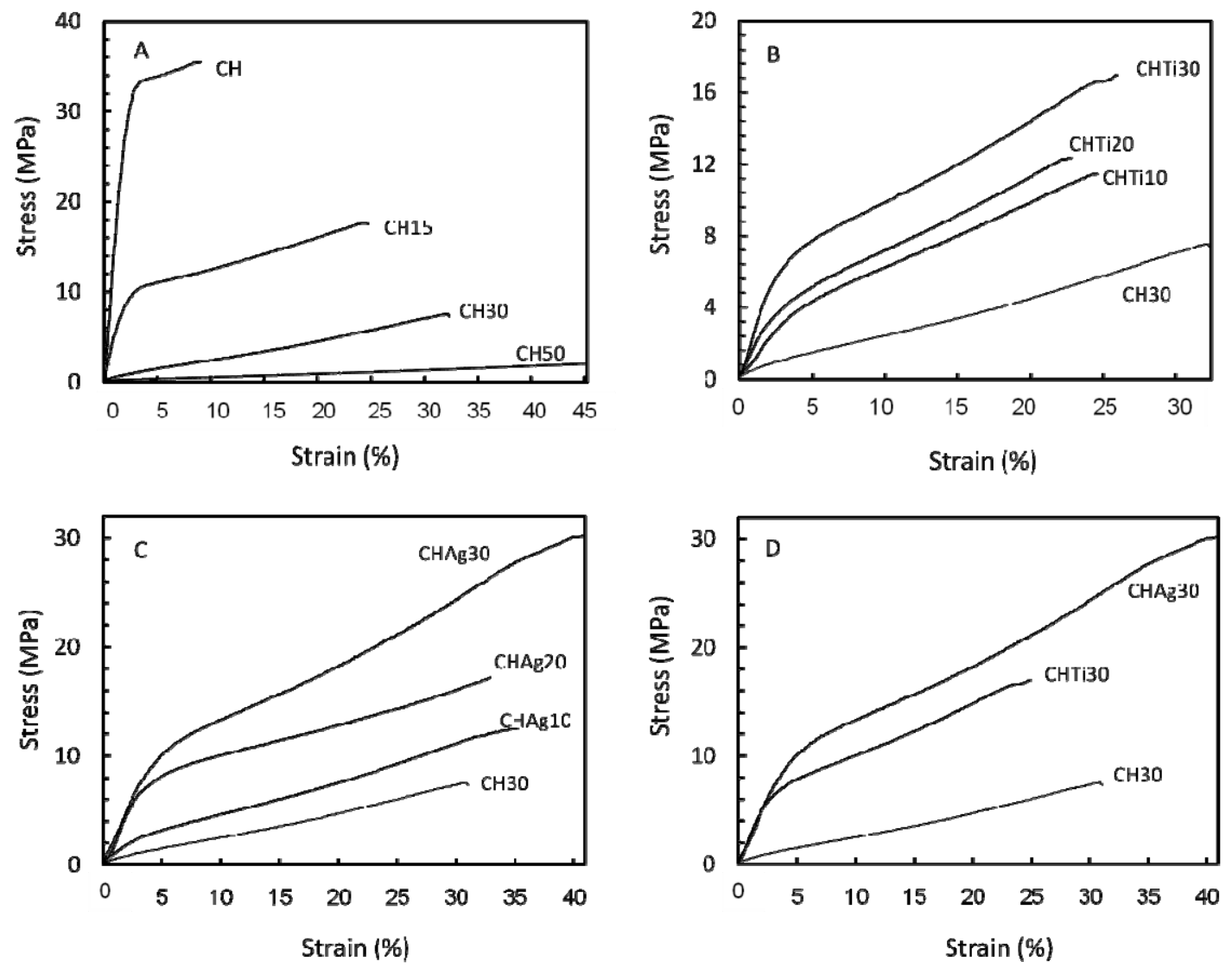

Figure 3.5: Typical stress-strain curves of (A) CH film containing $0 \%, 15 \%, 30 \%$ and $50 \%$ glycerine (by weight relative to $\mathrm{CH}$ ), (B) $\mathrm{CH}-\mathrm{TiO}_{2}$ composites containing $10 \%, 20 \%$ and $30 \%$ nanoparticle loadings (by weight relative to $\mathrm{CH}$ ), (C) $\mathrm{CH}-\mathrm{Ag}$ composites containing $10 \%, 20 \%$ and $30 \%$ nanoparticle loadings (by weight relative to $\mathrm{CH}$ ) and (D) comparison between the $\mathrm{CH} 30$ film, $\mathrm{CH}-\mathrm{TiO}_{2}$ and $\mathrm{CH}-\mathrm{Ag}$ composite films with $30 \%$ nanoparticle loadings (by weight relative to $\mathrm{CH}$ ).

Table 3.1: Properties of chitosan films with different percentages of glycerine (Gly). Thickness (thick), tensile strength (TS), Young's modulus (E), toughness (T), strain-at-break $(\gamma)$, swelling and contact angle (CA) are given for each film.

\begin{tabular}{|c|c|c|c|c|c|c|c|}
\hline $\begin{array}{l}\text { Gly } \\
\text { (\%) }\end{array}$ & $\begin{array}{l}\text { Thick } \\
(\mu \mathrm{m})\end{array}$ & $\begin{array}{c}\text { TS } \\
\text { (MPa) }\end{array}$ & $\begin{array}{c}\mathrm{E} \\
(\mathrm{MPa})\end{array}$ & $\begin{array}{c}\mathrm{T} \\
\left(\mathrm{J} \mathrm{g}^{-1}\right)\end{array}$ & $\begin{array}{c}\gamma \\
(\%)\end{array}$ & $\begin{array}{c}\text { Swelling } \\
\text { (\%) }\end{array}$ & $\begin{array}{l}\text { CA } \\
\left({ }^{\circ}\right)\end{array}$ \\
\hline 0 & $70 \pm 15$ & $39 \pm 5$ & $1223 \pm 173$ & $2.45 \pm 0.08$ & $10 \pm 2$ & N/A & $102 \pm 3$ \\
\hline 15 & $72 \pm 6$ & $19 \pm 8$ & $559 \pm 156$ & $4.46 \pm 0.32$ & $27 \pm 3$ & $>>5,000$ & $108 \pm 2$ \\
\hline 30 & $100 \pm 15$ & $6 \pm 1$ & $25 \pm 7$ & $1.27 \pm 0.01$ & $32 \pm 2$ & $823 \pm 31$ & $111 \pm 1$ \\
\hline 50 & $116 \pm 7$ & $2 \pm 1$ & $6 \pm 1$ & $0.75 \pm 0.05$ & $45 \pm 5$ & $331 \pm 28$ & $110 \pm 1$ \\
\hline
\end{tabular}




\subsubsection{Effect of different batch and molecular weight of $\mathbf{C H}$}

The effect of different batches of $\mathrm{CH}$ and molecular weight on mechanical characteristics was investigated by preparing CH30 films using: (i) medium molecular weight (MMW) with different batches (CH1 and $\mathrm{CH} 2$ ), and (ii) a high molecular weight (HMW) chitosan (CH3), see Table 3.2. The deacetylation degree (DD) values of the batches were similar for MMW, but there was a large difference in viscosity $(\eta)$ as supplied by the manufacturer (Sigma-Aldrich), i.e. $\eta=453 \mathrm{cP}$ for CH1 and $\eta=915$ cP for CH2.

Table 3.2: Properties of films prepared using chitosan from various sources (source), degree of deacetylation (DD), viscosity ( $\eta$ ), glycerin (Gly) (by weight relative to chitosan). "CH1" and "CH2" indicate two different batches of medium molecular weight chitosan, while "CH3" indicates high molecular weight chitosan, respectively. Tensile strength (TS), Young's modulus (E), and strain-at-break $(\gamma)$ of those $\mathrm{CH}$ films.

\begin{tabular}{|c|c|c|c|c|c|c|}
\hline Source & $\begin{array}{l}\text { DD } \\
(\%)\end{array}$ & $\begin{array}{c}\eta \\
\text { (cP) }\end{array}$ & $\begin{array}{l}\text { Gly } \\
\text { (\%) }\end{array}$ & $\begin{array}{c}\text { TS } \\
(\mathrm{MPa})\end{array}$ & $\begin{array}{c}\mathrm{E} \\
(\mathrm{MPa})\end{array}$ & $\begin{array}{c}\gamma \\
(\%)\end{array}$ \\
\hline $\begin{array}{l}\text { CH1, } \\
\text { this work }\end{array}$ & 75 & 453 & 30 & $6 \pm 1.0$ & $25 \pm 7$ & $32 \pm 2$ \\
\hline $\begin{array}{l}\text { CH2, } \\
\text { this worl }\end{array}$ & 79 & 915 & 30 & $8.0 \pm 0.4$ & $100 \pm 30$ & $34 \pm 2$ \\
\hline $\begin{array}{l}\text { CH3, } \\
\text { this work }\end{array}$ & 76 & 1,406 & 30 & $22 \pm 4.0$ & $500 \pm 134$ & $44 \pm 4$ \\
\hline Ref. ${ }^{190}$ & $>85$ & - & 25 & $41.6 \pm 5.9$ & - & $42.4 \pm 4$ \\
\hline Ref. ${ }^{79}$ & 90 & 110 & 25 & $32.9 \pm 0.7$ & - & $54.6 \pm 3$ \\
\hline Ref. ${ }^{193}$ & 90 & - & 28 & $17.3 \pm 2.8$ & $230 \pm 5.6$ & $44.2 \pm 8$ \\
\hline Ref. ${ }^{195}$ & 98 & - & 20 & $31.8 \pm 2.0$ & - & $45.7 \pm 3$ \\
\hline
\end{tabular}


It is well known that the viscosity of a polymer solution can be related to the molecular weight according to the Mark-Houwink-Sakurada (MHS) equation, which for $\mathrm{CH}$ has been determined as $\eta=1.49 \cdot 10^{-4} \mathrm{M}_{\mathrm{w}}{ }^{0.79} 311$. Hence, the MHS equation suggests that the molecular weights of $\mathrm{CH} 2$ and $\mathrm{CH} 3$ are 1.7 and 2.4 times that of CH1, respectively. These higher molecular weight materials exhibited higher TS and $\mathrm{E}$ values, i.e. $\mathrm{TS}=8.0 \pm 0.4 \mathrm{MPa}$ and $\mathrm{E}=100 \pm 30 \mathrm{MPa}$ for $\mathrm{CH} 2$ compared to $\mathrm{TS}=$ $22 \pm 4 \mathrm{MPa}$ and $\mathrm{E}=500 \pm 134 \mathrm{MPa}$ for CH3 (Table 3.2).

\subsubsection{Effect of addition of nanoparticles}

Inclusion of $\mathrm{TiO}_{2}$ and $\mathrm{Ag}$ resulted in mechanical reinforcement of CH30 materials (Figure 3.5, 3.6 and Table 3.3). The mechanical properties of these films increased with increasing $\mathrm{TiO}_{2}$ and $\mathrm{Ag}$ concentration. For example, addition of $30 \% \mathrm{TiO}_{2}$ (by weight relative to $\mathrm{CH}$ ) resulted in an 11.8 fold increase in Young's modulus (from 25 $\pm 7 \mathrm{MPa}$ to $294 \pm 11 \mathrm{MPa}$ ). Tensile strength and toughness values are both increased approximately 3 and 6 fold, respectively, i.e. from $6 \pm 1 \mathrm{MPa}$ to $20 \pm 6 \mathrm{MPa}$ and from $1.27 \pm 0.01 \mathrm{~J} \mathrm{~g}^{-1}$ to $7.2 \pm 1.5 \mathrm{~J} \mathrm{~g}^{-1}$, respectively, while the strain-at-break was not affected. Meanwhile, an addition of $30 \%$ of $\mathrm{Ag}$ (by weight relative to $\mathrm{CH}$ ) resulted in a 12.9 fold increase in Young's modulus, a 4.5 fold increase in tensile strength and a 6.3 fold increase in toughness, while the strain-at-break increased from $32 \pm 2 \%$ to 38 $\pm 4 \%$. Our results demonstrate that $\mathrm{CH}$-Ag materials have significantly higher tensile strength compared to $\mathrm{CH}-\mathrm{TiO}_{2}$ materials (Table 3.3).

It is suggested the improvement in the mechanical properties of $\mathrm{CH}-\mathrm{Ag}$ and $\mathrm{CH}-\mathrm{Ti}$ composites could result from electrostatic interactions between the amine group of $\mathrm{CH}$ with $\mathrm{Ag}$ ions and $\mathrm{Ti}$ ions ${ }^{312-314}$. In addition, it is likely that hydrogen bonding between $\mathrm{CH}$ with $\mathrm{TiO}_{2}$ nanoparticles is also a contributing factor for the 
observed increase in mechanical properties. For example, it has been. reported that the increased of tensile strength in polymer-silicate clay composites can be attributed to the formation of hydrogen bonding between the polymer and silicate clay ${ }^{315}$. While, it has also been suggested that mechanical reinforcement in composite materials depends on the possibility that the polymer optimizes its conformation with nanoscale components ${ }^{316}$.

Table 3.3: Properties of composite films prepared using chitosan with titanium dioxide $\left(\mathrm{TiO}_{2}\right)$ and silver (Ag) nanoparticles. Nanoparticles content (NP), thickness (Thick), tensile strength (TS), Young's modulus (E), toughness (T), strain-at-break $(\gamma)$, water vapour transmission rates (WVTR), swelling and contact angle (CA) are listed for the different composite materials. All samples were prepared with $30 \%$ glycerine content by weight relative to chitosan.

\begin{tabular}{|c|c|c|c|c|c|c|c|c|c|}
\hline Film & $\begin{array}{l}\text { NP } \\
(\%)\end{array}$ & $\begin{array}{l}\text { Thick } \\
(\mu \mathrm{m})\end{array}$ & $\begin{array}{c}\mathrm{TS} \\
(\mathrm{MPa})\end{array}$ & $\begin{array}{c}\mathrm{E} \\
(\mathrm{MPa})\end{array}$ & $\begin{array}{c}\mathrm{T} \\
\left(\mathrm{J} \mathrm{g}^{-1}\right)\end{array}$ & $\begin{array}{c}\gamma \\
(\%)\end{array}$ & $\begin{array}{c}\text { WVTR } \\
\left(\mathrm{g} \mathrm{m}^{-2} \mathrm{~d}^{-1}\right)\end{array}$ & $\begin{array}{c}\text { Swelling } \\
\text { (\%) }\end{array}$ & $\begin{array}{l}\text { CA } \\
\left(^{\circ}\right)\end{array}$ \\
\hline $\mathrm{CH}-$ & 10 & $76 \pm$ & $13 \pm$ & $99 \pm$ & 2.45 & $24 \pm$ & $413 \pm$ & $73 \pm 11$ & $97 \pm 0.5$ \\
\hline \multirow[t]{5}{*}{$\mathrm{TiO}_{2}$} & & 3 & 4 & 38 & \pm 0.1 & 2 & 10 & & \\
\hline & 20 & $79 \pm$ & $18 \pm$ & $276 \pm$ & 4.15 & $18 \pm$ & $410 \pm$ & $100 \pm 17$ & $93 \pm 2$ \\
\hline & & 6 & 1 & 83 & \pm 0.4 & 2 & 11 & & \\
\hline & 30 & $73 \pm$ & $20 \pm$ & $294 \pm$ & 7.20 & $26 \pm$ & $408 \pm$ & $105 \pm 15$ & $85 \pm 2$ \\
\hline & & 8 & 6 & 11 & \pm 1.5 & 4 & 13 & & \\
\hline $\mathrm{CH}-$ & 10 & $75 \pm$ & $12 \pm$ & $103 \pm$ & 3.24 & $33 \pm$ & $383 \pm$ & $>>1,000$ & $101 \pm 1$ \\
\hline \multirow[t]{5}{*}{$\mathrm{Ag}$} & & 8 & 2 & 29 & \pm 0.1 & 2 & 25 & & \\
\hline & 20 & $88 \pm$ & $14 \pm$ & $310 \pm$ & 4.10 & $35 \pm$ & $384 \pm$ & $1047 \pm 90$ & $103 \pm 1$ \\
\hline & & 20 & 2 & 187 & \pm 0.4 & 7 & 26 & & \\
\hline & 30 & $71 \pm$ & $27 \pm$ & $322 \pm$ & 8.00 & $38 \pm$ & $368 \pm$ & $1002 \pm 51$ & $106 \pm 1$ \\
\hline & & 11 & 4 & 145 & \pm 1.5 & 4 & 26 & & \\
\hline
\end{tabular}



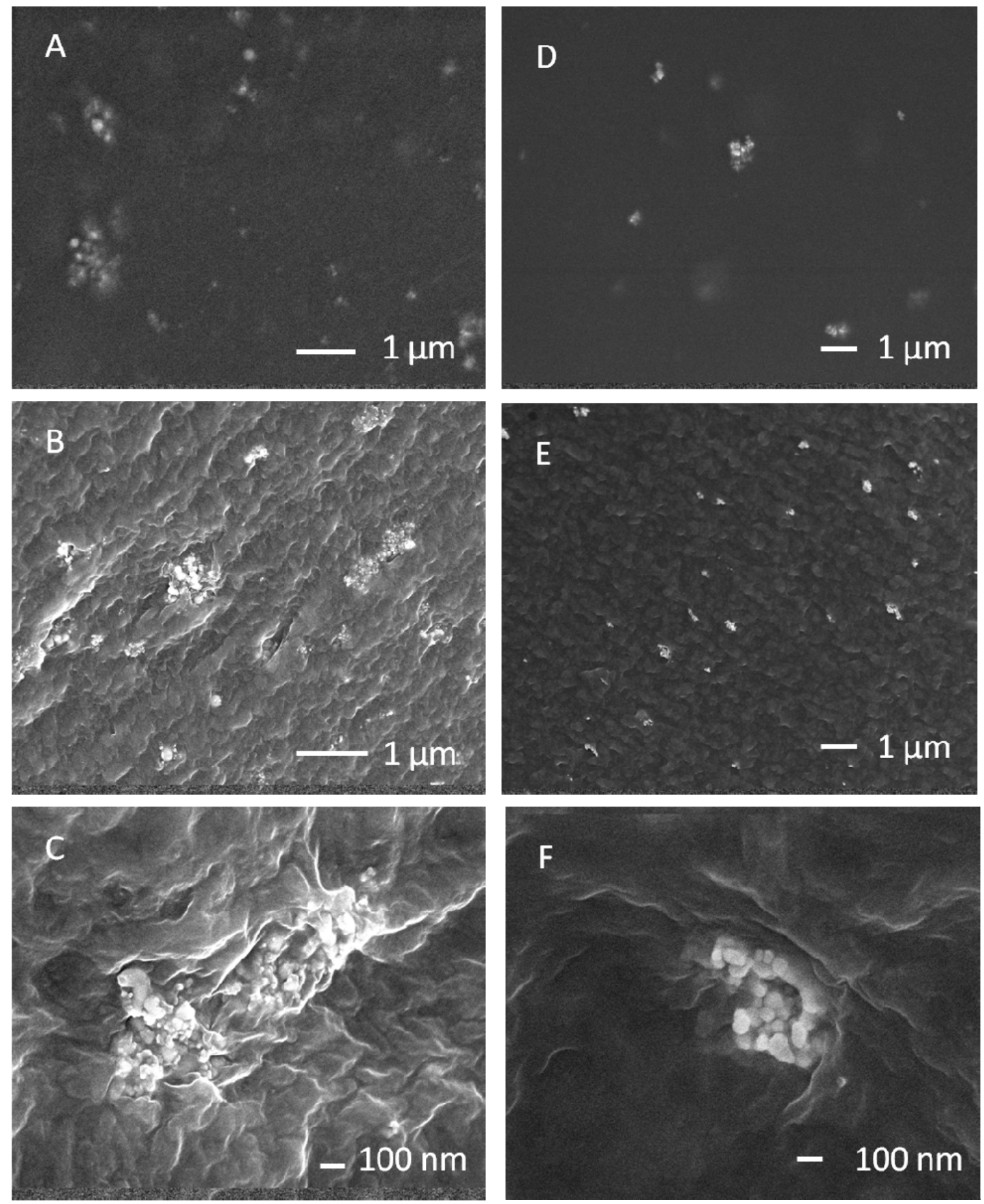

Figure 3.6: Scanning electron microscopy images of cross-sectional areas of (A) $\mathrm{CH}-\mathrm{Ag}$ composite film with 10\% nanoparticle loading (by weight relative to $\mathrm{CH}$ ) (CHAg10), (B and C) enlarged view of CHAg10 composite film, (D) CH-Ti composite film with $10 \%$ nanoparticle loading (by weight relative to $\mathrm{CH}$ ) (CHTi10), and (E-F) enlarged view of CHTi10 composite film.

\subsection{Swelling}

The swelling results show that addition of glycerine to the $\mathrm{CH}$ film results in a large reduction in water uptake (Table 3.1). For example, increasing the glycerine content 
from $15 \%$ to $30 \%$ reduced the swelling from $>>5000 \%$ to $823 \%$ (Table 3.1 ). Photographs of the swollen CH15 and CH30 films are shown in Figure 3.7.
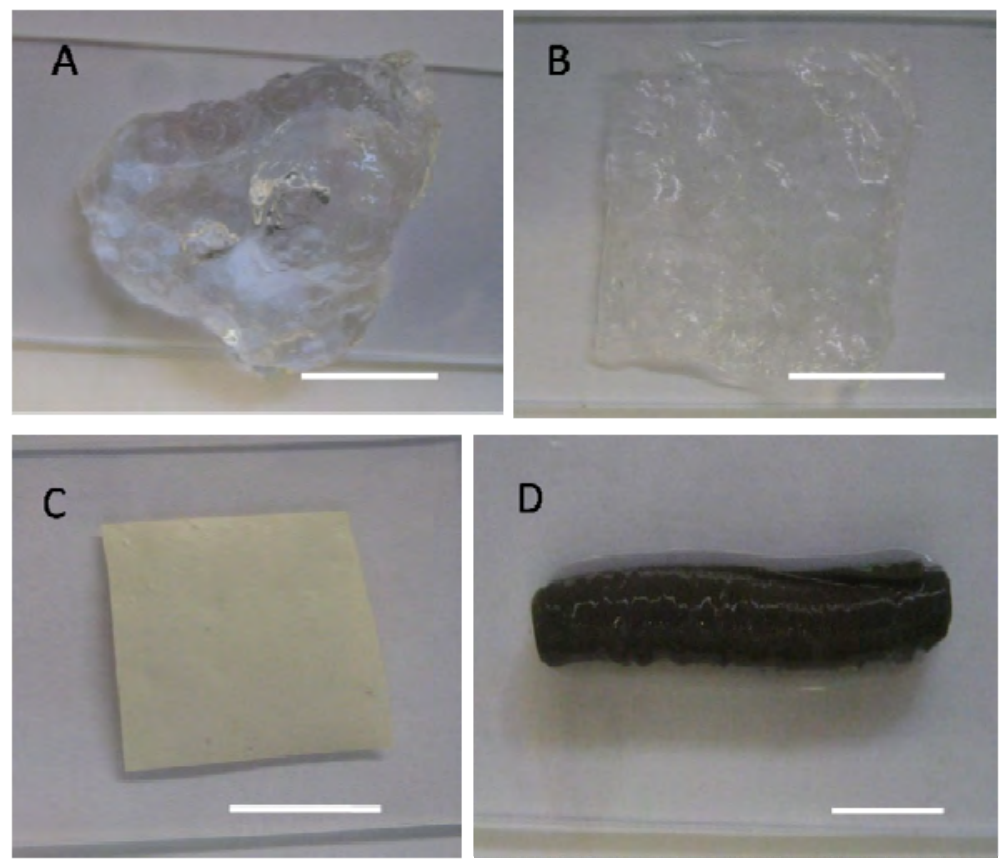

Figure 3.7: Swelling of films in Milli-Q water for 24h; (A) CH15 film, (B) CH50 film, (C) CHAg20 composite and (D) CH-Ti nacomposite. Scale bars represent $1 \mathrm{~cm}$.

It is suggested that the swelling of $\mathrm{CH}$ materials is a result of electrostatic repulsion between $\mathrm{CH}$ chains ${ }^{317}$. Previously, it has been hypothesised that swelling of $\mathrm{CH}$ composite films can be reduced by either prevention of chitosan chain movement or separation of the chitosan chains ${ }^{318}$. Therefore, it is likely that the observed reduction in swelling is due to hydrogen bonding between glycerine and chitosan which limits chitosan chain movement.

In comparison to $\mathrm{CH} 30$, addition of $\mathrm{Ag}(10 \%$, by weight relative to $\mathrm{CH}$ ) resulted in a large increase in swelling (from $823 \pm 31 \%$ to $4223 \pm 20 \%$ ), which is an almost 5 fold increase (Table 3.1 and 3.3). This is due to the interaction of the amine group $\left(\mathrm{NH}_{2}\right)$ in $\mathrm{CH}$ with $\mathrm{Ag}$ ions $\left(\mathrm{R}-\mathrm{NH}_{2} \mathrm{Ag}^{+}\right)^{319}$. The structure of $\mathrm{R}-\mathrm{NH}_{2} \mathrm{Ag}^{+}$ 
breaks up in water to $\mathrm{AgOH}$ and $\mathrm{R}-\mathrm{NH}_{3}{ }^{+}$and the $\mathrm{AgOH}$ molecules could interact with $\mathrm{Ag}^{+}$and form bio-conjugates with $\mathrm{CH}$. These bio-conjugates are responsible for water absorption. Similar results have been observed in water swelling for other $\mathrm{CH}$ Ag composite films ${ }^{79,244}$.

Addition of $\mathrm{TiO}_{2}$ nanoparticle decreased the swelling of $\mathrm{CH}-\mathrm{Ti}$ composites. For instance, an addition of $10 \%$ (by weight relative to $\mathrm{CH}$ ) of $\mathrm{TiO}_{2}$ resulted in a significant reduction in swelling (from $823 \pm 31 \%$ to $73 \pm 11 \%$ ), while increasing the $\mathrm{TiO}_{2}$ concentration to $30 \%$ increased the swelling to $\sim 105 \pm 15 \%$ (Table 3.1 and 3.3). It is suggested that this can be attributed to the strong hydrogen bonding interactions between $\mathrm{CH}$ and $\mathrm{TiO}_{2}$, which contributed to further interconnecting the $\mathrm{CH}$ chains (in addition to interconnections via CH-Gly hydrogen bonding), thereby reducing swelling.

\subsection{Contact angle}

The hydrophobicity of the $\mathrm{CH}$-composites was determined through contact angle (CA) measurements. The hydrophobicity of the $\mathrm{CH}$ films was found to increase with increasing glycerine content (Table 3.1). Additions of 10\%, 20\% and 30\% (by weight relative to $\mathrm{CH}$ ) of Ag-nanoparticles resulted in CA values of $101 \pm 1^{\circ}, 103 \pm 1^{\circ}$, and $106 \pm 1^{\circ}$, respectively. In contrast, the CA of CH30 was reduced from $111 \pm 1^{\circ}$ to 85 $\pm 2^{\circ}$ through addition of $\mathrm{TiO}_{2}$ nanoparticles (Table 3.3).

It is not clear at present why our values are higher than reported by Rhim and co-workers ${ }^{79}$. They had reported that the CA value of their $\mathrm{CH}$ film is at $45.6 \pm 0.2$. It is likely that, factors such as differences in molecular weight, deacetylation degree 
(DD), and the source of chitosan (as described in Table 3.2), could be responsible for the observed difference.

\subsection{Water vapour transmission rates (WVTR)}

Water vapour transmission rates (WVTR) of CH-composites are summarised in Table 3.3. The WVTR values of the $\mathrm{CH}-\mathrm{Ti}$ and $\mathrm{CH}-\mathrm{Ag}$ composites films were in the range of $408-413 \mathrm{~g} \mathrm{~m}^{-2} \mathrm{~d}^{-1}$ and $368-384 \mathrm{~g} \mathrm{~m}^{-2} \mathrm{~d}^{-1}$, respectively. These values are within the range of WVTR values $\left(90-2,893 \mathrm{~g} \mathrm{~m}^{-2} \mathrm{~d}^{-1}\right.$ ) reported for eight commercially available synthetic wound dressings ${ }^{297}$. In particular, the obtained values are directly comparable to those reported for the hydrocolloid based dressings known as IntraSite ${ }^{\circledR}\left(354 \pm 42 \mathrm{~g} \mathrm{~m}^{-2} \mathrm{~d}^{-1}\right)$ and Restore $\mathrm{Cx}{ }^{\circledR}\left(482 \pm 69 \mathrm{~g} \mathrm{~m}^{-2} \mathrm{~d}^{-1}\right)$.

\subsection{Cell study}

\subsubsection{Cell viability}

$\mathrm{CH}$ film and $\mathrm{CH}$-composites were neutralised with $\mathrm{NaOH}$ to remove any remaining acetic acid (necessary for solubility of $\mathrm{CH}$ in water). As prepared, $\mathrm{CH} 30$ films exhibited a low L929 cell viability (Figure 3.8 A). Several studies had reported that the potential cytotoxicity of chemically modified biomaterials could be from acetic acid residues ${ }^{320,321}$.

CH30 film treated with $\mathrm{NaOH}$ exhibit higher cell viability compared to asprepared CH30 films without treatment. The L929 cells adhering on CH30 film changed their morphology from spherical to elongated/spindle-like, which is typical of L929 fibroblast cells (Figure 3.8 B). It has been suggested that the adherence of L929 cells on $\mathrm{CH}$ film is a result of electrostatic interaction between positively charged CH chains and negatively charged L929 cell membrane ${ }^{199,322}$. This suggests 
that treated CH30 films support the attachment and growth of L929 cell. Our results are in agreement with previous studies of L929 on CH films ${ }^{200,203,323 .}$
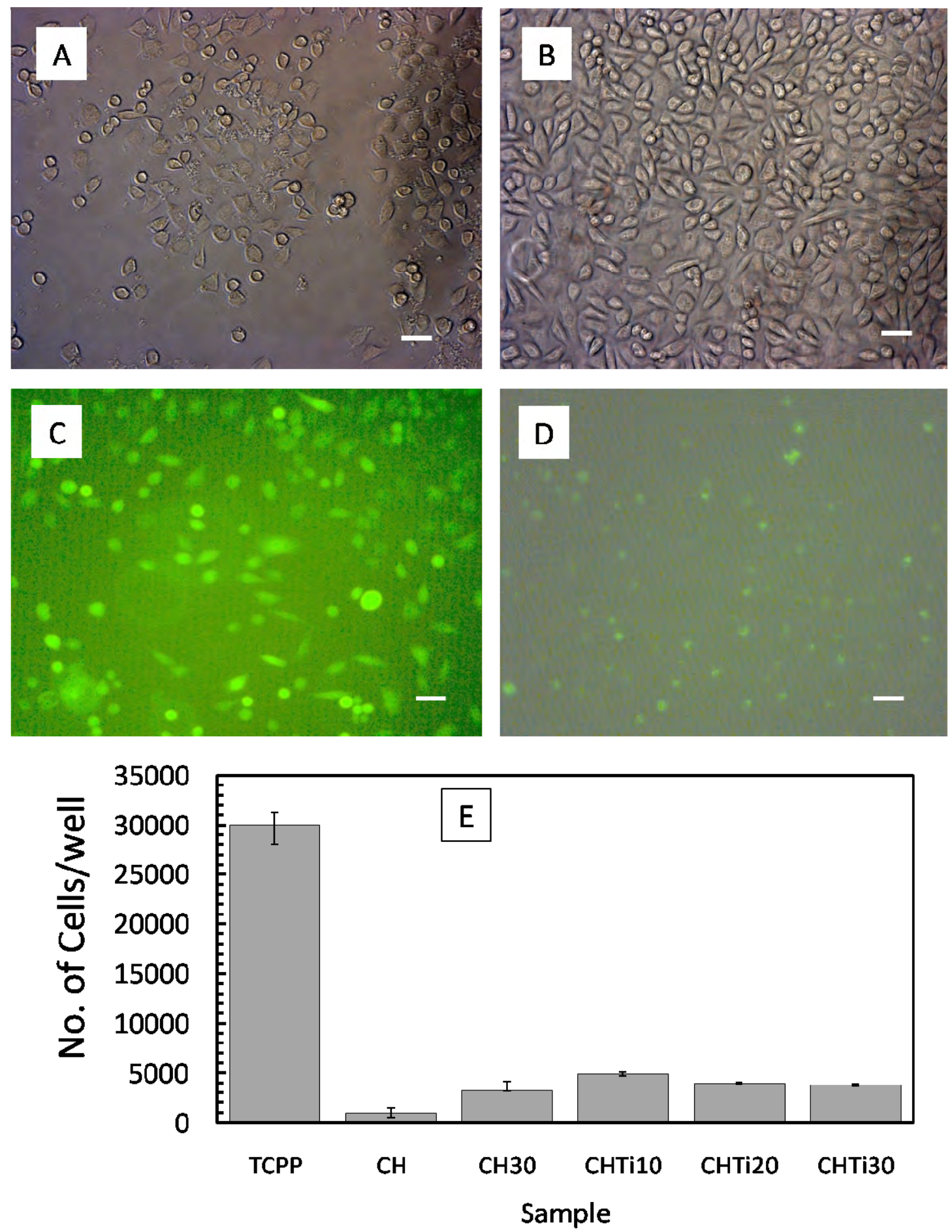

Figure 3.8: (A) As prepared CH30 films (without $1 \mathrm{M} \mathrm{NaOH}$ treatment), (B) CH30 film with $1 \mathrm{M} \mathrm{NaOH}$ treatment, (C) fluorescent image of adherent L929 cells on CHTi10 composite, (D) fluorescent image of dying cells on CHAg10 composite, and (E) cell proliferation of CH30 film and CH-Ti composites cultured in L929 cell for 72h. Errors represent one standard deviation from the measured values $(n=3)$. Scale bars represent $50 \mu \mathrm{m}$. 
Addition of $\mathrm{TiO}_{2}$ to $\mathrm{CH}$ film promotes $\mathrm{L} 929$ cell growth, whereas inclusion of Ag nanoparticles inhibits growth. Fluorescence imaging showed that cells on $\mathrm{CH}-\mathrm{Ti}$ composite are viable (Figure $3.8 \mathrm{C}$ ). However, the degree of fluorescence observed for cells on Ag containing films indicates that most cells are dying (Figure $3.8 \mathrm{D}$ ). Previously, it has been shown that chitosan-Ag films crosslinked with genipin were biocompatible with $\mathrm{L}-929$ cells ${ }^{244}$, while lactose-substitute chitosan-alginate-Ag hydrogels were found to be non-cytotoxic towards mouse-fibroblast-like (NIH-3T3), human hepatocarcinoma (HepG2) and human osteosarcoma (MG63) cells ${ }^{263}$. Our results may suggest that the observed cell death was due to nanoparticle contact with the cells ${ }^{324}$. As such, it is possible that the cell viability of the CH-Ti composites can be explained by the prevention of nanoparticle diffusion. Hence, it is likely that a nanoparticle containing material will be non-cytotoxic as long as contact between nanoparticles and cells is prevented, as is the case for the aforementioned hydrogel and cross-linked chitosan 244,263 .

This observation was further investigated by a so-called indirect contact assay on the supernatant of $\mathrm{CH}-\mathrm{Ti}$ and $\mathrm{CH}-\mathrm{Ag}$ composites. Figure 3.9 shows that the L929 cells in the supernatant containing $\mathrm{CH}-\mathrm{Ti}$ composite are viable, i.e. the cells elongated and adhered to the tissue culture polystyrene plate (TCPP). In contrast, L929 cells in supernatant containing $\mathrm{CH}-\mathrm{Ag}$ composite were not viable (Figure 3.9). It is suggested that the high swelling ratio of $\mathrm{CH}-\mathrm{Ag}$ composite compared to $\mathrm{CH}-\mathrm{Ti}$ composite (Table 3.3) may result in diffusion of Ag nanoparticle into the medium, and kill the cells. 

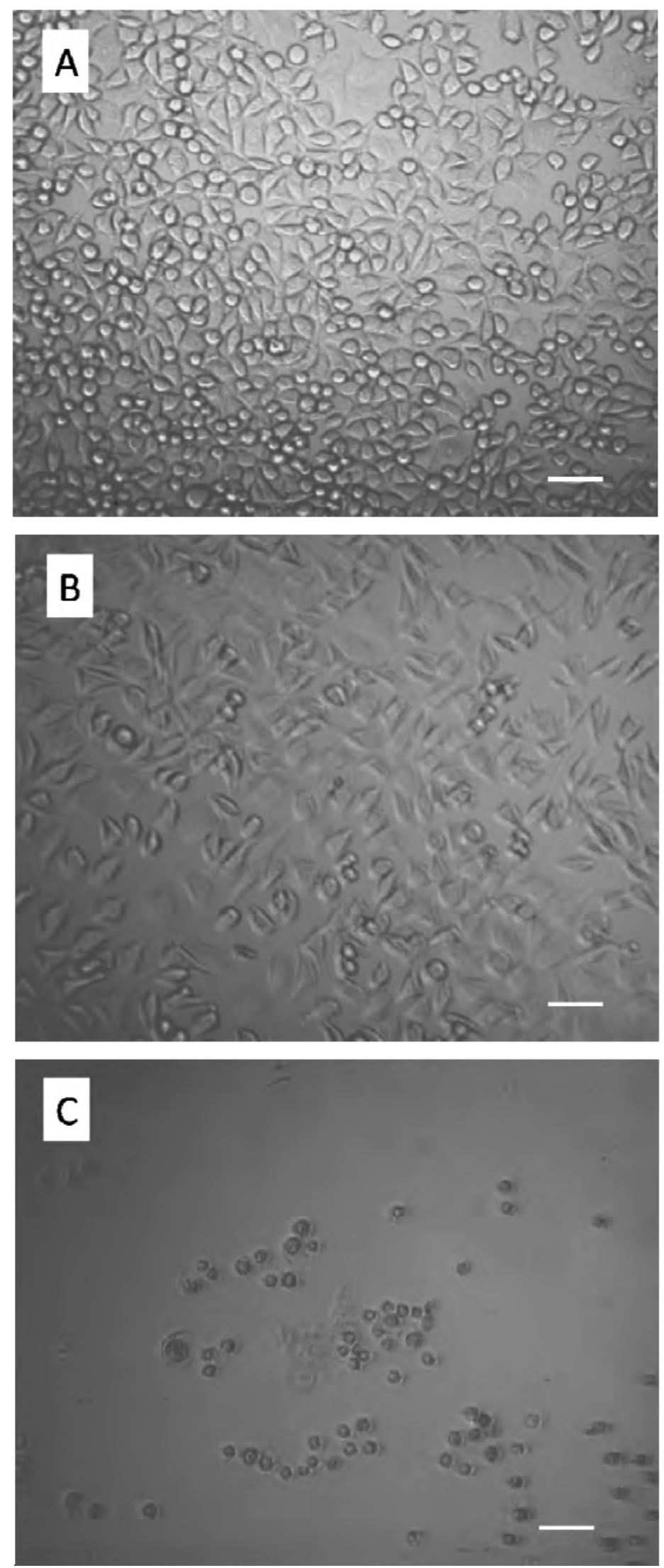

Figure 3.9: In-direct contact assay of the $\mathrm{CH}$-composites after incubated with $\mathrm{L} 929$ cell for 72h; (A) TCPP, (B) CHTi10, and (C) CHAg10. Scale bars represent $100 \mu \mathrm{m}$. 


\subsubsection{Cell proliferation}

Glycerine in $\mathrm{CH}$ film exhibits a significant effect on the L929 cell proliferation (Figure 3.8 E). For instance, the cell proliferation of $\mathrm{CH} 30$ multiples to 3200 cells/well after incubated for $72 \mathrm{~h}$, whereas $\mathrm{CH}$ film is only at 1000 cell/well (Figure 3.8 E). Cell proliferation on the $\mathrm{CH}-\mathrm{Ti}$ composites was improved compared to $\mathrm{CH} 30$ film (Figure 3.8 E). For instance, CHTi10 composite and CH30 film recorded 4900 cells/well and 3200 cells/well, respectively after incubated for 72h. However, cell proliferations were decreased upon additions 20\% and 30\% (by weight relative to $\mathrm{CH}$ ) of nanoparticle loadings (Figure $3.8 \mathrm{E}$ ). In contrast, the $\mathrm{CH}$-Ag composites show none of the cell proliferates on substrate which expected due to diffusion of $\mathrm{Ag}$ nanoparticles into the media and killed the cells.

A number of studies reported the influence of physic-chemistry of the surface toward biological response of viable cells such as hydrophobicity and hydrophilicity of materials $196,198,325-330$. An addition of glycerine was reported to improve the hydrophobicity and lead to a positive biological response of viable cells on the substrate ${ }^{60,331,332}$. This behaviour is in agreement with the cell proliferation recorded on $\mathrm{CH} 30$ and $\mathrm{CH}$ films. Incorporation of nanoparticles has been reported to increase surface area to volume ratio of nanocomposite for cells to adhere thus increases cell proliferation ${ }^{333}$. As consequent, this factor explained the higher cell proliferation obtained on the $\mathrm{CH}-\mathrm{Ti}$ composites compared to $\mathrm{CH} 30$ film (Figure $3.8 \mathrm{E}$ ). Not limited to that, inclusions of nanoparticles also had been reported to change surface topology of the nanocomposite which could affected cell proliferation ${ }^{334-336}$. 


\subsection{Antibacterial study}

The antibacterial activity of $\mathrm{CH} 30$ solution and $\mathrm{CH}$-composites dispersion was quantified by a viable cell count method (quantitative study). Table 3.4, shows that CH30 solution against Escherichia coli (E. coli) results in a 1 log cycle reduction compared to control (Table 3.4) which is in agreement with previously reported values ${ }^{136,206,212,337,338}$. As a comparison, the commercial antibiotic ampicillin (5 mg/ L) exhibited a 5 log cycle reduction compared with the control (Table 3.4).

Table 3.4: The number of viable bacterial colonies after 24 hours $\left(n_{\text {viable }}\right)$ of control, commercial antibiotic (ampicillin), CH30, and $\mathrm{CH}$-composites. Errors represent one standard deviation from the measured mean values $(n=3)$.

\begin{tabular}{cc}
\hline Sample & $\begin{array}{c}\mathrm{n}_{\text {viable }} \\
(\mathrm{CFU} / \mathrm{ml})\end{array}$ \\
\hline control & $8.0 \pm 0.5 \times 10^{8}$ \\
ampicillin & $1.3 \pm 0.1 \times 10^{4}$ \\
CH30 & $7.0 \pm 0.7 \times 10^{7}$ \\
CHAg10 & $8.0 \pm 1.4 \times 10^{6}$ \\
CHTi10 & $9.0 \pm 1.6 \times 10^{6}$ \\
\hline
\end{tabular}

Chitosan is well-known for its antimicrobial effect, which has been attributed to its ability to enter the bacterial cell wall through pervasion and to form a polymer membrane on the surface of the cell wall ${ }^{135,337}$. The former prevents nutrients from entering the bacterial cell, while the latter disturbs the physiological activity of the bacterium ${ }^{135}$. Chitosan has been reported to be effective against both Gram-negative and Gram-positive bacteria, although its effectiveness depends on its molecular weight, degree of deacetylation (DD) and concentration ${ }^{135,212,337 .}$ 
$\mathrm{CH}-\mathrm{TiO}_{2}$ and $\mathrm{CH}-\mathrm{Ag}$ composite films were characterised by two methods; i.e. quantitative (disk method) and qualitative (viable count method). The inclusion of Ag and $\mathrm{TiO}_{2}$ nanoparticles in chitosan solution increases the effectiveness against $E$. coli to a $2 \log$ cycle reduction compared to the control (Table 3.4). Similar results were reported for addition of $\mathrm{Ag}^{+}$ions to chitosan and $\mathrm{Ag}$ nanoparticles to genipincrosslinked chitosan materials ${ }^{79,244}$. The effectiveness of the $\mathrm{CH}$-composite dispersions is similar to that reported for crosslinked chitosan- $\mathrm{TiO}_{2}$-gelatin films, albeit that this was tested against the Gram-positive bacteria S. aureus ${ }^{255}$. The antibacterial activity of $\mathrm{TiO}_{2}$ materials originates from its photocatalytic properties ${ }^{258-}$ ${ }^{260}$. Upon exposure to a UV light containing light source, $\mathrm{TiO}_{2}$ generates superoxide ions and hydroxyl radicals ${ }^{258-260}$. It has been proposed that these ions and radicals operate in concert to attack phospholipids in E. coli ${ }^{259}$. The resulting lipid peroxidation reaction causes disruption of the bacterial cell membrane, leading to loss of viability by E. coli ${ }^{259}$.

The qualitative antibacterial studies of $\mathrm{CH}-\mathrm{Ag}$ and $\mathrm{CH}-\mathrm{TiO}_{2}$ dispersions and films showed that distinctive inhibition zones were only visible for $\mathrm{CH}-\mathrm{Ag}$ dispersions and films (Figure 3.10). The antibacterial activity increases with Ag nanoparticle contents, which is an agreement with previous study reported ${ }^{79}$. The $\mathrm{CH}$-Ag dispersions were found to be more effective towards E. coli compared to film. This may be due to the ability of the dispersions to diffuse into the Lysogeny broth agar (Figure 3.10). 

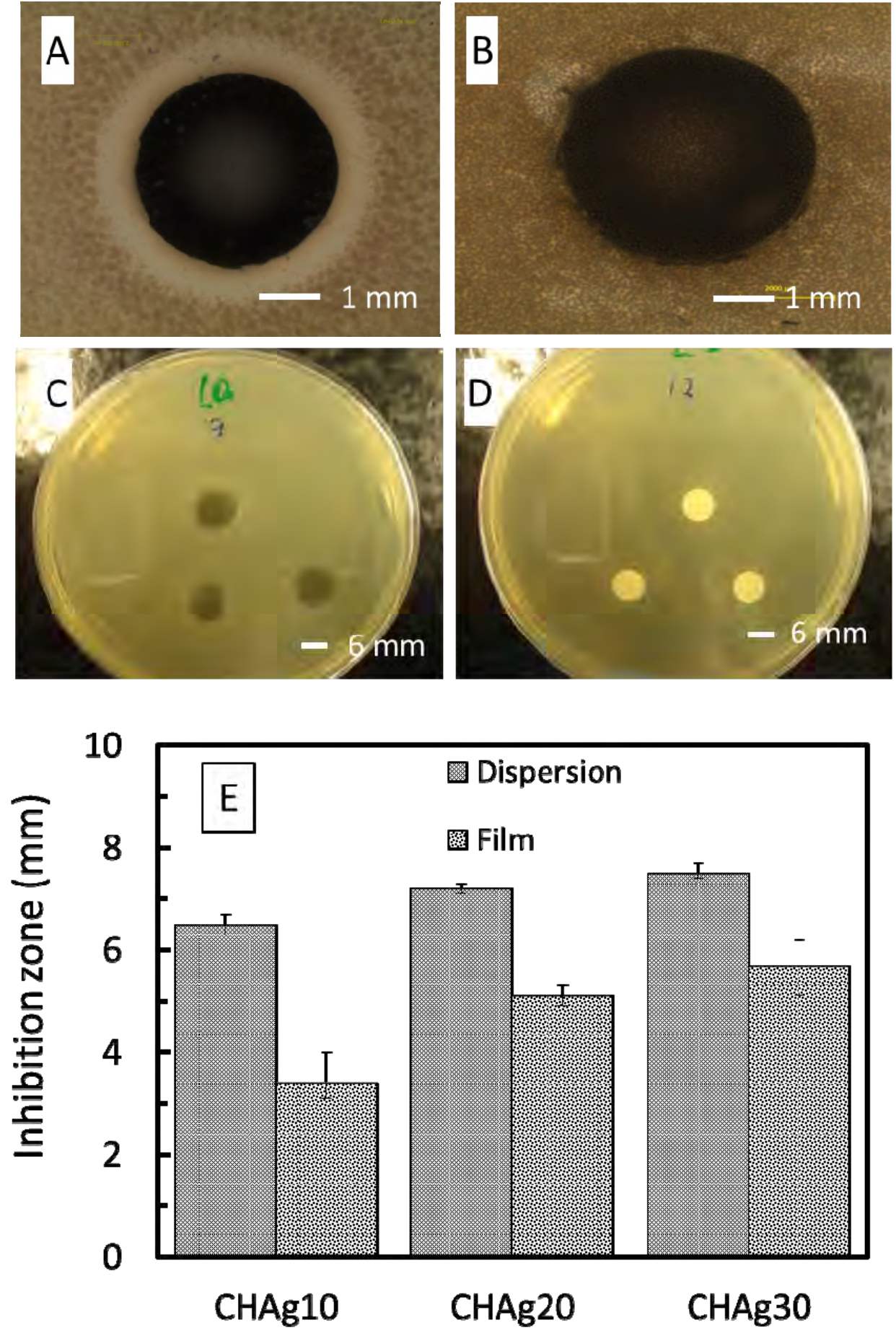

Figure 3.10: Antibacterial activity of samples quantified by a qualitative method against Escherichia coli incubated at $37^{\circ} \mathrm{C}$ for 24h. (A) CHAg20 dispersion, (B) CHTi20 dispersion, (C) CHAg20 composite, (D) CHTi20 composite, and (E) inhibition zone on the $\mathrm{CH}-\mathrm{Ag}$ dispersions and films. Errors represent one standard deviation from the measured mean values $(n=3)$.

The antibacterial activity of Ag nanoparticles and $\mathrm{Ag}^{+}$ions is well known ${ }^{245}$, 248, 339 , and it has been suggested that silver nanoparticles act in three ways against 
Gram-negative bacteria: (i) they attach to the surface of the bacterial cell membrane, significantly inhibiting permeability and respiration; (ii) they penetrate inside the bacteria and cause further damage; (iii) they release silver ions resulting in bacterial DNA losing its capacity for replication as well as inactivation of bacterial proteins ${ }^{245}$. Our materials yield promising antibacterial activities, which is further addressed in chapter 7.

\subsection{Antiviral activity in vitro}

The antiviral activitiy of CH30 films were investigated against green fluorescent protein restrain of Ross-river virus (GFP-RRV). The CH30 films were seeded with Vero cell $\left(1.5 \times 10^{5}\right.$ cells/well), and incubated for $20 \mathrm{~h}$. Then, the GFP-RRV was added and further incubated for 6h, 12h and 24h. The Vero cells infected with GFPRRV on CH30 film were comparable to a control after incubation for $6 \mathrm{~h}$ and $12 \mathrm{~h}$ (Figure 3.11 A - D). A few Vero cells were clearly infected by GFP-RRV, as evident from the debris around the cells (Figure 3.11 A - D).

It was assumed that the GFP-RRV were killed in the same way as the bacteria, as described previously ${ }^{245}$. The GFP-RRV penetrates into the Vero cells and replicates. The replication process resulted in death of Vero cells, leading debris around the cells. After 24h, the numbers of infected Vero cells were increased on the TCPP, but decreased on the CH30 film (Figure 3.11 E - F). This result indicates that CH30 films exhibit antiviral activity by protecting the Vero cells from infection by GFP-RRV. No clear explanation on the mechanism of this observation has been reported in the literature to date. Further studies using a plaque assay (quantitative) are needed to ascertain the number of cells infected. It was not possible to test $\mathrm{CH}-\mathrm{Ag}$ 
and $\mathrm{CH}-\mathrm{Ti}$ composite films, because of their opaque property, which prevents observation of the cell growth and infected cells.

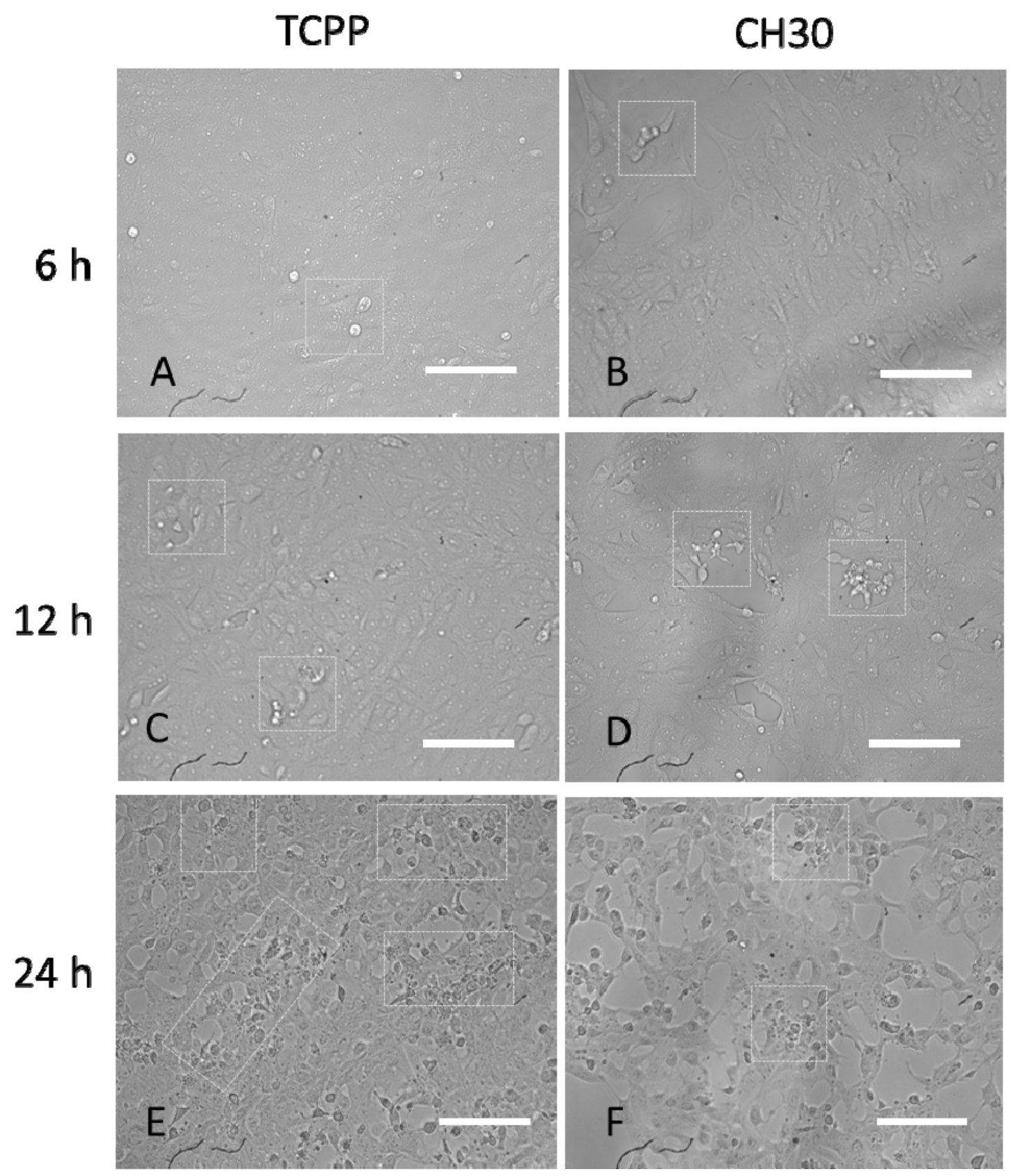

Figure 3.11: Vero cells infected by green fluorescent protein restrain of Ross-river virus (in boxes) on tissue culture polystyrene plate (TCPP) (as control) and CH30 film after incubated for $6 \mathrm{~h}, 12 \mathrm{~h}$ and $24 \mathrm{~h}$. Scale bars represent $50 \mu \mathrm{m}$. 


\subsection{Conclusion}

The physical properties, cell proliferation and antibacterial activities of $\mathrm{TiO}_{2}$ and Ag containing chitosan composite materials were investigated. Inclusion of glycerine in chitosan made the films mechanically weaker, but more flexible. This was attributed to a reduction in the attractive energy between $\mathrm{CH}-\mathrm{CH}$, due to formation of hydrogen bonding between $\mathrm{CH}-\mathrm{Gly}$.

$\mathrm{TiO}_{2}$ and Ag containing composite materials exhibited a significant mechanical reinforcement compared to chitosan films. For example, addition of $30 \%$ (by weight relative to $\mathrm{CH}$ ) $\mathrm{TiO}_{2}$ resulted in an 11.8-fold increase in Young's modulus, a 3-fold increase in tensile strength, and a 6-fold increase in toughness. In comparison, addition of $30 \%$ (by weight relative to $\mathrm{CH}$ ) Ag resulted in 12.9- fold and 6-fold increases in Young's modulus and toughness, respectively, but only a 3-fold increase in tensile strength. The extensibility of Ag containing materials was higher than $\mathrm{TiO}_{2}$ containing materials. The water vapour transmission rates (368 - $413 \mathrm{~g} \mathrm{~m}^{-2}$ $\mathrm{d}^{-1}$ ) were similar for both materials, and comparable to commercially available wound dressings. However, inclusion of Ag lowered the water resistance (increased swelling) of chitosan films from $823 \%$ up to $4,000 \%$, while incorporation of $\mathrm{TiO}_{2}$ resulted in a significant improvement in water resistance (to 100\%). It is hypothesised that these observations are related to the effect of the nanoparticles on the interconnection of chitosan chains, i.e. the strong hydrogen bonding between $\mathrm{CH}$ and $\mathrm{TiO}_{2}$ increases the interconnection, while Ag disrupts these interconnections, thereby increasing swelling.

In vitro cell studies found that $\mathrm{CH}-\mathrm{TiO}_{2}$ films supported the growth of cell, whereas $\mathrm{CH}-\mathrm{Ag}$ films did not. Proliferations of $\mathrm{L} 929$ cells on all $\mathrm{TiO}_{2}$ containing 
chitosan films were almost comparable to $\mathrm{CH}$ film. Fluorescence imaging showed that most cells on Ag containing films were dead. The antibacterial effectiveness by a quantitative method against E. coli, was similar for both $\mathrm{Ag}$ and $\mathrm{TiO}_{2}$ containing materials. In contrast, a qualitative method revealed that $\mathrm{CH}$-Ag composite displayed superior antibacterial activity compared to $\mathrm{CH}$-TiO2 composite. Preliminary results showed that chitosan is also effective in inhibiting virus (GFP-RRV) growth. 


\section{CHAPTER 4}

\section{CHARACTERISATION OF COMPOSITE MATERIALS FROM GELLAN GUM WITH TITANIUM DIOXIDE, SILVER AND ZINC OXIDE NANOPARTICLES}

Low acyl gelan gum (GG) produces firm, non-flexible and brittle films ${ }^{219}$. Glycerine was incorporated into GG to improve the flexibility and thereby the handle-ability of the films ${ }^{340}$. GG-composite films containing titanium dioxide $\left(\mathrm{TiO}_{2}\right)$, silver $(\mathrm{Ag})$ and zinc oxide $(\mathrm{ZnO})$ nanoparticles were characterised to investigate the effect of nanoparticles on the mechanical properties, swelling and water vapour transmission rates (WVTR). Biological activities (cell viability and cell proliferation) on the GG and GG-composite films were studied in vitro using mouse fibroblast (L929) cells. Furthermore, the antibacterial activities of GG film and GG-composites were evaluated using a Gram-negative bacterium, i.e. Escherichia coli (E. coli).

\subsection{Spectroscopy}

\subsubsection{UV-visible}

GG film and GG-composites were prepared by evaporative casting technique. The addition of glycerine does not change the absorption peak of the GG film (Figure 4.1 
A). The absorption peak observed for both GG and GG50 films at $250 \mathrm{~nm}$ corresponds to glucoronic acid of gellan gum ${ }^{341}$.
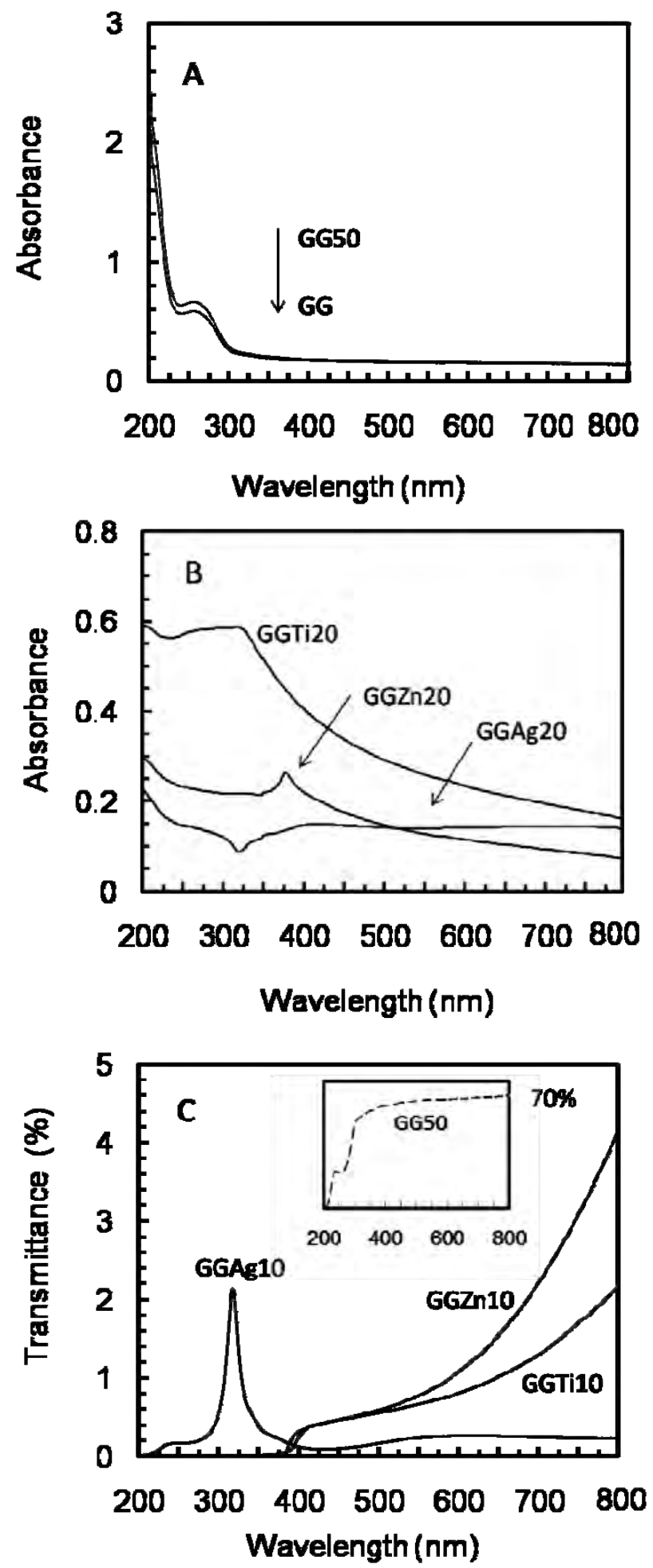

Figure 4.1: (A) UV-visible absorbance of the GG and GG50 films (pathlength=5 mm), (B) UV-visible absorbance of the GG-composite dispersions (pathlength=0.01 mm), (C) UVvisible transmittance of the GG-composites films (pathlength $=5 \mathrm{~mm}$ ); inset: transmittance of the GG50 film. All measurements of UV absorbance were carried out at $21^{\circ} \mathrm{C}$. 
The addition of anatase $\mathrm{TiO}_{2}$ and $\mathrm{ZnO}$ nanoparticles to GG solutions resulted in an absorption of specific characteristic bands in the near-UV spectral region at 320

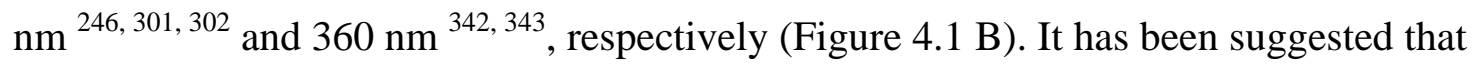
the blue shifted (transition to shorter wavelengths) of $\mathrm{ZnO}$ absorption from $385 \mathrm{~nm}$ (literature) ${ }^{344}$ to $360 \mathrm{~nm}$ (this study) is due to a smaller particle size ${ }^{344}$. The characteristic absorption band of Ag atoms in GG-Ag dispersions at $420 \mathrm{~nm}$ is barely observed as the Ag ions are expected to attach to the carboxylic groups of gellan gum 303 (Figure $4.1 \mathrm{~B}$ ).

The transmittance of GG50 film is around 70\% in the visible wavelength range (500-750 nm) (inset in Figure 4.1 C) which is evident from the images shown in Figure 4.2 A. The films of the GG-composites were not optically transparent as evident from the transmittance spectra (Figure 4.1 C) and the images (Figure 4.2 B, C and D).
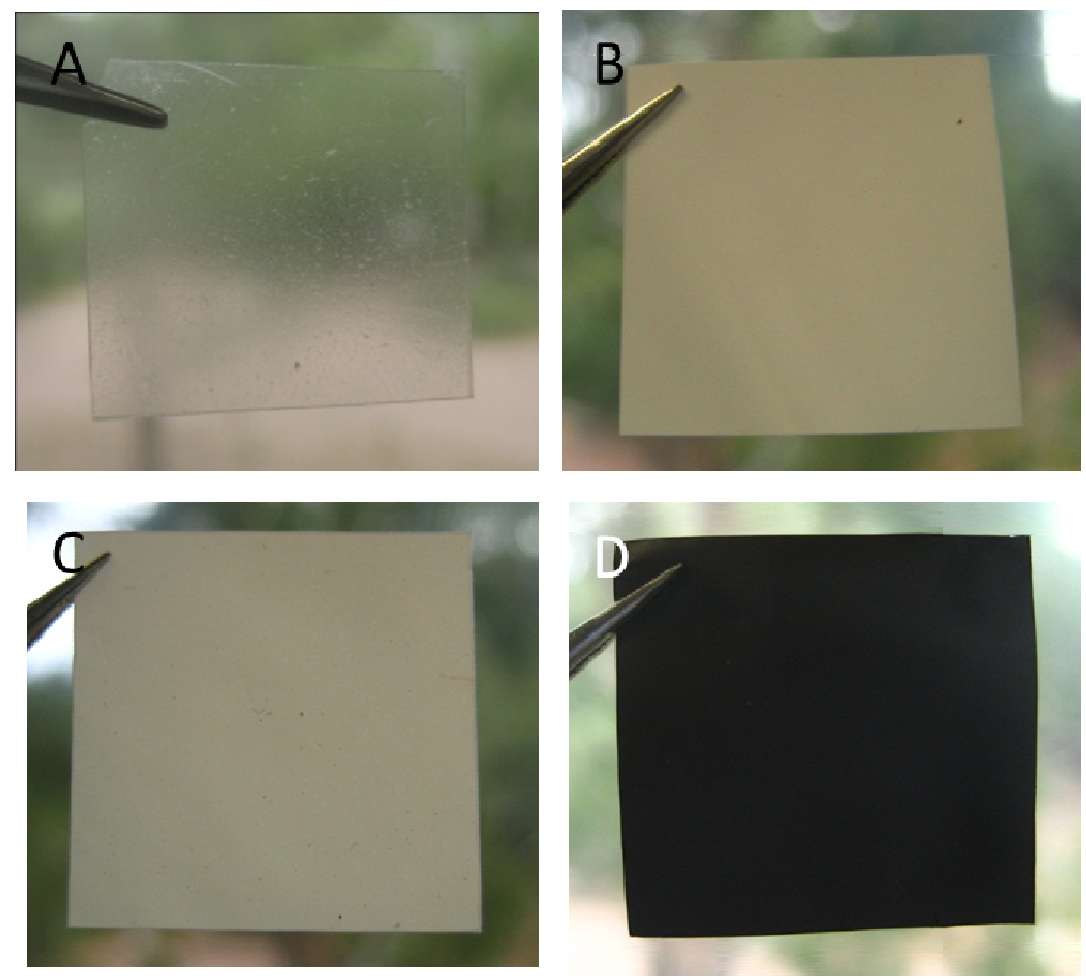

Figure 4.2: Photographs of the films; (A) GG50, (B) GGTi20 composite, (C) GGAg20 composite and (D) GGZn20 composite. Films dimension are $2 \mathrm{~cm} \times 2 \mathrm{~cm}$. 


\subsubsection{Circular dichroism}

The effect of glycerine on GG spectra is shown in Figure 4.3 A. GG films show a single band at $212 \mathrm{~nm}$, while GG50 films exhibit dual bands at $191 \mathrm{~nm}$ and $212 \mathrm{~nm}$. The absorption bands at $191 \mathrm{~nm}$ and $212 \mathrm{~nm}$ correspond to D-uronic and L-uronic acid residues of glycosidic acid in the gellan gum repeating unit ${ }^{345}$. The band observed at $191 \mathrm{~nm}$ in GG50 film is a result of an increases in the number of carboxyl groups from glycerine surrounding the gellan backbone (Figure $4.3 \mathrm{~A})^{345}$.

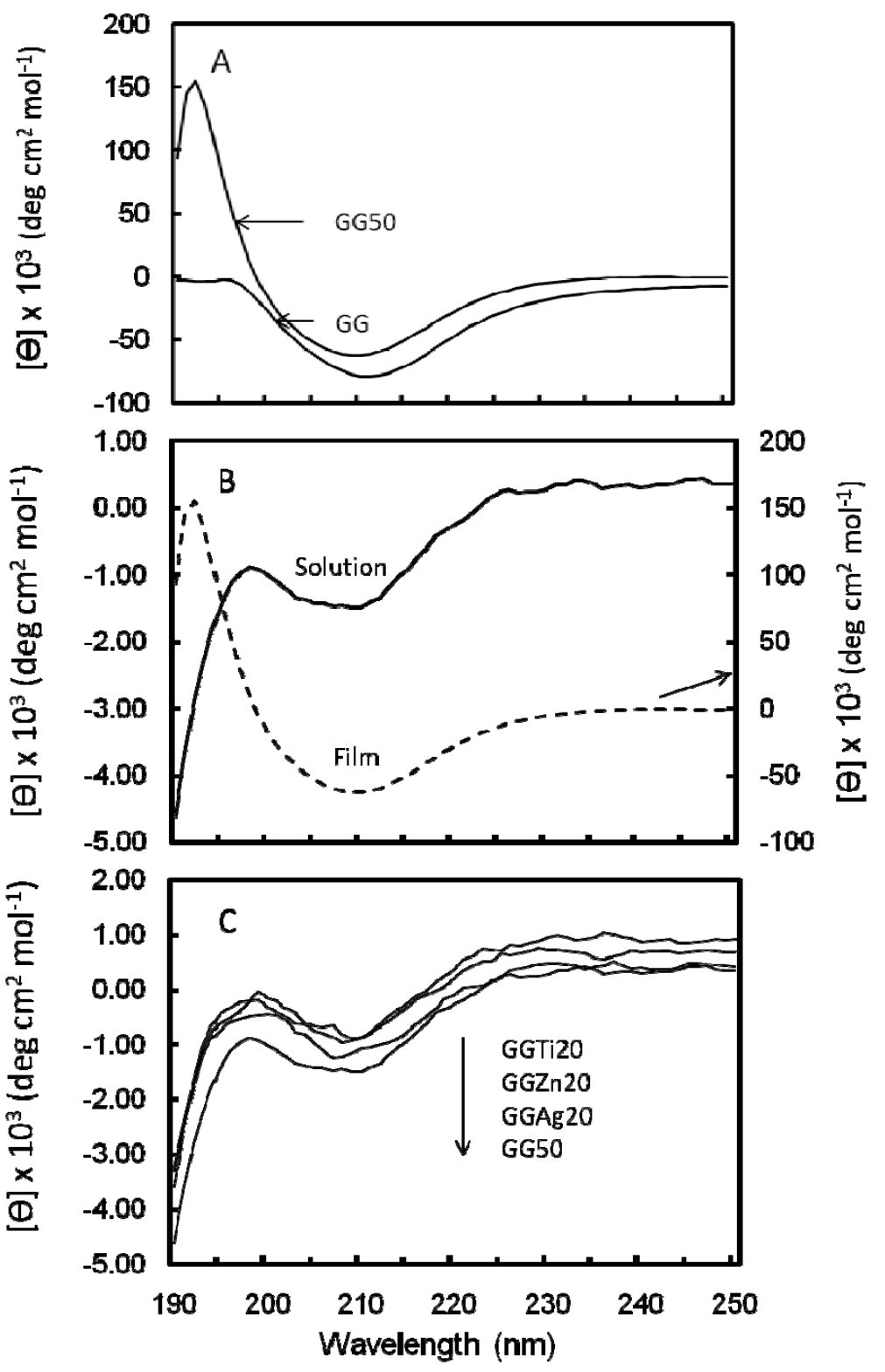

Figure 4.3: Circular dichroism (CD) spectra: (A) GG and GG50 films (pathlength=5 mm), (B) GG50 solution (pathlength=0.01 mm) and film (pathlength=5 mm), and (C) GG50 and GGcomposite dispersions (pathlength $=0.01 \mathrm{~mm}$ ). All measurements were carried out at $21^{\circ} \mathrm{C}$. 
The comparison of GG50 solution and film shows that these materials exhibit two bands, i.e. at $197 \mathrm{~nm}$ and $212 \mathrm{~nm}$ for solutions, and at $191 \mathrm{~nm}$ and $212 \mathrm{~nm}$ for films (Figure 4.3 B). These bands originate from D-uronic and L-uronic acid residues of glycosidic acid, respectively ${ }^{345}$. The band of GG50 solutions (197 nm) shifted to $191 \mathrm{~nm}$ in film which expected due to the transformation of GG from a random coil formation (solution) to a helical structure (film) ${ }^{345,346,347}$.

The addition of $20 \%$ (by weight relative to GG) $\mathrm{TiO}_{2}$, Ag, and $\mathrm{ZnO}$ nanoparticles to GG50 solution decreased the band intensity at $197 \mathrm{~nm}$ and $212 \mathrm{~nm}$ (Figure $4.3 \mathrm{C}$ ). This is possibly due to the attraction of those nanoparticles to the carboxyl groups of D-uronic and L-uronic acid residues of glycosidic acid and reduced the signal for both bands.

\subsection{Mechanical properties and microscopy}

\subsubsection{Effect of glycerine}

GG films are brittle, and not easy to handle, which makes it very difficult to measure their mechanical properties. The addition of glycerine significantly reduces their Young's modulus, but increases the toughness and strain-at-break values (Figure 4.4 A and Table 4.1). For example, the tensile strength (TS) and Young's modulus (E) of GG15 films decreased by 20\% (from $36 \pm 14 \mathrm{MPa}$ to $30 \pm 1 \mathrm{MPa}$ ) and $280 \%$ (from $2620 \pm 82 \mathrm{MPa}$ to $690 \pm 40 \mathrm{MPa}$ ), respectively; and toughness (T) and strain-at-break ( $\gamma$ ) by $385 \%$ (from $0.33 \pm 0.07 \mathrm{~J} \mathrm{~g}^{-1}$ to $1.6 \pm 0.2 \mathrm{~J} \mathrm{~g}^{-1}$ ) and $300 \%$ (from $1.8 \pm 0.4 \%$ to $7.8 \pm 0.4 \%$ ), respectively, compared to GG70 films (Table 4.1). 

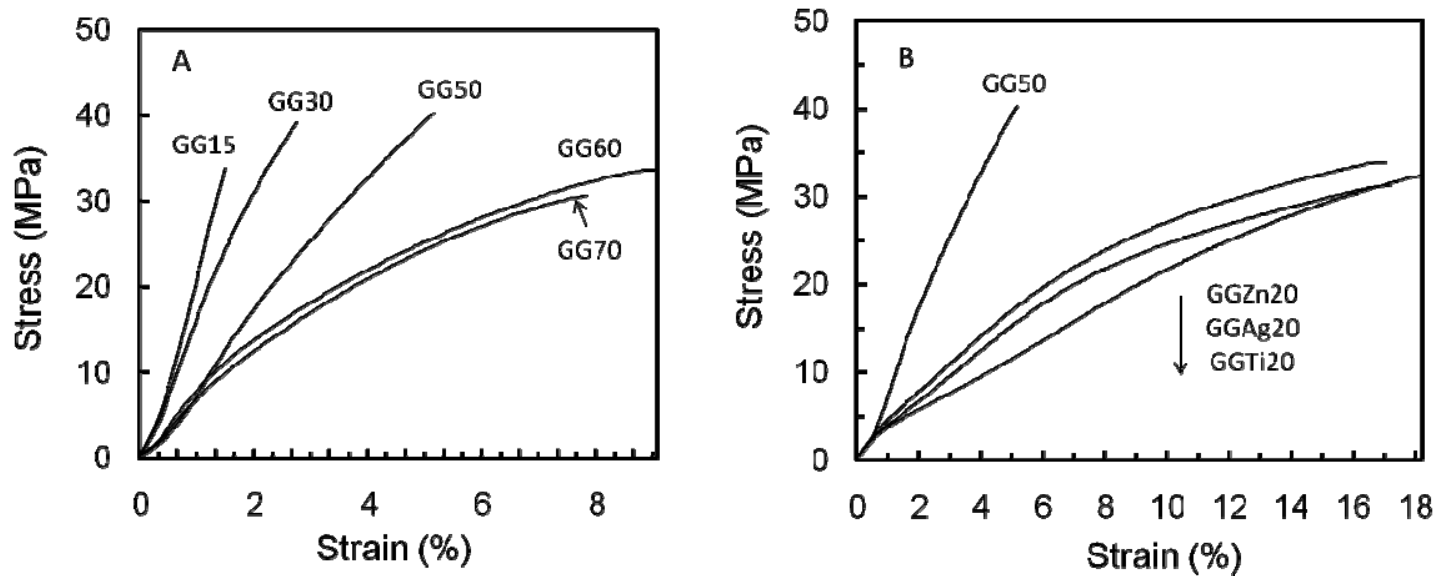

Figure 4.4: Typical stress-strain curves; (A) gellan gum (GG) with 15\% (GG15), 30\% (GG30), 50\% (GG50), 60\% (GG60) and 70\% (GG70) (by weight relative to GG) glycerine contents and (B) comparison of GG50 film and GG-composites films containing 20\% (by weight relative to GG) of $\mathrm{TiO}_{2}$ (GGTi20), Ag (GGAg20) and $\mathrm{ZnO}$ (GGZn20) nanoparticles loading.

The mechanism of formation of the GG films is closely related to the conformational transition from coil-to-helix structure. In aqueous solution at high temperatures $\left(\sim 60{ }^{\circ} \mathrm{C}\right)$, gellan gum chains are in disordered single coil state. Upon cooling from 60 to $30{ }^{\circ} \mathrm{C}{ }^{348}$, the gellan solution promotes the formation of double helices stabilised by internal hydrogen bonding ${ }^{216}$. This facilitates the tight packing GG chains, resulting in brittle films. The addition of glycerine, which contains three hydroxyl groups per repeating unit promotes the formation of hydrogen bonds between GG-Gly and replaces the hydrogen bonds between GG chains. The GG-Gly bonds decrease the intermolecular forces along polymer chains, which decreased Young's modulus and improves the strain-at-break values ${ }^{310}$. 
Table 4.1: Mechanical properties of gellan gum film containing different percentages of glycerine. Thickness (Thick), tensile strength (TS), Young's modulus (E), toughness (T) and strain-at-break $(\gamma)$ for the different GG materials are given.

\begin{tabular}{lccccc}
\hline $\begin{array}{l}\text { Glycerine } \\
(\%)\end{array}$ & Thick & TS & $\mathrm{E}$ & $\mathrm{T}$ & $\gamma$ \\
\hline 0 & $(\mu \mathrm{m})$ & $(\mathrm{MPa})$ & $(\mathrm{MPa})$ & $\left(\mathrm{J} \mathrm{g}^{-1}\right)$ & $(\%)$ \\
15 & $30 \pm 2$ & - & - & - & - \\
30 & $36 \pm 2$ & $36 \pm 14$ & $2620 \pm 82$ & $0.33 \pm 0.07$ & $1.8 \pm 0.4$ \\
50 & $33 \pm 4$ & $40 \pm 2$ & $1657 \pm 333$ & $0.34 \pm 0.04$ & $3.6 \pm 0.3$ \\
60 & $44 \pm 3$ & $41 \pm 2$ & $1097 \pm 162$ & $0.68 \pm 0.1$ & $5.4 \pm 0.3$ \\
70 & $52 \pm 4$ & $33 \pm 1$ & $810 \pm 172$ & $1.9 \pm 0.02$ & $9.4 \pm 0.5$ \\
& & & & & \\
\hline
\end{tabular}

\subsubsection{Effect of addition of nanoparticles}

Addition of $\mathrm{TiO}_{2}, \mathrm{ZnO}$ and Ag nanoparticles improved the T and $\gamma$ of GG50 films (Figure 4.4 B, Table 4.2). In contrast, the TS and E values were decreased. The T values increase for $\mathrm{GG}-\mathrm{TiO}_{2}$ composites with increasing nanoparticles, but decreases for GG-ZnO composites, while T has maximum at 20\% (by weight relative to GG) for GG-Ag composites (Table 4.2). In contrast, the $\mathrm{E}$ values decreased for GG-TiO${ }_{2}$ and GG-Ag composites with increasing nanoparticles, and optimum at 20\% (by weight relative to GG) for GG-ZnO composite. 
Table 4.2: Properties of GG50 and GG-composite films. Thickness (Thick), tensile strength (TS), Young's modulus (E), toughness (T), strain-at-break $(\gamma)$ and swelling for the different composite materials. All samples were prepared with $50 \%$ glycerine content by weight relative to gellan gum.

\begin{tabular}{lccccccc}
\hline & Thick & TS & $\mathrm{E}$ & $\mathrm{T}$ & $\gamma$ & \multicolumn{2}{c}{ Swelling (\%) } \\
\cline { 2 - 7 } Samples & $(\mu \mathrm{m})$ & $(\mathrm{MPa})$ & $(\mathrm{MPa})$ & $\left(\mathrm{J} \mathrm{g}^{-1}\right)$ & $(\%)$ & $\mathrm{pH} 1$ & $\mathrm{pH} 7$ \\
& & & & & & & \\
\hline GG50 & $44 \pm 2$ & $42 \pm 5$ & $1097 \pm 163$ & $0.68 \pm 0.1$ & $5 \pm 1$ & $51 \pm 1$ & $311 \pm 2$ \\
GGTi10 & $43 \pm 6$ & $27 \pm 7$ & $407 \pm 90$ & $1.22 \pm 0.1$ & $13 \pm 1$ & $77 \pm 1$ & $590 \pm 37$ \\
GGTi20 & $63 \pm 9$ & $28 \pm 3$ & $237 \pm 50$ & $1.29 \pm 0.4$ & $18 \pm 1$ & $78 \pm 1$ & $490 \pm 24$ \\
GGTi30 & $65 \pm 9$ & $27 \pm 5$ & $256 \pm 54$ & $1.76 \pm 0.2$ & $16 \pm 1$ & $70 \pm 3$ & $456 \pm 6$ \\
GGZn10 & $59 \pm 5$ & $28 \pm 5$ & $256 \pm 19$ & $4.33 \pm 0.6$ & $20 \pm 3$ & $98 \pm 5$ & $574 \pm 17$ \\
GGZn20 & $63 \pm 4$ & $31 \pm 3$ & $360 \pm 43$ & $3.34 \pm 0.2$ & $16 \pm 2$ & $95 \pm 2$ & $579 \pm 48$ \\
GGZn30 & $57 \pm 2$ & $26 \pm 4$ & $264 \pm 34$ & $1.48 \pm 0.5$ & $13 \pm 2$ & $91 \pm 5$ & $571 \pm 22$ \\
GGAg10 & $45 \pm 2$ & $26 \pm 2$ & $425 \pm 50$ & $1.63 \pm 0.1$ & $12 \pm 2$ & $80 \pm 5$ & $462 \pm 10$ \\
GGAg20 & $62 \pm 7$ & $30 \pm 4$ & $315 \pm 40$ & $2.93 \pm 0.4$ & $16 \pm 1$ & $79 \pm 2$ & $451 \pm 7$ \\
GGAg30 & $63 \pm 1$ & $24 \pm 2$ & $253 \pm 25$ & $1.06 \pm 0.1$ & $12 \pm 1$ & $64 \pm 3$ & $408 \pm 5$ \\
\hline
\end{tabular}

The conformational transition of GG from aqueous solution at high temperature $\left(\sim 60^{\circ} \mathrm{C}\right)$ to solid state $\left(\sim 30^{\circ} \mathrm{C}\right)$, i.e. from disordered single coil state to double helix leads to the intercalation of $\mathrm{TiO}_{2}, \mathrm{ZnO}$ and $\mathrm{Ag}$ nanoparticles into the GG matrix (Figure 4.5). 

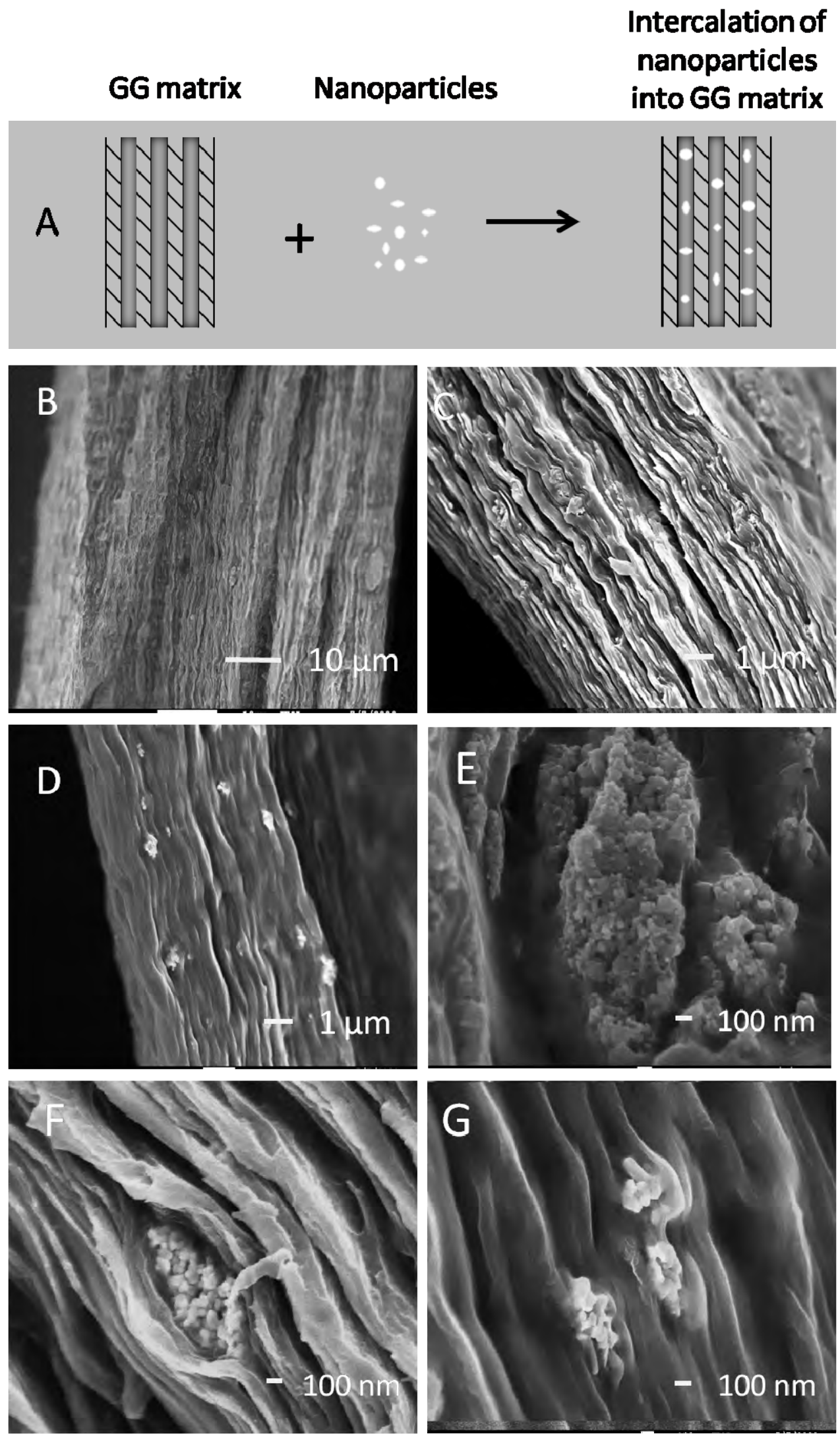

Figure 4.5: (A) Illustration of the intercalation of nanoparticles into GG matrix, (B-D) SEM images of cross-section of GG-composite films; (B) GGTi20 composite, (C) GGAg20 composite, (D) GGZn20 composites, (E-G) SEM images of nanoparticles agglomeration; (E) GGTi20 composite, (F) GGAg20 composite, and (G) GGZn20 composite. 
This phenomenon has been previously observed and is common in polymer/clay nanocomposites ${ }^{349,}{ }^{350}$. The intercalation process allows the GGcomposite to restrain the strain in tensile testing and thus improved the $\mathrm{T}$ and $\gamma$ of the GG-TiO 2 , GG-ZnO and GG-Ag composite films compared to GG50 films ${ }^{351}$ (Table 4.2). In contrast, this leads to less interaction between GG chains and therefore decreases in TS and E. The aggregation of nanoparticles within the GG matrix (Figure 4.5 E-G) could also contribute to the observed decrease in TS and improved $\gamma^{352}$.

\subsection{Water vapour transmission rates (WVTR)}

The water vapour transmission rates (WVTR) of GG50 films were found to be $\sim 977 \mathrm{~g}$ $\mathrm{m}^{-2} \mathrm{~d}^{-1}$, which is within the range of an ideal wound dressing (500-2000 $\left.\mathrm{g} \mathrm{m}^{-2} \mathrm{~d}^{-1}\right)$ as suggested by Queen and co-workers ${ }^{37}$ (Table 4.3). The WVTR values of GG50 films increased upon addition of $10 \%$ (by weight relative to GG) $\mathrm{TiO}_{2}, \mathrm{ZnO}$ and $\mathrm{Ag}$ nanoparticles. For example, the WVTR values of GGTi10, GGZn10 and GGAg10 composites were $1094 \mathrm{~g} \mathrm{~m}^{-2} \mathrm{~d}^{-1}, 1094 \mathrm{~g} \mathrm{~m}^{-2} \mathrm{~d}^{-1}$ and $1108 \mathrm{~g} \mathrm{~m}^{-2} \mathrm{~d}^{-1}$ compared to $977 \mathrm{~g}$ $\mathrm{m}^{-2} \mathrm{~d}^{-1}$ for GG 50 film. These WVTR values increased which can be expected based on the intercalation of nanoparticles in the GG matrix, lead to a less tight packing of GG chains (see Figure 4.5), which promotes water vapour transport rates. The WVTR values of GG-TiO 2 , GG-ZnO and GG-Ag composites at 20\% and 30\% (by weight relative to GG) of nanoparticles loadings were between 1042 and $1168 \mathrm{~g} \mathrm{~m}^{-2} \mathrm{~d}^{-1}$ (Table 4.3). The WVTR values of these GG-composites were expected to be related to the distribution of nanoparticles in the GG matrix. Permeance (P) values of the GG50 and GG-composites films show the same observations as WVTR values (Table 4.3). 
Table 4.3: Water vapour properties of GG50 and GG-composites films. Water vapour transmission rates (WVTR), water vapour permeability (WVP), and permeance (P) for the different composite materials are given.

\begin{tabular}{lcccc}
\hline Samples & Thickness & WVTR & WVP & P \\
& $(\mu \mathrm{m})$ & $\left(\mathrm{g} \mathrm{m}^{-2} \mathrm{~d}^{-1}\right)$ & $10^{-14} \times\left(\mathrm{kg} \mathrm{Pa}^{-1} \mathrm{~m}^{-1} \mathrm{~s}^{-1}\right)$ & $10^{-9} \times\left(\mathrm{kg} \mathrm{Pa}^{-1} \mathrm{~m}^{-2} \mathrm{~s}^{-1}\right)$ \\
\hline Blank & - & $3685 \pm 10$ & - & - \\
GG50 & $44 \pm 3$ & $977 \pm 5$ & $4.3 \pm 3$ & $0.96 \pm 5$ \\
GGTi10 & $50 \pm 5$ & $1094 \pm 6$ & $5.4 \pm 3$ & $1.08 \pm 6$ \\
GGTi20 & $68 \pm 8$ & $1042 \pm 8$ & $7.0 \pm 7$ & $1.03 \pm 8$ \\
GGTi30 & $67 \pm 8$ & $1048 \pm 1$ & $6.9 \pm 3$ & $1.04 \pm 5$ \\
GGZn10 & $55 \pm 4$ & $1094 \pm 2$ & $5.9 \pm 1$ & $1.08 \pm 2$ \\
GGZn20 & $47 \pm 3$ & $1058 \pm 8$ & $5.6 \pm 5$ & $1.05 \pm 8$ \\
GGZn30 & $60 \pm 1$ & $1168 \pm 13$ & $7.0 \pm 6$ & $1.16 \pm 1$ \\
GGAg10 & $53 \pm 2$ & $1108 \pm 10$ & $5.8 \pm 7$ & $1.09 \pm 1$ \\
GGAg20 & $64 \pm 6$ & $1117 \pm 6$ & $6.9 \pm 5$ & $1.10 \pm 5$ \\
GGAg30 & $61 \pm 1$ & $1079 \pm 4$ & $6.5 \pm 1$ & $1.07 \pm 4$ \\
\hline
\end{tabular}

\subsection{Swelling}

The swelling behaviour of the GG-composite films in buffer solutions at $\mathrm{pH} 1$ and $\mathrm{pH}$ 7 is summarised in Table 4.2. GG50 films in a buffer of $\mathrm{pH} 1$ exhibit low swelling at $51 \pm 1 \%$ due to anionic property, and those in a buffer of $\mathrm{pH} 7$ swell $311 \pm 2 \%$. Swelling increased dramatically upon addition of nanoparticles. In a buffer of $\mathrm{pH} 1$, GGTi10, GGAg10 and GGZn10 composite films swelled to about $77 \pm 1 \%$, $98 \pm 5 \%$ and $80 \pm 5 \%$ respectively; and in a buffer of pH 7 at $590 \pm 37 \%, 574 \pm 17 \%$ and $462 \pm$ $10 \%$, respectively (Table 4.2). It is postulated that the increase of swelling upon inclusion of nanoparticles is due to the intercalation of nanoparticles in GG-matrix. 
The intercalation leads to a less packing of GG chains which promotes the water absorption, and thus increased the swelling percentage.

\subsection{Cell studies}

\subsubsection{Cell viability}

\subsubsection{Effect of glycerine}

The effect of glycerine on L929 cell behaviour was investigated by morphological evaluation at time intervals of $24 \mathrm{~h}, 72 \mathrm{~h}$, and $144 \mathrm{~h}$ after seeding, as shown in Figure 4.6. The L929 cells were viable on the GG and GG50 films which indicate that both films support cell growth and therefore are unlikely to be cytotoxic.

\subsubsection{Effect of nanoparticles}

The effects of $\mathrm{TiO}_{2}$, Ag and $\mathrm{ZnO}$ nanoparticles incorporated in GG50 films on the behaviour of L929 cells were investigated. Within $24 \mathrm{~h}$ after cell seeding, the bright green fluorescent L929 cells were visible on the GGTi20 composite film (Figure 4.7 A) whereas lower numbers of viable cells were observed on GGAg20 and GGZn20 composites films (Figure 4.7 B and C). The lower number of L929 cells at 72h on the GGAg20 and GGZn20 composite films indicate that cells on these films had died (Figure 4.7 B and C). Within 72h, the viable cells number increased on the GGTi20 composite film (Figure 4.7 D).

The additions of these nanoparticles have been reported to have both beneficial 244, 353 and deleterious ${ }^{270,354}$ effects on cell behaviours. Most studies have reported that $\mathrm{TiO}_{2}$, Ag and $\mathrm{ZnO}$ nanoparticles kill cells if they are in direct contact to the nanoparticle which happens, for example when the nanoparticles are added to a 
medium containing cells $269,270,354-356$. In contrast, the likelihood of nanoparticles killing cells is reduced by incorporating nanoparticles into a polymer matric ${ }^{244,263,} 357$. Liu et al. ${ }^{244}$ reported that chitosan-Ag films crosslinked with genipin were compatible to L929 cells. Lactose-substituted chitosan-alginate-Ag hydrogels were found to be non-cytotoxic towards mouse-fibroblast-like (NIH-3T3), human hepatocarcinoma (HepG2), and human osteosarcoma (MG63) cells ${ }^{244,263 .}$
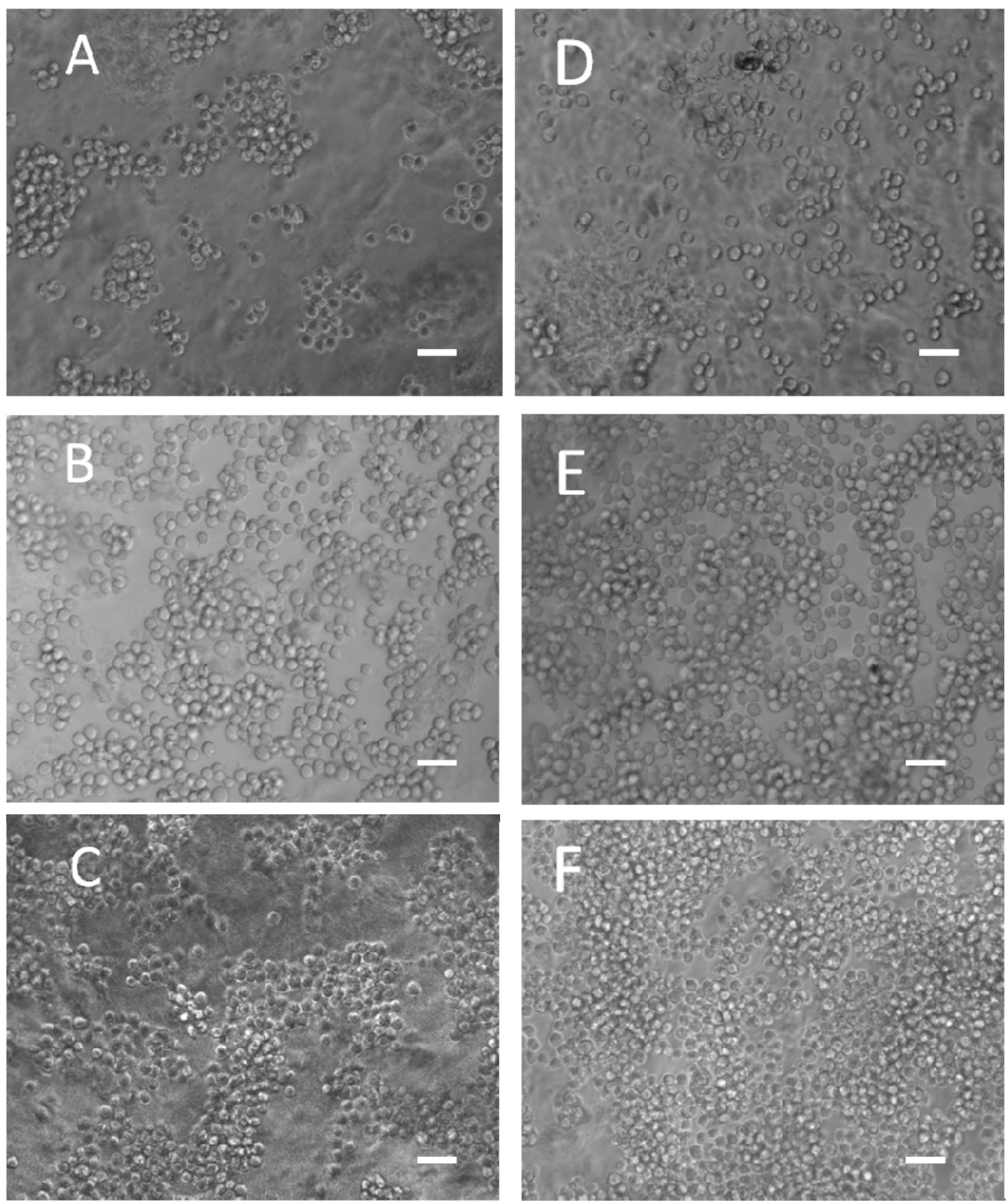

Figure 4.6: L929 cells grown on GG (A-C) and GG50 (D-F) films at different time intervals; (A and D) 24h, (B and E) 72h, and (C and F) 144h. The cells were viable on both films which indicate the films support cell growth. Scale bars represent $50 \mu \mathrm{m}$. 

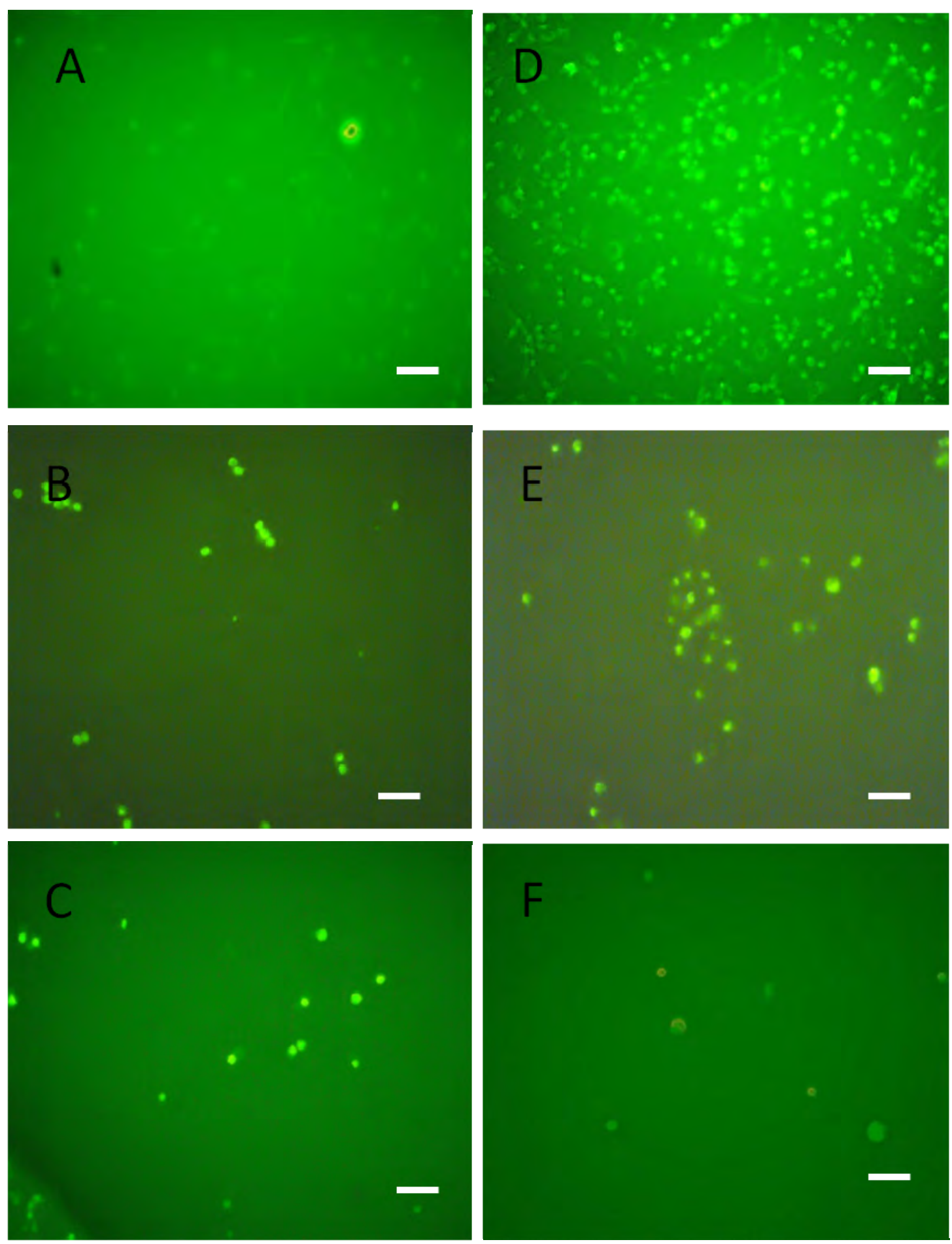

Figure 4.7: Fluorescence microscope images of the cytotoxic effect of incorporated $\mathrm{TiO}_{2}, \mathrm{Ag}$ and $\mathrm{ZnO}$ nanoparticles into the GG films after culture in the medium containing L929 cell lines for (A-C) 24h and (D-F) 72h; (A and D) GGTi20 composite, (B and E) GGAg20 composite, and (C and F) GGZn20 composite. Scale bars represent $50 \mu \mathrm{m}$.

An indirect contact assay was carried out to confirm the effect of $\mathrm{TiO}_{2}$, Ag and ZnO nanoparticles incorporated GG matrix on the L929 cells. The GG-TiO 2 , GG-Ag 
and GG-ZnO composites films were incubated into wells containing L929 cell suspension for $24 \mathrm{~h}$. The films were removed and the remaining cells in the media were imaged using light microscopy.
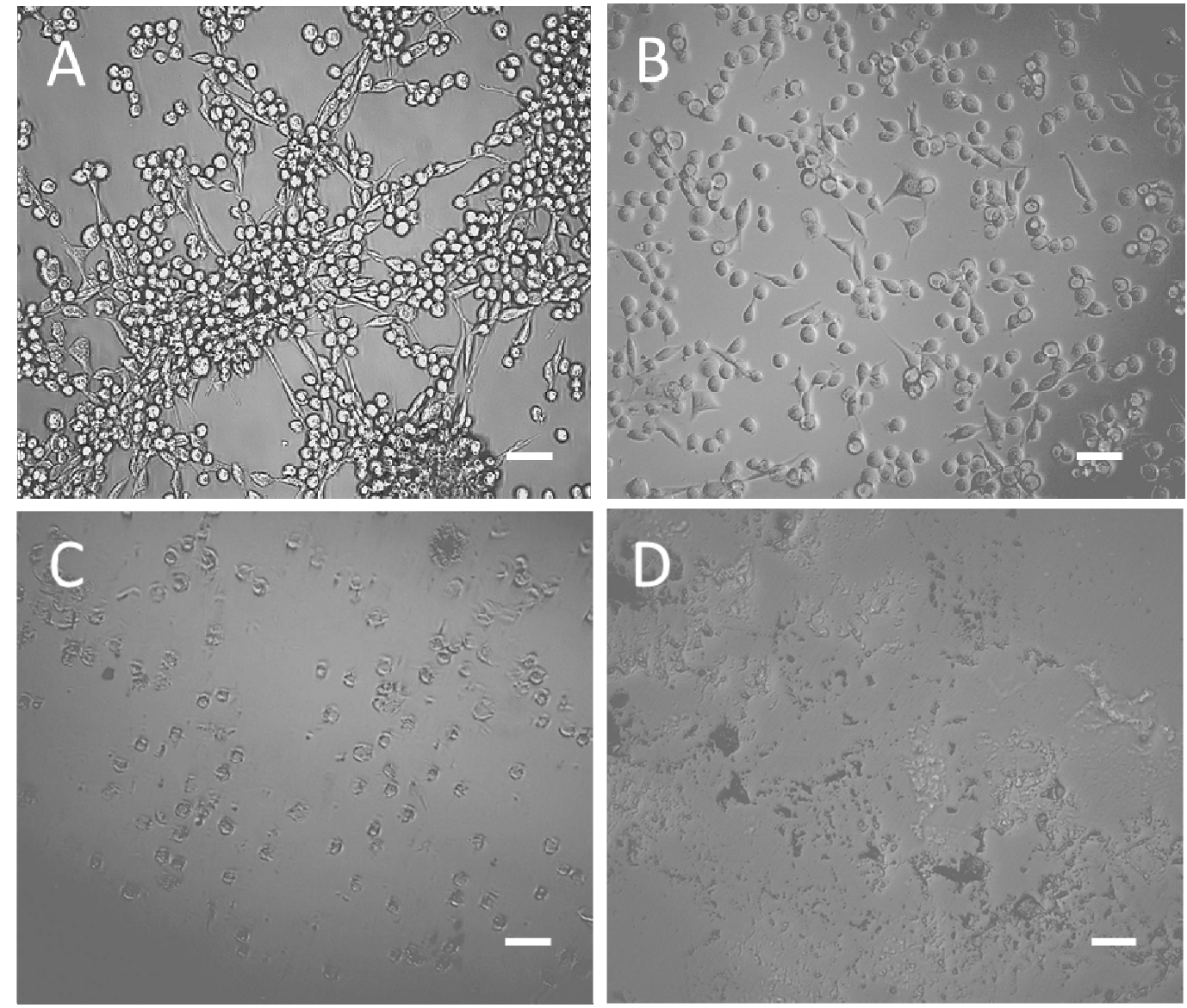

Figure 4.8: Cytotoxicity of the media containing L929 cells incubated with GG-TiO ${ }_{2}$, GG-Ag and GG-ZnO composites for 72h; (A) TCPP (negative control), (B) GGTi20 (C) GGAg20 and (D) GGZn20. Scale bars represent $50 \mu \mathrm{m}$.

The results show that the L929 cell morphology in the media after incubating with GG-Ag and GG-ZnO composites indicates that they are dying. This was expected due to leaking of $\mathrm{Ag}$ and $\mathrm{ZnO}$ nanoparticles into the media, which reduces the viability of L929 cells (Figure 4.8 C and D). In contrast, L929 cells incubated in the presence of $\mathrm{CH}-\mathrm{TiO}_{2}$ composite were adhering and elongating on the tissue culture polystyrene 
plate (TCPP) (Figure $4.8 \mathrm{~B}$ ). This suggests that the $\mathrm{TiO}_{2}$ nanoparticles in the GG matrix are prevented from diffusion into the media.

The L929 cell viability for GGTi20 composites was investigated further after culturing for $48 \mathrm{~h}$ and $144 \mathrm{~h}$. Figure 4.9 shows that viable L929 cells are distributed throughout the GGTi20 composite film, and some of them are clustered (Figure 4.9 D).
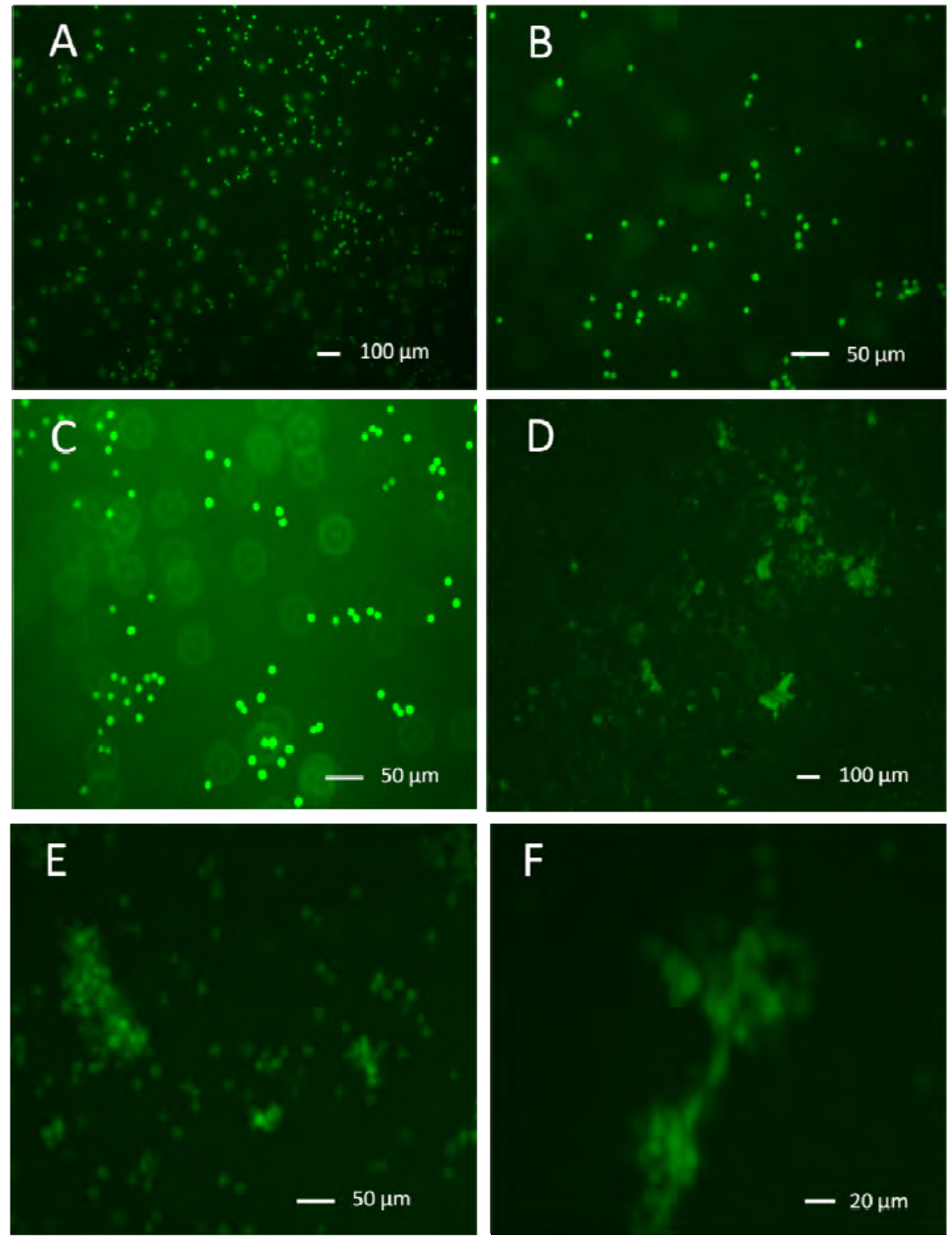

Figure 4.9: Representative fluorescent micrographs of live (green) surface of L929 cells in GGTi20 composite film after (A, B and C) 48h and (D, E, F) 144h of culture. 


\subsubsection{Cell proliferation}

The L929 cell proliferation on GG, GG50, and GGTi20 composite films was evaluated using the MTS assay as shown in Figure 4.10 D. The L929 cells were seeded at 5000 cells/well into a 96 well-plate that contained films and incubated for $24 \mathrm{~h}, 72 \mathrm{~h}$ and 144h in culture media. Prior to addition of the MTS reagent, the supernatant in wells was removed to remove cells that were not attached on the films, and fresh culture media added.
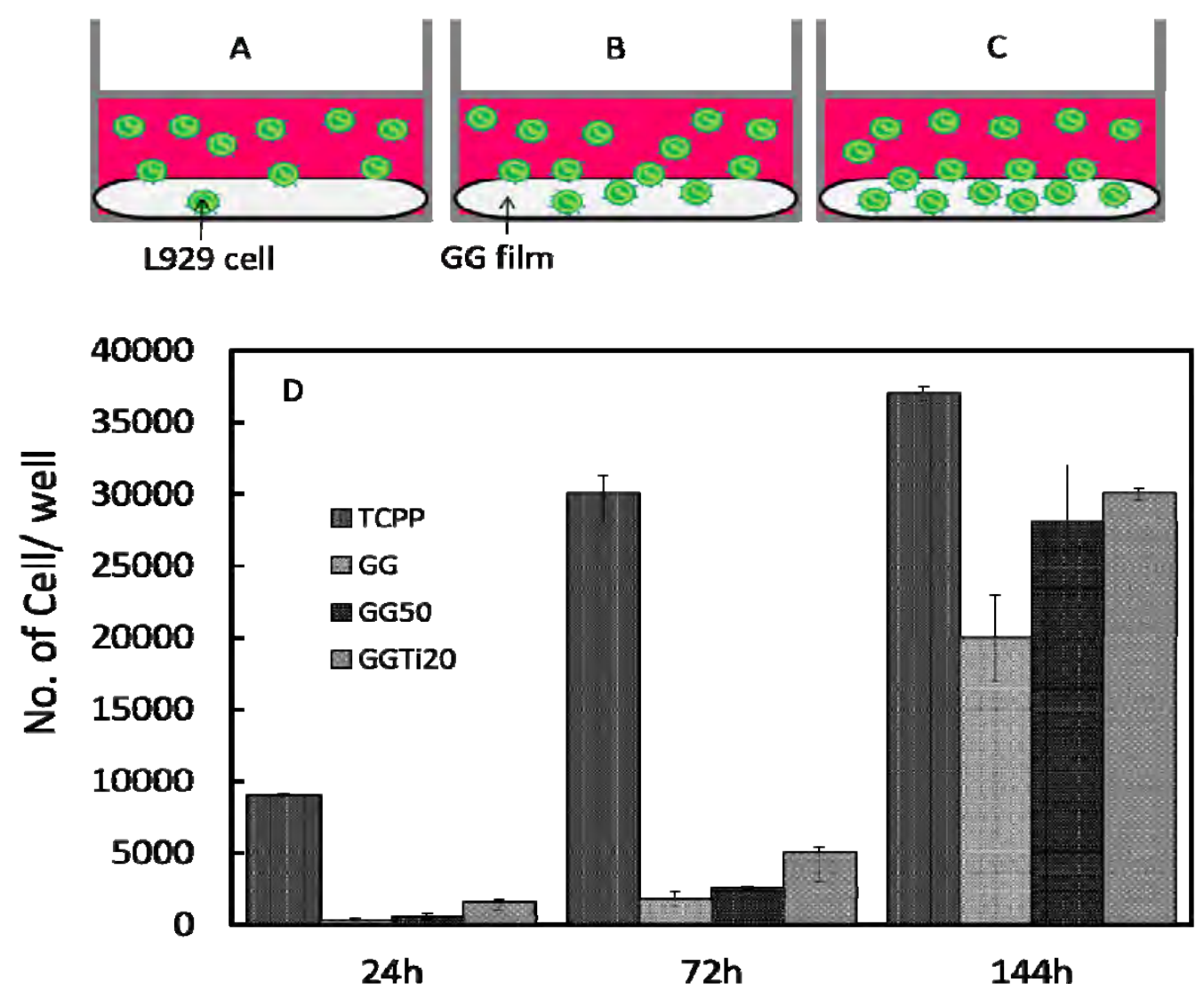

Figure 4.10: (A-C) Schematic of the attachment and proliferation of L929 cells in response to the gellan gum surface after $24 \mathrm{~h}, 72 \mathrm{~h}$ and $144 \mathrm{~h}$ following cell seeding and (D) the increase in attached L929 cell numbers after 24h, 72h and 144h of culture on GG, GG50 and GGTi20 composite films. Error bars represent standard errors of triplicate assays.

Within 24h period following cell seeding, the viable number of cells/well on GG, GG50 and GGTi20 composite films was approximately 300, 600 and 1600, 
respectively. In comparison, the number of L929 cells on TCPP was 9000 cells/well. Within $72 \mathrm{~h}$ period following cell seeding on GG film, the number of L929 cells attached to the film increased to 1800 cells/well or a 3 fold increase compared to that after 24h. The same increase (3 fold) was observed on GGTi20 composite film which increased to 5000 cells/well by 72h. For GG50 films the attached cell number increased to 2700 cells/well, which is a 9 fold increase compared to 24h of culture. The number of attached cells climbed sharply after 144h of culture (Figure 4.10 D).

As illustrated in Figure 4.10 A, the L929 cell started to response and adheres on the GG films' surface after incubation for $24 \mathrm{~h}$. The cell response to biomaterials depends on the physical property (hardness), hydrophilicity or hydrophobicity, and surface roughness of the materials ${ }^{196,198,328-330,358-362}$. For example, Hatano et al. ${ }^{359}$ found that surface roughness of modified polystyrene promotes the proliferation and gene expression levels of alkaline phosphate (ALP) and osteocalcin of the calvarial cells which decreased at a higher roughness of polystyrene. A low viable cell number recorded on the GG50 film after 24h of culture at 300 cells/well could be due to the removal of unattached cells from the surface of the film while pipetting the supernatant to replace with fresh medium prior addition of MTS reagent. Once the cells were attached to the surface of the film after $24 \mathrm{~h}$ of culture, the attached cells proliferated at approximately equal rates every $24 \mathrm{~h}$ until $72 \mathrm{~h}$ on the GG and GGTi20 composite films. Within $144 \mathrm{~h}$ of culture, the cell numbers increased at faster rates compared to $72 \mathrm{~h}$ of culture.

\subsection{Antibacterial study}

The antibacterial activity of GG50 film and GG-composite films was measured by qualitative (disk method) using the Gram-negative bacterium E. coli. The result shows 
that GG50 film does not show any inhibition around the disk (Figure 4.11 A). Similar results were reported on konjac glucomannan/gellan gum film ${ }^{363}$. Interestingly on GG-composite films containing 10\%, 20\% and 30\% (by weight relative to GG) of $\mathrm{TiO}_{2}$, Ag and $\mathrm{ZnO}$ nanoparticles, no inhibition was found which could be due to the limited contact of nanoparticles have with the LB agar to kill the bacteria (Figure 4.11 B-D). This is supported by SEM imaging which showing a little of nanoparticles exposed on the surfaces' of GG-Ag composite, GG-TiO ${ }_{2}$ composite and GG-ZnO composite films, thus reduce the effectiveness of nanoparticles to kill the E. coli (Figure 4.12).
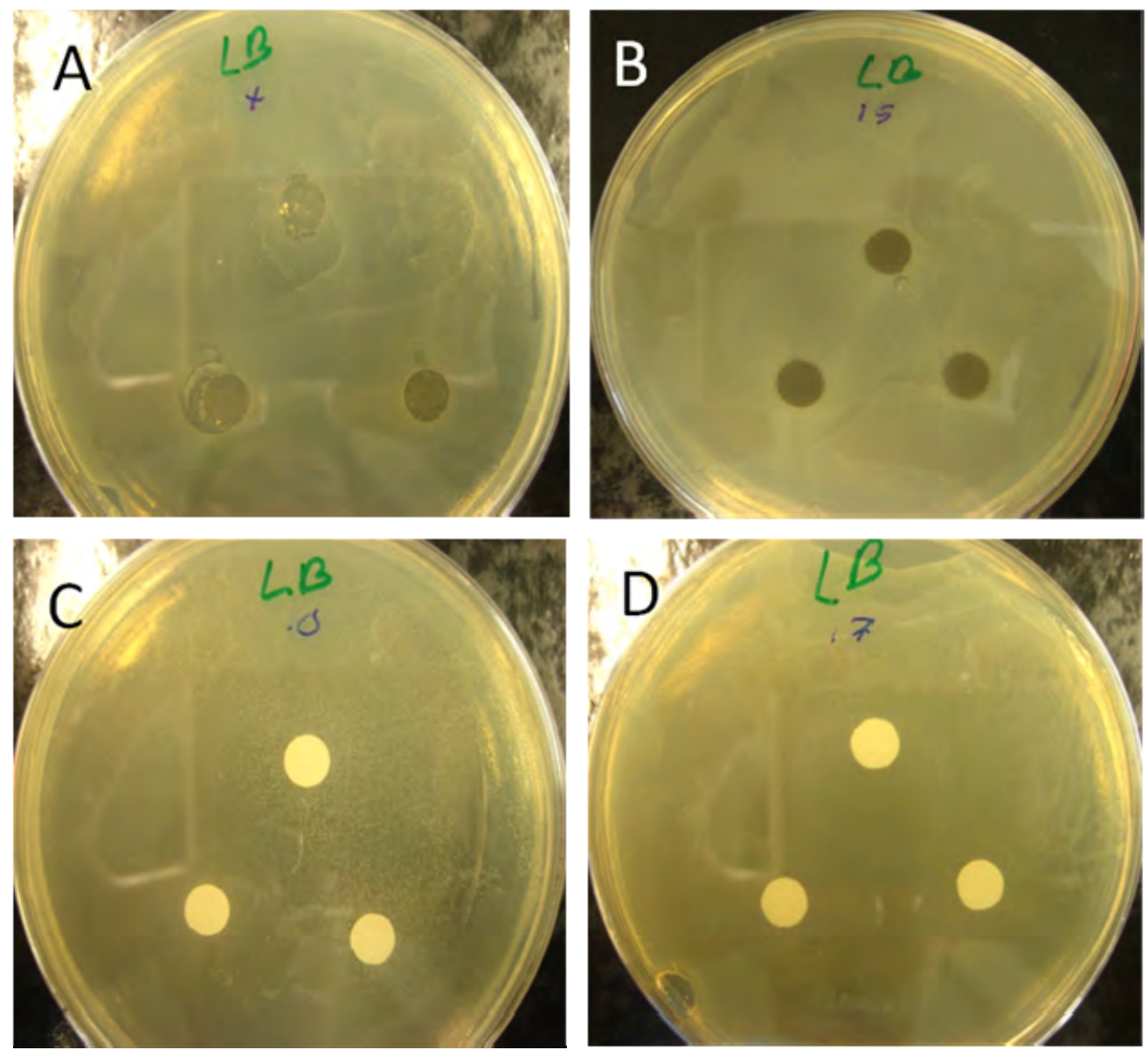

Figure 4.11: (A-D) Antibacterial activity of the GG50 film and GG-composites films quantified by qualitative method after incubated at $37{ }^{\circ} \mathrm{C}$ for $24 \mathrm{~h}$; (A) GG50 film, (B) GGAg30 composite, (C) GGTi30 composite and (D) GGZn30 composite. 

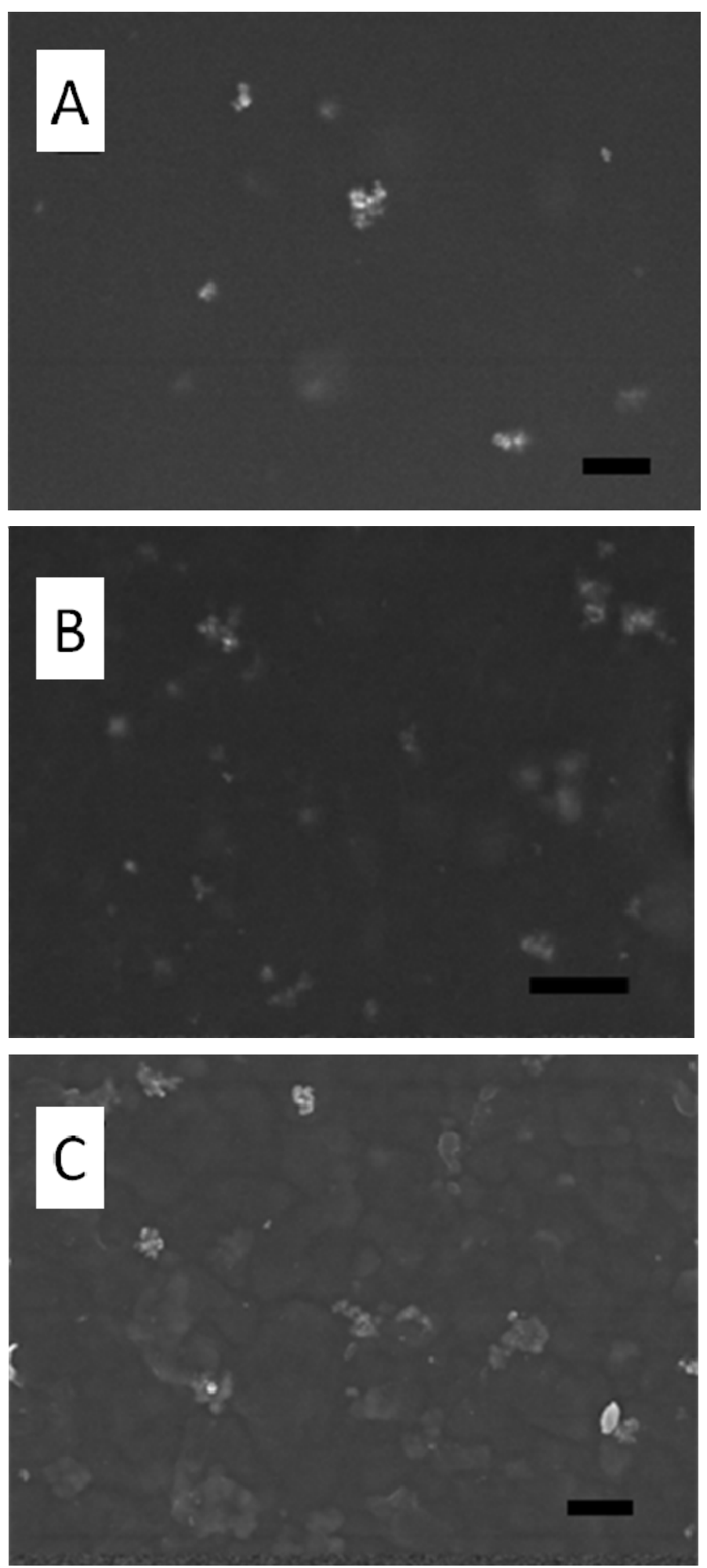

Figure 4.12: (A-C) SEM images of surfaces’ of GG-composites; (A) GGAg20 composite, (B) GGTi20 composite and (C) GGZn20 composite. Scale bars represent $1 \mu \mathrm{m}$. 


\subsection{Conclusion}

This study prepared gellan gum films and characterised their physical and biological properties. Circular dichroism spectroscopy confirmed the transition of GG from random coil (solution) to helix (film). The evaluation of the mechanical properties showed that inclusion of glycerine into the GG film improved the flexibility at a cost of reduced tensile strength and Young's modulus, which was attributed to changes in hydrogen bonding. Incorporation of $\mathrm{TiO}_{2}, \mathrm{Ag}$, and $\mathrm{ZnO}$ nanoparticles enhanced the toughness and strain-at-break of the GG50 films.

The water vapour transmission rates (WVTR) values were in the recommended range of an ideal wound dressing (977 - $\left.1168 \mathrm{~g} \mathrm{~m}^{-2} \mathrm{~d}^{-1}\right)$. The swelling of GGcomposites decreased upon addition of higher nanoparticles loadings. In-vitro tests performed with mouse fibroblast (L929 cells) on GG-composite films revealed that the cells remain viable on $\mathrm{GG}-\mathrm{TiO}_{2}$ composite and most of the cells on $\mathrm{Ag}$ and $\mathrm{ZnO}$ containing films died due to leakage of nanoparticles into the cultured media. Increases in cell proliferation were reported on longer incubation of the GG, GG50 and GG-TiO 2 composite films (up to 144h). The antibacterial activity showed that none of the GG50 or GG-composite films was resistant against E. coli. In summary, it can be concluded that gellan gum containing $\mathrm{TiO}_{2}$ nanoparticle films have generated promising results that can be applied in the development of wound dressing which is further investigate in chapter 7. 


\section{CHAPTER 5}

\section{CHARACTERISATION OF POLYELECTROLYTE COMPLEX FILMS FROM CHITOSAN AND GELLAN GUM}

Many studies have been devoted to the preparation of wound dressing from polysaccharides based polyelectrolyte complex (PEC) techniques 95, 310, 364-366. Chitosan-alginate ${ }^{95,295}$, chitosan-carrageenan ${ }^{149}$ and chitosan-heparin ${ }^{160}$ are mixable by stirring and the resulting solution can be cast into films. In contrast, chitosan $(\mathrm{CH})$ and gellan gum (GG) solutions are unable to be mixed together due to insoluble gellan gum in acidic medium. The mixing between $\mathrm{CH}$ and GG solutions results in the formation of a precipitate due to charge overcompensation at the interface in the form of fibres, capsules or coacervate structures depending on the complexation conditions $162,163,167,294$. There are no literature reports on the formation of CH-GG PEC-films. In this chapter, free standing $\mathrm{CH}$ and GG films are prepared by evaporative casting technique. PEC-films are formed by dipping free-standing films of either $\mathrm{CH}$ or GG into solutions of opposite charge. The effects of the order of addition and adjustment of $\mathrm{pH}$ of films and solutions on the mechanical properties, swelling and water vapour transmission rates (WVTR) are discussed. 


\subsection{Spectroscopy}

\subsubsection{UV-Visible}

UV-visible spectra of $\mathrm{CH}$, GG and PEC-films are shown in Figure 5.1. The $\mathrm{CH}$ and GG films show a peak at $200 \mathrm{~nm}$ and $250 \mathrm{~nm}$ corresponding to $\mathrm{N}$-acetylglucosamine and the carboxcylic group, respectively ${ }^{341,367}$ (Figure 5.1 A). pH adjusted films using $\mathrm{CH}(\mathrm{pH}=1.80)$ and $\mathrm{GG}(\mathrm{pH}=12.00)$ solutions showed no changes were observed in peaks and absorbance intensities compared to unadjusted $\mathrm{CH}$ and GG films (Figure $5.1 \mathrm{~B})$.
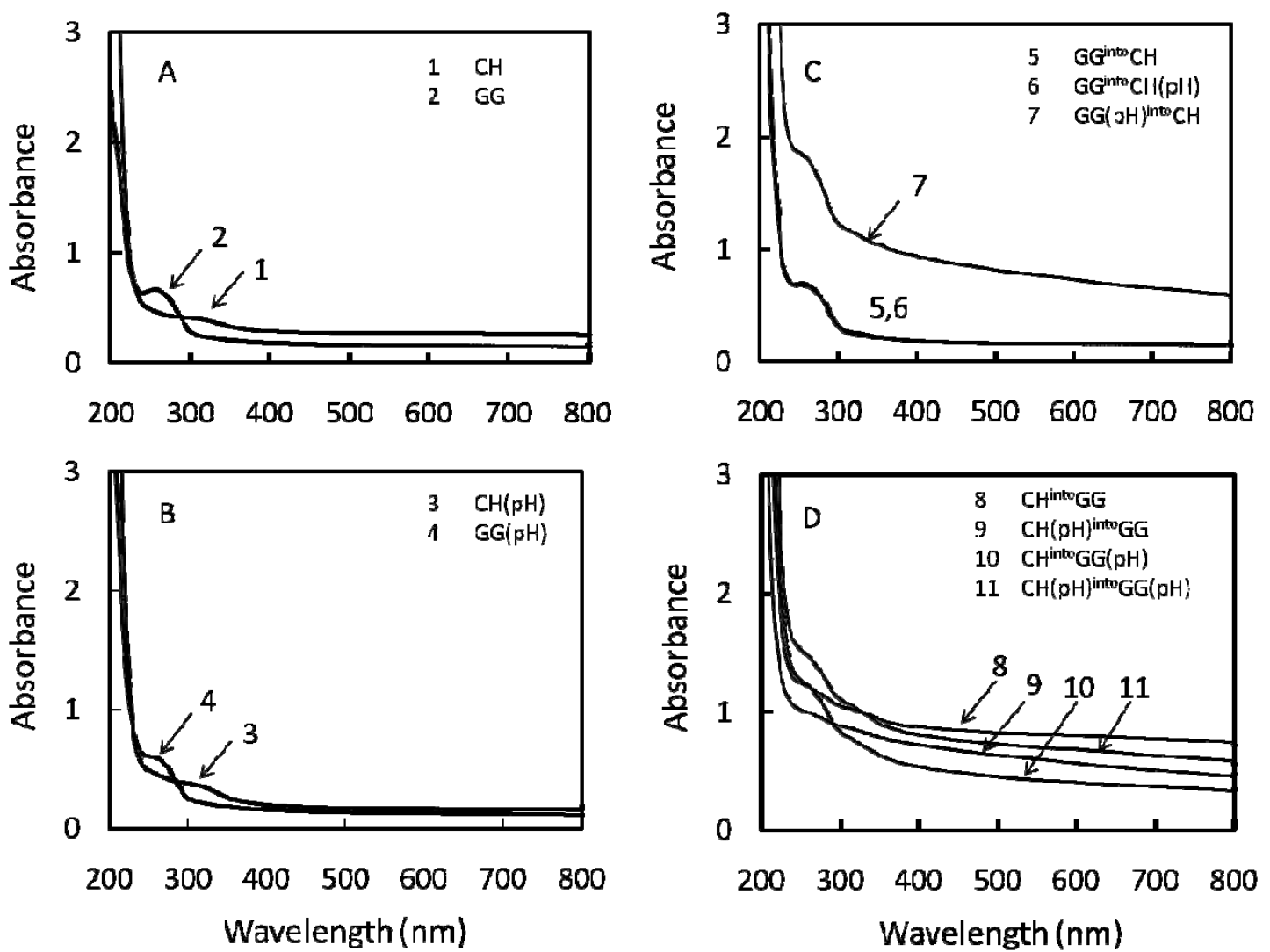

Figure 5.1: UV-visible absorbance spectra; (A) $\mathrm{CH}$ and GG films, (B) $\mathrm{pH}$ adjusted $\mathrm{CH}$ and GG films using $\mathrm{CH}(\mathrm{pH}=1.80)$ and $\mathrm{GG}(\mathrm{pH}=12.00)$ solutions and $(\mathrm{C}-\mathrm{D})$ polyelectrolyte complex (PEC)-films of $\mathrm{CH}$ and GG. 
PEC-films reveal that the order of addition of $\mathrm{GG}{ }^{\text {into }} \mathrm{CH}$ and $\mathrm{CH}^{\text {into }} \mathrm{GG}$ greatly affected the absorbance spectra regardless of pH modifications (Figure $5.1 \mathrm{C}$ and D). For example, UV-Vis of $\mathrm{GG}^{\text {into }} \mathrm{CH}, \mathrm{GG}{ }^{\text {into }} \mathrm{CH}(\mathrm{pH})$, and $\mathrm{GG}(\mathrm{pH}){ }^{\text {into }} \mathrm{CH}$ PEC-films show two bands at $200 \mathrm{~nm}$ and $250 \mathrm{~nm}$ corresponding to $\mathrm{CH}$ and GG, respectively (Figure $5.1 \mathrm{C}$ ). In contrast, UV-Vis spectra of $\mathrm{CH}^{\text {into }} \mathrm{GG}$ and $\mathrm{CH}(\mathrm{pH}){ }^{\text {into }} \mathrm{GG}$ PEC-films revealed that the $\mathrm{CH}$ peak was dominant, but the GG peak had disappeared. The spectra for $\mathrm{CH}^{\text {into }} \mathrm{GG}(\mathrm{pH})$ and $\mathrm{CH}(\mathrm{pH}){ }^{\text {into }} \mathrm{GG}(\mathrm{pH})$ PEC-films showed that the $\mathrm{CH}$ peak was dominant with a low absorbance intensity of GG (Figure $5.1 \mathrm{D}$ ). All CH, GG and PEC-films either with the order of addition of $\mathrm{CH}^{\text {into }} \mathrm{GG}$ or $\mathrm{GG}{ }^{\text {into }} \mathrm{CH}$ were transparent as evident from Figure 5.2 and 5.3.

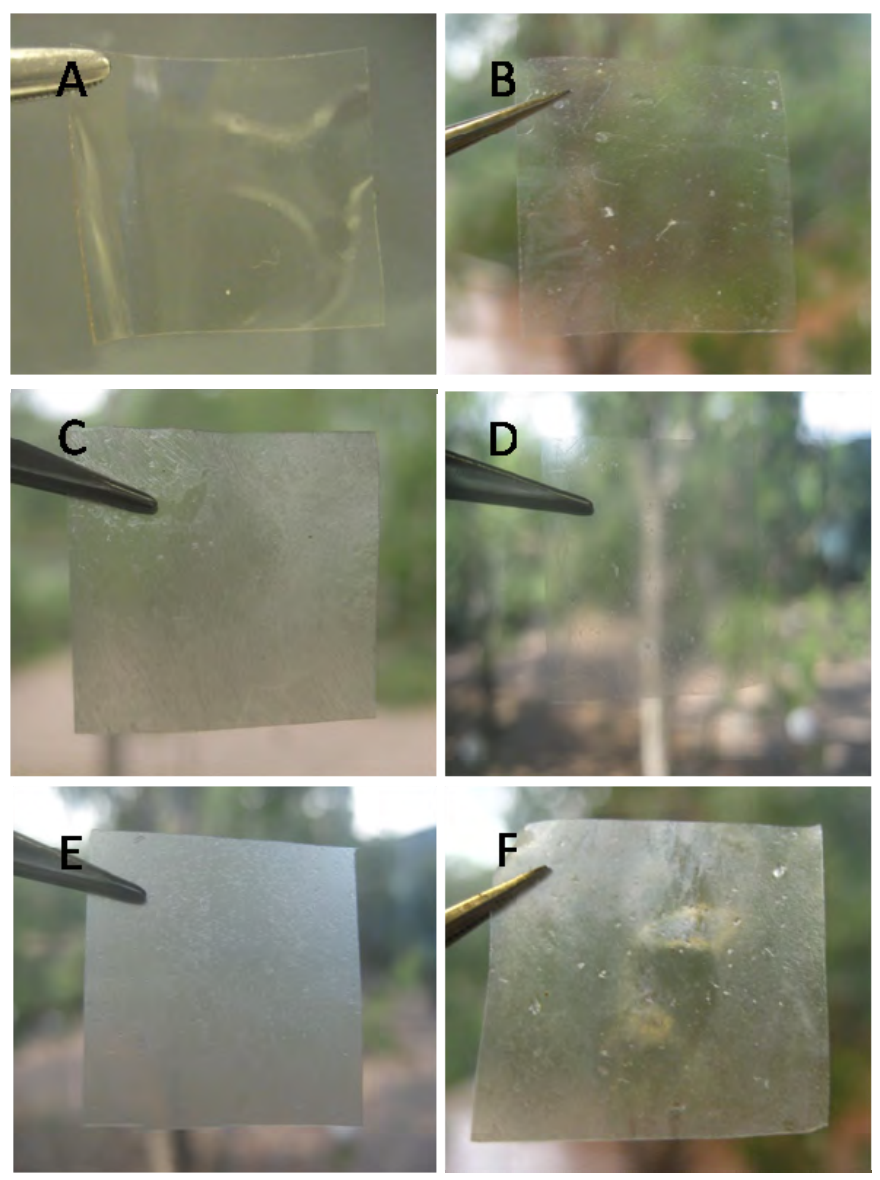

Figure 5.2: (A-B) Free-standing films; (A) $\mathrm{CH}$, (B) $\mathrm{CH}(\mathrm{pH})$, (C-F) PEC-films with the order of addition of $\mathrm{CH}^{\text {into }} \mathrm{GG}$; (C) $\mathrm{CH}^{\text {into }} \mathrm{GG}$, (D) $\mathrm{CH}(\mathrm{pH})^{\text {into }} \mathrm{GG}$, (E) $\mathrm{CH}^{\text {into }} \mathrm{GG}(\mathrm{pH})$ and (F) $\mathrm{CH}(\mathrm{pH}){ }^{\text {into }} \mathrm{GG}(\mathrm{pH})$. The naming of PEC-films as followed. For example, free-standing $\mathrm{CH}(\mathrm{pH})$ films dipped into GG solution is hereafter named as $\mathrm{CH}(\mathrm{pH}){ }^{\mathrm{into}} \mathrm{GG}$. 


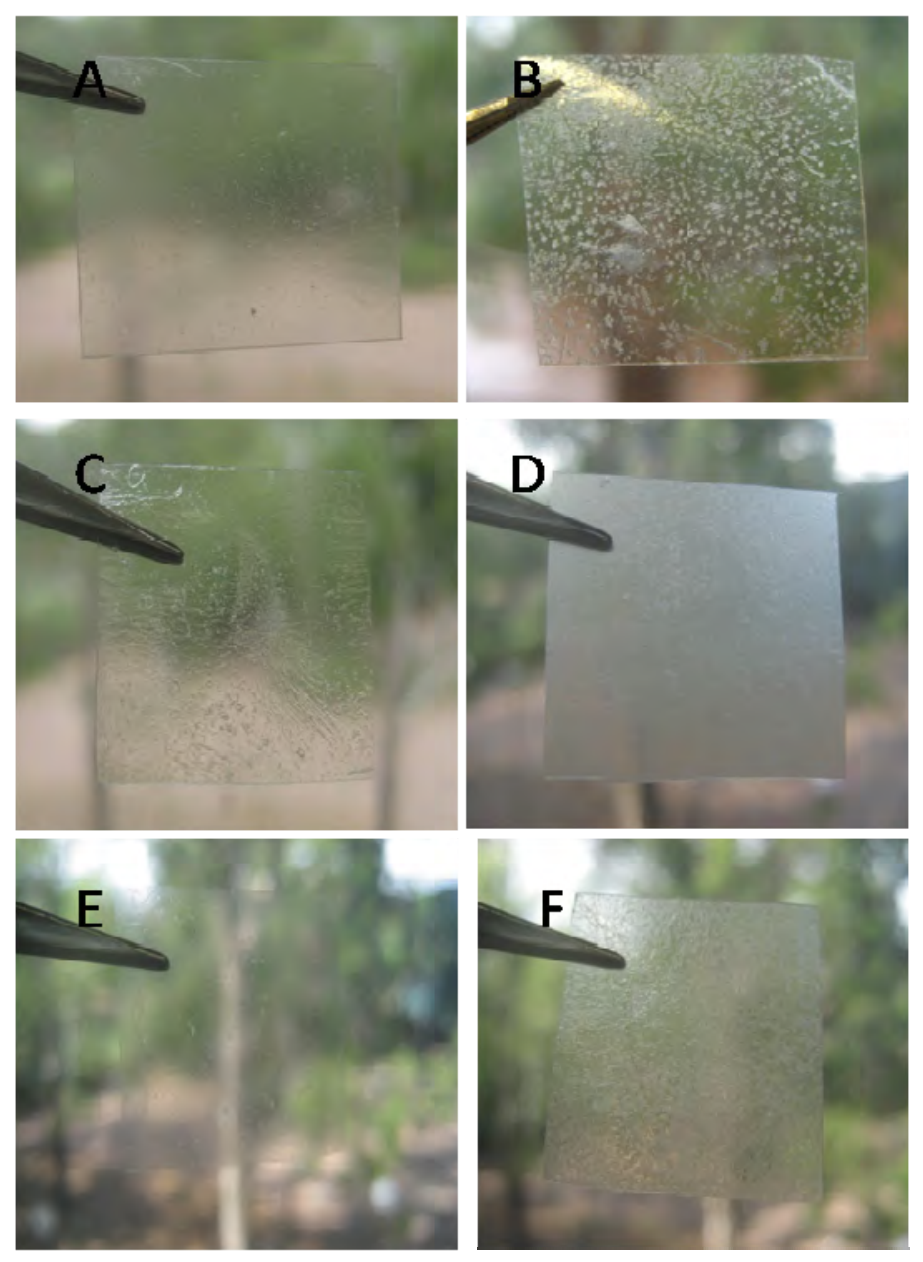

Figure 5.3: (A-B) Free-standing films; (A) GG, (B) GG(pH), (C-F) PEC-films with the order of addition of $\mathrm{GG}^{\text {into }} \mathrm{CH}$; (C) $\mathrm{GG}^{\text {into }} \mathrm{CH}$, (D) $\mathrm{GG}(\mathrm{pH}){ }^{\text {into }} \mathrm{CH}$, (E) $\mathrm{GG}^{\text {into }} \mathrm{CH}(\mathrm{pH})$ and (F) $\mathrm{GG}(\mathrm{pH}){ }^{\mathrm{into}} \mathrm{CH}(\mathrm{pH})$. The naming of PEC-films as followed. For example, free-standing $\mathrm{GG}(\mathrm{pH})$ films dipped into $\mathrm{CH}$ solution is hereafter named as $\mathrm{GG}(\mathrm{pH}){ }^{\mathrm{into}} \mathrm{CH}$.

\subsection{Mechanical properties}

\subsubsection{Chitosan and gellan gum films}

A comparison between $\mathrm{CH}$ and GG films revealed that $\mathrm{CH}$ films exhibit lower tensile strength (TS) and Young's modulus (E), but higher toughness (T) and strain-at-break ( $\gamma$ ) compared to GG films (Figure 5.4 and Table 5.1). In other words, $\mathrm{CH}$ films are flexible, while GG films are brittle. 

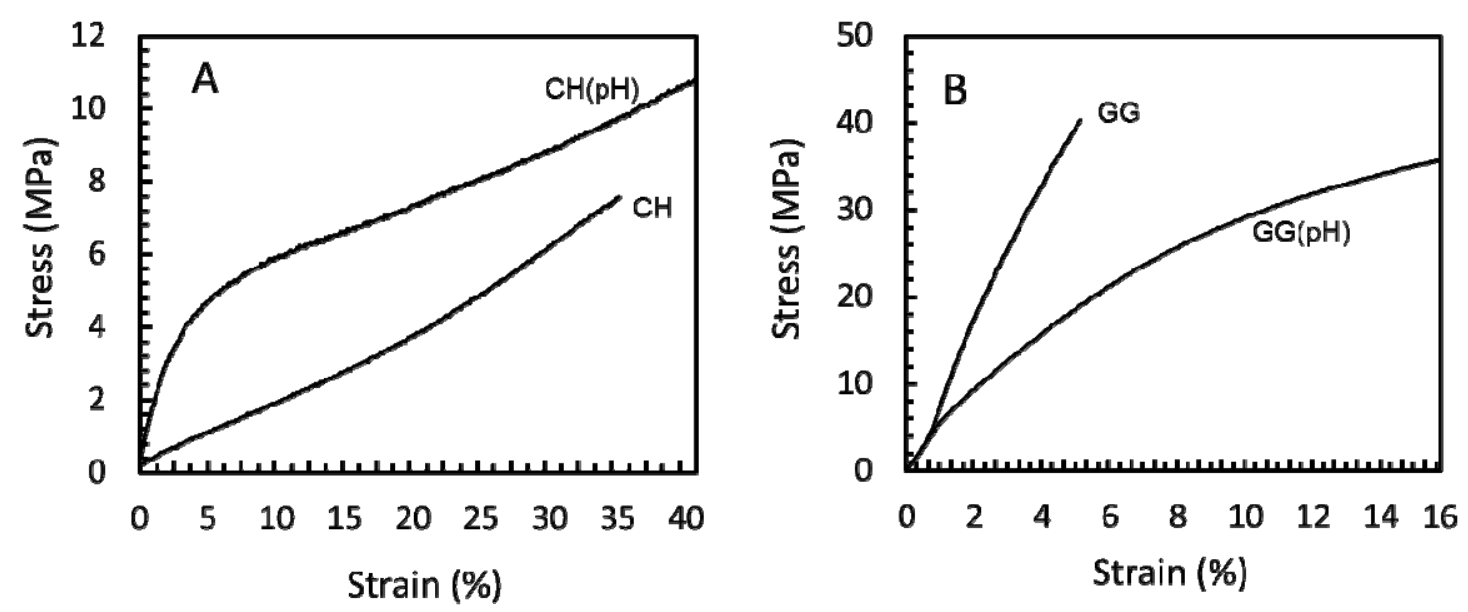

Figure 5.4: Stress-strain curves of films; (A) $\mathrm{CH}$ and $\mathrm{CH}(\mathrm{pH})$ and (B) GG and GG(pH).

\subsection{2 $\mathrm{pH}$ adjusted chitosan and gellan gum films}

It is assumed that changes in the $\mathrm{pH}$ of the solutions lead to changes in the ionic nature of the solutions. For example, most of the CH's amine groups will be protonated in a $\mathrm{CH}(\mathrm{pH})$ solution at $\mathrm{pH} \sim 1.8$, and most of the GG's carboxy groups will be deprotonated in a $\mathrm{GG}(\mathrm{pH})$ solution at $\mathrm{pH} \sim 12$. The effect of solution $\mathrm{pH}$ on the films' mechanical properties is profound. For example, films prepared using a $\mathrm{CH}(\mathrm{pH})$ solution at $\mathrm{pH} \sim 1.8$ exhibit a 4.8-fold increase in $\mathrm{E}$ compared to films prepared using $\mathrm{CH}$ solutions with $\mathrm{pH} \sim 5.6$ (Table 5.1). Smaller increases were observed for T (1.9 fold), TS (1.7 fold) and $\gamma$ (1.4 fold). In contrast, films prepared using GG solutions at $\mathrm{pH} \sim 12$ resulted in large increases in $\mathrm{T}$ ( 6.5 fold) and $\gamma$ (2.8 fold), but at the cost of a reduced E (1.9 fold decrease) and TS (1.3 fold) compared to films prepared using GG solutions at $\mathrm{pH} \sim 5.4$. The increase in TS values for the $\mathrm{CH}$ materials are likely related to the observed increase in density, from $655 \pm 71 \mathrm{~kg} \mathrm{~m}^{-3}$ to $1,372 \pm 40 \mathrm{~kg} \mathrm{~m}^{-3}(\mathrm{CH}(\mathrm{pH})$ film). The increased density would result in a closer packing of the biopolymers, which may inhibit sliding of the chains under stress in the 
load direction ${ }^{368}$. The opposite occurs for the chains in GG films, with a decrease in both density and TS.

\subsubsection{Polyelectrolyte complex-films}

The mechanical characteristics of $\mathrm{CH}$ and GG films change as a result of the PEC process. Immersing $\mathrm{CH}$ films into $\mathrm{GG}$ solution $\left(\mathrm{CH}^{\text {into }} \mathrm{GG}\right)$ resulted in an improvement of T, E and TS values coupled with a decreased in $\gamma$ values compared to $\mathrm{CH}$ films (Figure 5.5). PEC-films formed through immersing of GG films into $\mathrm{CH}$ solution $\left(G G^{\text {into }} \mathrm{CH}\right)$ resulted in the opposite trends: $\gamma$ improves, but $\mathrm{E}$ and TS values decreased compared to GG films.
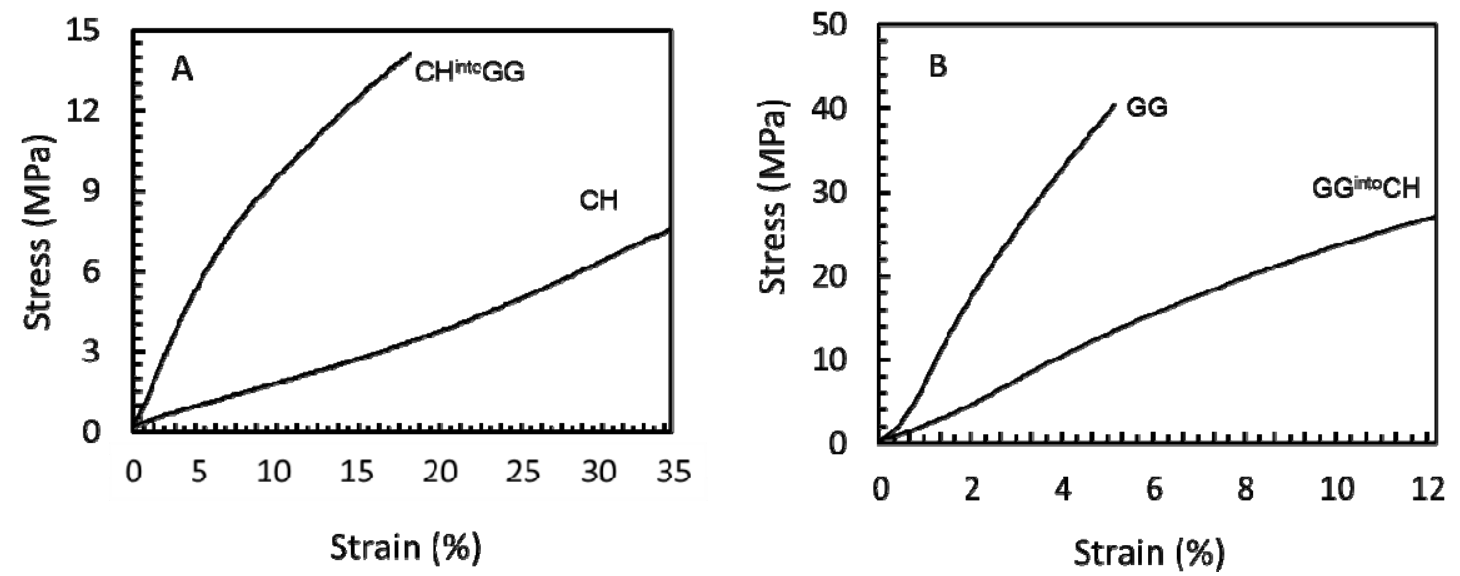

Figure 5.5: Stress-strain curves of films; (A) $\mathrm{CH}$ and $\mathrm{CH}^{\text {into }} \mathrm{GG}$ and (B) GG and $\mathrm{GG}{ }^{\text {into }} \mathrm{CH}$.

Changing the order of addition alters the biopolymer composition of the PECfilms (Table 5.1). For example, $\mathrm{CH}^{\text {into }} \mathrm{GG}$ exhibits higher $\mathrm{CH}$ :GG ratios compared to $G G{ }^{\text {into }} \mathrm{CH}$. The difference in the composition of PEC-films is reflected in the mechanical properties (Table 5.1). 
Table 5.1: Summary of composition of the films determined using elemental analysis, CH:GG ratios, tensile strength (TS), Young's modulus (E), toughness $(\mathrm{T})$ and strain-at-break $(\gamma)$ values.

\begin{tabular}{|c|c|c|c|c|c|c|c|c|c|c|}
\hline Film & $\begin{array}{c}\mathrm{C} \\
\text { (at.-\%) }\end{array}$ & $\begin{array}{c}\mathrm{H} \\
\text { (at.-\%) }\end{array}$ & $\begin{array}{c}\mathrm{N} \\
\text { (at.-\%) }\end{array}$ & $\begin{array}{l}\mathrm{CH} \\
(\%)\end{array}$ & $\begin{array}{l}\text { GG } \\
\text { (\%) }\end{array}$ & CH:GG & $\begin{array}{c}\text { TS } \\
\text { (MPa) }\end{array}$ & $\begin{array}{c}\mathrm{E} \\
(\mathrm{MPa})\end{array}$ & $\begin{array}{c}\mathrm{T} \\
\left(\mathrm{J} \mathrm{g}^{-1}\right)\end{array}$ & $\begin{array}{c}\gamma \\
(\%)\end{array}$ \\
\hline $\mathrm{CH}$ & 0.75 & 0.12 & 0.13 & 100 & 0 & - & $15 \pm 6$ & $25 \pm 7$ & $1.27 \pm 0.01$ & $32 \pm 2$ \\
\hline $\mathrm{CH}^{\mathrm{int}} \mathrm{GG}$ & 0.78 & 0.13 & 0.09 & 60 & 40 & 1.5 & $12 \pm 2$ & $103 \pm 4$ & $2.72 \pm 0.28$ & $19 \pm 1$ \\
\hline $\mathrm{CH}^{\text {into }} \mathrm{GG}(\mathrm{pH})$ & 0.80 & 0.14 & 0.06 & 32 & 68 & 0.47 & $26 \pm 6$ & $130 \pm 34$ & $7.20 \pm 2.58$ & $45 \pm 5$ \\
\hline $\mathrm{CH}(\mathrm{pH})$ & 0.75 & 0.12 & 0.13 & 100 & 0 & - & $10 \pm 1$ & $120 \pm 42$ & $2.44 \pm 0.21$ & $45 \pm 2$ \\
\hline $\mathrm{CH}(\mathrm{pH})^{\mathrm{into}} \mathrm{GG}$ & 0.80 & 0.14 & 0.06 & 32 & 68 & 1.0 & $16 \pm 1$ & $322 \pm 177$ & $3.47 \pm 1.07$ & $20 \pm 1$ \\
\hline $\mathrm{CH}(\mathrm{pH})^{\mathrm{into}} \mathrm{GG}(\mathrm{pH})$ & 0.79 & 0.13 & 0.08 & 51 & 49 & 0.56 & $23 \pm 4$ & $202 \pm 38$ & $4.11 \pm 1.36$ & $26 \pm 3$ \\
\hline GG & 0.87 & 0.13 & 0 & 0 & 100 & - & $42 \pm 5$ & $1097 \pm 163$ & $0.68 \pm 0.03$ & $5 \pm 1$ \\
\hline $\mathrm{GG}^{\text {into }} \mathrm{CH}$ & 0.83 & 0.14 & 0.03 & 18 & 82 & 0.22 & $20 \pm 8$ & $282 \pm 123$ & $0.76 \pm 0.31$ & $12 \pm 1$ \\
\hline $\mathrm{GG}^{\text {into }} \mathrm{CH}(\mathrm{pH})$ & 0.85 & 0.13 & 0.01 & 7 & 93 & 0.08 & $27 \pm 2$ & $1345 \pm 120$ & $0.81 \pm 0.81$ & $3 \pm 1$ \\
\hline GG(pH) & 0.87 & 0.13 & 0 & 0 & 100 & - & $32 \pm 8$ & $576 \pm 136$ & $4.45 \pm 1.19$ & $15 \pm 4$ \\
\hline $\mathrm{GG}(\mathrm{pH})^{\text {into }} \mathrm{CH}$ & 0.82 & 0.14 & 0.04 & 21 & 79 & 0.27 & $30 \pm 5$ & $329 \pm 81$ & $5.12 \pm 0.12$ & $22 \pm 3$ \\
\hline $\mathrm{GG}(\mathrm{pH}))^{\mathrm{int}} \mathrm{CH}(\mathrm{pH})$ & 0.85 & 0.14 & 0.01 & 5 & 95 & 0.05 & $21 \pm 3$ & $170 \pm 37$ & $2.05 \pm 1.37$ & $19 \pm 2$ \\
\hline
\end{tabular}


For example, changing the order of addition from $\mathrm{CH}^{\text {into }} \mathrm{GG}$ to $\mathrm{GG}^{\text {into }} \mathrm{CH}$ results in a 3.6-fold decrease in $\gamma$, i.e., from $2.72 \mathrm{~J} \mathrm{~g}^{-1}$ to $0.76 \mathrm{~J}^{-1}$. A smaller 1.6 fold reduction was observed for $\gamma$, while $\mathrm{E}$ and TS values improved 1.7 and 2.7 times, respectively.

\subsection{4 pH adjusted polyelectrolyte complex (PEC) films}

Using $\mathrm{CH}(\mathrm{pH})$ and $\mathrm{GG}(\mathrm{pH})$ solution for either the formation of $\mathrm{CH}$ and GG films, or the immersion solutions, or both, resulted in improvements in the mechanical characteristics. TS and density values of PEC-films prepared by immersing $\mathrm{CH}$ films into GG solutions increase linearly (Figure 5.6 A and D) with increasing CH:GG ratio (Figure 5.6 D).
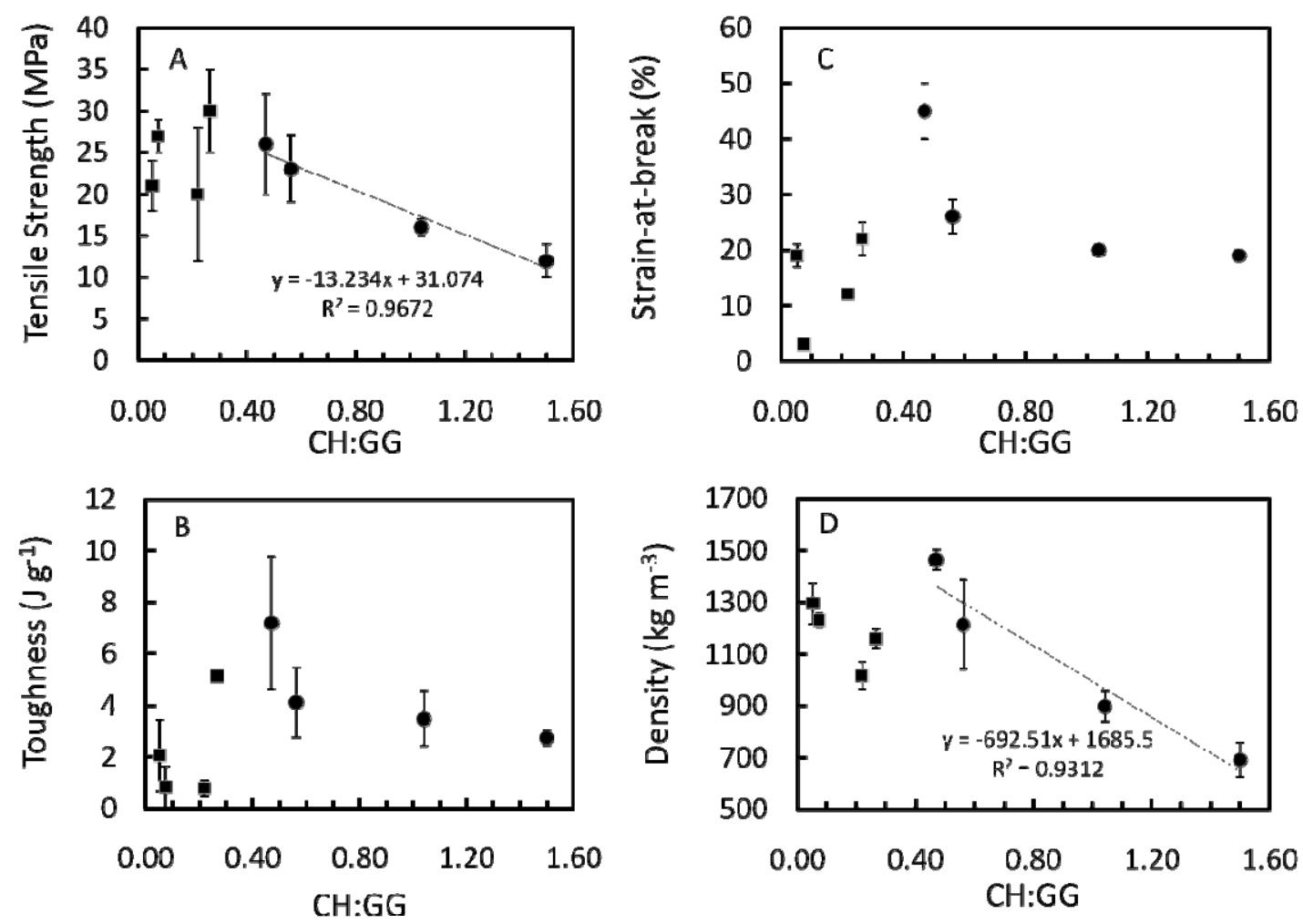

Figure 5.6: (A) Tensile strength, (B) toughness, (C) strain-at-break and (D) density as a function of CH:GG ratio for polyelectrolyte complex-films prepared by dipping $\mathrm{CH}$ into GG (spheres) and GG into CH (squares). 
Although there is no linear relationship, it is clear that $\mathrm{T}$ and $\gamma$ values increased (Figure 5.6 B and C) with increasing CH:GG ratio (Table 5.1). In contrast, it is not possible to observe any trends for PEC-films prepared by dipping GG films into $\mathrm{CH}$ solutions $\left(\mathrm{GG}^{\mathrm{into}} \mathrm{CH}\right)$. Overall, it appears that the highest mechanical values are observed for PEC-films with a CH:GG ratio of 0.47 , i.e. for films containing twice as much GG as CH (Table 5.1).

\subsection{Optical microscopy}

A cross-sectional analysis of these films shows that GG appears to diffuse into $\mathrm{CH}$ films (Figure 5.7 B), but $\mathrm{CH}$ does not diffuse into GG film (Figure $5.7 \mathrm{D}$ ). Optical microscopy suggests that the $\mathrm{GG}{ }^{\mathrm{into}} \mathrm{CH}$ PEC-film consists of an inner GG layer and two outer $\mathrm{CH}$ layers.
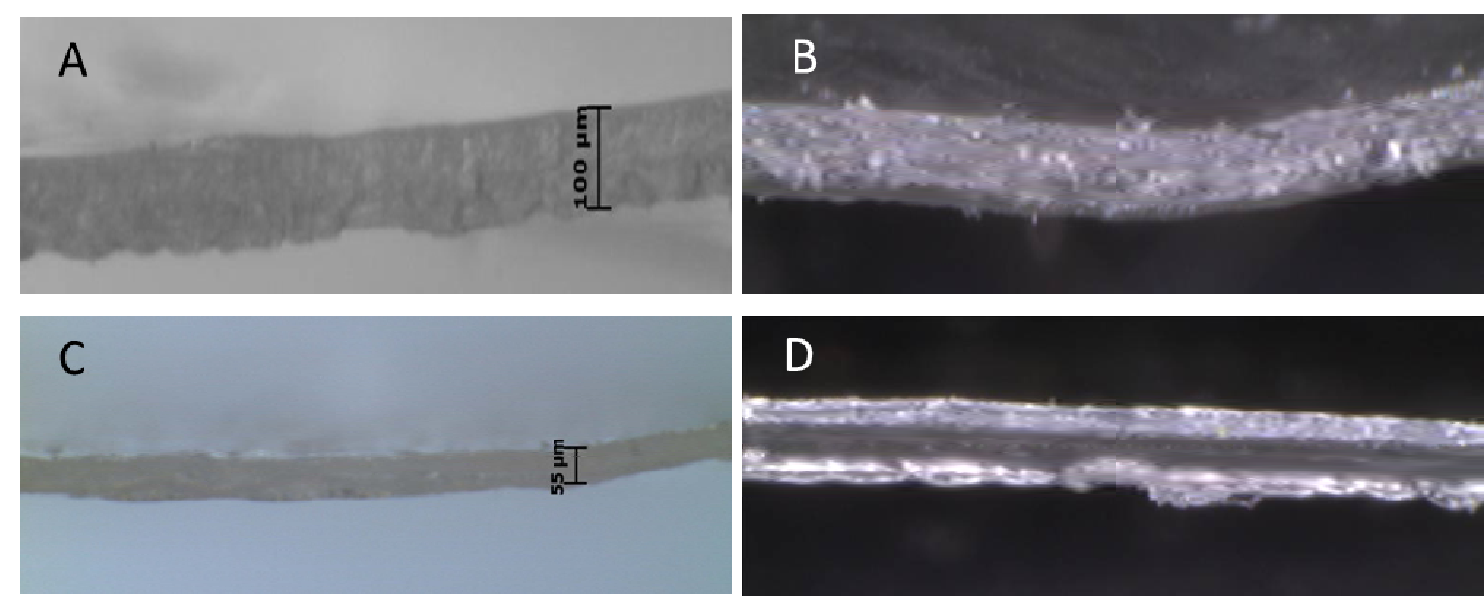

\section{D}

Figure 5.7: Optical microscope images of cross-section of films; (A) $\mathrm{CH}$, (B) $\mathrm{CH}^{\text {into }} \mathrm{GG},(\mathrm{C})$ GG and (D) $\mathrm{GG}^{\text {into }} \mathrm{CH}$.

It is well-known that the multilayer structure of PEC-films is affected by polymer charge density, polymer ionic strength, additive salt and type of polyion ${ }^{369}$. There are number of differences between the CH and GG films and the solutions used: 
(i) $\mathrm{CH}$ has an intrinsic $\mathrm{pK}=6.5$ and requires acidic conditions to be soluble in water ${ }^{1}$.

GG has an intrinsic $\mathrm{pK}=3.5$ and is soluble in water ${ }^{370}$, (ii) The $\mathrm{pH}$ of $\mathrm{CH}$ films is always near neutral, regardless of the $\mathrm{pH}$ of the solutions. For example, $\mathrm{CH}$ solutions of $\mathrm{pH}=1.8, \mathrm{pH}=2.8$ and $\mathrm{pH}=5.4$ resulted in films with $\mathrm{pH}$ values of $6.9,6.7$ and 7.4, respectively. GG solutions of $\mathrm{pH}=5.6$ and 12.0 resulted in films with $\mathrm{pH}$ values of 4.7 and 9.0, respectively; (iii) Chain stiffness or the persistence length of GG is reported to be $9.4 \mathrm{~nm}$ at $40{ }^{\circ} \mathrm{C}{ }^{371}$. The temperature of GG solution during the formation is even higher $\left(70{ }^{\circ} \mathrm{C}\right)$. Unlike $\mathrm{CH}$, gellan gum chains converts from a double-helix structure to random coils upon heating, and will be in random coil conformation at $70{ }^{\circ} \mathrm{C}$. The reported persistence length for $\mathrm{CH}(\mathrm{DD}=93 \%)$ is $81 \mathrm{~nm}$ at $25{ }^{\circ} \mathrm{C}^{372}$. In other words, it is suggested that $\mathrm{CH}$ chains are less flexible compared to GG chains. Therefore, it is likely that the difference in PEC composition shown in Table 5.1 may be attributed to the difference in persistence length, as well as being driven by alkalinity and acidity of films and solutions. For example, immersing an acidic GG film ( $\mathrm{pH} 4.7)$ into an acidic $\mathrm{CH}$ solution $\left(\mathrm{pH}=1.8\right.$, temperature $=25^{\circ} \mathrm{C}$ ) will impede diffusion of $\mathrm{CH}$ into GG due to electrostatic repulsion of the chains. This may result in the build-up of a separate $\mathrm{CH}$ layers on the GG film as shown in Figure 5.7 D. It is also possible that the small persistence length of GG in the $70{ }^{\circ} \mathrm{C}$ solution may aid the diffusion leading to the composition shown in Figure 5.7 B.

\subsection{Water vapour transmission rates (WVTR)}

The water vapour transmission rates (WVTR), water vapour permeability (WVP) and permeance (P) of the $\mathrm{CH}$, GG and PEC-films are summarized in Table 5.2. GG films show higher values of WVTR compared to those observed for $\mathrm{CH}$ films. The PECfilms exhibited a narrow range of WVTR values, between $910-1056 \mathrm{~g} \mathrm{~m}^{-2} \mathrm{~d}^{-1}$ that fall into the suggested range (500-2000 $\mathrm{g} \mathrm{m}^{-2} \mathrm{~d}^{-1}$ ) of providing adequate moisture that 
prevents wound dehydration ${ }^{37,373}$. The ability of $\mathrm{GG}$ to diffuse into $\mathrm{CH}$ films $\left(\mathrm{CH}^{\text {into }} \mathrm{GG}\right)$, but not vice versa, is reflected in the WVTR values. For example, $\mathrm{CH}^{\text {into }} \mathrm{GG}$ films exhibit higher WVTR (925 $\mathrm{g} \mathrm{m}^{-2} \mathrm{~d}^{-1}$ ) compared to $\mathrm{GG}^{\text {into }} \mathrm{CH}$ films (910 $\left.\mathrm{g} \mathrm{m}^{-2} \mathrm{~d}^{-1}\right)$. Higher WVTR values were also observed for $\mathrm{CH}^{\text {into }} \mathrm{GG}(\mathrm{pH})\left(974 \mathrm{~g} \mathrm{~m}^{-2}\right.$ $\mathrm{d}^{-1}$ ) compared to $\mathrm{GG}(\mathrm{pH}){ }^{\text {into }} \mathrm{CH}\left(932 \mathrm{~g} \mathrm{~m}^{-2} \mathrm{~d}^{-1}\right)$. The lower WVTR values of the $\mathrm{GG}^{\text {into }} \mathrm{CH}$ films could be due to the layered structure, which may and slows the transport of water vapours through the GG layer and two outer $\mathrm{CH}$ layers (Figure 5.7 D). Compared to $\mathrm{CH}^{\text {into }} \mathrm{GG}$, no separation layer formed (Figure 5.7 B), thus the water vapours could transfer easily and recorded higher WVTR (Table 5.2).

Table 5.2: Water vapour transmission rates (WVTR), water vapour permeability (WVP), permeance $(\mathrm{P})$ values, and percentage swelling upon immersion into buffer of $\mathrm{pH} 1$ and $\mathrm{pH} 7$ for 24 hours.

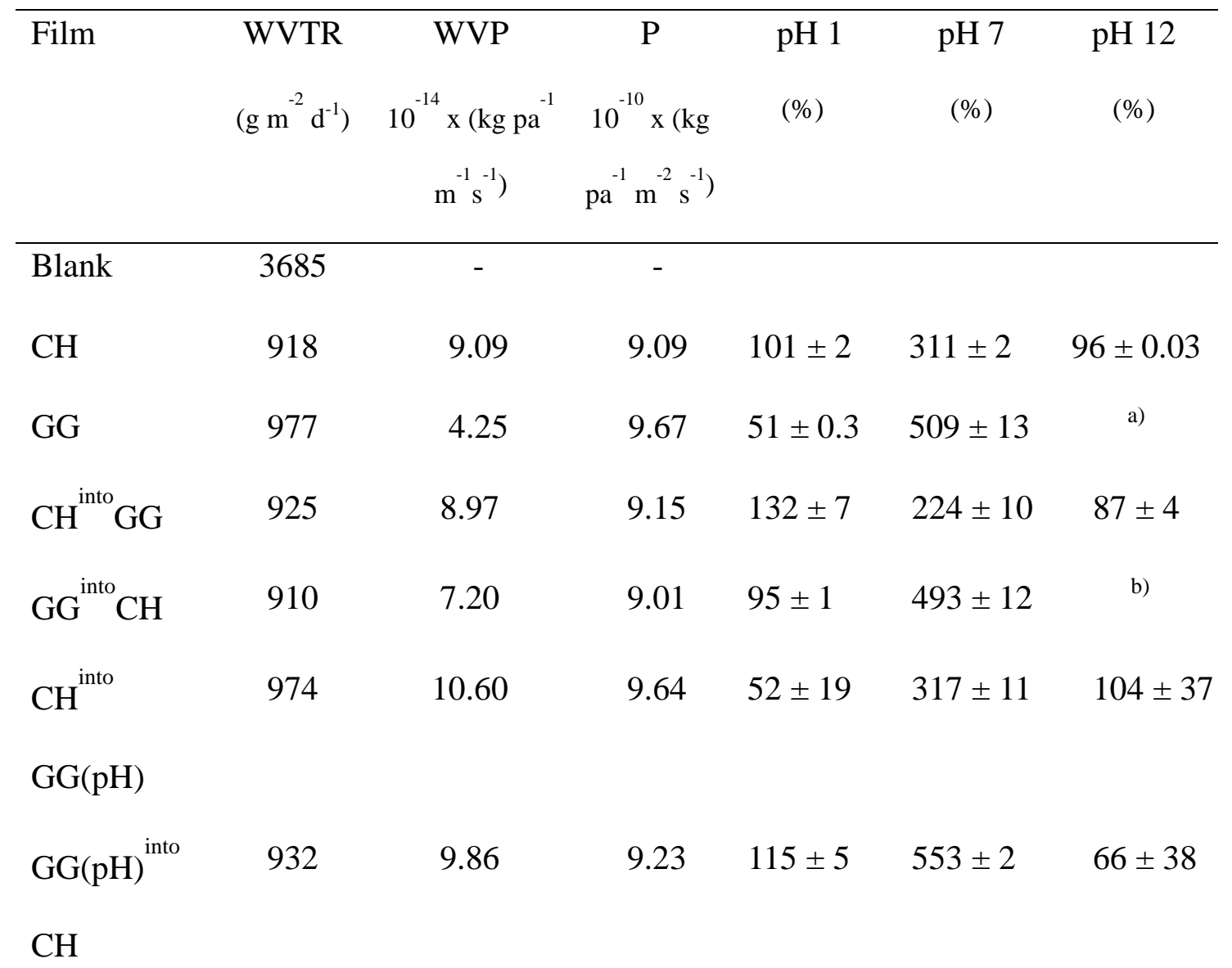




\begin{tabular}{|c|c|}
\hline $\mathrm{CH}(\mathrm{pH})^{\text {into }}$ & 1041 \\
\hline
\end{tabular}

$\mathrm{GG}(\mathrm{pH})$

$\begin{array}{llllllll}\mathrm{GG}(\mathrm{pH}) & \text { into } & 1056 & 8.78 & 10.50 & 145 \pm 84 & 674 \pm 22 & 53\end{array}$ $\mathrm{CH}(\mathrm{pH})$

a) film dissolved, ${ }^{\text {b) }}$ film split into separate layers

\subsection{Swelling}

The swelling of $\mathrm{CH}$, GG and PEC-films in buffer solutions at $\mathrm{pH} 1$ and $\mathrm{pH} 7$ are summarised in Table 5.2. GG films absorb more water than GG films in buffer solution at $\mathrm{pH} 7$, i.e. $509 \pm 13 \%$ compared to $311 \pm 2 \%$. It has been suggested that GG absorbs more water due to the higher number of hydroxyl groups compared to $\mathrm{CH}^{374}$. GG films were found to completely dissolve in buffer solutions of $\mathrm{pH}=12$.

For PEC-films, the order of addition played a significant role in the swelling behaviour. For example, in buffer at $\mathrm{pH}$ 7, $\mathrm{CH}^{\text {into }} \mathrm{GG}, \mathrm{CH}^{\text {into }} \mathrm{GG}(\mathrm{pH})$ and $\mathrm{CH}(\mathrm{pH}){ }^{\text {into }} \mathrm{GG}(\mathrm{pH})$ PEC-films were less susceptible to swelling compared to $\mathrm{GG}^{\text {into }} \mathrm{CH}, \mathrm{GG}(\mathrm{pH}){ }^{\text {into }} \mathrm{CH}$ and $\mathrm{GG}(\mathrm{pH}){ }^{\text {into }} \mathrm{CH}(\mathrm{pH})$, see Table 5.2. The larger amount of swelling observed for $\mathrm{GG}^{\text {into }} \mathrm{CH}, \mathrm{GG}(\mathrm{pH}){ }^{\mathrm{into}} \mathrm{CH}$ and $\mathrm{GG}(\mathrm{pH}){ }^{\mathrm{into}} \mathrm{CH}(\mathrm{pH})$ PEC-films may be attributed to the layered structure of these films. These films consist of a GG layer sandwiched between two outer layers of CH (Figure 5.7 D).

In buffer solution at $\mathrm{pH} 12$, the $\mathrm{GG}{ }^{\text {into }} \mathrm{CH}$ PEC-film split into two layers. The GG layer in the middle of the film was dissolved and two layers remaining were $\mathrm{CH}$ layer which covered the GG film (Figure $5.7 \mathrm{D}$ ). Interestingly, the $\mathrm{GG}(\mathrm{pH}){ }^{\mathrm{into}} \mathrm{CH}$ and 
$\mathrm{GG}(\mathrm{pH}){ }^{\mathrm{into}} \mathrm{CH}(\mathrm{pH})$ PEC-films did not exhibit separation of the layers. It is likely that this can be attributed an increase in the charge density of $\mathrm{GG}(\mathrm{pH})$ film, and thus improved electrostatic interaction with $\mathrm{CH}$.

\subsection{Conclusion}

PEC-films were prepared by dipping free-standing films of GG into $\mathrm{CH}$ solution $\left(\mathrm{GG}{ }^{\text {into }} \mathrm{CH}\right)$ and $\mathrm{CH}$ into GG solution $\left(\mathrm{CH}^{\text {into }} \mathrm{GG}\right)$. It was shown that the composition and mechanical characteristics depended on the solution and film $\mathrm{pH}$, as well as the order of addition. The results indicate that toughness, tensile strength, strain-at-break and density values of PEC-films prepared by immersing $\mathrm{CH}$ films into GG solutions increased with an increasing $\mathrm{CH}: \mathrm{GG}$ ratio. For example, tensile strength increased from $12 \mathrm{MPa}$ to $26 \mathrm{MPa}$ for an increase in $\mathrm{CH}$ :GG ratio from 0.47 to 1.50 . In contrast, it was not possible to observe similar trends for PEC-films prepared by the reverse addition. It is suggested that the observed behaviour can be attributed to differences in their film compositions, i.e. $\mathrm{GG}{ }^{\text {into }} \mathrm{CH}$ films consist of an inner GG layer and two outer $\mathrm{CH}$ layers, whereas for $\mathrm{CH}^{\text {into }} \mathrm{GG}$ films GG has diffused into the $\mathrm{CH}$ layer. The film composition; for example $\mathrm{GG}^{\text {into }} \mathrm{CH}$ PEC-film also affected the WVTR and swelling. The $\mathrm{GG}^{\text {into }} \mathrm{CH}$ film shows low amount of water vapours were able to diffuse into layered structure of the film, whereas absorbed higher swelling compared to $\mathrm{CH}^{\text {into }} \mathrm{GG}$ PEC-film. 


\section{CHAPTER 6}

\section{MECHANICAL PROPERTIES OF POLYELECTROLYTE COMPLEX COATED WOOL FIBRES USING CHITOSAN AND GELLAN GUM}

A polyelectrolyte complex (PEC) between chitosan (CH) and gellan gum (GG) on wool fibres was investigated. Pristine wool fibres were first coated in either $\mathrm{CH}$ or GG to modify surface charges. The single-coated wool fibres were then immersed in solution of opposite charge to form PEC-coated wool fibres. The effects of immersion duration, dyed, $\mathrm{pH}$ adjusted and order of addition of single-coated and PEC-coated wool fibres on the mechanical properties are discussed. Kubelka-Munk analysis was used to detect colorant changes in the PEC-coated wool fibres.

\subsection{Mechanical properties and microscopy}

\subsubsection{Single-coated wool fibres}

The mechanical properties of pristine wool fibres immersed in the $\mathrm{CH}$ solution $\mathrm{CH}-$ fibre) and GG solution (GG-fibre) for 2, 5, 10, 20 and 30 min are shown in Figure 6.1 and Table 6.1. CH-fibre and GG-fibre results showed significant improvements in Young's modulus (E) values after 2 min of immersion; i.e. E values have improved more than doubled compared to pristine wool fibres (Figure 6.1 B, Table 6.1). Smaller 
increases were observed for tensile strength (TS) and toughness (T) values, while strain-at-break $(\gamma)$ values decreased.
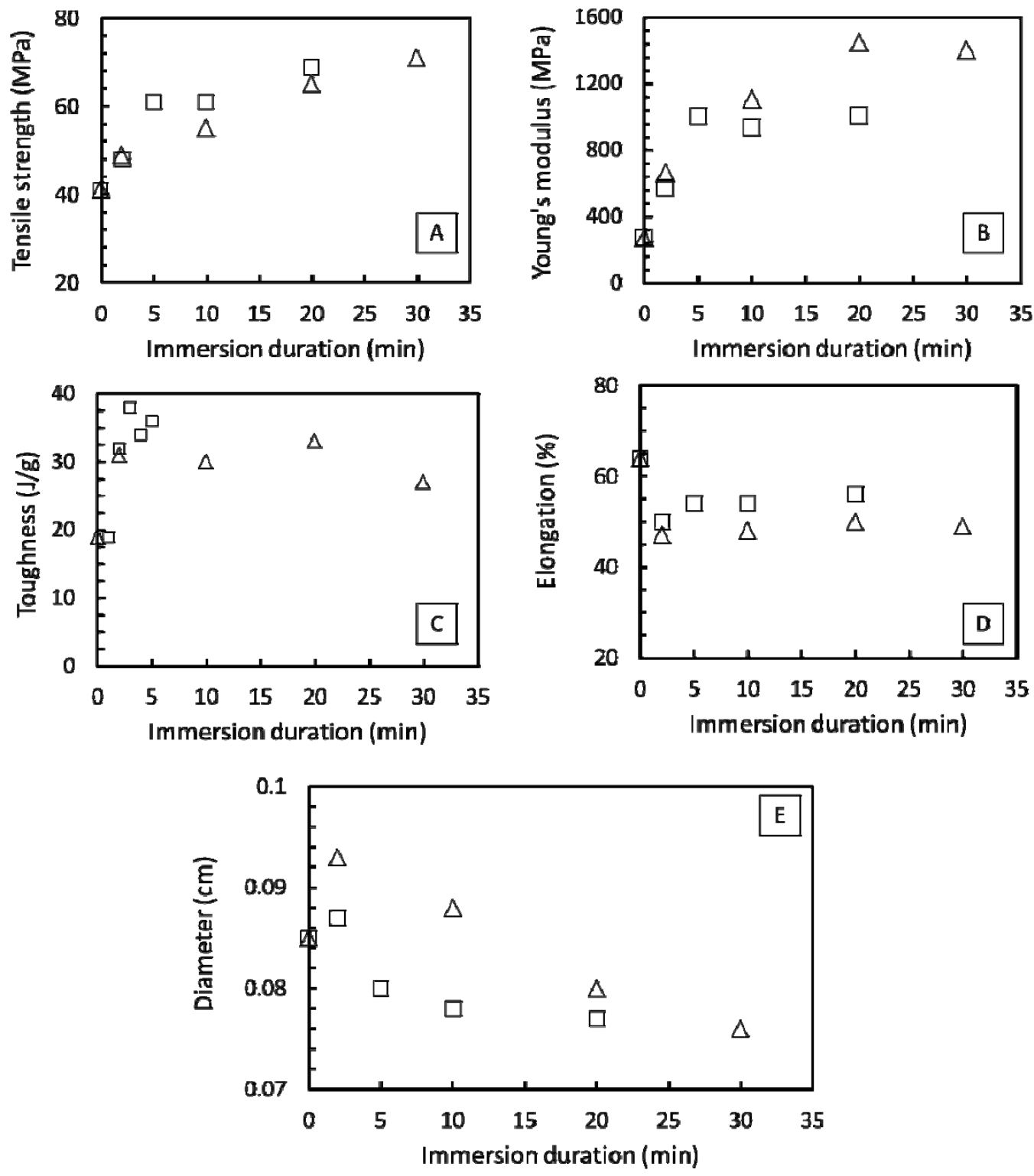

Figure 6.1: (A) Tensile strength, (B) Young's modulus, (C) toughness (D) strain-at-break and (E) diameter of $\mathrm{CH}$-fibre (triangles) and GG-fibre (squares) as function of immersion duration time (min).

The E values of $\mathrm{CH}$-fibre increased up to $20 \mathrm{~min}$ of immersion. In contrast, the $\mathrm{E}$ values of GG-fibre only needed 5 min of immersion to reach their maximum value. The $\gamma$ of CH-fibre and GG-fibre shows small changes after 5, 10, 20 and 30 
min of immersions (Figure 6.1 D). The diameter for both $\mathrm{CH}$-fibre and GG-fibre decreased (shrinkage) after 2 min of immersion and reached plateau values after 20 min and 5 min of immersions, respectively (Figure 6.1 E). The shrinkage observed for CH-fibre (20 min) and GG-fibre (5 min) is in agreement with the optimum E values for both fibres (Table 6.1).

Table 6.1: Mechanical properties of CH-fibre and GG-fibre at different immersion duration time. Tensile strength (TS), Young's modulus (E), toughness (T) and strain-at-break $(\gamma)$ for different single-coated fibre are given.

\begin{tabular}{|c|c|c|c|c|c|c|}
\hline Sample & $\begin{array}{c}\text { Immersion } \\
\text { (min) }\end{array}$ & $\begin{array}{l}\text { Diameter } \\
(\mu \mathrm{m})\end{array}$ & $\begin{array}{c}\mathrm{TS} \\
(\mathrm{MPa})\end{array}$ & $\begin{array}{c}\mathrm{E} \\
(\mathrm{MPa})\end{array}$ & $\begin{array}{c}\mathrm{T} \\
\left(\mathrm{J} \mathrm{g}^{-1}\right)\end{array}$ & $\begin{array}{c}\gamma \\
(\%)\end{array}$ \\
\hline $\begin{array}{l}\text { Pristine wool } \\
\text { fibre }\end{array}$ & - & $850 \pm 30$ & $41 \pm 1$ & $270 \pm 24$ & $19 \pm 11$ & $64 \pm 2$ \\
\hline \multirow[t]{4}{*}{ CH-fibre } & 2 & $930 \pm 10$ & $49 \pm 4$ & $662 \pm 52$ & $31 \pm 8$ & $47 \pm 2$ \\
\hline & 10 & $880 \pm 40$ & $55 \pm 5$ & $1103 \pm 117$ & $30 \pm 3$ & $48 \pm 2$ \\
\hline & 20 & $800 \pm 30$ & $65 \pm 4$ & $1447 \pm 191$ & $33 \pm 1$ & $50 \pm 3$ \\
\hline & 30 & $760 \pm 40$ & $73 \pm 7$ & $1400 \pm 250$ & $27 \pm 8$ & $49 \pm 6$ \\
\hline \multirow[t]{4}{*}{ GG-fibre } & 2 & $870 \pm 70$ & $48 \pm 8$ & $567 \pm 181$ & $32 \pm 2$ & $50 \pm 1$ \\
\hline & 5 & $800 \pm 70$ & $61 \pm 9$ & $1001 \pm 155$ & $38 \pm 1$ & $54 \pm 1$ \\
\hline & 10 & $780 \pm 50$ & $61 \pm 7$ & $932 \pm 143$ & $34 \pm 4$ & $54 \pm 1$ \\
\hline & 20 & $770 \pm 20$ & $69 \pm 7$ & $1004 \pm 56$ & $36 \pm 7$ & $56 \pm 1$ \\
\hline
\end{tabular}

Wool fibre has various functional groups such as hydroxyl, amino, imino and sulphydryl ${ }^{375,376}$. These functional groups are expected to bind with the amine $\left(\mathrm{NH}_{3}{ }^{+}\right)$and hydroxyl groups $(\mathrm{OH})$ of chitosan as well as with the hydroxyl $(\mathrm{OH})$ and carboxyl groups $(\mathrm{COOH})$ of gellan gum ${ }^{377}$. The $\mathrm{E}$ of $\mathrm{CH}$-fibre were higher than that 
of GG-fibre which may be attributed to stronger hydrogen bonding between functional groups of $\mathrm{CH}$ and the wool fibre ${ }^{378,379}$.
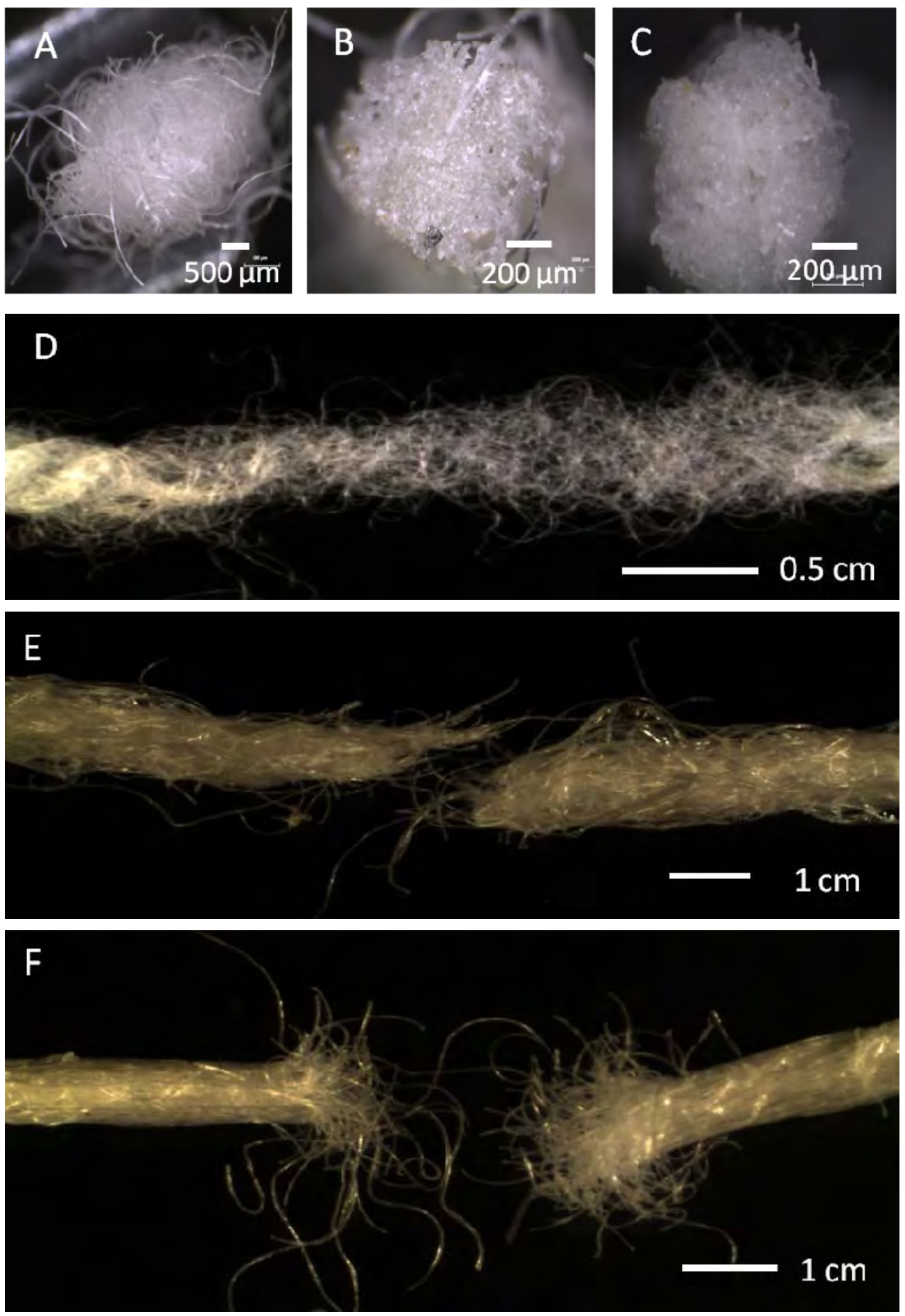

Figure 6.2: (A-C) Cross sectional area of single-coated fibres; (A) pristine wool fibre, (B) CH-fibre after 20 min of immersion, (C) GG-fibre after 5 min of immersion, (D-F) fractured topography (side view) of coated fibres from tensile testing; (D) pristine wool fibre, (E) $\mathrm{CH}$ fibre after 20 min of immersion and (F) GG-fibre after 5 min of immersion. 
A strong inter-fibre bonding is evident from the cross-section of the $\mathrm{CH}$-fibre after 20 min of immersion (Figure 6.2 B) as well as the fracture topography after tensile testing (Figure 6.2 E). This is in support of the proposed argument for stronger hydrogen bonding in $\mathrm{CH}$-fibres compared to GG-fibres. In contrast, GG-fibre shows the fibres are evenly bonded in the matrix after 5 min of immersion (Figure $6.2 \mathrm{C}$ ) but the number of fibres pulled out from the GG matrix (Figure 6.2 F) which resulted in higher strain-at-break values compared to CH-fibre (Table 6.1).

$\mathrm{CH}$-fibre required a longer immersion (20 $\mathrm{min}$ ) to reach optimum TS, E and T values, whereas GG-fibre reached optimum TS, E and T values after 5 min of immersion. The longer immersion time for $\mathrm{CH}$-fibre is expected due to difference in persistence length between $\mathrm{CH}$ and GG. The persistence length of $\mathrm{CH}$ (degree of deacetylation, $\mathrm{DD}=93 \%$ ) has been reported at $81 \mathrm{~nm}$, meanwhile GG at $9.4 \mathrm{~nm}$. In other words, it is suggested that GG chains are more flexible compared to $\mathrm{CH}$ chains and thus diffuse easily into wool fibre. In what follows, CH-fibre (20 min) and GGfibre (5 min) are used in the preparation of dyed-fibre, $\mathrm{pH}$ adjusted fibre and PECcoated fibres.

\subsubsection{Dyed single-coated fibre}

Adding a dye to $\mathrm{CH}$ solution significantly improved the TS and E values compared to pristine wool fibre and $\mathrm{CH}$-fibre (Table 6.2). For example, both the TS and E values of $\mathrm{CH}$-dye fibres improved to 2-folds of $\mathrm{CH}$-fibre. GG-dyed fibre shows 1-fold improvement in TS compared to GG-fibre. The T of CH-dyed and GG-dyed fibres decreased, whereas $\gamma$ does not significantly changes compared to fibres without dye modification (Table 6.2). 
Table 6.2: Mechanical properties of dyed single-coated fibre (unless stated otherwise), $\mathrm{pH}$ adjusted single-coated fibre and dyed with $\mathrm{pH}$ adjusted polyelectrolyte complex (PEC)-coated fibres. CH-fibres and CH solutions were dyed with food colour (blue); and GG-fibres and GG solutions were dyed with yellow colour. Single-coated fibres immersed in CH and GG solution for $20 \mathrm{~min}$ and $5 \mathrm{~min}$, respectively. For PEC-coated fibres, $\mathrm{CH}$ single-coated fibre immersed in GG solution for 20 min ( $\mathrm{CH}^{\text {into }} \mathrm{GG}$ ) and GG single-coated fibre immersed in $\mathrm{CH}$ solution for 5 min $\left(\mathrm{GG}^{\text {into }} \mathrm{CH}\right)$. Tensile strength (TS), Young's modulus (E), toughness (T) and strain-at-break $(\gamma)$ of coated fibres are given.

\begin{tabular}{|c|c|c|c|c|c|}
\hline Sample & $\begin{array}{l}\text { Diameter } \\
\qquad(\mu \mathrm{m})\end{array}$ & $\begin{array}{c}\mathrm{TS} \\
(\mathrm{MPa})\end{array}$ & $\begin{array}{c}\mathrm{E} \\
(\mathrm{MPa})\end{array}$ & $\begin{array}{c}\mathrm{T} \\
\left(\mathrm{J} \mathrm{g}^{-1}\right)\end{array}$ & $\begin{array}{c}\gamma \\
(\%)\end{array}$ \\
\hline Pristine wool fibre & $850 \pm 30$ & $41 \pm 1$ & $270 \pm 24$ & $19 \pm 11$ & $64 \pm 2$ \\
\hline CH (without dye) & $800 \pm 30$ & $65 \pm 4$ & $1447 \pm 191$ & $33 \pm 1$ & $50 \pm 3$ \\
\hline $\mathrm{CH}$ & $620 \pm 40$ & $105 \pm 9$ & $2380 \pm 275$ & $28 \pm 1.5$ & $48 \pm 2$ \\
\hline GG (without dye) & $800 \pm 70$ & $61 \pm 9$ & $1001 \pm 155$ & $38 \pm 1$ & $54 \pm 1$ \\
\hline GG & $680 \pm 50$ & $72 \pm 9$ & $959 \pm 103$ & $31 \pm 0.3$ & $58 \pm 2$ \\
\hline $\mathrm{CH}(\mathrm{pH})$ & $740 \pm 60$ & $82 \pm 9$ & $1577 \pm 257$ & $30 \pm 1.4$ & $52 \pm 1$ \\
\hline $\mathrm{GG}(\mathrm{pH})$ & $660 \pm 40$ & $42 \pm 4$ & $814 \pm 150$ & $23 \pm 2.0$ & $63 \pm 3$ \\
\hline $\mathrm{CH}^{\text {into }} \mathrm{GG}$ & $620 \pm 60$ & $111 \pm 14$ & $2356 \pm 108$ & $26 \pm 0.4$ & $48 \pm 2$ \\
\hline $\mathrm{GG}^{\text {into }} \mathrm{CH}$ & $690 \pm 50$ & $92 \pm 7$ & $1290 \pm 109$ & $32 \pm 0.6$ & $58 \pm 1$ \\
\hline $\mathrm{CH}^{\mathrm{into}} \mathrm{GG}(\mathrm{pH})$ & $730 \pm 40$ & $43 \pm 3$ & $1065 \pm 111$ & $17 \pm 0.6$ & $57 \pm 2$ \\
\hline $\mathrm{GG}^{\text {into }} \mathrm{CH}(\mathrm{pH})$ & $700 \pm 60$ & $69 \pm 16$ & $798 \pm 140$ & $36 \pm 1.5$ & $59 \pm 2$ \\
\hline $\mathrm{CH}(\mathrm{pH}){ }^{\text {into }} \mathrm{GG}$ & $790 \pm 70$ & $64 \pm 3$ & $949 \pm 83$ & $34 \pm 0.9$ & $58 \pm 2$ \\
\hline $\mathrm{GG}(\mathrm{pH}){ }^{\mathrm{into}} \mathrm{CH}$ & $690 \pm 30$ & $63 \pm 1$ & $918 \pm 66$ & $28 \pm 0.1$ & $70 \pm 5$ \\
\hline $\mathrm{CH}(\mathrm{pH}){ }^{\mathrm{into}} \mathrm{GG}(\mathrm{pH})$ & $750 \pm 60$ & $36 \pm 2$ & $769 \pm 60$ & $20 \pm 0.8$ & $60 \pm 2$ \\
\hline $\mathrm{GG}(\mathrm{pH}){ }^{\mathrm{into}} \mathrm{CH}(\mathrm{pH})$ & $650 \pm 30$ & $60 \pm 3$ & $945 \pm 155$ & $26 \pm 0.6$ & $70 \pm 1$ \\
\hline
\end{tabular}

Food colours (blue and yellow) have active ingredients such as concentrated dye (anthraquinone and triphenylmethane), citric acid, a synthetic colorant (E124, 
Ponceau for blue and E102, Tartrazine for yellow) and preservative (E211, sodium benzoate). Citric acid may form H-bonds with hydroxyl groups and amino groups of $\mathrm{CH}$ as well as enabling ester crosslinking ${ }^{380,381}$. Anthraquinone and triphenylmethane compounds also expected to interact with hydroxyl groups and amino groups in $\mathrm{CH}$ 382 which reflected in improved TS and E values of $\mathrm{CH}$-dyed fibre. On the other hand, GG-dyed fibre results showed that the TS improved which could be due to hydrogen bonding between carboxyl groups of GG with citric acid ${ }^{383}$.

\subsection{3 pH adjusted single-coated fibre}

Pristine wool fibres immersed in $\mathrm{pH}$ adjusted dyed solutions of $\mathrm{CH}(\mathrm{pH}=1.8)$ and $\mathrm{GG}$ ( $\mathrm{pH}=12)$, respectively showed that TS and $\mathrm{E}$ values decreased, while $\gamma$ values increased compared to those samples prepared using dyed solutions without $\mathrm{pH}$ modification (Table 6.2). For example, the TS and $\mathrm{E}$ of $\mathrm{CH}$-dyed $(\mathrm{pH})$ fibres decreased to $82 \pm 9 \mathrm{MPa}$ and $1577 \pm 257 \mathrm{MPa}$, respectively compared to $\mathrm{CH}$-dyed fibre (TS= $105 \pm 9 \mathrm{MPa}$ and $\mathrm{E}=2380 \pm 275 \mathrm{MPa}$ ) (Table 6.2). In contrast, the toughness improved for $\mathrm{CH}$-dyed $(\mathrm{pH})$ fibre, but decreased for GG-dyed $(\mathrm{pH})$ fibre compared to those prepared without $\mathrm{pH}$ modification.

\subsubsection{Dyed and pH adjusted polyelectrolyte complex-coated fibre}

The mechanical properties of dyed and $\mathrm{pH}$ adjusted polyelectrolyte complex (PEC)coated fibres are summarised in Table 6.2. $\mathrm{CH}^{\text {into }}$ GG PEC-coated fibres exhibited an increase in TS values, but no significant change in $\mathrm{E}, \mathrm{T}$ and $\gamma$ values compared to single-coated $\mathrm{CH}$-dyed fibres. Modification of the $\mathrm{pH}$ of $\mathrm{CH}^{\text {into }} \mathrm{GG}$ PEC-coated fibre; i.e. fibre and/or solution ( $\mathrm{CH}^{\text {into }} \mathrm{GG}(\mathrm{pH}), \mathrm{CH}(\mathrm{pH}){ }^{\text {into }} \mathrm{GG}$, and $\mathrm{CH}(\mathrm{pH}){ }^{\text {into }} \mathrm{GG}(\mathrm{pH})$ ) resulted no mechanical reinforcement compared to single-coated $\mathrm{CH}$-dyed and $\mathrm{CH}-$ dyed $(\mathrm{pH})$ fibres. Those PEC-coated fibres (pH-modified) showed that the mechanical 
characteristics are comparable to single-coated GG-dyed or GG-dyed (pH) fibres (Table 6.2). For example, the TS, E, T and $\gamma$ values of $\mathrm{CH}^{\text {into }} \mathrm{GG}(\mathrm{pH})$ PEC-coated fibre were $43 \pm 3 \mathrm{MPa}, 1065 \pm 111 \mathrm{MPa}, 17 \pm 0.6 \mathrm{~J} \mathrm{~g}^{-1}$ and $57 \pm 2 \%$, respectively. In comparison, the TS, E, T and $\gamma$ values of single-coated GG-dyed (pH) fibre were 42 $\pm 4 \mathrm{MPa}, 814 \pm 150 \mathrm{MPa}, 23 \pm 2 \mathrm{~J} \mathrm{~g}^{-1}$ and $63 \pm 3 \%$. The same observations were made for the $\mathrm{CH}(\mathrm{pH}){ }^{\mathrm{into}} \mathrm{GG}$ and $\mathrm{CH}(\mathrm{pH}){ }^{\text {into }} \mathrm{GG}(\mathrm{pH})$ PEC-coated fibres (Table 6.2). These fibres exhibit mechanical characteristics comparable to those of single-coated GG-dyed and GG-dyed (pH) fibres, respectively.

These observations are supported by changes in color of the $\mathrm{CH}^{\text {into }} \mathrm{GG}$, $\mathrm{CH}^{\text {into }} \mathrm{GG}(\mathrm{pH}), \mathrm{CH}(\mathrm{pH}){ }^{\text {into }} \mathrm{GG}$, and $\mathrm{CH}(\mathrm{pH}){ }^{\mathrm{into}} \mathrm{GG}(\mathrm{pH})$. For example, Figure 6.3 showed the colour changed in $\mathrm{CH}(\mathrm{pH}){ }^{\mathrm{into}} \mathrm{GG}(\mathrm{pH})$. Initially, CH-dyed (pH) and GGdyed $(\mathrm{pH})$ (both fibres and solutions) are blue and yellow colors, respectively. By dipping $\mathrm{CH}$-dyed $(\mathrm{pH})$ fibres into GG-dyed $(\mathrm{pH})$ solution, the color of this PECcoated fibre altered to green after 0.5, 1 and 5 min of immersion (Figure 6.3 A). The green colour partially changed to yellow after $10 \mathrm{~min}$ of immersion and completely changed to yellow after 20 min immersion (Figure 6.3 A). These colour changes were also followed using Kubelka-munk analysis as detailed in experimental (chapter 2) ${ }^{384}$. The results showed that the K/S values of red are smaller than the green values after $0.5,1$ and 5 min of immersion, which is reflected in the change to green colour of pH-modified PEC-coated fibre (Figure 6.3 B). 

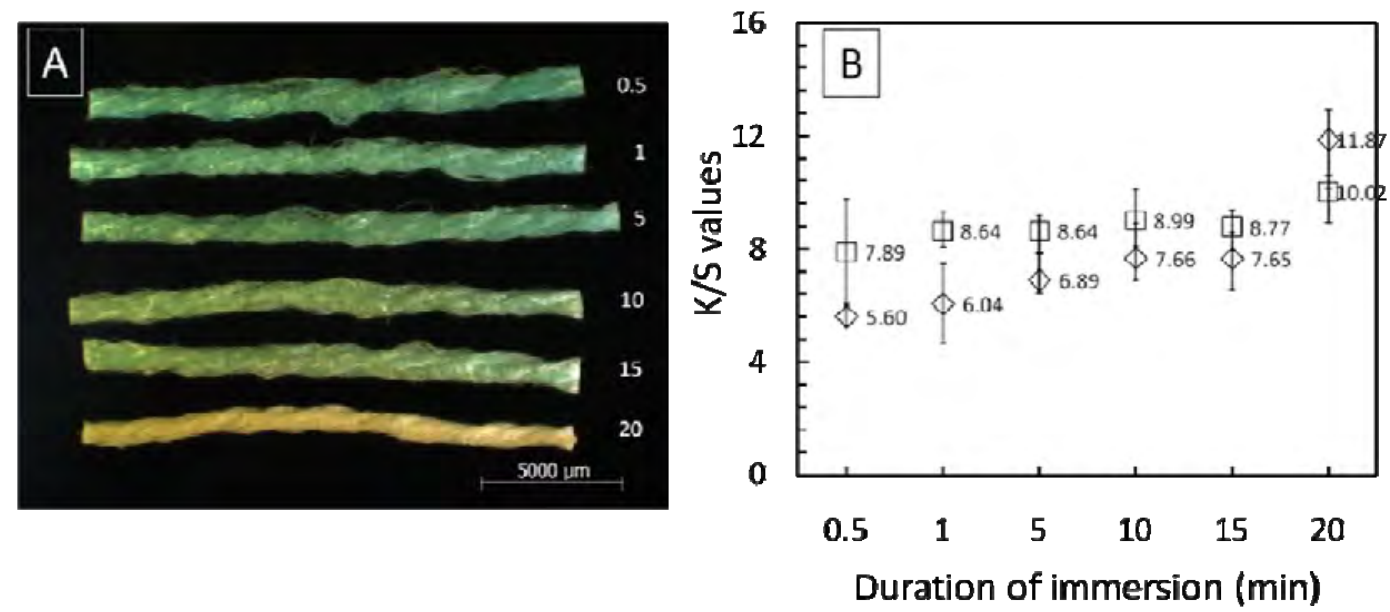

Figure 6.3: (A) Colour transformation of $\mathrm{CH}(\mathrm{pH}){ }^{\mathrm{into}} \mathrm{GG}(\mathrm{pH})$ PEC-coated fibre at $0.5,1,5,10$, 15 and 20 min of immersions and (B) K/S values of red $(\diamond)$ and green ( $\square$ ) channels as a function of duration of immersions.

In contrast, $G \mathrm{GG}^{\mathrm{into}} \mathrm{CH}$ PEC-coated fibre showed significant improvements in TS and E values compared to GG-dyed fibre (Table 6.2). $\mathrm{pH}$ modification of $\mathrm{GG}^{\text {into }} \mathrm{CH}$ (fibres and solutions) resulted in mechanical reinforcement of $\mathrm{GG}^{\text {into }} \mathrm{CH}(\mathrm{pH}), \mathrm{GG}(\mathrm{pH}){ }^{\mathrm{into}} \mathrm{CH}$ and $\mathrm{GG}(\mathrm{pH}){ }^{\text {into }} \mathrm{CH}(\mathrm{pH})$ PEC-coated fibres compared to single-coated GG-dyed or GG-dyed (pH) fibres (Table 6.2). For example, the $\mathrm{GG}(\mathrm{pH}){ }^{\mathrm{into}} \mathrm{CH}$ PEC-coated fibre exhibited the following characteristics, TS=63 \pm 1 MPa, E=918 \pm MPa, $\mathrm{T}=28 \pm 0.1 \mathrm{~J} \mathrm{~g}^{-1}$ and $\gamma=70 \pm 5 \%$. For comparison, the TS, E, T and $\gamma$ values of single-coated GG-dyed $(\mathrm{pH})$ fibres were $42 \pm 4 \mathrm{MPa}, 814 \pm 150$ MPa, $23 \pm 2 \mathrm{~J} \mathrm{~g}^{-1}$ and $63 \pm 1 \%$, respectively. The same mechanical trends were observed for $\mathrm{GG}^{\text {into }} \mathrm{CH}(\mathrm{pH})$ and $\mathrm{GG}(\mathrm{pH}){ }^{\text {into }} \mathrm{CH}(\mathrm{pH})$ PEC-coated fibres compared to GG-dyed and GG-dyed (pH) fibres (Table 6.2). For colour changes, this order of addition resulted in PEC-coated fibres with a cross-section showing a green colour covering the outer layer and a yellow colour in the core of these fibres (Figure 6.4). 

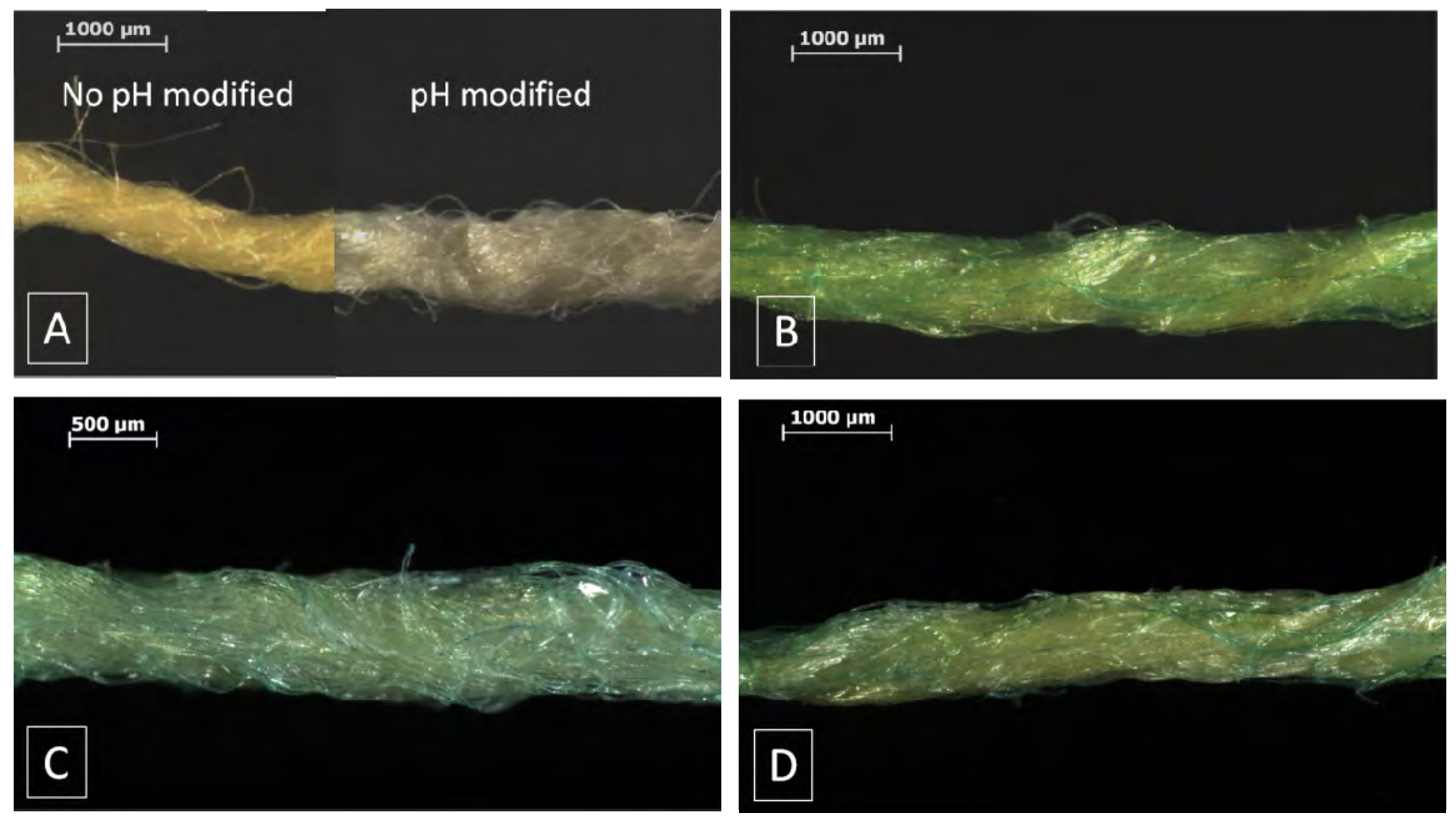

Figure 6.4: (A) Single-coated fibres GG-dyed fibres before and after $\mathrm{pH}$ modification, (B-D) PEC-coated fibres; (B) $\mathrm{GG}^{\text {into }} \mathrm{CH},(\mathrm{C}) \mathrm{GG}{ }^{\text {into }} \mathrm{CH}(\mathrm{pH})$ and (D) $\mathrm{GG}(\mathrm{pH}){ }^{\text {into }} \mathrm{CH}(\mathrm{pH})$. Those PECcoated fibres are covered with a green colour on the outer layer and yellow colour at core of each fibre.

Why the mechanical characteristics as well as colour of PEC-coated wool changed by reversing the order of addition, for example in $\mathrm{CH}(\mathrm{pH}){ }^{\mathrm{into}} \mathrm{GG}(\mathrm{pH})$ and $\mathrm{GG}(\mathrm{pH}){ }^{\mathrm{into}} \mathrm{CH}(\mathrm{pH})$. As explained in chapter 5 (polyelectrolyte complex-films), there are a number of differences between $\mathrm{CH}$ and GG materials which influenced those properties as followed. (1) $\mathrm{CH}$ has an intrinsic $\mathrm{pK}=6.5^{385}$ and GG has an intrinsic $\mathrm{pK}=3.5^{386}$ over a wide range of solution $\mathrm{pH}$; (2) The $\mathrm{pH}$ of $\mathrm{CH}$-dyed fibre are always near neutral, regardless of the $\mathrm{pH}$ of $\mathrm{CH}$-dyed solution used to immerse the fibres. For example, $\mathrm{CH}$-dyed solutions of $\mathrm{pH}=1.76 \pm 0.04$ and $\mathrm{pH}=5.54 \pm 0.04$ resulted in $\mathrm{CH}-$ dyed fibres with the $\mathrm{pH}$ values of $6.8 \pm 0.05$ and $7.3 \pm 0.05$, respectively. GG-dyed solutions of $\mathrm{pH}=5.57 \pm 0.04$ and $12.15 \pm 0.12$ resulted in GG-dyed fibres with $\mathrm{pH}$ values of $5.91 \pm 0.09$ and $8.95 \pm 0.13$, respectively; and (3) Chain stiffness or the persistence length of $\mathrm{CH}(\mathrm{DD}=93 \%)$ is $81 \mathrm{~nm}$ at $25^{\circ} \mathrm{C}^{372}$, whereas $\mathrm{GG}$ is $9.4 \mathrm{~nm}$ at $40{ }^{\circ} \mathrm{C}^{371}$. From the difference in $\mathrm{pH}$ of $\mathrm{CH}$-dyed fibre and GG-dyed solution as well 
as persistence length of $\mathrm{CH}$ and GG, it is likely that the mechanical characteristics of $\mathrm{CH}^{\text {into }} \mathrm{GG}(\mathrm{pH}), \quad \mathrm{CH}(\mathrm{pH}){ }^{\text {into }} \mathrm{GG}$, and $\quad \mathrm{CH}(\mathrm{pH}){ }^{\text {into }} \mathrm{GG}(\mathrm{pH}) \quad$ PEC-coated fibres are governed by diffusion of GG-dyed solution into $\mathrm{CH}$-dyed fibre. This argument is in agreement with colour changes observed, for example in $\mathrm{CH}(\mathrm{pH}){ }^{\mathrm{into}} \mathrm{GG}(\mathrm{pH})$ PECcoated fibres as shown in Figure 6.3 A. For this PEC-coated fibre, GG-dyed (pH) solutions are expected to have high degree of dissociation of $\mathrm{COO}^{-221}(\mathrm{pH}=12.15 \pm$ 0.12). Unlike GG-dyed ( $\mathrm{pH})$ solution, $\mathrm{CH}$-dyed $(\mathrm{pH})$ fibres are expected to have low degree of dissociation of $\mathrm{NH}_{3}{ }^{+387}(\mathrm{pH}=6.8 \pm 0.05)$. During short immersion times (0.5, 1 and $5 \mathrm{~min})$, the $\mathrm{COO}^{-}$groups of the GG-dyed $(\mathrm{pH})$ solutions are expected to interact with $\mathrm{NH}_{3}{ }^{+}$from $\mathrm{CH}$-dyed (pH) fibre, and change to green colour (Figure 6.3 A). But, after a long immersion time (20 min), the charge density of $\mathrm{CH}$-dyed $(\mathrm{pH})$ fibre in GG-dyed $(\mathrm{pH})$ solution is expected to reduce, which leaves the $\mathrm{COO}^{-}$from GG-dyed $(\mathrm{pH})$ solution is only in $\mathrm{CH}$-dyed $(\mathrm{pH})$ fibre. As a result, this interaction altered the colour of $\mathrm{CH}(\mathrm{pH}){ }^{\mathrm{into}} \mathrm{GG}(\mathrm{pH})$ PEC-coated fibre from green to yellow colour (Figure 6.3 A).

In contrast, $\mathrm{CH}$ is unable to penetrate into $\mathrm{GG}$ in $\mathrm{GG}^{\text {into }} \mathrm{CH}, \mathrm{GG}{ }^{\text {into }} \mathrm{CH}(\mathrm{pH})$ and $\mathrm{GG}(\mathrm{pH}){ }^{\mathrm{into}} \mathrm{CH}(\mathrm{pH})$ PEC-coated fibres as shown in Figure 6.4. This could be due to higher persistence length of $\mathrm{CH}\left(81 \mathrm{~nm}\right.$ at $\left.25{ }^{\circ} \mathrm{C}\right){ }^{372}$ compared GG $\left(9.4 \mathrm{~nm}\right.$ at $\left.40{ }^{\circ} \mathrm{C}\right)$ 371. However, the electrostatic interaction is expected to occur between $\mathrm{CH}$-dyed solution (cationic) and GG-dyed fibre (anionic). This interaction reinforced those PEC-coated fibres which resulting in improved mechanical characteristics (Table 6.2). The electrostatic interaction is also in agreement with the observed colour change of those PEC-coated fibres to green colour in the outer layer of fibre, but maintained the yellow colour in the core of PEC-coated fibres (Figure 6.4). 


\subsection{Conclusion}

In this chapter, single-coated and PEC-coated fibres using $\mathrm{CH}$ and $\mathrm{GG}$ were successfully developed. Pristine wool fibre immersed in $\mathrm{CH}$ and GG solutions showed optimum TS, E, T and $\gamma$ values after immersion for $20 \mathrm{~min}$ and $5 \mathrm{~min}$, respectively. CH-dyed and GG-dyed fibres showed that the mechanical characteristics were improved compared to without dye modification. In contrast, $\mathrm{pH}$ modified of CH-dyed and GG-dyed fibres decreased the mechanical characteristics. PEC-coated fibres were prepared by dipping $\mathrm{CH}$-dyed fibres into GG-dyed solution ( $\mathrm{CH}^{\text {into }} \mathrm{GG}$ ) and GG-dyed fibre into $\mathrm{CH}$-dyed solution $\left(\mathrm{GG}^{\text {into }} \mathrm{CH}\right)$. The order of addition was found to affect the mechanical characteristics of PEC-coated fibres; i.e. $\mathrm{CH}^{\text {into }} \mathrm{GG}$ showed no mechanical reinforcement. In contrast $\mathrm{GG}^{\mathrm{into}} \mathrm{CH}$ showed mechanical reinforcements compared to single-coated CH-dyed and GG-dyed fibres, respectively. $\mathrm{pH}$ modification of these PEC-coated fibres showed similar mechanical behaviour. It is suggested that the difference in observed mechanical characteristics is due to the ability of GG-dyed solution to diffuse into $\mathrm{CH}$-dyed fibre. This behaviour governed the mechanical characteristics of $\mathrm{CH}$-dyed fibre, which is also evident from colour changes of this PEC-coated fibre. In contrast, $\mathrm{CH}$-dyed solution was unable to diffuse into GG-dyed fibre. Electrostatic interaction was expected to occur on the outer layer of GG-dyed fibre (anionic) with $\mathrm{CH}$-dyed solution (cationic) which resulted in improvement of mechanical characteristics. This is in agreement with a green colour observed on the outer layer of this PEC-coated fibre and a yellow colour in the core of the fibre. 


\section{CHAPTER 7}

\section{POLYELECTROLYTE COMPLEX FILMS CONSISTING OF ANTI-BACTERIAL AND CELL SUPPORTING LAYERS}

This chapter discusses polyelectrolyte complex films (hereafter referred to as dual layer films) for wound dressing applications. The upper layer was designed to act as a bacterial resistance layer and the bottom layer to promote cell viability and proliferation. In chapters 3 and 4, the quantitative and qualitative of antibacterial properties of $\mathrm{CH}$ and GG-composites against Escherichia coli (E. Coli) showed that, both of those composites exhibit low antibacterial resistance. Therefore, in this chapter, levofloxacin, an antibiotic was incorporated into $\mathrm{CH}$ films (CH-Lev) to improve the biopolymer's antibacterial properties. GG-composites incorporated with titanium dioxide $\left(\mathrm{GG}-\mathrm{TiO}_{2}\right)$ exhibit optimum cell viability and proliferation on mouse fibroblast cells (L929) (chapter 4), and thus these were used as bottom layer. The dual layer films were prepared by pouring a CH-Lev solution onto the surface of a GG$\mathrm{TiO}_{2}$ composite film in a mould. The mechanical characteristics, water vapour transmission rates (WVTR) and swelling of dual layer films and a commercial wound dressing (Cutifilm) were assessed. In addition, the cell viability and cell proliferation 
of dual layer films tested using L929 cells and antibacterial activity of CH-Lev against E. coli are discussed.

\subsection{Spectroscopy}

\subsubsection{UV-visible and circular dichroism}

CH-Lev films exhibited specific characteristic absorption bands of levofloxacin in the ultraviolet region at $227 \mathrm{~nm}$ and $298 \mathrm{~nm}$ (Figure $7.1 \mathrm{~A})^{279,388-390}$. The intensity of the CH-Lev films (at $298 \mathrm{~nm}$ ) increased with increasing amounts of levofloxacin (Figure 7.1 A). Dual layer films consisting of $\mathrm{CH}-\mathrm{Lev01}(0.4 \% \mathrm{w} / \mathrm{w}$ of levofloxacin in $\mathrm{CH}$ film) and GGTi20 layers exhibit none of the characteristic absorption bands of levofloxacin, i.e. at $227 \mathrm{~nm}$ and $298 \mathrm{~nm}$. It is likely that these bands are masked by the strong absorbance of GGTi20 composite in this wavelength region.
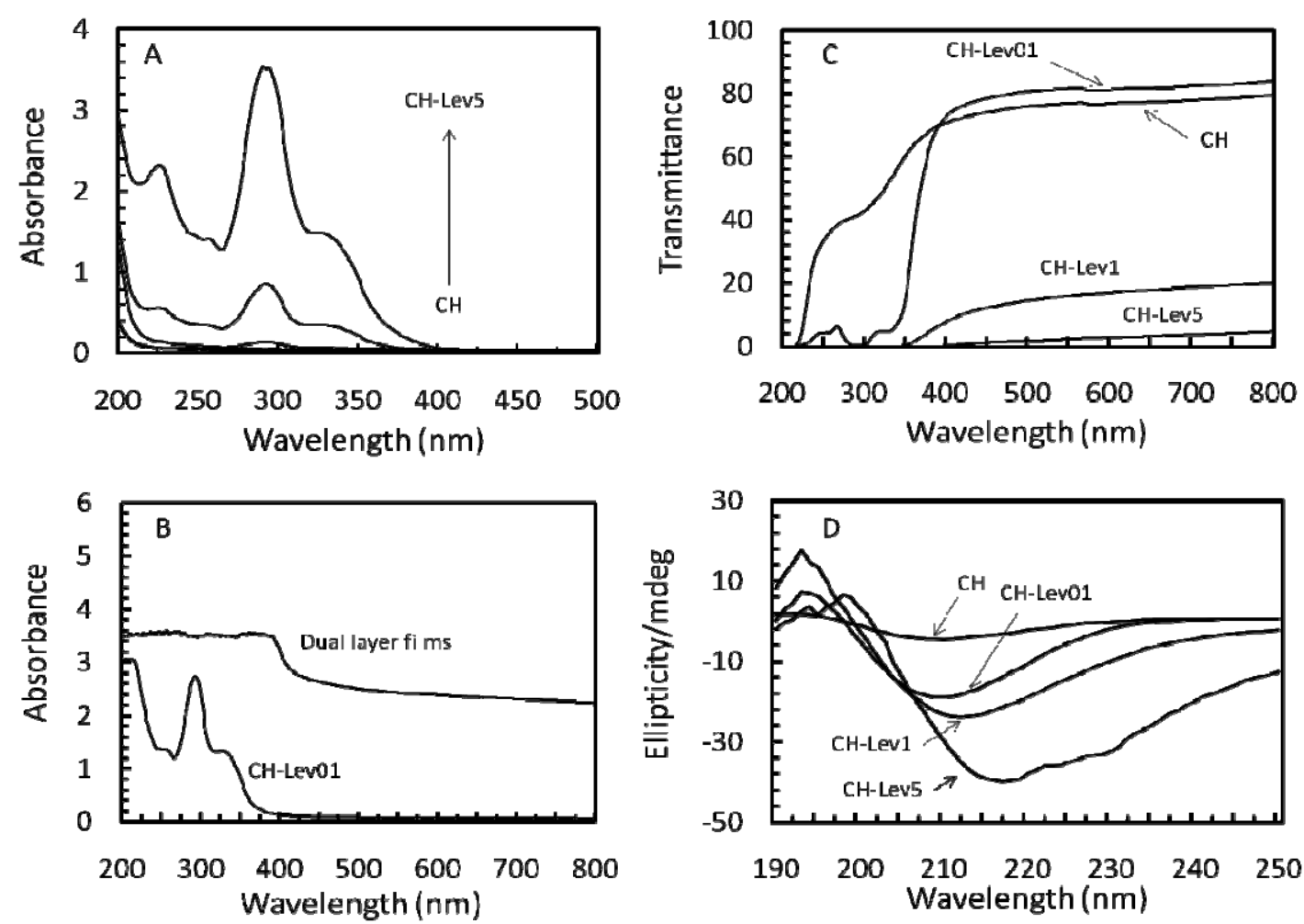

Figure 7.1: (A) UV-visible absorption of $\mathrm{CH}$, CH-Lev01, CH-Lev1 and $\mathrm{CH}-\mathrm{Lev} 5$ films, (B) UV-visible absorption of CH-Lev01 film and dual layer films (C) transmittance of the $\mathrm{CH}$, CH-Lev01, CH-Lev1, and CH-Lev5 films and (D) circular dichroism spectra of CH film with different amounts of levofloxacin. All measurements were carried out at $21^{\circ} \mathrm{C}$ using a $5 \mathrm{~mm}$ cuvette. 
The transmittance of $\mathrm{CH}$ and $\mathrm{CH}-\mathrm{Lev01}$ films in the visible wavelength range $(500-750 \mathrm{~nm}$ ) is $80 \%$ (Figure $7.1 \mathrm{C}$ and Figure $7.2 \mathrm{~A}$ ). The transmittance of films with higher levofloxacin concentrations decreases sharply, i.e. the values for $\mathrm{CH}$ Lev1 $(4.0 \% \mathrm{w} / \mathrm{w})$ and CH-Lev5 $(16.0 \% \mathrm{w} / \mathrm{w})$ films are $20 \%$ and 5\%, respectively (Figure $7.1 \mathrm{C}$ ).
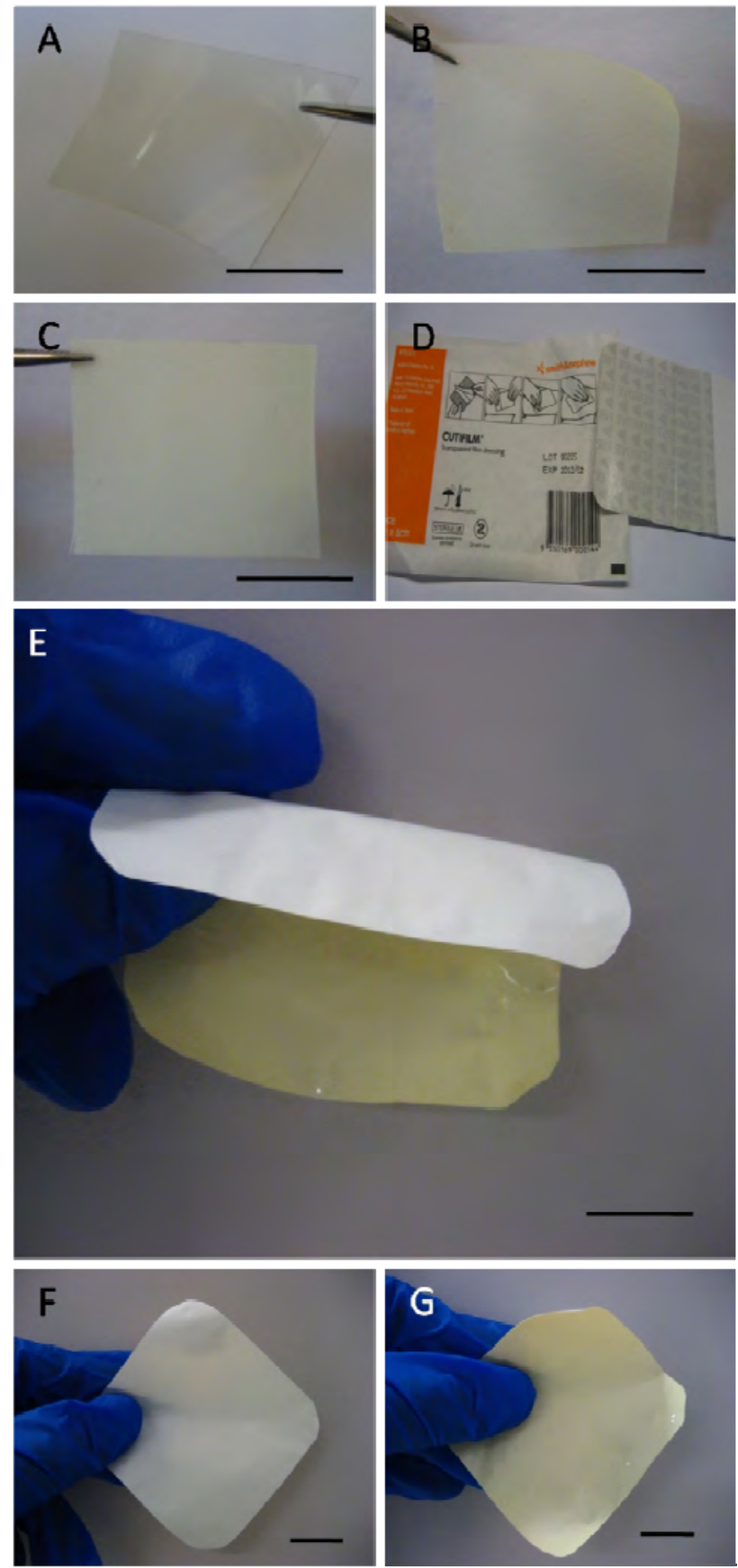

Figure 7.2: Photographs of films; (A) CH-Lev01, (B) CH-Lev1, (C) CH-Lev5, (D) Cutifilm ${ }^{\mathrm{TM}}$ and (E-G) dual layer films at different angles. The dual layer films were robust and flexible which could be easily folded and rolled-up without breaking. Scale bars represent $1 \mathrm{~cm}$. 
The effect of levofloxacin in $\mathrm{CH}$ films was measured by circular dichroism (CD) (Figure 7.1 D). Addition of levofloxacin to $\mathrm{CH}$ resulted in a shift of the $\mathrm{CD}$ band to a longer wavelength, i.e. from $\lambda=210 \mathrm{~nm}$ to $\lambda=218 \mathrm{~nm}$, as well as an increase in the molar ellipticity. For example, the molar ellipticity of $\mathrm{CH}$ films is at $\sim 5$ mdeg and increased to $\sim 40$ mdeg for CH-Lev5 film. The observed changes CD band shift and intensity increase could be due to ionic interactions $\left(\mathrm{NH}_{3}{ }^{+}-\mathrm{COO}^{-}\right)$and hydrogen bonding (H-OH) between $\mathrm{CH}$ and levofloxacin ${ }^{391,345,389}$.

\subsection{Mechanical properties and microscopy}

\subsubsection{Chitosan-levofloxacin films}

The mechanical properties of $\mathrm{CH}$ film; i.e. tensile strength (TS), Young's modulus (E), toughness $(\mathrm{T})$ and strain-at-break $(\gamma)$ values are $21 \pm 3 \mathrm{MPa}, 657 \pm 236 \mathrm{MPa}$, $5.32 \pm 0.11 \mathrm{~J} \mathrm{~g}^{-1}$, and $32 \pm 2 \%$, respectively. The addition of levofloxacin $(0.4 \% \mathrm{w} / \mathrm{w}$ in CH-Lev01 film) increased the TS and $\gamma$ compared to those observed for $\mathrm{CH}$ film

(Figure 7.3 A, 7.4, see also Table 7.1). However, addition of higher amounts of levofloxacin resulted in significant decreases in film toughness and ductility. For example, the $\mathrm{T}$ and $\gamma$ values of $\mathrm{CH}-\mathrm{Lev} 5$ films reduced by $67 \%$ and $60 \%$ compared to that of $\mathrm{CH}$ film, respectively. The decrease in mechanical characteristics (TS, E, T and $\gamma$ ) of the CH-Lev1 (4\% w/w) and CH-Lev5 (16\% w/w) films compared to the $\mathrm{CH}$ film may be attributed to disruption of $\mathrm{CH}$ intra-chain interactions as a result of intermolecular interactions between $\mathrm{CH}$ and levofloxacin (Table 7.1). 

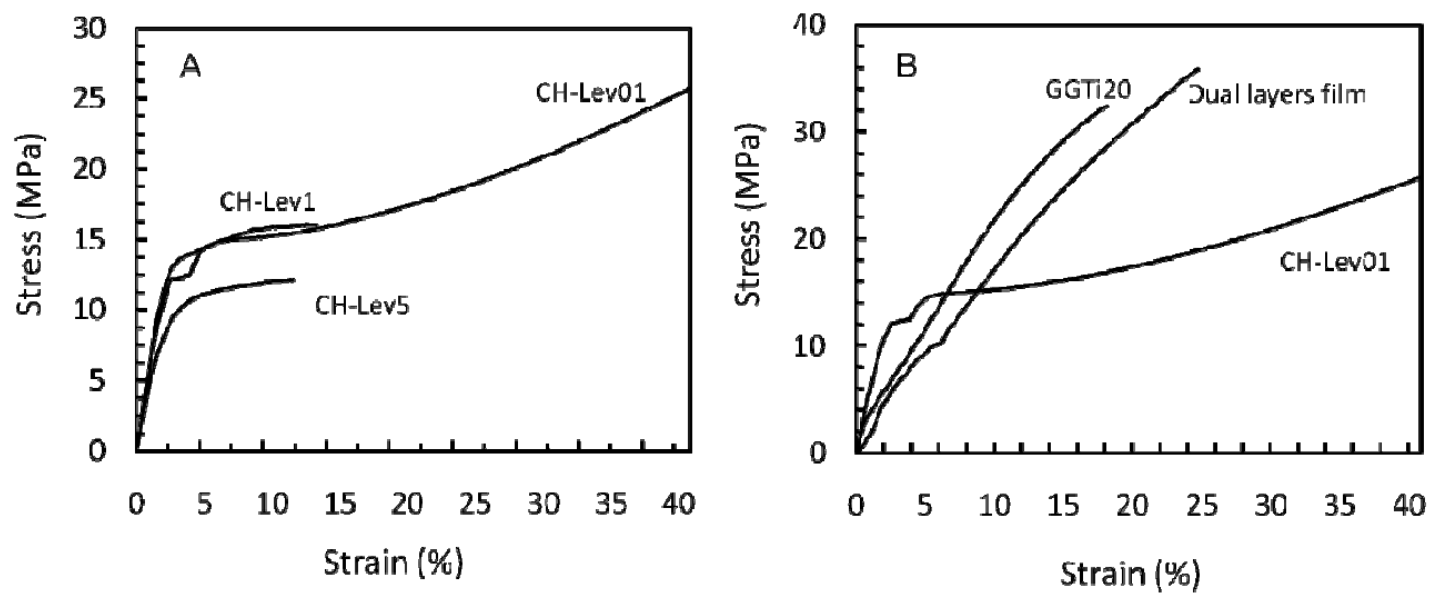

Figure 7.3: (A) Typical stress-strain curves of the CH-Lev01, CH-Lev1 and CH-Lev5 films, and (B) comparison stress-strain curves of the CH-Lev01 film, GGTi20 composite and dual layer films.
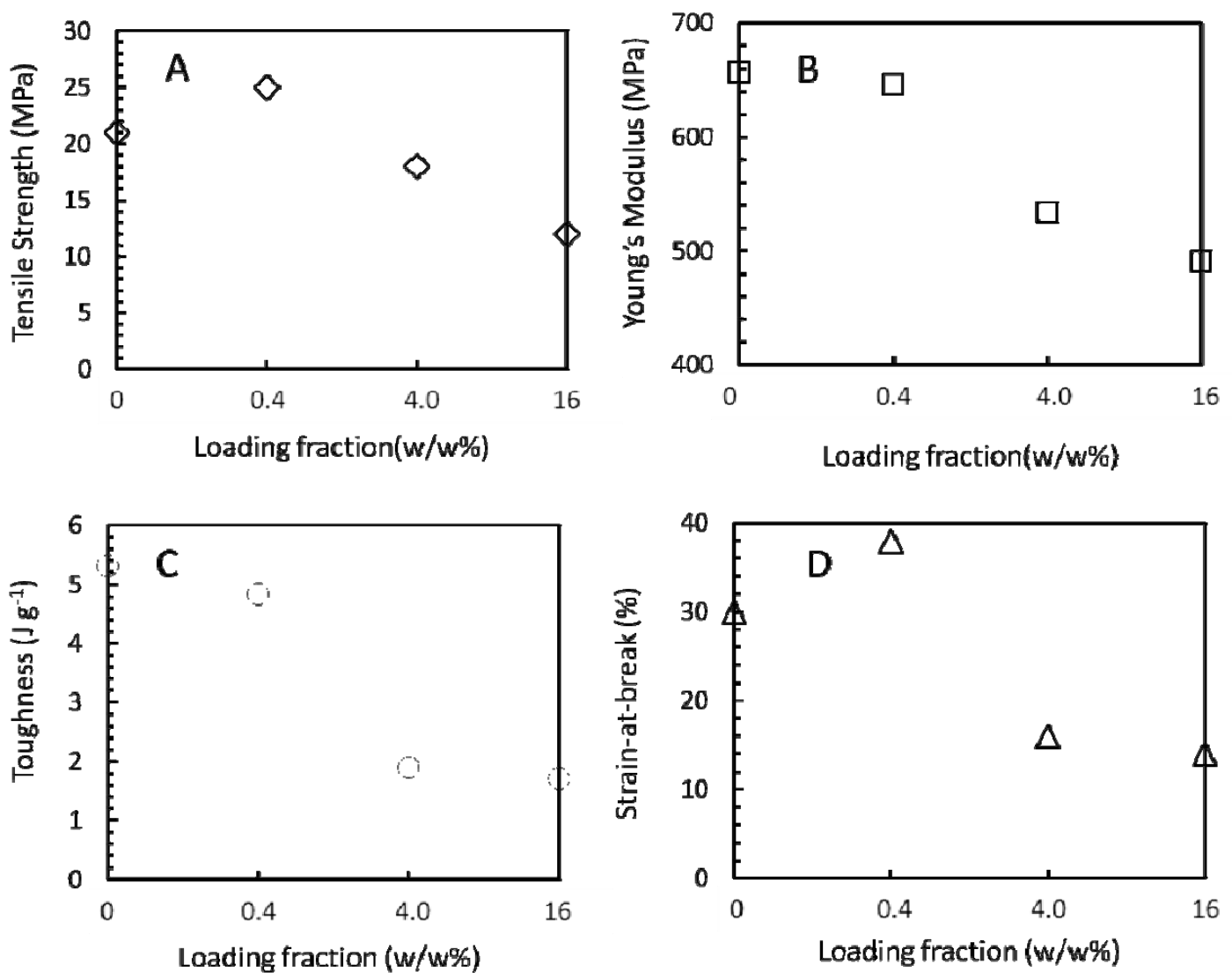

Figure 7.4: Representative of (A) tensile strength, (B) Young's modulus, (C) toughness and (D) strain-at-break of chitosan films as a function of levofloxacin contents (by weight relative to $\mathrm{CH}$ ). 
Table 7.1: Mechanical properties of CH film, CH-Lev01 film, CH-Lev1 film, CH-Lev5 film, GGTi20 composite, dual layer films and Cutifilm ${ }^{\mathrm{TM}}$. Thickness (Thick), tensile strength (TS), Young's modulus (E), toughness $(\mathrm{T})$ and strain-at-break $(\gamma)$ for the different materials are given.

\begin{tabular}{|c|c|c|c|c|c|c|}
\hline Film & $\begin{array}{l}\text { Levofloxacin } \\
\text { (w/w,\%) }\end{array}$ & $\begin{array}{l}\text { Thick } \\
(\mu \mathrm{m})\end{array}$ & $\begin{array}{c}\mathrm{TS} \\
(\mathrm{MPa})\end{array}$ & $\begin{array}{c}\mathrm{E} \\
(\mathrm{MPa})\end{array}$ & $\begin{array}{c}\mathrm{T} \\
\left(\mathrm{J} \mathrm{g}^{-1}\right)\end{array}$ & $\begin{array}{l}\gamma \\
(\%)\end{array}$ \\
\hline $\mathrm{CH}$ & - & $96 \pm 15$ & $21 \pm 3$ & $657 \pm 236$ & $5.32 \pm 0.11$ & $32 \pm 2$ \\
\hline CH-Lev01 & 0.4 & $115 \pm 7$ & $25 \pm 2$ & $646 \pm 143$ & $4.84 \pm 0.19$ & $38 \pm 2$ \\
\hline CH-Lev1 & 4.0 & $99 \pm 10$ & $18 \pm 3$ & $534 \pm 252$ & $1.90 \pm 0.11$ & $16 \pm 4$ \\
\hline CH-Lev5 & 16.0 & $103 \pm 10$ & $12 \pm 2$ & $491 \pm 92$ & $1.71 \pm 0.19$ & $14 \pm 3$ \\
\hline GGTi20 & - & $63 \pm 9$ & $28 \pm 3$ & $237 \pm 14$ & $1.29 \pm 0.4$ & $18 \pm 1$ \\
\hline Dual layer & - & $144 \pm 2$ & $35 \pm 1$ & $228 \pm 25$ & $3.61 \pm 0.3$ & $24 \pm 1$ \\
\hline Cutifilm $^{\mathrm{TM}}$ & - & $60 \pm 4$ & $6.5 \pm 2$ & $132 \pm 19$ & $40.0 \pm 1.0$ & $400 \pm 30$ \\
\hline
\end{tabular}

\subsubsection{Dual layer films}

The mechanical robustness and flexibility of films is crucial in wound dressing applications. CH-Lev01 and GGTi20 composites were selected to form dual layer films as they offer the best combination of mechanical characteristics (Figure 7.3 B and Table 7.1). The dual layer films were mechanically robust and could be easily folded and rolled-up without breaking (Figure 7.2).

Table 7.1 shows that there is a synergistic effect between the layers as the mechanical characteristics are different from the values of the individual layers. For example, the TS value of the dual layer films is more than $20 \%$ higher compared to that of the individual CH-Lev01 and GGTi20 composite. In addition, the T and $\gamma$ values of the dual layer films are in between the values of the individual layers. In 
comparison, a commercial dressing, Cutifilm ${ }^{\mathrm{TM}}$ showed low tensile strength $(6.5 \pm 2$ MPa) and Young's modulus (132 $\pm 19 \%$ ), but extreme strain-at-break at $400 \pm 30 \%$, which may be a result of the reinforcement effect of adhesive (use to stick the dressing to the wound) in the film (Table 7.1).

The cross sections of the dual layer films are shown in Figure 7.5. No layer separation between the CH-Lev01 and GGTi20 composite could be observed indicating perfect formation of the dual layer films. Aggregates of $\mathrm{TiO}_{2}$ nanoparticles ( 100 nm) throughout the GG matrix were clearly observed (Figure 7.5 C and D).
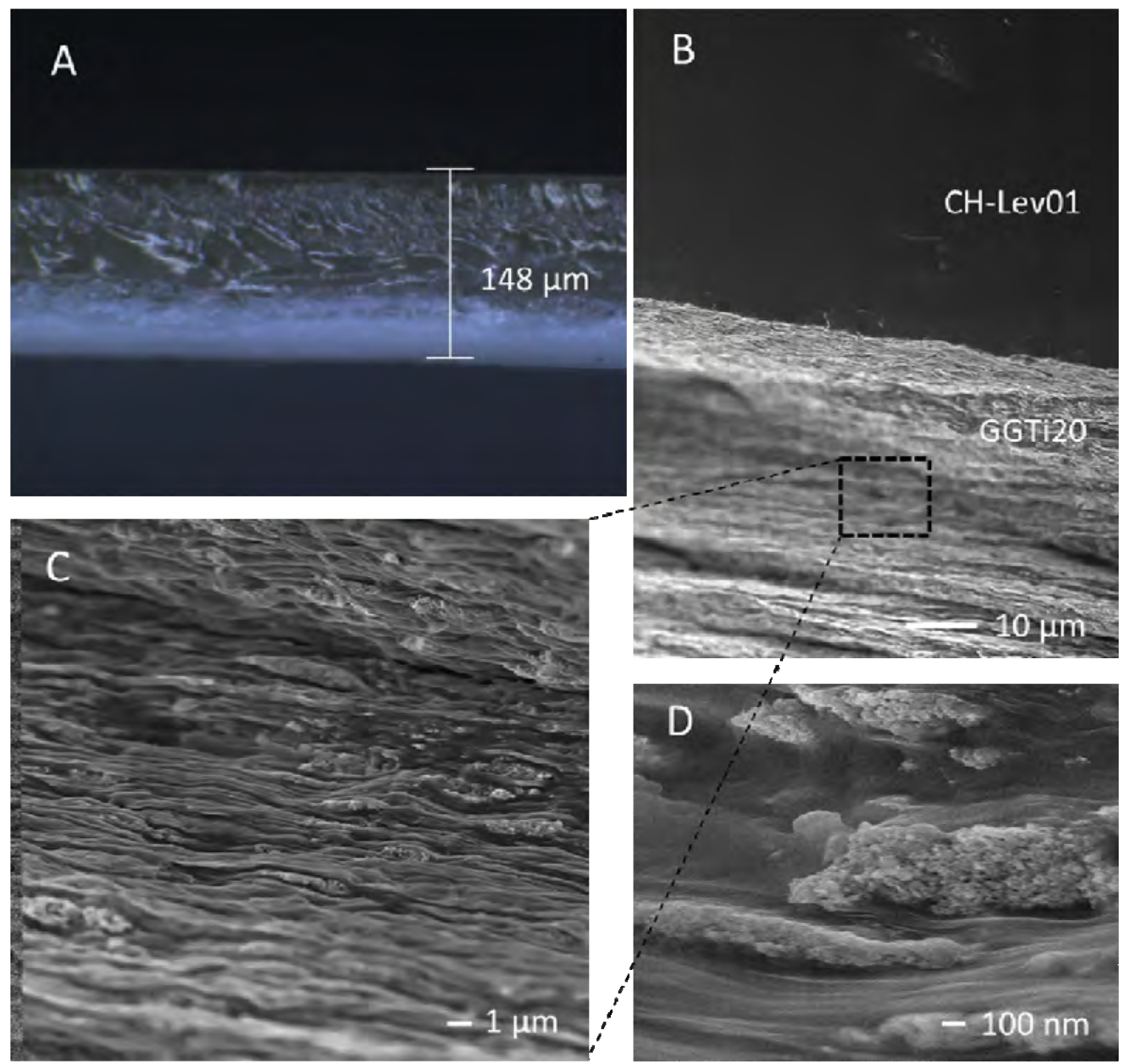

Figure 7.5: (A) Optical imaging of cross-section of dual layer films (upper layer is CH-Lev01, bottom layer is GGTi20 composite), (B) field emission-SEM (FE-SEM) imaging of a freezefractured dual layer films, (C) enlargement of finely dispersed titanium dioxide $\left(\mathrm{TiO}_{2}\right)$ nanoparticles throughout the GG matrix and (D) aggregation of $\mathrm{TiO}_{2}$ nanoparticles in the GG matrix. 


\subsection{Swelling}

The swelling of a wound dressing reflects its capability to absorb body fluid (exudates) ${ }^{392}$. GGTi20 composites are able to absorb more water than CH-Lev01 films in buffer solution at $\mathrm{pH} 7$, i.e. $490 \pm 24 \%$ compared to $73 \pm 1 \%$, respectively (Table 7.2). It has been suggested that gellan gum can absorb more water compared to chitosan due to a higher number of the hydroxyl groups ${ }^{374}$. Furthermore, the presence of $20 \%$ (by weight relative to GG) $\mathrm{TiO}_{2}$ nanoparticles leads to a less tight packing of GG chains, which promotes swelling. Combining these films into a dual layer films results a similar swelling behaviour in buffer solution at $\mathrm{pH} 7(430 \pm 89 \%)$. As a comparison to dual layer films, Cutifilm ${ }^{\mathrm{TM}}$, which is designed as waterproof dressing showed a small amount of swelling in buffer solution at pH 7 (10 $\pm 4 \%)$.

Table 7.2: Properties of films. Thickness (Thick), water vapours transmission rates (WVTR), water vapour permeability (WVP), permeance (P) and swelling for the different materials are given.

\begin{tabular}{|c|c|c|c|c|c|c|c|}
\hline \multirow[t]{3}{*}{ Samples } & \multirow{3}{*}{$\begin{array}{l}\text { Thick } \\
(\mu \mathrm{m})\end{array}$} & WVTR & WVP & $\mathrm{P}$ & \multicolumn{3}{|c|}{ Swelling (\%) } \\
\hline & & \multirow[t]{2}{*}{$\left(\mathrm{g} \mathrm{m}^{-2} \mathrm{~d}^{-1}\right)$} & $10^{-14} \times(\mathrm{kg}$ & $10^{-10} \times(\mathrm{kg}$ & $\mathrm{pH} 1$ & $\mathrm{pH} 7$ & pH 12 \\
\hline & & & $\left.\mathrm{Pa}^{-1} \mathrm{~m}^{-1} \mathrm{~s}^{-1}\right)$ & $\left.\mathrm{Pa}^{-1} \mathrm{~m}^{-2} \mathrm{~s}^{-1}\right)$ & & & \\
\hline Blank & - & 3685 & - & - & - & - & - \\
\hline CH-Lev01 & $105 \pm 7$ & 866 & 9.0 & 8.6 & $108 \pm 1$ & $73 \pm 1$ & $96 \pm 2$ \\
\hline GGTi20 & $63 \pm 9$ & 1042 & 7.0 & 10.3 & $78 \pm 0.1$ & $490 \pm 24$ & a) \\
\hline Double layer & $148 \pm 8$ & 853 & 12.4 & 8.4 & $91 \pm 2$ & $430 \pm 89$ & b) \\
\hline \multicolumn{8}{|l|}{ films } \\
\hline CutifilmT & $60 \pm 4$ & 197 & 1.17 & 1.95 & $5 \pm 2$ & $10 \pm 4$ & $3 \pm 3$ \\
\hline
\end{tabular}

a) film dissolved; ${ }^{\text {b) }}$ film split to separate layers 


\subsection{Water vapour transmission rates (WVTR)}

The water vapour transmission rates (WVTR) of GGTi20 composites are higher compared to that of CH-Lev01 films, i.e. $1042 \mathrm{~g} \mathrm{~m}^{-2} \mathrm{~d}^{-1}$ compared to $866 \mathrm{~g} \mathrm{~m}^{-2} \mathrm{~d}^{-1}$, respectively (Table 7.2). Combining these films into a dual layer films results in a WVTR value of $853 \mathrm{~g} \mathrm{~m}^{-2} \mathrm{~d}^{-1}$ which is within the recommend range (500-2000 $\mathrm{g} \mathrm{m}^{-2}$ $\mathrm{d}^{-1}$ ) for wound dressings ${ }^{37}$. The WVTR value of the dual layer films is comparable to reported WVTR values for commercial wound dressing such as, for example Cutifilm $^{\mathrm{TM}}\left(197 \mathrm{~g} \mathrm{~m}^{-2} \mathrm{~d}^{-1}\right)$, Tegaderm $\left(491 \pm 44 \mathrm{~g} \mathrm{~m}^{-2} \mathrm{~d}^{-1}\right){ }^{37}$, Bioclusive (382 $\pm 26 \mathrm{~g} \mathrm{~m}^{-}$ $\left.{ }^{2} \mathrm{~d}^{-1}\right)^{37}$, Duoderm $\left(886 \pm 60 \mathrm{~g} \mathrm{~m}^{-2} \mathrm{~d}^{-1}\right)^{373}$ and Instrasite $\left(354 \pm 42 \mathrm{~g} \mathrm{~m}^{-2} \mathrm{~d}^{-1}\right)^{373}$.

\subsection{Cell studies}

\subsubsection{Cell viability and proliferation}

The effect of levofloxacin in $\mathrm{CH}$ films $(0.4 \% \mathrm{w} / \mathrm{w}$ relative to $\mathrm{CH})$ on $\mathrm{L} 929$ cells behaviour was investigated by morphological evaluation at time intervals of $24 \mathrm{~h}, 72 \mathrm{~h}$ and 144h, as shown in Figure 7.6. The L929 cells were viable on the surface of $\mathrm{CH}$ Lev01 films. The increase in cell density between $24 \mathrm{~h}$ and $144 \mathrm{~h}$ indicates that $\mathrm{CH}-$ Lev01 films supported cell growth, and are therefore unlikely to be cytotoxic. These results are in agreement with previous studies showing that levofloxacin had a relatively mild detrimental effect on cells ${ }^{289,290}$.

The cell viability of cells on dual layer films was also investigated. Due to the non-transparency of GGTi20 composite (chapter 4), the films were stained with calcein-AM to confirm cell viability. Fluorescent microscopy images showed that $72 \mathrm{~h}$ after cell seeding bright green fluorescent L929 cells were clearly visible on both sides of dual layer films, i.e. on the surface of the CH-Lev01 and GGTi20 layers (Figure 7.7). 

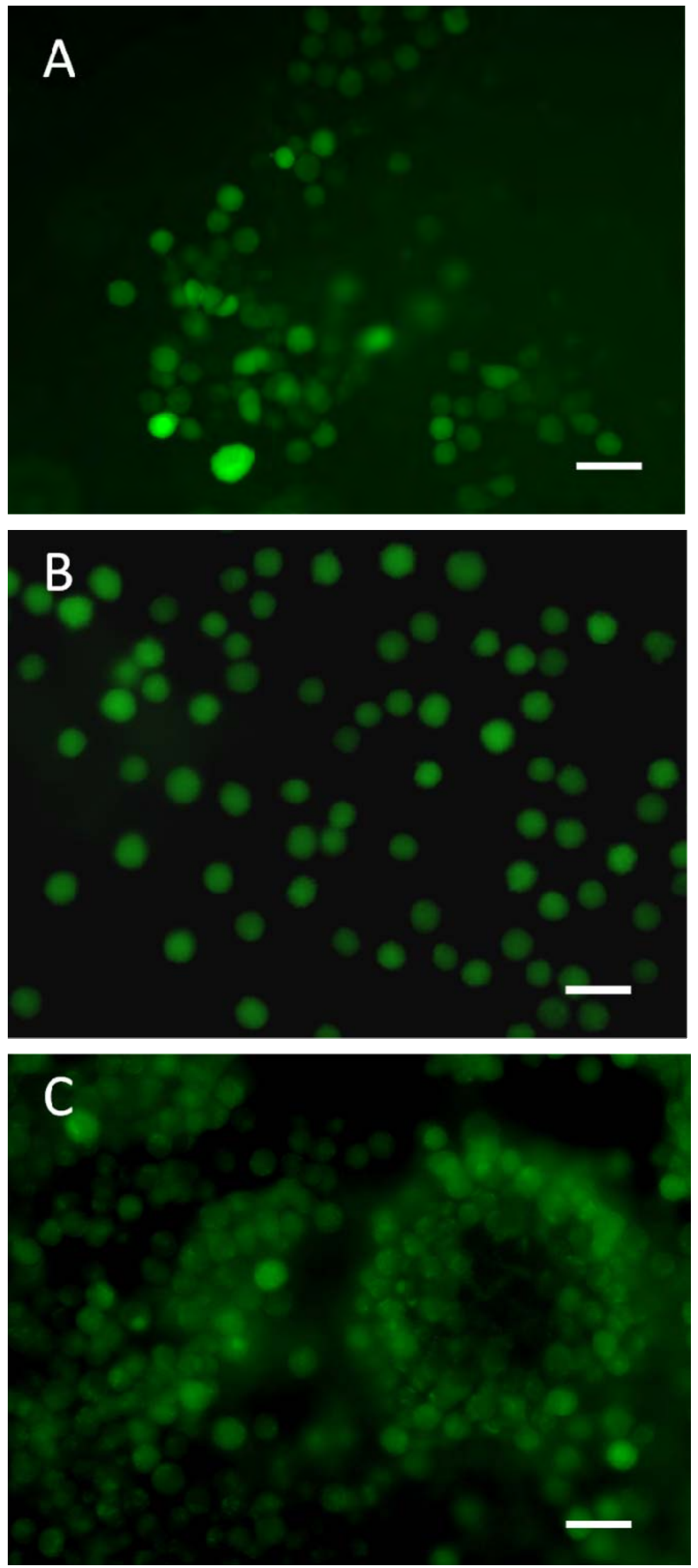

Figure 7.6: Fluorescence microscope images of L929 cells on the CH-Lev01 film after (A) 24h, (B) $72 \mathrm{~h}$ and (C) $144 \mathrm{~h}$. Scale bars indicate $20 \mu \mathrm{m}$. 

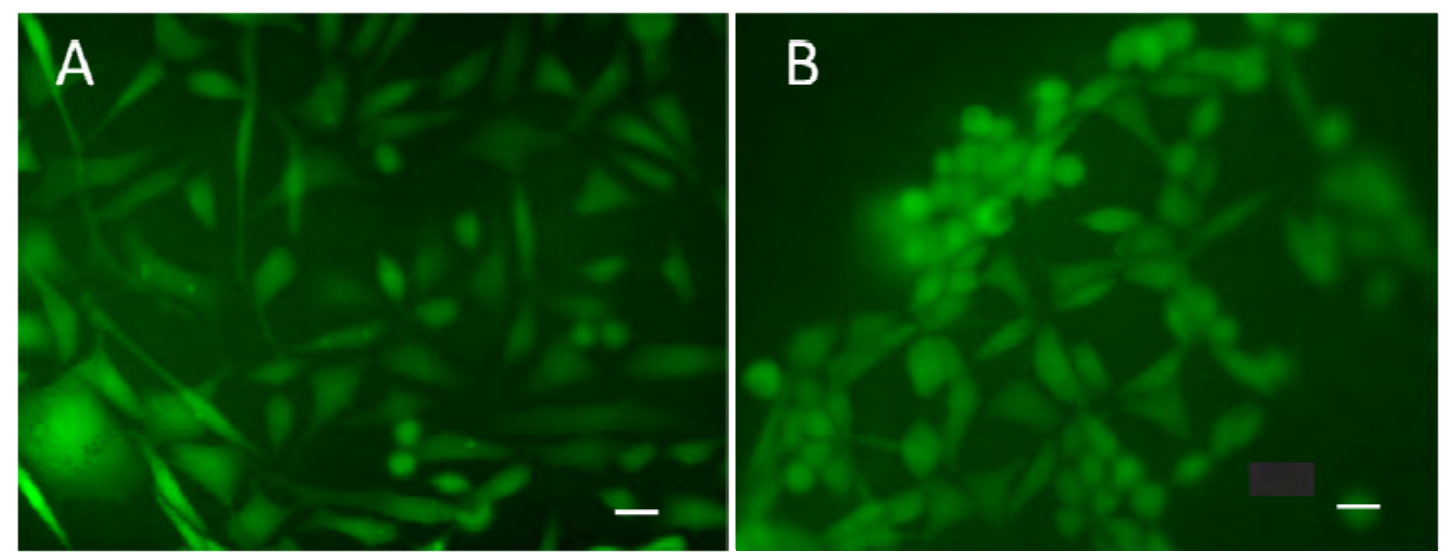

Figure 7.7: Fluorescence microscope images of L929 cells on the (A) CH-Lev01 and (B) GGTi20 surfaces of a dual layer film after incubating for $72 \mathrm{~h}$. Scale bar represents $20 \mu \mathrm{m}$.

Cell proliferation on dual layer films was evaluated using the MTS assay. The proliferation studies revealed that cell numbers on the GGTi20 surface of dual layer films after 72 and $144 \mathrm{~h}$ were 5300 and 23000 cells/well, respectively. This suggests that the release of levofloxacin does not adversely affect cell viability and proliferation on dual layer films.

Several studies have investigated the cell behaviour on commercial wound dressings ${ }^{56,393-395}$. Phan et al. ${ }^{395}$ reported that keratinocyte cells in Tegaderm ${ }^{\text {TM }}$ grew at a slow rate even after being cultured for $120 \mathrm{~h}$. In another report, Draye et al. ${ }^{56}$ studied the cytotoxicities with MTT assay of semi-occlusive polyurethane (PU) dressings (Tegaderm and Opsite) and a hydrocolloid dressing (DuoDERM) on epidermal keratinocytes. The results showed that after incubation for $144 \mathrm{~h}$, the keratinocyte cell survival increased on Opsite, decreased on Duoderm, while cell survival rates were retained on Tegarderm. 


\subsection{Antibacterial activities}

Antibacterial activities of CH-Lev films were quantified by qualitative and in vitro quantitative methods against Gram-negative bacteria (E. coli). The qualitative studies showed that the inhibition zones around the $\mathrm{CH}-\mathrm{Lev}$ disks increased with increasing amount of levofloxacin (Figure 7.8 and 7.9 A). For example, the inhibition zone of a CH-Lev5 film was 1.7 times larger than that of a CH-Lev01 film.
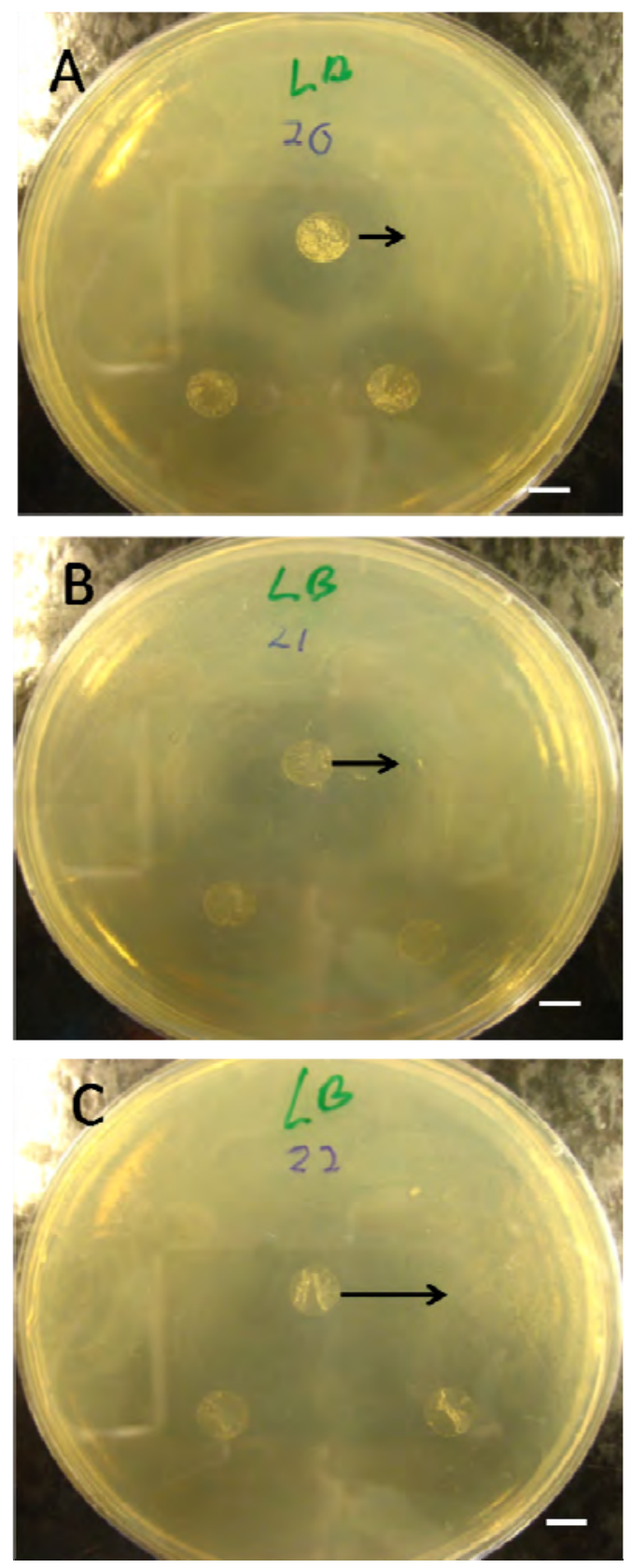

Figure 7.8: Photograph of qualitative antimicrobial test of (A) CH-Lev01, (B) CH-Lev1 and (C) CH-Lev5 films against E. coli. The inhibition zone is indicated by the arrow. Scale bars indicate $6 \mathrm{~mm}$. 

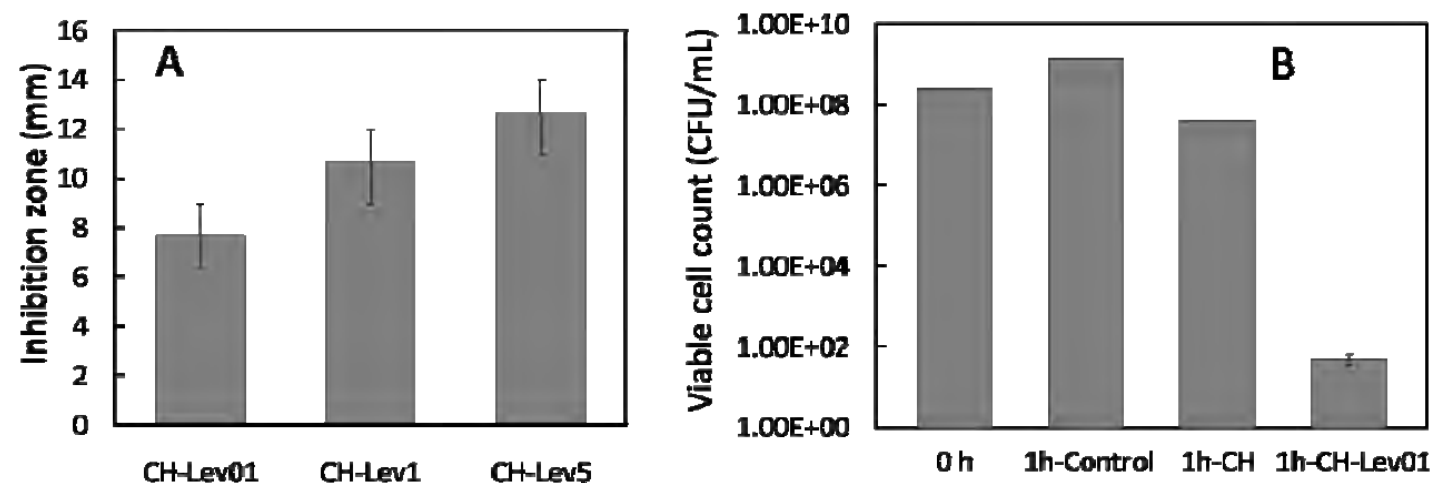

Figure 7.9 : (A) Inhibition zones for CH-Lev films against E. coli after 24h of incubation and (B) Effectiveness expressed in a viable colony counts (CFU/mL) for CH-Lev01, $\mathrm{CH}$ and control (innoculum without film) against $E$. coli after $1 \mathrm{~h}$. " 0 h" indicates the number of colonies in the inoculums.

In the quantitative tests, the antibacterial effectiveness of $\mathrm{CH}$ and $\mathrm{CH}-\mathrm{Lev01}$ films was evaluated using a viable cell count method of the Gram-negative bacterium E. coli. Release studies showed that virtually all the levofloxacin is released from the $\mathrm{CH}-\mathrm{Lev}$ film within $30 \mathrm{~min}$ in PBS at $37^{\circ} \mathrm{C}$ (Figure $7.10 \mathrm{~A}$ and B). The diffusion constant for levofloxacin release from the film was obtained by fitting the loss data to the expected profile for Fickian diffusion from a thin film ${ }^{300}$. The molar absorption coefficient obtained from Figure 7.10 C was used to convert the data from Figure 7.10 B into Figure 7.10 D curve. Figure 7.10 D shows that this loss profile fits a diffusion coefficient $1 \times 10^{-7} \mathrm{~cm}^{2} \mathrm{~s}^{-1}$. This rapid release of levofloxacin is responsible for the observed effectiveness in reducing bacterial growth. For example, after $1 \mathrm{~h}$ incubation only a small amount of bacterial colonies were surviving on the CH-Lev01 films, indicating a 7-8 log cycle reduction compared with the control (Figure 7.9 B). In contrast, $\mathrm{CH}$ films demonstrated a bacteriostatic effect against E. coli, which is consistent with previous observations ${ }^{79}$. 

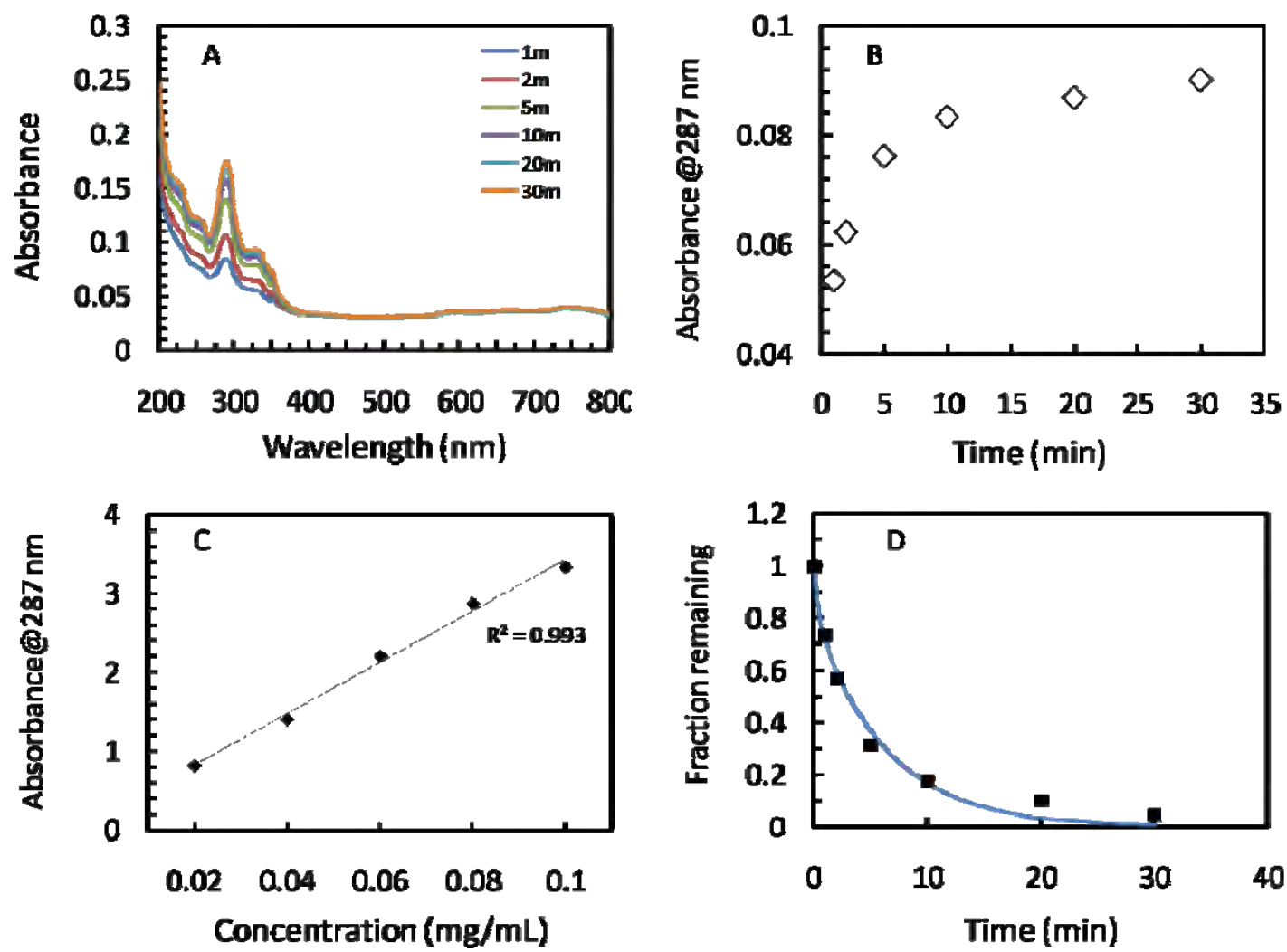

Figure 7.10: (A) UV-vis spectra of PBS solution at $37^{\circ} \mathrm{C}$ at increasing CH-Lev01 film immersion time, (B) absorbance of levofloxacin from a CH-Lev01 film at $287 \mathrm{~nm}$ versus immersion time, (C) absorbance of levofloxacin from a CH-Lev01 film at $287 \mathrm{~nm}$ versus levofloxacin concentration, and (D) loss of levofloxacin from a CH-Lev01 film (squares) compared with theoretical prediction of calculated loss assuming diffusion coefficient of $1.0 \mathrm{x}$ $10^{-7} \mathrm{~cm}^{2} \mathrm{~s}^{-1}$ (solid line).

The strong antibacterial activity of levofloxacin against E. coli has been reported in many studies through inhibition replication and transcription of bacteria DNA $283,291-293,396$. For example, Fu et al. ${ }^{291}$ measured the antibacterial activity of levofloxacin, ofloxacin, ciprofloxacin and norfloxacin against number of organisms such as Staphylococcus aureus (S. aureus), Xanthomonas malthophuia (X. malthophuia), Escherichia coli (E. coli), Bacteroides fragilis (B. fragilis) and methicillin-resistant Staphylococcus aureus (MRSA). Results showed that levofloxacin is more active than ciprofloxacin and other fluoro-quionolones against $S$. aureus including MRSA, X. malthophuia and B. fragilis. Furthermore, in-vivo results 
indicated that levofloxacin was more active than ciprofloxacin against selected Gramnegative organisms due to greater tissue penetration.

Holland and co-workers ${ }^{393}$ reported the antibacterial activities of commercial wound dressings (Opsite and Tegaderm) against Escherichia coli (E. coli), staphylococcus aweus (S. aweus), Streptococcus pyogenes (S. pyogenes) and Pseudomonas aeruginos (P. aeruginos). After $2 \mathrm{~h}$ of incubation against E. coli, Opsite and Tegaderm recorded significant reduction in viable bacterial colonies. It is suggested that the anti-bacterial activity of the $\mathrm{CH}-\mathrm{lev01}$ films is comparable to that of commercially available materials.

\subsection{Conclusion}

The dual layer films were prepared by pouring a CH-Lev01 solution onto the surface of a GGTi20 composite. The choice of materials to form the dual layer films was justified as follows. The addition of small amounts of levofloxacin $(0.4 \% \mathrm{w} / \mathrm{w})$ did not significantly affect the mechanical characteristics of $\mathrm{CH}$ films. Release studies show that the antibacterial effectiveness of the $\mathrm{CH}-\mathrm{Lev01}$ results from the fast release of levofloxacin. Addition of titanium dioxide $\left(\mathrm{TiO}_{2}\right)$ nanoparticles enhances the ductility of GG resulting in tougher materials, coupled with a loss in Young's modulus and tensile strength. Furthermore, GG films incorporate $\mathrm{TiO}_{2}$ supported the growth of viable L929 cells. It was evident that CH-Lev01 and GGTi20 films offered the best combination of mechanical and bio-characteristics and these were combined to form dual-layered films. These dual layer films exhibit anti-bacterial activity on one side, while supporting the growth of L929 cells on the other side. This chapter contributes towards the development of PEC materials for future wound dressing applications. 


\section{CHAPTER 8}

\section{CONCLUSIONS AND RECOMMENDATIONS}

\subsection{General conclusion}

This work successfully explored the formation of wound dressing through a polyelectrolyte complex using chitosan (CH) and gellan gum (GG), i.e. polyelectrolyte complex (PEC) films (PEC-film) and PEC-coated wool fibres. PECfilms and PEC-coated wool fibres were prepared by dipping free-standing $\mathrm{CH}$ and GG films (chapters 3-4, aim 1), and CH and GG-coated fibres into oppositely charged biopolymer solutions (chapters 5-6, aim 2), respectively. The results showed that GG solutions were able to diffuse into $\mathrm{CH}$ materials. In contrast, $\mathrm{CH}$ solutions were unable to diffuse into GG materials resulting in a layered structure, i.e. an inner GG layer and two outer $\mathrm{CH}$ layers. The formation of this layered structure was applied in the development of PEC-films (hereafter referred as dual layer films) with an eye towards future wound dressing applications (chapter 7, aim 3). The dual layer films consisted of two layers. The upper layer was designed to act as a bacterial resistance layer to minimise the infection in the wound, while the bottom layer was to promote cell viability and proliferation. 
$\mathrm{CH}$ films were incorporated with $\mathrm{TiO}_{2}$ and $\mathrm{Ag}$ nanoparticles (chapter 3, aim 1). In-vitro tests performed using mouse fibroblasts cells (L929) found that the $\mathrm{CH}$ $\mathrm{TiO}_{2}$ composite were not cytotoxic, while $\mathrm{CH}$-Ag composite were toxic to these cells. Proliferation of $\mathrm{L929}$ cells on $\mathrm{CH}-\mathrm{TiO}_{2}$ composites did not show improvement compared to $\mathrm{CH}$ films. Qualitative antibacterial studies showed that the inhibition zones around $\mathrm{CH}-\mathrm{Ag}$ (composite and dispersion) against Escherichia coli (E. coli) were superior compared to $\mathrm{CH}-\mathrm{Ti}$. Quantitative antibacterial tests revealed similar numbers of viable cell colonies of $E$. coli on both composites. Due to the low antibacterial resistance of these composites $\left(\mathrm{CH}-\mathrm{Ag}\right.$ and $\left.\mathrm{CH}-\mathrm{TiO}_{2}\right)$, an antibiotic, levofloxacin was incorporated in $\mathrm{CH}$ films (chapter 7). Qualitative results indicated that even the lowest levofloxacin concentration $(0.4 \% \mathrm{w} / \mathrm{w}$ in $\mathrm{CH}-\mathrm{Lev01}$ film) exhibited film inhibition zones which were 4-fold larger compared to those observed for the highest nanoparticle loading ( $30 \%$ by weight relative to $\mathrm{CH}$ ) in $\mathrm{CH}-\mathrm{Ag}$ composites. In addition, the viable cell count method for CH-Lev01 films showed that only a small amount of bacterial colonies survived after $1 \mathrm{~h}$ incubation, i.e. a 7-8 log cycle reduction compared to the innoculum without films. The rapid antibacterial response to the gram-negative bacterium, E. coli colonies was attributed to fast release (within $30 \mathrm{~min}$ ) of nearly all of the antibiotic from the film into the solution.

GG films were incorporated with $\mathrm{TiO}_{2}$, Ag and $\mathrm{ZnO}$ nanoparticles (chapter 4, aim 1). In-vitro tests, GG-TiO 2 , GG-Ag and GG-ZnO composites revealed that the L929 cells remain viable on $\mathrm{GG}-\mathrm{TiO}_{2}$ composite. Most of the cells on $\mathrm{Ag}$ and $\mathrm{ZnO}$ containing composites died due to the leakage of nanoparticles into the culture media. $\mathrm{CH}-\mathrm{Ti}$ composites showed significant increases in cell proliferation, i.e. about 50\% compared to GG film after incubation for $144 \mathrm{~h}$. The antibacterial activity of the GG- 
$\mathrm{TiO}_{2}$, GG-Ag and GG-ZnO composites quantified by inhibition method showed that none of the films was resistant against $E$. coli.

The mechanical characteristics and composition of PEC-films depended on the solution and film $\mathrm{pH}$, as well as the order of addition (chapter 5, aim 2). The results indicated that toughness, tensile strength and strain-at-break of PEC-films of biopolymers prepared by immersing $\mathrm{CH}$ films into $\mathrm{GG}$ solutions $\left(\mathrm{CH}^{\text {into }} \mathrm{GG}\right)$ increased with increasing CH:GG ratio. In contrast, it was not possible to observe similar trends in the mechanical characteristics for PEC-films prepared by the reverse addition $\left(\mathrm{GG}^{\text {into }} \mathrm{CH}\right)$. It is suggested that the observed behaviour (mechanical characteristics) can be attributed to differences in their film composition. $\mathrm{GG}^{\text {into }} \mathrm{CH}$ films were found to consist of an inner GG layer and two outer $\mathrm{CH}$ layers, whereas for $\mathrm{CH}^{\text {into }} \mathrm{GG}$ films, GG diffuses into the $\mathrm{CH}$ layer. The diffusion of GG solution into $\mathrm{CH}$ layer was related to differences in $\mathrm{pH}$ and persistence length of GG and $\mathrm{CH}$.

Similar mechanical characteristics were observed for PEC-coated wool fibres (chapter 6, aim 2). PEC-coated wool fibres prepared by dipping CH-dyed fibres into GG-dyed solutions ( $\left.\mathrm{CH}^{\text {into }} \mathrm{GG}\right)$, and GG-dyed fibres into $\mathrm{CH}$-dyed solutions $\left(G G^{\text {into }} \mathrm{CH}\right)$ showed that the order of addition influences the mechanical behaviour. For example, fibres prepared using $\mathrm{CH}^{\text {into }} \mathrm{GG}$ showed no mechanical reinforcement compared to single-coated (CH-dyed) fibres. In contrast, $\mathrm{GG}^{\text {into }} \mathrm{CH}$ fibre exhibited improved mechanical characteristics compared to single-coated GG-dyed fibres. pH modification of these PEC-coated wool fibres resulted in similar observations. It is suggested that the different mechanical characteristics observed for $\mathrm{CH}^{\text {into }} \mathrm{GG}$ fibres were due to the ability of the GG-dyed solution to diffuse into $\mathrm{CH}$-dyed fibre. In 
contrast, $\mathrm{CH}$-dyed solution was unable to diffuse into GG-dyed fibre (GG $\left.{ }^{\text {into }} \mathrm{CH}\right)$. These hypotheses are supported by colour changes in PEC-coated wool fibres.

An ideal wound dressing should be capable of being resistance to bacteria and non-toxic to cells. In addition, it should offer an adequate mechanical toughness and be permeable to water vapour. In the development of dual layer films (chapter 7, aim 3), the choice of materials was justified as follows. CH-Lev01 films were used as the upper layer as it displayed promising bacterial resistance against E. coli, compared to $\mathrm{CH}$-Ag composites. GG-TiO 2 composite films were was chosen as the bottom layer as it exhibited the best cell viability and cell proliferation, compared to $\mathrm{CH}$ and GG films. The dual layer films, (prepared by pouring a CH-Lev01 solution onto the surface of a GG-TiO 2 composite) were mechanically robust and could be easily folded and rolled up without breaking (chapter 7). Combining these two layers resulted in a synergistic effect on the mechanical characteristics, i.e. the tensile strength values of the dual layer films are $>20 \%$ higher compared to either the $\mathrm{CH}$ Lev01 or the $\mathrm{GG}-\mathrm{TiO}_{2}$ layers. The toughness and strain-at-break values of the dual layer films are in between those of the values observed for the individual layers. The water vapour transmission rates (WVTR) of the dual layer films are $853 \mathrm{~g} \mathrm{~m}^{-2} \mathrm{~d}^{-1}$, which is within the recommended range (500-2000 $\left.\mathrm{g} \mathrm{m}^{-2} \mathrm{~d}^{-1}\right)$ for wound dressings 52 . Furthermore, the WVTR value of dual layer films is comparable to WVTR values reported for commercial wound dressing such as, Cutifilm, Tegaderm, Bioclusive, Duoderm and Intrasite ${ }^{37,373}$. It was evident that combining CH-Lev01 and GG-TiO 2 composite into dual layer films offered the best combination of mechanical and biocharacteristics (chapter 7). In particular, the dual layer films exhibit antibacterial activity on one side, while supporting the growth of L929 cells on the other side. As 
such, it should be clear that this thesis contributes to the development of PEC materials for future wound dressing applications.

\subsection{Future recommendations}

The release of levofloxacin in CH-Lev films discussed in this thesis is a good indicator that the dual layer films (consisting of CH-Lev01 and GG-TiO ${ }_{2}$ composite) could be suitable as drug release materials. Drug release studies involving polyelectrolyte complexes from chitosan, poly (dimethyldiallyl ammonium chloride), carboxymethyl cellulose sodium, dextran sulphate, alginate, and poly(styrenesulfonate) have been reported ${ }^{397,}{ }^{398}$. These studies investigated the release of ibuprofen ${ }^{397,399}$, ketoprofen and cytochalasin D ${ }^{400}$, which could be incorporated into $\mathrm{CH}$ film and provide pain relief ${ }^{401,402}$.

The use of polyelectrolyte films from $\mathrm{CH}$ and GG as implanted materials is another interesting prospect. For example, levofloxacin could be used to provide an antibacterial barrier ${ }^{278}$ without compromising the ability to support cell growth. It has already been shown that multilayer polyelectrolyte films incorporated with defensin can be used to combat bacterial colonisation on implanted materials ${ }^{403}$. Bacterialresistance against penicillin such as Staphylococcus aureus (S. aureus) and methicillin (known as methicillin-resistant Staphylococcus aureus, MRSA) is causing major problems in hospitals ${ }^{404}$. S. aureus can spread easily, especially in hospitals, through contact with pus from an infected wound, skin-to-skin contact with infected person, or contact with objects such as towels, sheets or clothing used by an infected person ${ }^{405,406}$. The incorporation of antibiotics such as levofloxacin into PEC-coated wool fibres should be investigated to fight those anti-biotic resistant bacteria and help to stop the spreading of MRSA in hospitals. 


\section{PUBLICATIONS BY THE AUTHOR}

Khairul Anuar Mat Amin and Marc in het Panhuis. Polyelectrolyte complex materials from chitosan and gellan gum. Carbohydrate Polymers 2011; 86: 352-358.

Khairul Anuar Mat Amin, Kerry J. Gilmore, Jake Matic, Stephen Poon, Mark J. Walker, Mark R. Wilson and Marc in het Panhuis. Polyelectrolyte complex materials consisting of anti-bacterial and cell supporting layers. Macromolecular Bioscience (2011), DOI: 10.1 002/mabi.2011 00317.

Khairul Anuar Mat Amin, Jake Matic, Stephen Poon, Mark J. Walker, Mark R. Wilson and Marc in het Panhuis. Reinforced materials based on chitosan, $\mathrm{TiO}_{2}$ and Ag composites. Polymers (accepted subject to revisions).

Khairul Anuar Mat Amin, Jake Matic, Stephen Poon, Mark J. Walker, Mark R. Wilson and Marc in het Panhuis. $\mathrm{TiO}_{2}$ and Ag containing chitosan materials: physical properties, cell proliferation and antibacterial activity. Proceedings of Malaysia Polymer International Conference (MPIC 2009) 2009; 162-165. 


\section{BIBLIOGRAPHY}

1. Myers BA. Wound management:Principles and practice, 2 edn Pearson Education, Inc: Upper Saddle River, New Jersey, 2008.

2. Worldwide surgical sealants, glues, wound closure and anti-adhesion markets, 2010.

3. Sharon Baranoski, Ayello EA. Wound care essentials-practice prinsiples, Lippincott Williams \& Wilkins: United States of America, 2004.

4. Bayley EW. Wound healing in the patient with burns. Nursing Clinics of North America 1990; 25(1): 205-222.

5. Richard R, Johnson RM. Managing superficial burn wounds. Advances in Skin \& Wound Care 2002; 15(5): 246.

6. Richard R. Assessment and diagnosis of burn wounds. Advances in Skin \& Wound Care 1999; 12(9): 468.

7. Nelson DB, Dilloway MA. Principles, products, and practical aspects of wound care. Critical Care Nursing Quarterly 2002; 25(1): 33-54.

8. Carville K. Wound care manual, 5 edn Silver Chain Foundation: Australia, 2007.

9. Edlich RF, Rodeheaver GT, Morgan RF, Berman DE, Thacker JG. Principles of emergency wound management. Annals of Emergency Medicine 1988; 17(12): 1284-1302.

10. Percival NJ. Classification of wounds and their management. Surgery (Oxford) 2002; 20(5): 114-117.

11. Singh A, Halder S, Chumber S, Misra MC, Sharma LK, Srivastava A, Menon GR. Meta-analysis of randomized controlled trials on hydrocolloid occlusive dressing versus conventional gauze dressing in the healing of chronic wounds. Asian Journal of Surgery 2004; 27(4): 326-332.

12. Pat C, Gary Sibbald R. The effect of a silver-containing hydrofiber ${ }^{\circledR}$ dressing on superficial wound bed and bacterial balance of chronic wounds. International Wound Journal 2005; 2(4): 348-356.

13. Ågren MS, Engel MA, Mertz PM. Collagenase during burn wound healing: Influence of a hydrogel dressing and pulsed electrical stimulation. Plastic and Reconstructive Surgery 1994; 94(3): 518-524. 
14. Balakrishnan B, Mohanty M, Umashankar PR, Jayakrishnan A. Evaluation of an in situ forming hydrogel wound dressing based on oxidized alginate and gelatin. Biomaterials 2005; 26(32): 6335-6342.

15. Prevel CD, Eppley BL, Summerlin D-J, Sidner R, Jackson JR, McCarty M, Badylak SF. Small intestinal submucosa: Utilization as a wound dressing in full-thickness rodent wounds. Annals of Plastic Surgery 1995; 35(4): 381-388.

16. Lu G, Ling K, Zhao P, Xu Z, Deng C, Zheng H, Huang J, Chen J. A novel in situ-formed hydrogel wound dressing by the photocross-linking of a chitosan derivative. Wound Repair and Regeneration 2010; 18(1): 70-79.

17. Yang X, Yang K, Wu S, Chen X, Yu F, Li J, Ma M, Zhu Z. Cytotoxicity and wound healing properties of pva/ws-chitosan/glycerol hydrogels made by irradiation followed by freeze-thawing. Radiation Physics and Chemistry 2010; 79(5): 606-611.

18. Westaby S. Wound care, William Heinemann Medical Books Ltd: London, 1985.

19. Myers BA. Wound management, principles and practice, 2nd edn Pearson Education, Inc.: New Jersey, 2008.

20. Robert G. Growth factors and chronic wound healing: Past, present, and future. Advances in Skin \& Wound Care 2004; 17(1): 24.

21. Schakenraad JM, Hardonk MJ, Feijen J, Molenaar I, Nieuwenhuis P. Enzymatic activity toward poly(l-lactic acid) implants. Journal of Biomedical Materials Research 1990; 24(5): 529-545.

22. Kainulainen V, Wang H, Schick C, Bernfield M. Syndecans, heparan sulfate proteoglycans, maintain the proteolytic balance of acute wound fluids. Journal of Biological Chemistry 1998; 273(19): 11563-11569.

23. Steed DL. The role of growth factors in wound healing. The Surgical clinics of North America 1997; 77(3): 575.

24. Carol H. Wound healing. Orthopaedic Nursing 2005; 24(2): 143.

25. Robert IB. Povidone-iodine solution in wound treatment. Physical Therapy 1998; 78(2): 212.

26. Clark JJBSNRNC. Wound repair and factors influencing healing. Critical Care Nursing Quarterly 2002; 25(1): 1-12.

27. Hunt TK. Wound healing and wound infection. What surgeons and anesthesiologists can do. Surg Clin North Am 1997; 77(3): 587.

28. Branom RNRNBSNC. Is this wound infected? Critical Care Nursing Quarterly 2002; 25(1): 55-62. 
29. Park GB. Burn wound coverings. Artificial Cells, Blood Substitutes and Biotechnology 1978; 6(1): 1-35.

30. Mary J, Julia D, Amanda C. Dressing wounds. Nursing Standard 1998; 12(39): 47.

31. Murakami K, Ishihara $\mathrm{M}$, Aoki H, Nakamura S, Nakamura S-I, Yanagibayashi S, Takikawa M, Kishimoto S, Yokoe H, Kiyosawa T, Sato Y. Enhanced healing of mitomycin c-treated healing-impaired wounds in rats with hydrosheets composed of chitin/chitosan, fucoidan, and alginate as wound dressings. Wound Repair and Regeneration 2010; 18(5): 478-485.

32. Shalumon KT, Anulekha KH, Nair SV, Nair SV, Chennazhi KP, Jayakumar R. Sodium alginate/poly(vinyl alcohol)/nano zno composite nanofibers for antibacterial wound dressings. Int. J. Biol. Macromol. 2011; 49(3): 247-254.

33. Wang T, Zhu X-K, Xue X-T, Wu D-Y. Hydrogel sheets of chitosan, honey and gelatin as burn wound dressings. Carbohydrate Polymers; (0).

34. Wenger CB. Heat of evaporation of sweat: Thermodynamic considerations. $J$ Appl Physiol 1972; 32(4): 456-459.

35. Lamke LO, Nilsson GE, Reithner HL. The evaporative water loss from burns and the water-vapour permeability of grafts and artificial membranes used in the treatment of burns. Burns 1977; 3(3): 159-165.

36. Ehleben CM, Randolph May S, Still JM. Pain associated with an adherent polyurethane wound dressing. Burns 1985; 12(2): 122-126.

37. Queen D, Gaylor JDS, Evans JH, Courtney JM, Reid WH. The preclinical evaluation of the water vapour transmission rate through burn wound dressings. Biomaterials 1987; 8(5): 367-371.

38. Kokabi M, Sirousazar M, Hassan ZM. Pva-clay nanocomposite hydrogels for wound dressing. European Polymer Journal 2007; 43(3): 773-781.

39. Meng X, Tian F, Yang J, He C-N, Xing N, Li F. Chitosan and alginate polyelectrolyte complex membranes and their properties for wound dressing application. Journal of Materials Science: Materials in Medicine 2010; 21(5): 1751-1759.

40. Hwang M-R, Kim J, Lee J, Kim Y, Kim J, Chang S, Jin S, Kim J, Lyoo W, Han S, Ku S, Yong C, Choi H-G. Gentamicin-loaded wound dressing with polyvinyl alcohol/dextran hydrogel: Gel characterization and \&lt;i\&gt;in vivo\&lt;/i\&gt; healing evaluation. Aaps Pharmscitech 2010; 11(3): 10921103.

41. Arias-Moscoso JL, Soto-Valdez H, Plascencia-Jatomea M, Vidal-Quintanar R-L, Rouzaud-Sández O, Ezquerra-Brauer JM. Composites of chitosan with acid-soluble collagen from jumbo squid (dosidicus gigas) by-products. Polym. Int. 2011; 60(6): 924-931. 
42. Luo Y, Diao H, Xia S, Dong L, Chen J, Zhang J. A physiologically active polysaccharide hydrogel promotes wound healing. Journal of Biomedical Materials Research Part A 2010; 94A(1): 193-204.

43. Huang M-H, Yang M-C. Swelling and biocompatibility of sodium alginate/poly $(\gamma$-glutamic acid) hydrogels. Polymers for Advanced Technologies 2010; 21(8): 561-567.

44. Sung JH, Hwang M-R, Kim JO, Lee JH, Kim YI, Kim JH, Chang SW, Jin SG, Kim JA, Lyoo WS, Han SS, Ku SK, Yong CS, Choi H-G. Gel characterisation and in vivo evaluation of minocycline-loaded wound dressing with enhanced wound healing using polyvinyl alcohol and chitosan. International Journal of Pharmaceutics 2010; 392(1-2): 232-240.

45. Wu P, Nelson EA, Reid WH, Ruckley CV, Gaylor JDS. Water vapour transmission rates in burns and chronic leg ulcers: Influence of wound dressings and comparison with in vitro evaluation. Biomaterials 1996; 17(14): 1373-1377.

46. Okan D, Woo K, Ayello EA, Sibbald G. The role of moisture balance in wound healing. Advances in Skin \& Wound Care 2007; 20(1): 39-53.

47. Murakami K, Aoki H, Nakamura S, Nakamura S-i, Takikawa M, Hanzawa M, Kishimoto S, Hattori H, Tanaka Y, Kiyosawa T, Sato Y, Ishihara M. Hydrogel blends of chitin/chitosan, fucoidan and alginate as healing-impaired wound dressings. Biomaterials 2010; 31(1): 83-90.

48. Varaprasad K, Mohan YM, Vimala K, Mohana Raju K. Synthesis and characterization of hydrogel-silver nanoparticle-curcumin composites for wound dressing and antibacterial application. Journal of Applied Polymer Science 2011; 121(2): 784-796.

49. Nangia A, Gambhir R, Maibach H. Factors influencing the performance of temporary skin substitutes. Clinical Materials 1991; 7(1): 3-13.

50. Hanks CT, Wataha JC, Sun Z. In vitro models of biocompatibility: A review. Dental Materials 1996; 12(3): 186-193.

51. Wataha JC. Biocompatibility of dental casting alloys: A review. The Journal of Prosthetic Dentistry 2000; 83(2): 223-234.

52. Rogero SO, Malmonge SM, Lugão AB, Ikeda TI, Miyamaru L, Cruz ÁS. Biocompatibility study of polymeric biomaterials. Artificial Organs 2003; 27(5): 424-427.

53. Roy N, Saha N, Humpolicek P, Saha P. Permeability and biocompatibility of novel medicated hydrogel wound dressings. Soft Materials 2010; 8(4): 338357. 
54. Lee KY, Ha WS, Park WH. Blood compatibility and biodegradability of partially n-acylated chitosan derivatives. Biomaterials 1995; 16(16): 12111216.

55. Hirano S, Noishiki Y. The blood compatibility of chitosan and nacylchitosans. Journal of Biomedical Materials Research 1985; 19(4): 413417.

56. Draye J-P, Delaey B, Van de Voorde A, Van Den Bulcke A, De Reu B, Schacht E. In vitro and in vivo biocompatibility of dextran dialdehyde crosslinked gelatin hydrogel films. Biomaterials 1998; 19(18): 1677-1687.

57. Mi F-L, Shyu S-S, Wu Y-B, Lee S-T, Shyong J-Y, Huang R-N. Fabrication and characterization of a sponge-like asymmetric chitosan membrane as a wound dressing. Biomaterials 2001; 22(2): 165-173.

58. Berscht PC, Nies B, Liebendörfer A, Kreuter J. In vitro evaluation of biocompatibility of different wound dressing materials. Journal of Materials Science: Materials in Medicine 1995; 6(4): 201-205.

59. Zhou Y, Yang D, Chen X, Xu Q, Lu F, Nie J. Electrospun water-soluble carboxyethyl chitosan/poly(vinyl alcohol) nanofibrous membrane as potential wound dressing for skin regeneration. Biomacromolecules 2007; 9(1): 349354.

60. Tanodekaew S, Prasitsilp M, Swasdison S, Thavornyutikarn B, Pothsree T, Pateepasen R. Preparation of acrylic grafted chitin for wound dressing application. Biomaterials; 25(7-8): 1453-1460.

61. Muzzarelli RAA, Guerrieri M, Goteri G, Muzzarelli C, Armeni T, Ghiselli R, Cornelissen $\mathrm{M}$. The biocompatibility of dibutyryl chitin in the context of wound dressings. Biomaterials 2005; 26(29): 5844-5854.

62. Azad AK, Sermsintham N, Chandrkrachang S, Stevens WF. Chitosan membrane as a wound-healing dressing: Characterization and clinical application. Journal of Biomedical Materials Research Part B: Applied Biomaterials 2004; 69B(2): 216-222.

63. Hsu S-h, Chang Y-B, Tsai C-L, Fu K-Y, Wang S-H, Tseng H-J. Characterization and biocompatibility of chitosan nanocomposites. Colloids and Surfaces B: Biointerfaces 2011; 85(2): 198-206.

64. Agrawal CM, Ray RB. Biodegradable polymeric scaffolds for musculoskeletal tissue engineering. Journal of Biomedical Materials Research 2001; 55(2): 141-150.

65. Sharma B, Elisseeff JH. Engineering structurally organized cartilage and bone tissues. Annals of Biomedical Engineering 2004; 32(1): 148-159. 
66. Prendergast PJ, Huiskes R, Søballe K. Biophysical stimuli on cells during tissue differentiation at implant interfaces. Journal of biomechanics 1997; 30(6): 539-548.

67. Revathi G, Puri J, Jain BK. Bacteriology of burns. Burns 1998; 24(4): 347349 .

68. Harrison-Balestra C, Cazzaniga AL, Davis SC, Mertz PM. A wound-isolated pseudomonas aeruginosa grows a biofilm in vitro within 10 hours and is visualized by light microscopy. Dermatologic Surgery 2003; 29(6): 631-635.

69. Biofilm formation. Science 1998; 280(5361): 173.

70. Costerton JW, Stewart PS, Greenberg EP. Bacterial biofilms: A common cause of persistent infections. Science 1999; 284(5418): 1318-1322.

71. Chen SP, Wu GZ, Zeng HY. Preparation of high antimicrobial activity thiourea chitosan-ag+ complex. Carbohydrate Polymers 2005; 60(1): 33-38.

72. Hajkova P, Spatenka P, Horsky J, Horska I, Kolouch A. Photocatalytic effect of tio2 films on viruses and bacteria. Plasma Processes and Polymers 2007; 4(S1): S397-S401.

73. Percival SL, Slone W, Linton S, Okel T, Corum L, Thomas JG. The antimicrobial efficacy of a silver alginate dressing against a broad spectrum of clinically relevant wound isolates. International Wound Journal 2011; 8(3): 237-243.

74. Singh B, Pal L. Development of sterculia gum based wound dressings for use in drug delivery. European Polymer Journal 2008; 44(10): 3222-3230.

75. Hashimoto T, Suzuki Y, Tanihara M, Kakimaru Y, Suzuki K. Development of alginate wound dressings linked with hybrid peptides derived from laminin and elastin. Biomaterials; 25(7-8): 1407-1414.

76. Ong S-Y, Wu J, Moochhala SM, Tan M-H, Lu J. Development of a chitosanbased wound dressing with improved hemostatic and antimicrobial properties. Biomaterials 2008; 29(32): 4323-4332.

77. Sikareepaisan P, Ruktanonchai U, Supaphol P. Preparation and characterization of asiaticoside-loaded alginate films and their potential for use as effectual wound dressings. Carbohydrate Polymers 2011; 83(4): 14571469.

78. Ruiz-Cardona L, Sanzgiri YD, Benedetti LM, Stella VJ, Topp EM. Application of benzyl hyaluronate membraned as potential wound dressings:Evaluation of water vapour and gas permeabilities. Biomaterials 1996; 17: 1639. 
79. Rhim JW, Hong SI, Park HM, Ng PKW. Preparation and characterization of chitosan-based nanocomposite films with antimicrobial activity. Journal of Agricultural and Food Chemistry 2006; 54(16): 5814-5822.

80. Kim JO, Park JK, Kim JH, Jin SG, Yong CS, Li DX, Choi JY, Woo JS, Yoo BK, Lyoo WS, Kim J-A, Choi H-G. Development of polyvinyl alcoholsodium alginate gel-matrix-based wound dressing system containing nitrofurazone. International Journal of Pharmaceutics 2008; 359(1-2): 79-86.

81. Loke W-K, Lau S-K, Yong LL, Khor E, Sum CK. Wound dressing with sustained anti-microbial capability. Journal of Biomedical Materials Research 2000; 53(1): 8-17.

82. Ramli NA, Wong TW. Sodium carboxymethylcellulose scaffolds and their physicochemical effects on partial thickness wound healing. International Journal of Pharmaceutics 2011; 403(1-2): 73-82.

83. Mi F-L, Wu Y-B, Shyu S-S, Chao A-C, Lai J-Y, Su C-C. Asymmetric chitosan membranes prepared by dry/wet phase separation: A new type of wound dressing for controlled antibacterial release. Journal of Membrane Science 2003; 212(1-2): 237-254.

84. Kujawa P, Moraille P, Sanchez J, Badia A, Winnik FM. Effect of molecular weight on the exponential growth and morphology of hyaluronan/chitosan multilayers:\&nbsp; a surface plasmon resonance spectroscopy and atomic force microscopy investigation. Journal of the American Chemical Society 2005; 127(25): 9224-9234.

85. Hoogeveen NG, Cohen Stuart MA, Fleer GJ, Böhmer MR. Formation and stability of multilayers of polyelectrolytes. Langmuir 1996; 12(15): 36753681.

86. Joanny JF. Polyelectrolyte adsorption and charge inversion. The European Physical Journal B - Condensed Matter and Complex Systems 1999; 9(1): 117-122.

87. Woelki S, Kohler H-H. Effect of dispersion forces on the potential of charged interfaces. Chemical Physics 2004; 306(1-3): 209-217.

88. Jin W, Toutianoush A, Tieke B. Use of polyelectrolyte layer-by-layer assemblies as nanofiltration and reverse osmosis membranes. Langmuir 2003; 19(7): 2550-2553.

89. Stanton BW, Harris JJ, Miller MD, Bruening ML. Ultrathin, multilayered polyelectrolyte films as nanofiltration membranes. Langmuir 2003; 19(17): 7038-7042.

90. Miller MD, Bruening ML. Controlling the nanofiltration properties of multilayer polyelectrolyte membranes through variation of film composition. Langmuir 2004; 20(26): 11545-11551. 
91. Toutianoush A, Tieke B. Pervaporation separation of alcohol/water mixtures using self-assembled polyelectrolyte multilayer membranes of high charge density. Materials Science and Engineering: C 2002; 22(2): 459-463.

92. Krasemann L, Tieke B. Ultrathin self-assembled polyelectrolyte membranes for pervaporation. Journal of Membrane Science 1998; 150: 23-30.

93. van den Beucken JJJP, Vos MRJ, Thüne PC, Hayakawa T, Fukushima T, Okahata Y, Walboomers XF, Sommerdijk NAJM, Nolte RJM, Jansen JA. Fabrication, characterization, and biological assessment of multilayered DNAcoatings for biomaterial purposes. Biomaterials 2006; 27(5): 691-701.

94. Donald TH. Physics of polypeptide multilayer films. Journal of Biomedical Materials Research Part B: Applied Biomaterials 2006; 78B(2): 243-252.

95. Hong H-J, Jin S-E, Park J-S, Ahn WS, Kim C-K. Accelerated wound healing by smad3 antisense oligonucleotides-impregnated chitosan/alginate polyelectrolyte complex. Biomaterials 2008; 29(36): 4831-4837.

96. Z. Tang YWPPNAK. Biomedical applications of layer-by-layer assembly: From biomimetics to tissue engineering. Advanced Materials 2006; 18(24): 3203-3224.

97. Huiguang Zhu JJMABJS. Protein electrostatic self-assembly on poly $(<$ font size $=$ '-2' $>$ dl $<$ /font $>$-lactide) scaffold to promote osteoblast growth. Journal of Biomedical Materials Research Part B: Applied Biomaterials 2004; 71B(1): 159-165.

98. Yan-Peng J, Fu-Zhai C. Surface modification of polyester biomaterials for tissue engineering. Biomedical Materials 2007; (4): R24.

99. Hillberg AL, Tabrizian M. Biorecognition through layer-by-layer polyelectrolyte assembly:\&nbsp; in-situ hybridization on living cells. Biomacromolecules 2006; 7(10): 2742-2750.

100. K. Köhler GBS. Heat treatment of polyelectrolyte multilayer capsules: A versatile method for encapsulation. Advanced Functional Materials 2007; 17(13): 2053-2061.

101. Lvov Y, Decher G, Moehwald H. Assembly, structural characterization, and thermal behavior of layer-by-layer deposited ultrathin films of poly(vinyl sulfate) and poly(allylamine). Langmuir 1993; 9(2): 481-486.

102. Lvov Y, Decher G, Sukhorukov G. Assembly of thin films by means of successive deposition of alternate layers of DNA and poly(allylamine). Macromolecules 1993; 26(20): 5396-5399.

103. Decher G. Fuzzy nanoassemblies: Toward layered polymeric multicomposites. Science 1997; v277(n5330): p1232(6). 
104. Bertrand P, Jonas A, Laschewsky A, Legras R. Ultrathin polymer coatings by complexation of polyelectrolytes at interfaces: Suitable materials, structure and properties. Macromolecular Rapid Communications 2000; 21(7): 319348.

105. Johansson JA, Halthur T, Herranen M, Soderberg L, Elofsson U, Hilborn J. Build-up of collagen and hyaluronic acid polyelectrolyte multilayers. Biomacromolecules 2005; 6(3): 1353-1359.

106. Serizawa T, Yamaguchi M, Akashi M. Alternating bioactivity of polymeric layer-by-layer assemblies:\&nbsp; anticoagulation vs procoagulation of human blood. Biomacromolecules 2002; 3(4): 724-731.

107. Boulmedais F, Bozonnet M, Schwinte P, Voegel JC, Schaaf P. Multilayered polypeptide films: Secondary structures and effect of various stresses. Langmuir 2003; 19(23): 9873-9882.

108. Yoo D, Shiratori SS, Rubner MF. Controlling bilayer composition and surface wettability of sequentially adsorbed multilayers of weak polyelectrolytes. Macromolecules 1998; 31(13): 4309-4318.

109. Ninham BW, Kurihara K, Vinogradova OI. Hydrophobicity, specific ion adsorption and reactivity. Colloids and Surfaces A: Physicochemical and Engineering Aspects 1997; 123-124: 7-12.

110. Phuvanartnuruks V, McCarthy TJ. Stepwise polymer surface modification: Chemistrylayer-by-layer deposition. Macromolecules 1998; 31(6): 19061914.

111. Ulman A. Formation and structure of self-assembled monolayers. Chemical Reviews 1996; 96(4): 1533-1554.

112. Berger J, Reist M, Mayer JM, Felt O, Gurny R. Structure and interactions in chitosan hydrogels formed by complexation or aggregation for biomedical applications. European Journal of Pharmaceutics and Biopharmaceutics 2004; 57(1): 35-52.

113. Decher G, Hong JD, Schmitt J. Buildup of ultrathin multilayer films by a selfassembly process: Iii. Consecutively alternating adsorption of anionic and cationic polyelectrolytes on charged surfaces. Thin Solid Films 1992; 210211(Part 2): 831-835.

114. Ladam G, Schaad P, Voegel JC, Schaaf P, Decher G, Cuisinier F. In situ determination of the structural properties of initially deposited polyelectrolyte multilayers. Langmuir 1999; 16(3): 1249-1255.

115. Ruths J, Essler F, Decher G, Riegler H. Polyelectrolytes i: Polyanion/polycation multilayers at the air/monolayer/water interface as elements for quantitative polymer adsorption studies and preparation of hetero-superlattices on solid surfacesâ€ Langmuir 2000; 16(23): 8871-8878. 
116. Elbert DL, Herbert CB, Hubbell JA. Thin polymer layers formed by polyelectrolyte multilayer techniques on biological surfaces. Langmuir 1999; 15(16): 5355-5362.

117. Picart C, Lavalle P, Hubert P, Cuisinier FJG, Decher G, Schaaf P, Voegel JC. Buildup mechanism for poly(l-lysine)/hyaluronic acid films onto a solid surface. Langmuir 2001; 17(23): 7414-7424.

118. Lavalle P, Gergely C, Cuisinier FJG, Decher G, Schaaf P, Voegel JC, Picart C. Comparison of the structure of polyelectrolyte multilayer films exhibiting a linear and an exponential growth regime: An in situ atomic force microscopy study. Macromolecules 2002; 35(11): 4458-4465.

119. DeLongchamp DM, Kastantin M, Hammond PT. High-contrast electrochromism from layer-by-layer polymer films. Chemistry of Materials 2003; 15(8): 1575-1586.

120. Picart C, Mutterer,J., Richert, L., Luo, Y., Prestwich, G. D., Schaaf, P., Voegel,J.-C., and Lavalle, P. . Molecular basis for the explanation of the exponential growth of polyelectrolyte multilayers. PNAS 2002; 99(October 1): 12531-12535.

121. McAloney RA, Sinyor M, Dudnik V, Goh MC. Atomic force microscopy studies of salt effects on polyelectrolyte multilayer film morphology. Langmuir 2001; 17(21): 6655-6663.

122. Dubas ST, Schlenoff JB. Factors controlling the growth of polyelectrolyte multilayers. Macromolecules 1999; 32(24): 8153-8160.

123. Ruths J, Essler F, Decher G, Riegler H. Langmuir 2000; 16: 8871.

124. Boddohi S, Killingsworth CE, Kipper MJ. Polyelectrolyte multilayer assembly as a function of ph and ionic strength using the polysaccharides chitosan and heparin. Biomacromolecules 2008; 9(7): 2021-2028.

125. Losche M, Schmitt J, Decher G, Bouwman WG, Kjaer K. Detailed structure of molecularly thin polyelectrolyte multilayer films on solid substrates as revealed by neutron reflectometry. Macromolecules 1998; 31(25): 8893-8906.

126. Caruso F, Niikura K, Furlong DN, Okahata Y. 1. Ultrathin multilayer polyelectrolyte films on gold: Construction and thickness determination. Langmuir 1997; 13(13): 3422-3426.

127. Lvov Y, Ariga K, Ichinose I, Kunitake T. Assembly of multicomponent protein films by means of electrostatic layer-by-layer adsorption. Journal of the American Chemical Society 1995; 117(22): 6117-6123.

128. Fou AC, Rubner MF. Molecular-level processing of conjugated polymers. 2. Layer-by-layer manipulation of in-situ polymerized p-type doped conducting polymers. Macromolecules 1995; 28(21): 7115-7120. 
129. Shah AA, Hasan F, Hameed A, Ahmed S. Biological degradation of plastics: A comprehensive review. Biotechnol. Adv. 2008; 26(3): 246-265.

130. Chillo S, Flores S, Mastromatteo M, Conte A, Gerschenson L, Del Nobile MA. Influence of glycerol and chitosan on tapioca starch-based edible film properties. Journal of Food Engineering 2008.

131. Vargas M, Albors A, Chiralt A, González-Martínez C. Characterization of chitosan-oleic acid composite films. Food Hydrocolloids 2008; (in press).

132. Ma L, Gao C, Mao Z, Zhou J, Shen JC, Hu X, Han C. Collagen/chitosan porous scaffolds with improved biostability for skin tissue engineering. Biomaterials 2003; 24: 4833-4841.

133. Cao WL, Wang AJ, Jing DH, Gong YD, Zhao NM, Zhang XF. Novel biodegradable films and scaffolds of chitosan blended with poly(3hydroxybutyrate). Journal of Biomaterials Science-Polymer Edition 2005; 16(11): 1379-1394.

134. Shanmugasundaram N, Ravichandran P, Reddy PN, Ramamurty N, Pal S, Rao KP. Collagen-chitosan polymeric scaffolds for the in vitro culture of human epidermoid carcinoma cells. Biomaterials 2001; 22: 1943-1951.

135. Zheng LY, Zhu JF. Study on antimicrobial activity of chitosan with different molecular weights. Carbohydrate Polymers 2003; 54: 527-530.

136. Chiu HT, Chen RL, Wu PY, Chiang TY. A study on the effects of the degree of deacetylation of chitosan films on physical and antibacterial properties. Polymer-Plastics Technology and Engineering 2007; 46: 1121-1127.

137. Qin C, Li H, Xiao Q, Liu Y, Zhu J, Du Y. Water-solubility of chitosan and its antimicrobial activity. Carbohydrate Polymers 2006; 63: 367-374.

138. Xu HT, Ma L, Shi HF, Gao CY, Han CM. Chitosan-hyaluronic acid hybrid film as a novel wound dressing: In vitro and in vivo studies. Polymers for Advanced Technologies 2007; 18: 869-875.

139. Wittaya-areekul S, Prahsarn C. Development and in vitro evaluation of chitosan-polysaccharides composite wound dressings. International Journal of Pharmaceutics 2006; 313: 123-128.

140. Guan M, Ren L, Wu T, Sun LP, Li LR, Zhang QQ. Potential wound dressing with improved antimicrobial property. Journal of Applied Polymer Science 2007; 105(3): 1679-1686.

141. Aoyagi S, Onishi H, Machida Y. Novel chitosan wound dressing loaded with minocycline for the treatment of severe burn wounds. International Journal of Pharmaceutics 2007; 330(1-2): 138-145. 
142. Dallan PRM, Luz Moreira P, Petinari L, Malmonge SM, Beppu MM, Genari S, Moraes AM. Effects of chitosan solution concentration and incorporation of chitin and glycerol on dense chitosan membrane properties. $J$ Biomed Mater Res Part B: Appl Biomater 2007; 80(B): 394-405.

143. Prabaharan M, Rodriguez-Perez MA, de Saja JA, Mano JF. Preparation and characterization of poly(l-lactic acid)-chitosan hybrid scaffolds with drug release capability. J Biomed Mater Res Part B: Appl Biomater 2007; 81(B): 427-434.

144. Krauland AH, Jos'e Alonso M. Chitosan/cyclodextrin nanoparticles as macromolecular drug delivery system. International Journal of Pharmaceutics 2007; 340: 134-142.

145. Sæther HV, Holme HK, Maurstad G, Smidsrød O, Stokke BT. Polyelectrolyte complex formation using alginate and chitosan. Carbohydrate Polymers 2008; 74(4): 813-821.

146. Li X, Xie H, Lin J, Xie W, Ma X. Characterization and biodegradation of chitosan-alginate polyelectrolyte complexes. Polymer Degradation and Stability 2009; 94(1): 1-6.

147. Briones AV, Sato T. Encapsulation of glucose oxidase (god) in polyelectrolyte complexes of chitosan-carrageenan. Reactive and Functional Polymers 2010; 70(1): 19-27.

148. Hugerth A, Caram-Lelham N, Sundelöf L-O. The effect of charge density and conformation on the polyelectrolyte complex formation between carrageenan and chitosan. Carbohydrate Polymers 1997; 34(3): 149-156.

149. Park SY, Lee BI, Jung ST, Park HJ. Biopolymer composite films based on [kappa]-carrageenan and chitosan. Materials Research Bulletin; 36(3-4): 511519.

150. Rao MS, Kanatt SR, Chawla SP, Sharma A. Chitosan and guar gum composite films: Preparation, physical, mechanical and antimicrobial properties. Carbohydrate Polymers 2010; 82(4): 1243-1247.

151. Argin-Soysal S, Kofinas P, Lo YM. Effect of complexation conditions on xanthan-chitosan polyelectrolyte complex gels. Food Hydrocolloids 2009; 23(1): 202-209.

152. Naidu VGM, Madhusudhana K, Sashidhar RB, Ramakrishna S, Khar RK, Ahmed FJ, Diwan PV. Polyelectrolyte complexes of gum kondagogu and chitosan, as diclofenac carriers. Carbohydrate Polymers 2009; 76(3): 464471.

153. Yin YJ, Yao KD, Cheng GX, Ma JB. Properties of polyelectrolyte complex films of chitosan and gelatin. Polym. Int. 1999; 48(6): 429-432. 
154. Mi F-L, Sung H-W, Shyu S-S. Drug release from chitosan-alginate complex beads reinforced by a naturally occurring cross-linking agent. Carbohydrate Polymers 2002; 48(1): 61-72.

155. Xu Y, Zhan C, Fan L, Wang L, Zheng H. Preparation of dual crosslinked alginate-chitosan blend gel beads and in vitro controlled release in oral sitespecific drug delivery system. International Journal of Pharmaceutics 2007; 336(2): 329-337.

156. Pasparakis G, Bouropoulos N. Swelling studies and in vitro release of verapamil from calcium alginate and calcium alginate-chitosan beads. International Journal of Pharmaceutics 2006; 323(1-2): 34-42.

157. Watthanaphanit A, Supaphol P, Tamura H, Tokura S, Rujiravanit R. Wet-spun alginate/chitosan whiskers nanocomposite fibers: Preparation, characterization and release characteristic of the whiskers. Carbohydrate Polymers 2010; 79(3): 738-746.

158. Watthanaphanit A, Supaphol P, Furuike T, Tokura S, Tamura H, Rujiravanit R. Novel chitosan-spotted alginate fibers from wet-spinning of alginate solutions containing emulsified chitosan-citrate complex and their characterization. Biomacromolecules 2008; 10(2): 320-327.

159. Iwasaki N, Yamane S-T, Majima T, Kasahara Y, Minami A, Harada K, Nonaka S, Maekawa N, Tamura H, Tokura S, Shiono M, Monde K, Nishimura S-I. Feasibility of polysaccharide hybrid materials for scaffolds in cartilage tissue engineering: Evaluation of chondrocyte adhesion to polyion complex fibers prepared from alginate and chitosan. Biomacromolecules 2004; 5(3): 828-833.

160. Boddohi S, Moore N, Johnson PA, Kipper MJ. Polysaccharide-based polyelectrolyte complex nanoparticles from chitosan, heparin, and hyaluronan. Biomacromolecules 2009; 10(6): 1402-1409.

161. Amaike M, Senoo Y, Yamamoto H. Sphere, honeycomb, regularly spaced droplet and fiber structures of polyion complexes of chitosan and gellan. Macromol. Rapid Commun. 1998; 19: 287-289.

162. Yamamoto H, Senoo Y. Polyion complex fiber and capsule formed by selfassembly of chitosan and gellan at solution interfaces. Macromol. Chem. Phys. 2000; 201: 84-92.

163. Yamamoto H, Ohkawa K, Nakamura E, Miyamoto K, Komai T. Preparation of polyion complex capsule and fiber of chitosan and gellan-sulfate at aqueous interface. Bull. Chem. Soc. Jpn. 2003; 76(10): 2053-2057.

164. Ohkawa K, Yamada M, Nishida A, Nishi N, Yamamoto H. Biodegradation of chitosan-gellan and poly(l-lysine)-gellan polyion complex fibers by pure cultures of soil filamentous fungi. Journal of Polymers and the Environment 2000; 8(2): 59-66. 
165. Ohkawa K, Kitagawa T, Yamamoto H. Preparation and characterization of chitosan-gellan hybrid capsules formed by self-assembly at an aqueous solution interface. Macromol. Mater. Eng. 2004; 289: 33-40.

166. Fujii T, Ogiwara D, Ohkawa K, Yamamoto H. Alkaline phosphatase encapsulated in gellan-chitosan hybrid capsules. Macromol. Biosci. 2005; 5: 394-400.

167. Amaike M, Senoo Y, Yamamoto H. Sphere, honeycomb, regularly spaced droplet and fiber structures of polyion complexes of chitosan and gellan. Macromolecular Rapid Communications 1998; 19(6): 287-289.

168. Stawski D, Bellmann C. Electrokinetic properties of polypropylene textile fabrics containing deposited layers of polyelectrolytes. Colloids and Surfaces A: Physicochemical and Engineering Aspects 2009; 345(1-3): 191-194.

169. Dubas ST, Kumlangdudsana P, Potiyaraj P. Layer-by-layer deposition of antimicrobial silver nanoparticles on textile fibers. Colloids and Surfaces A: Physicochemical and Engineering Aspects 2006; 289(1-3): 105-109.

170. Połowiński S. Deposition of polymer complex layers onto nonwoven textiles. Journal of Applied Polymer Science 2007; 103(3): 1700-1705.

171. Stefan P. Nonwoven fabrics modified with deposited nanolayers. Polimery 2007; 52(5): 357-361.

172. Stefan Połowiński, Stawski D. Thermogravimetric measurements of poly(propylene) nonwovens containing deposited layers of polyelectrolytes and colloidal particles of noble metals. FIBRES \& TEXTILES in Eastern Europe October / December 2007; 15(4 (63)): 82-85.

173. Ravi Kumar MNV. A review of chitin and chitosan applications. Reactive and Functional Polymers 2000; 46(1): 1-27.

174. Aspinall GO. The polysaccharides, vol. 2. Academic Press, Inc: London, 1983.

175. Agullo E, Rodriguez MS, Ramos V, Albertengo L. Present and future role of chitin and chitosan in food. Macromolecular Bioscience 2003; 3(10): 521530 .

176. Gunnar Kratz MB, Claes Arnander, Olle Larm. Immobilised heparin accelerates the healing of human wounds in vivo. Scandinavian Journal of Plastic and Reconstructive Surgery and Hand Surgery 1998; 32(4): 381-386.

177. Kratz G, Arnander C, Swedenborg J, Back M, Falk C, Gouda I, Larm O. Heparin-chitosan complexes stimulate wound healing in human skin. Scandinavian Journal of Plastic and Reconstructive Surgery and Hand Surgery 1997; 31(2): 119-123. 
178. Xu HT, Ma L, Shi HF, Gao CY, Han CM. Chitosan-hyaluronic acid hybrid film as a novel wound dressing: In vitro and in vivo studies. Polymers for Advanced Technologies 2007; 18(11): 869-875.

179. Giunchedi P, Genta I, Conti B, Muzzarelli RAA, Conte U. Preparation and characterization of ampicillin loaded methylpyrrolidinone chitosan and chitosan microspheres. Biomaterials 1998; 19(1-3): 157-161.

180. Madihally SV, Matthew HWT. Porous chitosan scaffolds for tissue engineering. Biomaterials 1999; 20(12): 1133-1142.

181. Wan AGA, Khor E, Wong JM, Hastings GW. Promotion of calcification on carboxymethylchitin discs. Biomaterials 1996; 17(15): 1529-1534.

182. Amiji MM. Permeability and blood compatibility properties of chitosanpoly(ethylene oxide) blend membranes for haemodialysis. Biomaterials 1995; 16(8): 593-599.

183. de la Fuente M, Raviña M, Paolicelli P, Sanchez A, Seijo B, Alonso MJ. Chitosan-based nanostructures: A delivery platform for ocular therapeutics. Advanced Drug Delivery Reviews 2010; 62(1): 100-117.

184. Braga MEM, Pato MTV, Silva HSRC, Ferreira EI, Gil MH, Duarte CMM, de Sousa HC. Supercritical solvent impregnation of ophthalmic drugs on chitosan derivatives. The Journal of Supercritical Fluids 2008; 44(2): 245-257.

185. Yi H, Wu L-Q, Bentley WE, Ghodssi R, Rubloff GW, Culver JN, Payne GF. Biofabrication with chitosan. Biomacromolecules 2005; 6(6): 2881-2894.

186. Park JW, Choi K-H, Park KK. Acid-base equilibria and related properties of chitosan. Bulletin of Korean Chemical Society 1983; 4(2): 68-72.

187. Kulikov SN, Chirkov SN, Il'ina AV, Lopatin SA, Varlamov VP. Effect of the molecular weight of chitosan on its antiviral activity in plants. Applied Biochemistry and Microbiology 2006; 42(2): 200-203.

188. Liu N, Chen XG, Park HJ, Liu CG, Liu CS, Meng XH, Yu LJ. Effect of mw and concentration of chitosan on antibacterial activity of escherichiaa coli. Carbohydrate Polymers 2006; 64: 60-65.

189. No HK, Young Park N, Ho Lee S, Meyers SP. Antibacterial activity of chitosans and chitosan oligomers with different molecular weights. Int. J. Food Microbiol. 2002; 74(1-2): 65-72.

190. Rhim JW, Weller CL, S HK. Characteristics of chitosan films as affected by the type of solvent acid. Food Sci. Biotechnol. 1998; 7(4): 263-268.

191. Kienzle-Sterzer CA, Rodriguez-Sanchez D, Rha C. Mechanical properties of chitosan films: Effect of solvent acid. Makromol. Chem 1982; 183: 13531359. 
192. Srivinasa PC, Ramesh MN, Kumar KR, Tharanathan RN. Properties of chitosan films prepared under different drying conditions. Journal of Food Engineering 2004; 63: 79-85.

193. Pereda M, Aranguren MI, Marcovich NE. Characterization of chitosan/caseinate films. Journal of Applied Polymer Science 2008; 107: 1080-1090.

194. Tsai GJ, Su WH, Chen HC, Pan CL. Antimicrobial activity of shrimp chitin and chitosan from different treatments and applications of fish preservation. Fish. Sci. 2002; 68(1): 170-177.

195. Suyatma NE, Tighzert L, Copinet A. Effects of hydrophilic plasticizers on mechanical, thermal, and surface properties of chitosan films. Journal of Agricultural and Food Chemistry 2005; 53(10): 3950-3957.

196. Ruardy TG, Moorlag HE, Schakenraad JM, Van Der Mei HC, Busscher HJ. Growth of fibroblasts and endothelial cells on wettability gradient surfaces. Journal of Colloid and Interface Science 1997; 188(1): 209-217.

197. Ponsonnet L, Reybier K, Jaffrezic N, Comte V, Lagneau C, Lissac M, Martelet C. Relationship between surface properties (roughness, wettability) of titanium and titanium alloys and cell behaviour. Materials Science and Engineering: C 2003; 23(4): 551-560.

198. Wang Y-W, Wu Q, Chen G-Q. Reduced mouse fibroblast cell growth by increased hydrophilicity of microbial polyhydroxyalkanoates via hyaluronan coating. Biomaterials 2003; 24(25): 4621-4629.

199. Prasitsilp M, Jenwithisuk R, Kongsuwan K, Damrongchai N, Watts P. Cellular responses to chitosan in vitro: The importance of deacetylation. Journal of Materials Science: Materials in Medicine 2000; 11(12): 773-778.

200. Neamnark A, Sanchavanakit N, Pavasant P, Bunaprasert T, Supaphol P, Rujiravanit R. In vitro biocompatibility evaluations of hexanoyl chitosan film. Carbohydrate Polymers 2007; 68(1): 166-172.

201. Cheng M, Deng J, Yang F, Gong Y, Zhao N, Zhang X. Study on physical properties and nerve cell affinity of composite films from chitosan and gelatin solutions. Biomaterials 2003; 24(17): 2871-2880.

202. Jongwattanapisan P, Charoenphandhu N, Krishnamra N, Thongbunchoo J, Tang IM, Hoonsawat R, Smith SM, Pon-On W. In vitro study of the sbf and osteoblast-like cells on hydroxyapatite/chitosan-silica nanocomposite. Materials Science and Engineering: C 2011; 31(2): 290-299.

203. Wenling C, Duohui J, Jiamou L, Yandao G, Nanming Z, Xiufang Z. Effects of the degree of deacetylation on the physicochemical properties and schwann cell affinity of chitosan films. J. Biomater. Appl. 2005; 20(2): 157-177. 
204. Chatelet C, Damour O, Domard A. Infuence of the degree of acetylation on some biological properties

of chitosan films. Biomaterials 2001; 22: 261.

205. No HK, Park NY, Lee SH, Meyers SP. Antibacterial activity of chitosans and chitosan oligomers with different molecular weights. Int. J. Food Microbiol. 2002; 74: 65-72.

206. Chung Y-C, Chen C-Y. Antibacterial characteristics and activity of acidsoluble chitosan. Bioresour. Technol. 2008; 99(8): 2806-2814.

207. Chen Y-M, Chung Y-C, Wang LW, Chen K-T, Li S-Y. Antibacterial properties of chitosan in waterborne pathogen. Journal of Environmental Science and Health, Part A: Toxic/Hazardous Substances and Environmental Engineering 2002; 37(7): 1379 - 1390.

208. Elghaouth A, Arul J, Grenier J, Asselin A. Antifungal activity of chitosan on 2 postharvest pathogens of strawberry fruits. Phytopathology 1992; 82(4): 398402.

209. Chirkov SN. The antiviral activity of chitosan (review). Applied Biochemistry and Microbiology 2002; 38(1): 1-8.

210. Pospieszny H, Atabekov JG. Effect of chitosan on the hypersensitive reaction of bean to alfalfa mosaic virus. Plant Science 1989; 62(1): 29-31.

211. Guang Liu W, De Yao K. Chitosan and its derivatives--a promising non-viral vector for gene transfection. J. Control. Release 2002; 83(1): 1-11.

212. Rabea EI, Badawy MET, Stevens CV, Smagghe G, Steurbaut W. Chitosan as antimicrobial agent: Applications and mode of action. Biomacromolecules 2003; 4(6): 1457-1465.

213. Pospieszny H, Chirkov S, Atabekov J. Induction of antiviral resistance in plants by chitosan. Plant Science 1991; 79(1): 63-68.

214. Pospieszny H. Antiviroid activity of chitosan. Crop Prot. 1997; 16(2): 105106.

215. Iriti M, Sironi M, Gomarasca S, Casazza AP, Soave C, Faoro F. Cell deathmediated antiviral effect of chitosan in tobacco. Plant Physiology and Biochemistry; 44(11-12): 893-900.

216. Chandrasekaran R, Radha A. Molecular architectures and functionalproperties of gellan gum and related polysaccharides. Trends Food Sci. Technol. 1995; 6(5): 143-148.

217. Jansson P-E, Lindberg B, Sandford PA. Structural studies of gellan gum, an extracellular polysaccharide elaborated by pseudomonas elodea. Carbohydr. Res. 1983; 124(1): 135-139. 
218. Kuo M-S, Mort AJ, Dell A. Identification and location of l-glycerate, an unusual acyl substituent in gellan gum. Carbohydr. Res. 1986; 156: 173-187.

219. CPKelco. Kelcogel® gellan gum book, 5th edn www.CPkelco.com.

220. Kang KS, Veeder GT, Mirrasoul PJ, Kaneko T, Cottrell IW. Agar-like polysaccharide produced by a pseudomonas species: Production and basic properties. Appl. Environ. Microbiol. 1982; 43(5): 1086-1091.

221. Yamamoto F, Cunha RL. Acid gelation of gellan: Effect of final ph and heat treatment conditions. Carbohydrate Polymers 2007; 68(3): 517-527.

222. Yuguchi Y, Mimura M, Kitamura S, Urakawa H, Kajiwara K. Structural characteristics of gellan in aqueous solution. Food Hydrocolloids 1993; 7(5): 373-385.

223. Milas M, Shi X, Rinaudo M. On the physicochemical properties of gellan gum. Biopolymers 1990; 30(3-4): 451-464.

224. Ogawa E. Temperature dependence of the conformational properties of sodium-type gellan gum in aqueous solutions. In: Nishinari K (ed) Physical chemistry and industrial application of gellan gum, vol. 114. Springer Berlin / Heidelberg, 1999, pp 8-14.

225. Quinn FX, Hatakeyama T, Yoshida H, Takahashi M, Hatakeyama H. The conformational properties of gellan gum hydrogels. Polymer Gels and Networks 1993; 1(2): 93-114.

226. Nishinari K, Miyoshi E, Takaya T, Williams PA. Rheological and dsc studies on the interaction between gellan gum and konjac glucomannan. Carbohydrate Polymers; 30(2-3): 193-207.

227. Nishinari K. Gellan gum: Structures, properties and functions - international workshop on gellan and related polysaccharides (iwgrp) - 14-15 november, 1994, osaka, japan - introduction. Carbohydrate Polymers 1996; 30(2-3): 7576.

228. Camelin I, Lacroix C, Paquin C, Prevost H, Cachon R, Divies C. Effect of chelatants on gellan gel rheological properties and setting temperature for immobilization of living bifidobacteria. Biotechnology Progress 1993; 9(3): 291-297.

229. Yang L, Paulson AT. Effects of lipids on mechanical and moisture barrier properties of edible gellan film. Food Research International 2000; 33(7): 571-578.

230. Harris JE. Gelrite as an agar substitute for the cultivation of mesophilic methanobacterium and methanobrevibacter species. Appl. Environ. Microbiol. 1985; 50(4): 1107-1109. 
231. Colegrove GT. Agricultural applications of microbial polysaccharides. Industrial \& Engineering Chemistry Product Research and Development 1983; 22(3): 456-460.

232. Kumar SC, Satish CS, Shivakumar HG. Formulation and evaluation of chitosan-gellan based methotrexate implants. Journal of Macromolecular Science, Part A: Pure and Applied Chemistry 2008; 45(8): 643 - 649.

233. Smith AM, Shelton RM, Perrie Y, Harris JJ. An initial evaluation of gellan gum as a material for tissue engineering applications. J. Biomater. Appl. 2007; 22(3): 241-254.

234. Balasubramaniam J, Kumar MT, Pandit JK, Kant S. Gellan-based scleral implants of indomethacin: In vitro and in vivo evaluation. Drug Delivery 2004; 11(6): 371-379.

235. Singh BN, Kim KH. Effects of divalent cations on drug encapsulation efficiency of deacylated gellan gum. Journal of Microencapsulation 2005; 22(7): 761-771.

236. Greaves JL, Wilson CG, Rozier A, Grove J, Plazonnet B. Scintigraphic assessment of an ophthalmic gelling vehicle in man and rabbit. Current Eye Research 1990; 9(5): 415-420.

237. Lee M-W, Chen H-J, Tsao S-W. Preparation, characterization and biological properties of gellan gum films with 1-ethyl-3-(3dimethylaminopropyl)carbodiimide cross-linker. Carbohydrate Polymers 2010; 82(3): 920-926.

238. Wang C, Gong Y, Lin Y, Shen J, Wang D-A. A novel gellan gel-based microcarrier for anchorage-dependent cell delivery. Acta Biomaterialia 2008; 4(5): 1226-1234.

239. Oliveira JT, Santos TC, Martins L, Picciochi R, Marques AP, Castro AG, Neves NM, Mano JF, Reis RL. Gellan gum injectable hydrogels for cartilage tissue engineering applications: In vitro studies and preliminary in vivo evaluation. Tissue Engineering Part A 2010; 16(1): 343-353.

240. Akita H, Hattori T. Studies on molecular composite. I. Processing of molecular composites using a precursor polymer for poly(p-phenylene benzobisthiazole). Journal of Polymer Science Part B: Polymer Physics 1999; 37(3): 189-197.

241. Akita H, Kobayashi H. Studies on molecular composite. Iii. Nano composites consisting of poly(p-phenylene benzobisthiazole) and thermoplastic polyamide. Journal of Polymer Science Part B: Polymer Physics 1999; 37(3): 209-218. 
242. Casariego A, Souza BWS, Cerqueira MA, Teixeira JA, Cruz L, Díaz R, Vicente AA. Chitosan/clay films' properties as affected by biopolymer and clay micro/nanoparticles' concentrations. Food Hydrocolloids 2009; 23(7): 1895-1902.

243. Liu H, Brinson LC. Reinforcing efficiency of nanoparticles: A simple comparison for polymer nanocomposites. Composites Science and Technology 2008; 68(6): 1502-1512.

244. Liu BS, Huang TB. Nanocomposites of genipin-crosslinked chitosan/silver nanoparticles - structural reinforcement and antimicrobial properties. Macromolecular Bioscience 2008; 8(10): 932-941.

245. Jose Ruben $M$, et al. The bactericidal effect of silver nanoparticles. Nanotechnology 2005; 16(10): 2346.

246. Gao L, Zhang Q. Effects of amorphous contents and particle size on the photocatalytic properties of tio2 nanoparticles. Scripta Materialia 2001; 44(89): 1195-1198.

247. Li Q, Mahendra S, Lyon DY, Brunet L, Liga MV, Li D, Alvarez PJJ. Antimicrobial nanomaterials for water disinfection and microbial control: Potential applications and implications. Water Research 2008; 42(18): 45914602.

248. Feng QL, Wu J, Chen GQ, Cui FZ, Kim TN, Kim JO. A mechanistic study of the antibacterial effect of silver ions on escherichia coli and staphylococcus aureus. Journal of Biomedical Materials Research 2000; 52(4): 662-668.

249. KIM JP, CHO I, H, KIM IK, KIM CU, HEO NH, SUH SY. Manufacturing of anti-viral inorganic materials from colloidal silver and titanium oxide. Revue Roumaine de Chimie 2006; 51(11): 1121-1129.

250. Tio2 global study forecasts new decade. Paint \& Coatings Industry 1993; 9(7): 10.

251. Li Q, Su H, Tan T. Synthesis of ion-imprinted chitosan-tio2 adsorbent and its multi-functional performances. Biochemical Engineering Journal 2008; 38(2): 212-218.

252. Guan H, Chi D, Yu J, Li X. A novel photodegradable insecticide: Preparation, characterization and properties evaluation of nano-imidacloprid. Pest. Biochem. Physiol. 2008; 92(2): 83-91.

253. Rani VVD, Ramachandran R, Chennazhi KP, Tamura H, Nair SV, Jayakumar R. Fabrication of alginate/nanotio2 needle composite scaffolds for tissue engineering applications. Carbohydrate Polymers 2011; 83(2): 858-864.

254. Zhao L, Chang J, Zhai W. Preparation and hl-7702 cell functionality of titania/chitosan composite scaffolds. Journal of Materials Science: Materials in Medicine 2009; 20(4): 949-957. 
255. Peng CC, Yang MH, Chiu WT, Chiu CH, Yang CS, Chen YW, Chen KC, Peng RY. Composite nano-titanium oxide-chitosan artificial skin exhibits strong wound-healing effect-an approach with anti-inflammatory and bactericidal kinetics. Macromolecular Bioscience 2008; 8(4): 316-327.

256. Son B, Yeom B-Y, Song SH, Lee C-S, Hwang TS. Antibacterial electrospun chitosan/poly(vinyl alcohol) nanofibers containing silver nitrate and titanium dioxide. Journal of Applied Polymer Science 2009; 111(6): 2892-2899.

257. Zan L, Fa W, Peng T, Gong Z-k. Photocatalysis effect of nanometer tio2 and tio2-coated ceramic plate on hepatitis b virus. Journal of Photochemistry and Photobiology B: Biology 2007; 86(2): 165-169.

258. Sunada K, Kikuchi Y, Hashimoto K, Fujishima A. Bactericidal and detoxification effects of tio2 thin film photocatalysts. Environmental Science \& Technology 1998; 32(5): 726-728.

259. Maness P-C, Smolinski S, Blake DM, Huang Z, Wolfrum EJ, Jacoby WA. Bactericidal activity of photocatalytic tio2 reaction: Toward an understanding of its killing mechanism. Appl. Environ. Microbiol. 1999; 65(9): 4094-4098.

260. Chung C-J, Lin H-I, Chou C-M, Hsieh P-Y, Hsiao C-H, Shi Z-Y, He J-L. Inactivation of staphylococcus aureus and escherichia coli under various light sources on photocatalytic titanium dioxide thin film. Surface and Coatings Technology 2009; 203(8): 1081-1085.

261. Slama T. Gram-negative antibiotic resistance: There is a price to pay. Critical Care 2008; 12(Suppl 4): S4.

262. Silver S. Bacterial silver resistance: Molecular biology and uses and misuses of silver compounds. FEMS Microbiology Reviews 2003; 27(2-3): 341-353.

263. Travan A, Pelillo C, Donati I, Marsich E, Benincasa M, Scarpa T, Semeraro S, Turco G, Gennaro R, Paoletti S. Non-cytotoxic silver nanoparticlepolysaccharide nanocomposites with antimicrobial activity. Biomacromolecules 2009; 10(6): 1429-1435.

264. Lu S, Gao W, Gu HY. Construction, application and biosafety of silver nanocrystalline chitosan wound dressing. Burns 2008; 34(5): 623-628.

265. Sanpui P, Murugadoss A, Prasad PVD, Ghosh SS, Chattopadhyay A. The antibacterial properties of a novel chitosan-ag-nanoparticle composite. Int. J. Food Microbiol. 2008; 124(2): 142-146.

266. Franklin NM, Rogers NJ, Apte SC, Batley GE, Gadd GE, Casey PS. Comparative toxicity of nanoparticulate zno, bulk zno, and zncl2 to a freshwater microalga (pseudokirchneriella subcapitata): The importance of particle solubility. Environmental Science \& Technology 2007; 41(24): 84848490 . 
267. Aydin Sevinç B, Hanley L. Antibacterial activity of dental composites containing zinc oxide nanoparticles. Journal of Biomedical Materials Research Part B: Applied Biomaterials 2010; 94B(1): 22-31.

268. Wang X, Du YM, Liu H. Preparation, characterization and antimicrobial activity of chitosan - zn complex. Carbohydrate Polymers 2004; 56(1): 21-26.

269. ZHENG Y, Li R. In vitro and in vivo biocompatibility studies of zno nanoparticles. International Journal of Modern Physics B 2009; Vol. 23(6 \& 7): 1566-1571.

270. Hanley C, Thurber A, Hanna C, Punnoose A, Zhang J, Wingett D. The influences of cell type and zno nanoparticle size on immune cell cytotoxicity and cytokine induction. Nanoscale Research Letters 2009; 4(12): 1409-1420.

271. In vitro cytotoxicity assessment of selected nanoparticles using human skin fibroblasts. AATEX 14; August 21-25,; Tokyo, Japan. Japanese Society for Alternatives to Animal Experiments, 2007.

272. Lin W, Xu Y, Huang C-C, Ma Y, Shannon K, Chen D-R, Huang Y-W. Toxicity of nano- and micro-sized zno particles in human lung epithelial cells. Journal of Nanoparticle Research 2009; 11(1): 25-39.

273. Sawai J, Igarashi H, Hashimoto A, Kokugan T, Shimizu M. Evaluation of growth inhibitory effect of ceramics powder slurry on bacteria by conductance method. JOURNAL OF CHEMICAL ENGINEERING OF JAPAN 1995; 28(3): 288-293.

274. Sawai J. Quantitative evaluation of antibacterial activities of metallic oxide powders (zno, mgo and cao) by conductimetric assay. Journal of Microbiological Methods 2003; 54(2): 177-182.

275. Huang Z, Zheng X, Yan D, Yin G, Liao X, Kang Y, Yao Y, Huang D, Hao B. Toxicological effect of zno nanoparticles based on bacteria. Langmuir 2008; 24(8): 4140-4144.

276. Sawai J, Shoji S, Igarashi H, Hashimoto A, Kokugan T, Shimizu M, Kojima $H$. Hydrogen peroxide as an antibacterial factor in zinc oxide powder slurry. $J$. Ferment. Bioeng. 1998; 86(5): 521-522.

277. Brayner R, Ferrari-Iliou R, Brivois N, Djediat S, Benedetti MF, Fiévet F. Toxicological impact studies based on escherichia coli bacteria in ultrafine zno nanoparticles colloidal medium. Nano Letters 2006; 6(4): 866-870.

278. Garrison MW. Pharmacodynamic assessment of the activity of high-dose (750 $\mathrm{mg}$ ) levofloxacin, ciprofloxacin, and gatifloxacin against clinical strains of pseudomonas aeruginosa. Diagnostic Microbiology and Infectious Disease 2006; 54(1): 51-56. 
279. Santoro MIRM, Kassab NM, Singh AK, Kedor-Hackmam ERM. Quantitative determination of gatifloxacin, levofloxacin, lomefloxacin and pefloxacin fluoroquinolonic antibiotics in pharmaceutical preparations by highperformance liquid chromatography. Journal of Pharmaceutical and Biomedical Analysis 2006; 40(1): 179-184.

280. Böttcher S, Baum Hv, Hoppe-Tichy T, Benz C, Sonntag HG. An hplc assay and a microbiological assay to determine levofloxacin in soft tissue, bone, bile and serum. Journal of Pharmaceutical and Biomedical Analysis 2001; 25(2): 197-203.

281. Altiokka G, Atkosar Z, Can NO. The determination of levofloxacin by flow injection analysis using uv detection, potentiometry, and conductometry in pharmaceutical preparations. Journal of Pharmaceutical and Biomedical Analysis 2002; 30(3): 881-885.

282. Croom KF, Goa KL. Levofloxacin: A review of its use in the treatment of bacterial infections in the united states.(adis drug evaluation). Drugs 2003; 63(24): 2769(34).

283. Oates JA, Wood AJJ, Hooper DC, Wolfson JS. Fluoroquinolone antimicrobial agents. New England Journal of Medicine 1991; 324(6): 384-394.

284. Huang W, Zheng Q, Sun W, Xu H, Yang X. Levofloxacin implants with predefined microstructure fabricated by three-dimensional printing technique. International Journal of Pharmaceutics 2007; 339(1-2): 33-38.

285. Keating GM. Levofloxacin $0.5 \%$ ophthalmic solution: A review of its use in the treatment of external ocular infections and in intraocular surgery.(adis drug evaluation)(clinical report). Drugs 2009; 69(9): 1267(20).

286. Dajcs JJ, Thibodeaux BA, Marquart ME, Girgis DO, Traidej M, O'Callaghan RJ. Effectiveness of ciprofloxacin, levofloxacin, or moxifloxacin for treatment of experimental staphylococcus aureus keratitis. Antimicrob. Agents Chemother. 2004; 48(6): 1948-1952.

287. Raizman MB, Rubin JM, Graves AL, Rinehart M. Tear concentrations of levofloxacin following topical administration of a single dose of $0.5 \%$ levofloxacin ophthalmic solution in healthy volunteers. Clinical Therapeutics 2002; 24(9): 1439-1450.

288. Holland EJ, McCarthy M, Holland S. The ocular penetration of levofloxacin $1.5 \%$ and gatifloxacin $0.3 \%$ ophthalmic solutions in subjects undergoing corneal transplant surgery. Current Medical Research and Opinion 2007; 23(12): 2955-2960.

289. Bezwada P, Clark LA, Schneider S. Intrinsic cytotoxic effects of fluoroquinolones on human corneal keratocytes and endothelial cells. Current Medical Research and Opinion 2008; 24(2): 419-424. 
290. Paul DH, Steven AP, Peter DB, Michael JP, et al. Inhibitory effects of the quinolone antibiotics trovafloxacin, ciprofloxacin, and levofloxacin on osteoblastic cells in vitro. Journal of Orthopaedic Research 2000; 18(5): 721.

291. Fu KP, Lafredo SC, Foleno B, Isaacson DM, Barrett JF, Tobia AJ, Rosenthale ME. In vitro and in vivo antibacterial activities of levofloxacin (l-ofloxacin), an optically active ofloxacin. Antimicrob. Agents Chemother. 1992; 36(4): 860-866.

292. Bucaneve G, Micozzi A, Menichetti F, Martino P, Dionisi MS, Martinelli G, Allione B, D'Antonio D, Buelli M, Nosari AM, Cilloni D, Zuffa E, Cantaffa R, Specchia G, Amadori S, Fabbiano F, Deliliers GL, Lauria F, Foà R, Del Favero A. Levofloxacin to prevent bacterial infection in patients with cancer and neutropenia. New England Journal of Medicine 2005; 353(10): 977-987.

293. Drago L, De Vecchi E, Mombelli B, Nicola L, Valli M, Gismondo MR. Activity of levofloxacin and ciprofloxacin against urinary pathogens. Journal of Antimicrobial Chemotherapy 2001; 48(1): 37-45.

294. Yamamoto H, Horita C, Senoo Y, Nishida A, Ohkawa K. Polyion complex fiber and capsule formed by self-assembly of poly-l-lysine and gellan at solution interfaces. Journal of Applied Polymer Science 2001; 79(3): 437-446.

295. Lawrie G, Keen I, Drew B, Chandler-Temple A, Rintoul L, Fredericks P, Grøndahl L. Interactions between alginate and chitosan biopolymers characterized using ftir and xps. Biomacromolecules 2007; 8(8): 2533-2541.

296. Mao R, Tang J, Swanson BG. Texture properties of gellan gels as affected by temperature. Journal of Texture Studies 1999; 30(4): 409-433.

297. P. Wu, A. C. Fisher, P. P. Foo, D. Queen, Gaylor JDS. Biomaterials 1995; 16: 171.

298. Limem M, McCallum D, Wallace GG, in het Panhuis M, Calvert P. Inkjet printing of self-assembling polyelectrolyte hydrogels. Soft Matter 2011.

299. Amirshahi SH, Pailthorpe MT. Applying the kubelka-munk equation to explain the color of blends prepared from precolored fibers. Textile Research Journal 1994; 64(6): 357-364.

300. Crank J. Mathematics of diffusion, 2nd ed edn Oxford Clarendon Press, Oxford 1975.

301. Bian C, Yu Y, Xue G. Synthesis of conducting polyaniline/tio2 composite nanofibres by one-step in situ polymerization method. Journal of Applied Polymer Science 2007; 104(1): 21-26.

302. Liu ZL, Cui ZL, Zhang ZK. The structural defects and uv-vis spectral characterization of tio2 particles doped in the lattice with cr3+ cations. Materials Characterization 2005; 54(2): 123-129. 
303. Twu Y-K, Chen Y-W, Shih C-M. Preparation of silver nanoparticles using chitosan suspensions. Powder Technology 2008; 185(3): 251-257.

304. Kittur FS, Vishu Kumar AB, Varadaraj MC, Tharanathan RN. Chitooligosaccharides--preparation with the aid of pectinase isozyme from aspergillus niger and their antibacterial activity. Carbohydr. Res. 2005; 340(6): 1239-1245.

305. Kumar ABV, Gowda LR, Tharanathan RN. Non-specific depolymerization of chitosan by pronase and characterization of the resultant products. European Journal of Biochemistry 2004; 271(4): 713-723.

306. Hornof MD, Kast CE, Bernkop-Schnürch A. In vitro evaluation of the viscoelastic properties of chitosan-thioglycolic acid conjugates. European Journal of Pharmaceutics and Biopharmaceutics 2003; 55(2): 185-190.

307. Buffington LA, Stevens ES. Far-ultraviolet circular dichroism of solutions, gels, and films of chitins. Journal of the American Chemical Society 1979; 101(18): 5159-5162.

308. Singh J, Dutta PK. Preparation, circular dichroism induced helical conformation and optical property of chitosan acid salt complexes for biomedical applications. Int. J. Biol. Macromol. 2009; 45(4): 384-392.

309. Rout DK, Pulapura SK, Gross RA. Gel-sol transition and thermotropic behavior of a chitosan derivative in lyotropic solution. Macromolecules 1993; 26(22): 6007-6010.

310. Silva CL, Pereira JC, Ramalho A, Pais AACC, Sousa JJS. Films based on chitosan polyelectrolyte complexes for skin drug delivery: Development and characterization. Journal of Membrane Science 2008; 320(1-2): 268-279.

311. Kasaai MR, Arul J, Charlet G. Intrinsic viscosity-molecular weight relationship for chitosan. Journal of Polymer Science Part B: Polymer Physics 2000; 38(19): 2591-2598.

312. Zainal Z, Hui LK, Hussein MZ, Abdullah AH, Hamadneh IR. Characterization of tio2-chitosan/glass photocatalyst for the removal of a monoazo dye via photodegradation-adsorption process. Journal of Hazardous Materials 2009; 164(1): 138-145.

313. Shi X, Cassagneau T, Caruso F. Electrostatic interactions between polyelectrolytes and a titania precursor: Thin film and solution studies. Langmuir 2002; 18(3): 904-910.

314. Stoimenov PK, Klinger RL, Marchin GL, Klabunde KJ. Metal oxide nanoparticles as bactericidal agents. Langmuir 2002; 18(17): 6679-6686.

315. Sinha Ray S, Okamoto M. Polymer/layered silicate nanocomposites: A review from preparation to processing. Progress in Polymer Science 2003; 28(11): 1539-1641. 
316. Podsiadlo P, Tang Z, Shim BS, Kotov NA. Counterintuitive effect of molecular strength and role of molecular rigidity on mechanical properties of layer-by-layer assembled nanocomposites. Nano Letters 2007; 7(5): 12241231.

317. Qu X, Wirsén A, Albertsson AC. Novel ph-sensitive chitosan hydrogels: Swelling behavior and states of water. Polymer 2000; 41(12): 4589-4598.

318. Tanabe T, Okitsu N, Tachibana A, Yamauchi K. Preparation and characterization of keratin-chitosan composite film. Biomaterials 2002; 23(3): 817-825.

319. Wei D, Ye Y, Jia X, Yuan C, Qian W. Chitosan as an active support for assembly of metal nanoparticles and application of the resultant bioconjugates in catalysis. Carbohydr. Res. 2010; 345(1): 74-81.

320. Kim TH, Park IK, Nah JW, Choi YJ, Cho CS. Galactosylated chitosan/DNA nanoparticles prepared using water-soluble chitosan as a gene carrier. Biomaterials 2004; 25(17): 3783-3792.

321. Kim K, Kwon S, Park JH, Chung H, Jeong SY, Kwon IC, Kim I-S. Physicochemical characterizations of self-assembled nanoparticles of glycol chitosan-deoxycholic acid conjugates. Biomacromolecules 2005; 6(2): 11541158.

322. Ding Z, Chen J, Gao S, Chang J, Zhang J, Kang ET. Immobilization of chitosan onto poly--lactic acid film surface by plasma graft polymerization to control the morphology of fibroblast and liver cells. Biomaterials 2004; 25(6): 1059-1067.

323. Mao JS, Cui YL, Wang XH, Sun Y, Yin YJ, Zhao HM, De Yao K. A preliminary study on chitosan and gelatin polyelectrolyte complex cytocompatibility by cell cycle and apoptosis analysis. Biomaterials 2004; 25(18): 3973-3981.

324. Geiser M, Rothen-Rutishauser B, Kapp N, Schürch S, Kreyling W, Schulz H, Semmler M, Hof VI, Heyder J, Gehr P. Ultrafine particles cross cellular membranes by nonphagocytic mechanisms in lungs and in cultured cells. Environ Health Perspect 2005; 113(11).

325. van Wachem PB, Beugeling T, Feijen J, Bantjes A, Detmers JP, van Aken WG. Interaction of cultured human endothelial cells with polymeric surfaces of different wettabilities. Biomaterials 1985; 6(6): 403-408.

326. Altankov G, Groth TH. Reorganization of substratum-bound fibronection on hydrophilic and hydrophobic materials is related to biocompatibility. Journal of materials science : Materials in medicine 1994; 5: 732-737.

327. Klee D, Villari V, Hocker H. Surface modification of a new flexible polymer with improved cell adhesion. Journal of materials science : Materials in medicine 1994; 5: 592-595. 
328. Ueda-Yukoshi T, Matsuda T. Cellular responses on a wettability gradient surface with continuous variations in surface compositions of carbonate and hydroxyl groups. Langmuir 1995; 11(10): 4135-4140.

329. Lee JH, Khang G, Lee JW, Lee HB. Interaction of different types of cells on polymer surfaces with wettability gradient. Journal of Colloid and Interface Science 1998; 205(2): 323-330.

330. Discher DE, Janmey P, Wang Y-l. Tissue cells feel and respond to the stiffness of their substrate. Science 2005; 310(5751): 1139-1143.

331. Xu YX, Kim KM, Hanna MA, Nag D. Chitosan-starch composite film: Preparation and characterization. Ind. Crop. Prod. 2005; 21(2): 185-192.

332. Suzuki T, Mizushima Y, Umeda T, Ohashi R. Further biocompatibility testing of silica-chitosan complex membrane in the production of tissue plasminogen activator by epithelial and fibroblast cells. J. Biosci. Bioeng. 1999; 88(2): 194199.

333. Kim H-W, Kim H-E, Salih V. Stimulation of osteoblast responses to biomimetic nanocomposites of gelatin-hydroxyapatite for tissue engineering scaffolds. Biomaterials 2005; 26(25): 5221-5230.

334. Zhuang $\mathrm{H}$, Zheng $\mathrm{J}$, Gao $\mathrm{H}$, De Yao K. In vitro biodegradation and biocompatibility of gelatin/montmorillonite-chitosan intercalated nanocomposite. Journal of Materials Science: Materials in Medicine 2007; 18(5): 951-957.

335. Sarasam AR, Krishnaswamy RK, Madihally SV. Blending chitosan with polycaprolactone: Effects on physicochemical and antibacterial properties. Biomacromolecules 2006; 7(4): 1131-1138.

336. Rana V, Kushwaha O, Singh R, Mishra S, Ha C-S. Tensile properties, cell adhesion, and drug release behavior of chitosan-silver-gelatin nanohybrid films and scaffolds. Macromolecular Research 2010; 18(9): 845-852.

337. Ying-chien CHUNG, Ya-ping SU, Chiing-chang CHEN, Guang JIA, WANG H-l, J C Gaston WU, LIN J-g. Relationship between antibacterial activity of chitosan and surface characteristics of cell wall. Acta Pharmacol Sin 2004; 25(7): 932-936.

338. Wang X, Du Y, Yang J, Wang X, Shi X, Hu Y. Preparation, characterization and antimicrobial activity of chitosan/layered silicate nanocomposites. Polymer 2006; 47(19): 6738-6744.

339. Sondi I, Salopek-Sondi B. Silver nanoparticles as antimicrobial agent: A case study on e. Coli as a model for gram-negative bacteria. Journal of Colloid and Interface Science 2004; 275(1): 177-182. 
340. Gontard N, Guilbert S, Cuq JL. Water and glycerol as plasticizers affect mechanical and water vapor properties of an edible wheat film. J. Food Sci. 1993; 58: 206-211.

341. Hawkins CL, Davies MJ. Degradation of hyaluronic acid, poly- and monosaccharides, and model compounds by hypochlorite: Evidence for radical intermediates and fragmentation. Free Radical Biology and Medicine 1998; 24(9): 1396-1410.

342. Meulenkamp EA. Synthesis and growth of zno nanoparticles. The Journal of Physical Chemistry B 1998; 102(29): 5566-5572.

343. Singh AK. Synthesis, characterization, electrical and sensing properties of zno nanoparticles. Advanced Powder Technology; In Press, Corrected Proof.

344. Hariharan C. Photocatalytic degradation of organic contaminants in water by zno nanoparticles: Revisited. Applied Catalysis A: General 2006; 304: 55-61.

345. Morris ER, Rees DA, Sanderson GR, Thom D. Conformation and circular dichroism of uronic acid residues in glycosides and polysaccharides. Journal of the Chemical Society, Perkin Transactions 2 1975; (13): 1418-1425.

346. Chakrabarti B, Park JW, Stevens ES. Glycosaminoglycans: Structure and interactio. Critical Reviews in Biochemistry and Molecular Biology 1980; 8(3): 225-313.

347. Ogawa E, Takahashi R, Yajima H, Nishinari K. Effects of molar mass on the coil to helix transition of sodium-type gellan gums in aqueous solutions. Food Hydrocolloids; 20(2-3): 378-385.

348. Milas M, Rinaudo M. The gellan sol-gel transition. Carbohydrate Polymers; 30(2-3): 177-184.

349. Belova V, Möhwald H, Shchukin DG. Sonochemical intercalation of preformed gold nanoparticles into multilayered clays. Langmuir 2008; 24(17): 9747-9753.

350. Maiti P, Nam PH, Okamoto M, Hasegawa N, Usuki A. Influence of crystallization on intercalation, morphology, and mechanical properties of polypropylene/clay nanocomposites. Macromolecules 2002; 35(6): 20422049.

351. Danusso F, Tieghi G. Strength versus composition of rigid matrix particulate composites. Polymer 1986; 27(9): 1385-1390.

352. Fu S-Y, Feng X-Q, Lauke B, Mai Y-W. Effects of particle size, particle/matrix interface adhesion and particle loading on mechanical properties of particulate-polymer composites. Composites Part B: Engineering 2008; 39(6): 933-961. 
353. Zhu L, Ye X, Tang G, Zhao N, Gong Y, Zhao Y, Zhao J, Zhang X. Corrosion test, cell behavior test, and in vivo study of gradient tio2 layers produced by compound electrochemical oxidation. Journal of Biomedical Materials Research Part A 2006; 78A(3): 515-522.

354. Jin C-Y, Zhu B-S, Wang X-F, Lu Q-H. Cytotoxicity of titanium dioxide nanoparticles in mouse fibroblast cells. Chemical Research in Toxicology 2008; 21(9): 1871-1877.

355. Li J, Guo D, Wang X, Wang H, Jiang H, Chen B. The photodynamic effect of different size zno nanoparticles on cancer cell proliferation in vitro. Nanoscale Research Letters 2010; 5(6): 1063-1071.

356. Vamanu CI, Cimpan MR, Høl PJ, Sørnes S, Lie SA, Gjerdet NR. Induction of cell death by tio2 nanoparticles: Studies on a human monoblastoid cell line. Toxicology in Vitro 2008; 22(7): 1689-1696.

357. Dimitrievska S, Petit A, Ajji A, Bureau MN, Yahia LH. Biocompatibility of novel polymer-apatite nanocomposite fibers. Journal of Biomedical Materials Research Part A 2008; 84A(1): 44-53.

358. Altankov G, Groth T. Reorganization of substratum-bound fibronectin on hydrophilic and hydrophobic materials is related to biocompatibility. Journal of Materials Science: Materials in Medicine 1994; 5(9): 732-737.

359. Hatano K, Inoue H, Kojo T, Matsunaga T, Tsujisawa T, Uchiyama C, Uchida Y. Effect of surface roughness on proliferation and alkaline phosphatase expression of rat calvarial cells cultured on polystyrene. Bone 1999; 25(4): 439-445.

360. Campoccia D, Arciola CR, Cervellati M, Maltarello MC, Montanaro L. In vitro behaviour of bone marrow-derived mesenchymal cells cultured on fluorohydroxyapatite-coated substrata with different roughness. Biomaterials 2003; 24(4): 587-596.

361. Deligianni DD, Katsala ND, Koutsoukos PG, Missirlis YF. Effect of surface roughness of hydroxyapatite on human bone marrow cell adhesion, proliferation, differentiation and detachment strength. Biomaterials 2001; 22(1): 87-96.

362. van den Dolder J, de Ruijter AJE, Spauwen PHM, Jansen JA. Observations on the effect of bmp-2 on rat bone marrow cells cultured on titanium substrates of different roughness. Biomaterials 2003; 24(11): 1853-1860.

363. Xu X, Li B, Kennedy JF, Xie BJ, Huang M. Characterization of konjac glucomannan-gellan gum blend films and their suitability for release of nisin incorporated therein. Carbohydrate Polymers 2007; 70(2): 192-197. 
364. Tsao CT, Chang CH, Lin YY, Wu MF, Wang JL, Young TH, Han JL, Hsieh KH. Evaluation of chitosan/[gamma]-poly(glutamic acid) polyelectrolyte complex for wound dressing materials. Carbohydrate Polymers; In Press, Corrected Proof.

365. Denuziere A, Ferrier D, Damour O, Domard A. Chitosan-chondroitin sulfate and chitosan-hyaluronate polyelectrolyte complexes: Biological properties. Biomaterials 1998; 19(14): 1275-1285.

366. Luo K, Yin J, Song Z, Cui L, Cao B, Chen X. Biodegradable interpolyelectrolyte complexes based on methoxy poly(ethylene glycol)-bpoly( $\alpha$, l-glutamic acid) and chitosan. Biomacromolecules 2008; 9(10): 26532661.

367. Butler MF, Ng Y-F, Pudney PDA. Mechanism and kinetics of the crosslinking reaction between biopolymers containing primary amine groups and genipin. Journal of Polymer Science Part A: Polymer Chemistry 2003; 41(24): 39413953.

368. Kuboe Y, Tonegawa H, Ohkawa K, Yamamoto H. Quinone cross-linked polysaccharide hybrid fiber. Biomacromolecules 2003; 5(2): 348-357.

369. Atiyeh B, Amm C, El Musa K. Improved scar quality following primary and secondary healing of cutaneous wounds. Aesthetic Plastic Surgery 2003; 27(5): 411-417.

370. Gilchrist T, Martin AM. Wound treatment with sorbsan -- an alginate fibre dressing. Biomaterials 1983; 4(4): 317-320.

371. Baxter S, Zivanovic S, Weiss J. Molecular weight and degree of acetylation of high-intensity ultrasonicated chitosan. Food Hydrocolloids 2005; 19(5): 821830.

372. Zhang X, Yang D, Nie J. Chitosan/polyethylene glycol diacrylate films as potential wound dressing material. Int. J. Biol. Macromol. 2008; 43(5): 456462.

373. Wu P, Fisher AC, Foo PP, Queen D, Gaylor JDS. In vitro assessment of water vapour transmission of synthetic wound dressings. Biomaterials 1995; 16(3): 171-175.

374. Abramovic H, Klofutar C. Water adsorption isotherms of some gellan gum samples. Journal of Food Engineering 2006; 77(3): 514-520.

375. Kantouch A, Heheish A, Bendak A. Ceiv initiated graft polymerization of methyl methacrylate on wool fibres. European Polymer Journal 1971; 7(2): 153-163.

376. Sun D, Stylios GK. Fabric surface properties affected by low temperature plasma treatment. Journal of Materials Processing Technology 2006; 173(2): 172-177. 
377. Cardamone JM, Yao J, Nuńez A. Controlling shrinkage in wool fabrics: Effective hydrogen peroxide systems. Textile Research Journal 2004; 74(10): 887-898.

378. Strnad S, Šauper O, Jazbec A, Stana-Kleinschek K. Influence of chemical modification on sorption and mechanical properties of cotton fibers treated with chitosan. Textile Research Journal 2008; 78(5): 390-398.

379. Lim S-H, Hudson SH. Application of a fibre-reactive chitosan derivative to cotton fabric as a zero-salt dyeing auxiliary. Coloration Technology 2004; 120(3): 108-113.

380. Chung Y-S, Lee K-K, Kim J-W. Durable press and antimicrobial finishing of cotton fabrics with a citric acid and chitosan treatment. Textile Research Journal 1998; 68(10): 772-775.

381. Shu XZ, Zhu KJ, Song W. Novel ph-sensitive citrate cross-linked chitosan film for drug controlled release. International Journal of Pharmaceutics 2001; 212(1): 19-28.

382. Verma P, Baldrian P, Nerud F. Decolorization of structurally different synthetic dyes using cobalt(ii)/ascorbic acid/hydrogen peroxide system. Chemosphere 2003; 50(8): 975-979.

383. Marshall WE, Wartelle LH, Boler DE, Johns MM, Toles CA. Enhanced metal adsorption by soybean hulls modified with citric acid. Bioresour. Technol. 1999; 69(3): 263-268.

384. Barron V, Torrent J. Use of the kubelka-munk theory to study the influence of iron oxides on soil colour. Journal of Soil Science 1986; 37(4): 499-510.

385. Liu W, Sun S, Cao Z, Zhang X, Yao K, Lu WW, Luk KDK. An investigation on the physicochemical properties of chitosan/DNA polyelectrolyte complexes. Biomaterials 2005; 26(15): 2705-2711.

386. Sworn G, Sanderson GR, Gibson W. Gellan gum fluid gels. Food Hydrocolloids 1995; 9(4): 265-271.

387. Domard A. Ph and c.D. Measurements on a fully deacetylated chitosan: Application to cuii--polymer interactions. Int. J. Biol. Macromol. 1987; 9(2): 98-104.

388. Kassab NM, Amaral MSd, Singh AK, Santoro MIRM. Development and validation of uv spectrophotometric method for determination of levofloxacin in pharmaceutical dosage forms. Química Nova 2010; 33: 968-971.

389. Liu S, Zhang L-W, Zhang X-X. Interaction between fluoroquinolones and bovine serum albumin studied by affinity capillary electrophoresis. Analytical Sciences 2006; 22(12): 1515-1518. 
390. Hurtado FK, Nogueira DR, Bortolini F, da Silva LM, Zimmermann E, Souza MJe, de Melo J, Rolim CMB. Determination of levofloxacin in a pharmaceutical injectable formulation by using hplc and uv spectrophotometric methods. Journal of Liquid Chromatography \& Related Technologies 2007; 30(13): 1981 - 1989.

391. Smitha B, Sridhar S, Khan AA. Polyelectrolyte complexes of chitosan and poly(acrylic acid) as proton exchange membranes for fuel cells $†$. Macromolecules 2004; 37(6): 2233-2239.

392. Simchowitz L, Roos A. Regulation of intracellular ph in human neutrophils. The Journal of General Physiology 1985; 85(3): 443-470.

393. Holland KT, Davis W, Ingham E, Gowland G. A comparison of the in-vitro antibacterial and complement activating effect of [']opsite' and [']tegaderm' dressings. Journal of Hospital Infection 1984; 5(3): 323-328.

394. Ravenscroft MJ, Harker J, Buch KJ. A prospective, randomised, controlled trial comparing wound dressings used in hip and knee surgery: Aquacel and tegaderm versus cutiplast. Ann R Coll Surg Engl. 2006; 88(1): 18-22.

395. Phan TT, Lim IJ, Tan EK, Bay BH, Lee ST. Evaluation of cell culture on the polyurethane-based membrane (tegaderm\&lt;sup\&gt;tm\&lt;/sup\&gt;): Implication for tissue engineering of skin. Cell and Tissue Banking 2005; 6(2): 91-97.

396. Montanari MP, Mingoia M, Marchetti F, Varaldo PE. In vitro activity of levofloxacin against gram-positive bacteria. Chemotherapy 1999; 45(6): 411.

397. Qiu X, Leporatti S, Donath E, Möhwald H. Studies on the drug release properties of polysaccharide multilayers encapsulated ibuprofen microparticles. Langmuir 2001; 17(17): 5375-5380.

398. Ai H, Jones SA, de Villiers MM, Lvov YM. Nano-encapsulation of furosemide microcrystals for controlled drug release. J. Control. Release 2003; 86(1): 59-68.

399. Zhu Y, Shi J, Shen W, Dong X, Feng J, Ruan M, Li Y. Stimuli-responsive controlled drug release from a hollow mesoporous silica sphere/polyelectrolyte multilayer core-shell structure. Angewandte Chemie International Edition 2005; 44(32): 5083-5087.

400. Berg MC, Zhai L, Cohen RE, Rubner MF. Controlled drug release from porous polyelectrolyte multilayers. Biomacromolecules 2005; 7(1): 357-364.

401. Jørgensen B, Friis GJ, Gottrup F. Pain and quality of life for patients with venous leg ulcers: Proof of concept of the efficacy of biatain ${ }^{\circledR}$-ibu, a new pain reducing wound dressing. Wound Repair and Regeneration 2006; 14(3): 233239. 
402. Woo KY, Harding K, Price P, Sibbald G. Minimising wound-related pain at dressing change: Evidence-informed practice. International Wound Journal 2008; 5(2): 144-157.

403. Etienne O, Picart C, Taddei C, Keller P, Hubsch E, Schaaf P, Voegel JC, Haikel Y, Ogier JA, Egles C. Polyelectrolyte multilayer film coating and stability at the surfaces of oral prosthesis base polymers: An in vitro and in vivo study. Journal of Dental Research 2006; 85(1): 44-48.

404. Enright MC, Robinson DA, Randle G, Feil EJ, Grundmann H, Spratt BG. The evolutionary history of methicillin-resistant staphylococcus aureus (mrsa). Proceedings of the National Academy of Sciences 2002; 99(11): 7687-7692.

405. Peacock JE, Marsik FJ, Wenzel RP. Methicillin-resistant staphylococcus aureus: Introduction and spread within a hospital. Annals of Internal Medicine 1980; 93(4): 526-532.

406. Andersen BM, Lindemann R, Bergh K, Nesheim BI, Syversen G, Solheim N, Laugerud F. Spread of methicillin-resistant staphylococcus aureus in a neonatal intensive unit associated with understaffing, overcrowding and mixing of patients. Journal of Hospital Infection 2002; 50(1): 18-24. 
